University of Nebraska - Lincoln

DigitalCommons@University of Nebraska - Lincoln

1987

\title{
Patterns of Dental Evolution in Early Eocene Anaptomorphine Primates (Omomyidae) From the Bighorn Basin, Wyoming
}

Thomas M. Bown

U.S. Geological Survey

Kenneth D. Rose

Johns Hopkins University, kdrose@jhmi.edu

Follow this and additional works at: https://digitalcommons.unl.edu/usgsstaffpub

Part of the Earth Sciences Commons

Bown, Thomas M. and Rose, Kenneth D., "Patterns of Dental Evolution in Early Eocene Anaptomorphine Primates (Omomyidae) From the Bighorn Basin, Wyoming" (1987). USGS Staff -- Published Research. 208. https://digitalcommons.unl.edu/usgsstaffpub/208

This Article is brought to you for free and open access by the US Geological Survey at DigitalCommons@University of Nebraska - Lincoln. It has been accepted for inclusion in USGS Staff -- Published Research by an authorized administrator of DigitalCommons@University of Nebraska - Lincoln. 
The Paleontological Society

MEMOIR 23

\section{PATTERNS OF DENTAL EVOLUTION IN EARLY EOCENE ANAPTOMORPHINE PRIMATES (OMOMYIDAE) FROM THE BIGHORN BASIN, WYOMING}

\section{Thomas M. Bown AND KenNETH D. RoSe}

U.S. Geological Survey, Denver, Colorado 80225 and Department of Cell Biology and Anatomy, The Johns Hopkins University, Baltimore, Maryland 21205

Copyright (C) 1987 by

THE PALEONTOLOGICAL SOCIETY, INC.

SEPTEMBER 1987 


\section{CONTENTS}

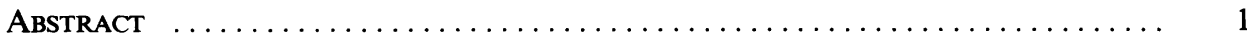

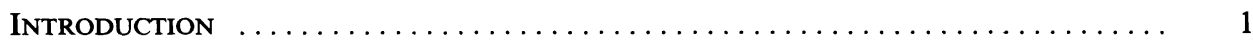

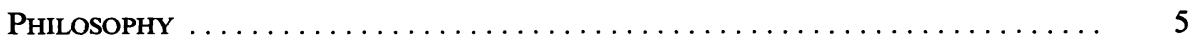

PunCtUATEd Equilibria and GradUalisM $\ldots \ldots \ldots \ldots \ldots \ldots \ldots \ldots \ldots \ldots . \ldots \ldots$

Geologic Setting of Bighorn Basin Anaptomorphine Primates ....... 13

STRATIGRAPHIC AND LOCALITY DATA FOR BIGHORN BASIN ANAPTOMORPHINE

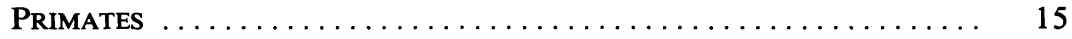

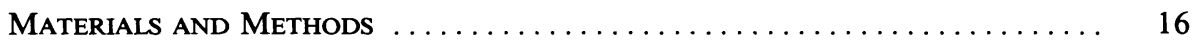

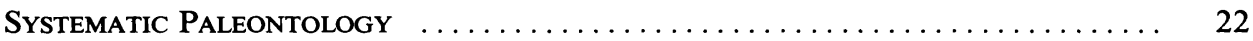

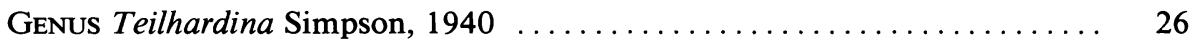

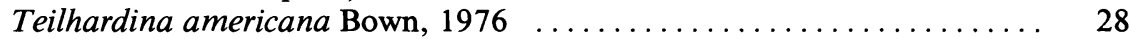

Teilhardina crassidens $\mathbf{n}$. sp. ......................... 31

$T$. americana- $T$. crassidens intermediates .................. 35

Teilhardina tenuicula (Jepsen, 1930) n. comb. ................ 38

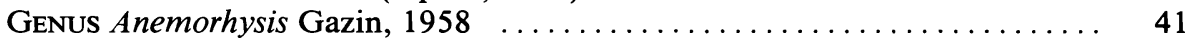

Anemorhysis pattersoni Bown and Rose, $1984 \ldots \ldots \ldots \ldots \ldots \ldots . \ldots 43$

Anemorhysis wortmani Bown and Rose, $1984 \ldots \ldots \ldots \ldots \ldots \ldots 44$

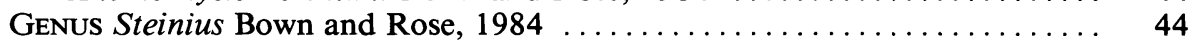

Steinius vespertinus (Matthew, 1915) $\ldots \ldots \ldots \ldots \ldots \ldots \ldots \ldots \ldots . \ldots \ldots$

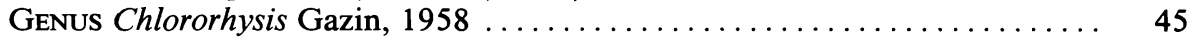

Chlororhysis incomptus Bown and Rose, $1984 \ldots \ldots \ldots \ldots \ldots \ldots . \ldots 45$

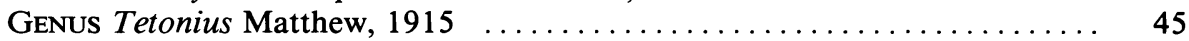

Tetonius homunculus (Cope, 1882) ...................... 46

Tetonius mckennai $\mathrm{n}$. sp. ............................ 49

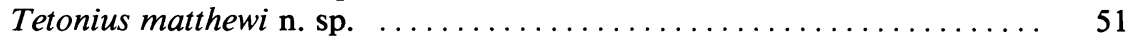

Tetonius sp. ....................................... 54

Tetonius-Pseudotetonius intermediates $\ldots \ldots \ldots \ldots \ldots \ldots \ldots \ldots \ldots \ldots$

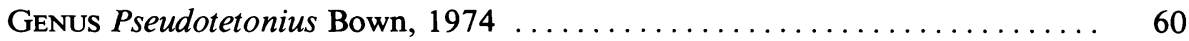

Pseudotetonius ambiguus (Matthew, 1915) $\ldots \ldots \ldots \ldots \ldots \ldots \ldots . \ldots 6$

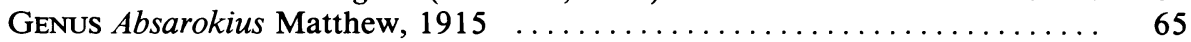

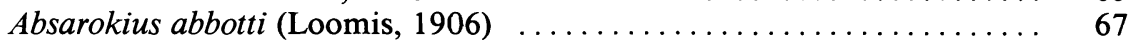

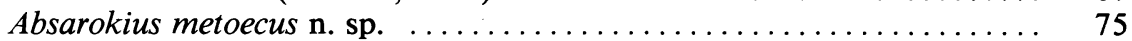

Absarokius gazini n. sp. ........................... 77

Absarokius nocerai (Robinson, 1966) n. comb. .............. 79

Absarokius australis n. sp. ........................... 80

Genus Strigorhysis Bown, $1979 \ldots \ldots \ldots \ldots \ldots \ldots \ldots \ldots \ldots \ldots \ldots \ldots \ldots$

Strigorhysis cf. $S$. bridgerensis Bown, $1979 \ldots \ldots \ldots \ldots \ldots \ldots \ldots \ldots . \ldots 6$

Strigorhysis huerfanensis $\mathrm{n} . \mathbf{s p} . \ldots \ldots \ldots \ldots \ldots \ldots \ldots \ldots \ldots \ldots$

Evolution of ANAPtomorphine Primates in the Bighorn Basin $\ldots \ldots \ldots \ldots .90$

Evolution IN THE TEILHARDINA-ANEMORHYSIS ClADE ............... 91

Evolution in the Tetonius-PSEudotetonius Clade ................ 101

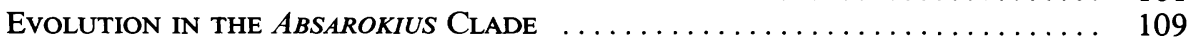

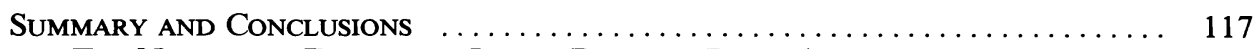

The Nature of Evolution In the Bighorn Basin ANAPTOMORPHINe ReCORD

IMPLICATIONS OF GRADUAL EVOLUTION FOR TAXONOMIC AND BIOSTRATIGRAPHIC

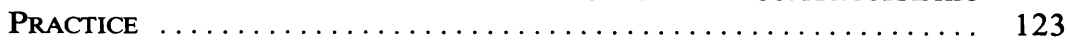

EvolutIONARY RATES IN BIGHORN BASIN ANAPTOMORPHINES $\ldots \ldots \ldots \ldots \ldots \ldots . \ldots \ldots$

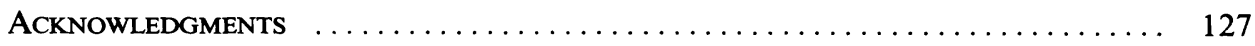

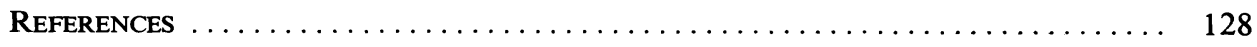




\section{APPENDiCES}

1-Specimen data for lower teeth of Teilhardina americana Bown ....

2-Specimen data for upper teeth of Teilhardina americana Bown ....

3-Specimen data for lower teeth of Teilhardina crassidens $\mathrm{n}$. sp. .....

4-Specimen data for upper teeth of Teilhardina crassidens $\mathrm{n}$. sp. ....

5-Specimen data for lower teeth of Teilhardina americana-Teilhardina crassidens intermediates

6-Specimen data for upper teeth of Teilhardina americana-Teilhardina

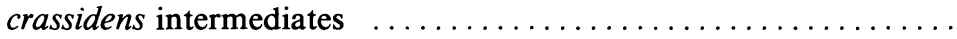

7-Specimen data for lower teeth of Teilhardina tenuicula (Jepsen) $\mathrm{n}$. comb., Tetonius mckennai n. sp., Anemorhysis pattersoni Bown and Rose, A. wortmani Bown and Rose, Chlororhysis incomptus Bown and Rose, and Steinius vespertinus (Matthew)

8-Specimen data for type specimens of Teilhardina tenuicula (Jepsen) n. comb. and Tetonius homunculus (Cope), and for upper teeth of Anemorhysis pattersoni Bown and Rose and Steinius vespertinus (Matthew)

9-Specimen data for lower teeth of Tetonius matthewi $\mathbf{n}$. sp.

10-Specimen data for undifferentiated upper teeth of Tetonius matthewi

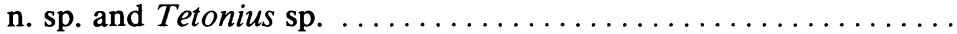

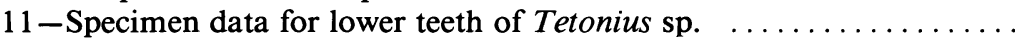

12-Specimen data for lower teeth of Tetonius matthewi-Pseudotetonius

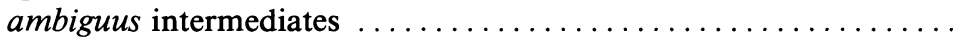

13-Specimen data for upper teeth of Tetonius matthewi-Pseudotetonius

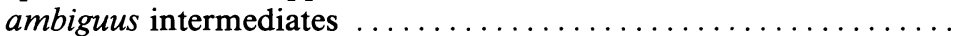

14-Specimen data for lower teeth of Pseudotetonius ambiguus (Matthew)

15-Specimen data for upper teeth of Pseudotetonius ambiguus (Matthew)

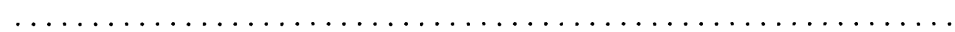

16-Specimen data for lower teeth of Absarokius abbotti (Loomis) ..... 17-Specimen data for upper teeth of Absarokius abbotti (Loomis) ..... 18-Specimen data for lower teeth of Absarokius metoecus n. sp. ...... 19-Specimen data for upper teeth of Absarokius metoecus n. sp. ...... 20-Specimen data for type specimens of Absarokius nocerai (Robinson) n. comb. and $A$. witteri Morris, and for type and referred specimens

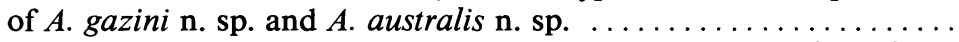

21-Specimen data for type and referred specimens of Strigorhysis huerfanensis n. sp., S. rugosus Bown, S. bridgerensis Bown, Strigorhysis cf. $S$. bridgerensis Bown, and Aycrossia lovei Bown

\section{ILLUSTRATIONS}

FIGURES

FroNTISPIECE-Life restoration of Tetonius $\ldots \ldots \ldots \ldots \ldots \ldots \ldots \ldots$

1-Base map of the Bighorn Basin, northwest Wyoming .............
$2-$ Measured sections and localities yielding fossils of anaptomorphine primates in the southeastern Bighorn Basin

3-Measured sections and localities yielding fossils of anaptomorphine primates in the south-central Bighorn Basin ...............

4-Axes of orientation for measuring teeth of anaptomorphine primates

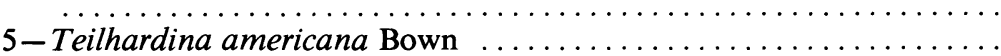

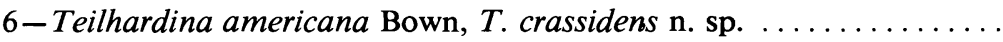

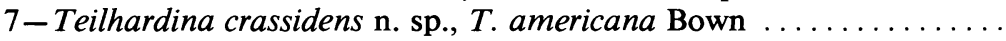

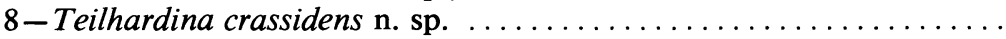

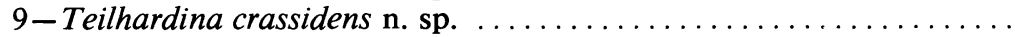

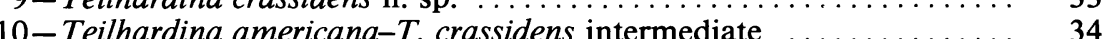


11-Teilhardina americana-T. crassidens intermediate ........... 36

12-Teilhardina spp. ................................. 37

13-Teilhardina americana-T. tenuicula intermediate .......... 38

14-Teilhardina tenuicula (Jepsen) n. comb. ................. 39

15-Tetonius, Teilhardina .......................... 40

16-Position of holotype of Tetonius homunculus (Cope) with respect to

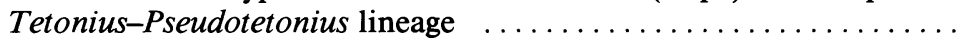

17-Holotype of Tetonius matthewi n. sp. . . . . . . . . . . . . 50

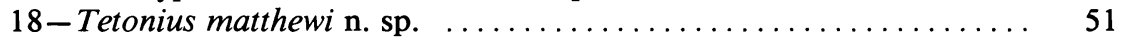

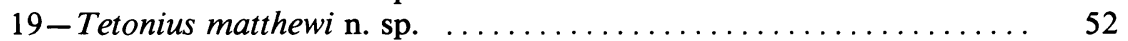

20-Tetonius matthewi $\mathrm{n}$. sp. ....................... 53

21-Tetonius matthewi-Pseudotetonius ambiguus intermediate (stage 2) 55

22-Tetonius matthewi-Pseudotetonius ambiguus intermediate (stage 2/4)

23-Tetonius matthewi-Pseudotetonius ambiguus intermediate (stage 3 ) 56

24-Tetonius matthewi-Pseudotetonius ambiguus intermediates (stages 2

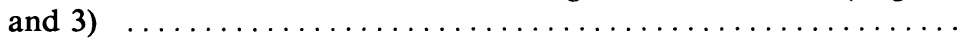

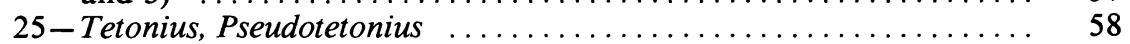

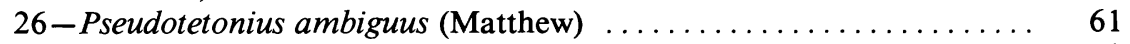

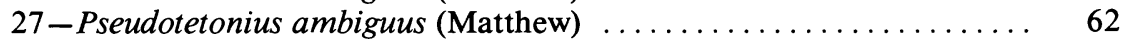

$28-$ Pseudotetonius ambiguus (Matthew) $\ldots \ldots \ldots \ldots \ldots \ldots \ldots \ldots$

29-Pseudotetonius ambiguus (Matthew) .................. 64

30-Pseudotetonius ambiguus (Matthew), Absarokius gazini n. sp. .... 65

$31-$ Absarokius abbotti (Loomis) $\ldots \ldots \ldots \ldots \ldots \ldots \ldots \ldots \ldots \ldots . \ldots \ldots$

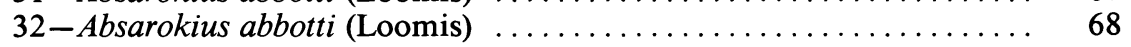

33-Absarokius abbotti (Loomis), A. metoecus n. sp. ............. 69

34-Absarokius metoecus n. sp., A. abbotti (Loomis) ............. 70

35-Stratigraphic plot of $\mathrm{p} 4 \mathrm{~L}$ in Absarokius ................ 73

36 -Stratigraphic plot of $\mathrm{p} 4 \mathrm{H}$ in Absarokius ................ 74

$37-$ Scatter diagram of $\mathrm{p} 4 \mathrm{H}$ and $\mathrm{p} 4$ area in Absarokius . . . . . . . 75

38-Absarokius metoecus $\mathrm{n}$. sp. ........................... 78

39-Absarokius metoecus n. sp. ....................... 78

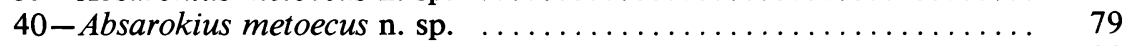

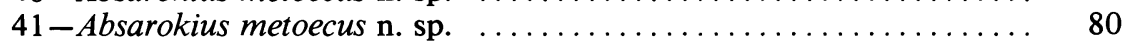

42-Absarokius metoecus n. sp. ....................... 81

43-Absarokius metoecus n. sp., Strigorhysis . ............... 82

44-Holotypes of four species of Absarokius . . . . . . . . . . . . 83

45-Holotype of Absarokius australis n. sp. ................ 84

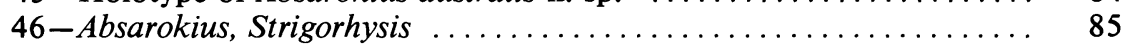

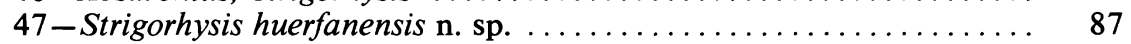

$48-$ Strigorhysis bridgerensis Bown $\ldots \ldots \ldots \ldots \ldots \ldots \ldots \ldots \ldots \ldots, 88$

$49-$ Aycrossia lovei Bown .......................... 89

50 -Plot of $\mathrm{ml}$ area in Bighorn Basin omomyids $\ldots \ldots \ldots \ldots \ldots \ldots .90$

$51-$ Plot of $\mathrm{p} 3$ area in Bighorn Basin omomyids $\ldots \ldots \ldots \ldots \ldots \ldots \ldots . . \ldots 1$

$52-$ Plot of p4 area in Bighorn Basin omomyids .............. 92

53-Plot of $\mathrm{m} 1$ area in Bighorn Basin omomyids $\ldots \ldots \ldots \ldots \ldots . . \ldots 3$

$54-$ Plot of $\mathrm{m} 2$ area in Bighorn Basin omomyids $\ldots \ldots \ldots \ldots \ldots \ldots . \ldots 3$

55 -Plot of P4 area in Bighorn Basin omomyids . . . . . . . . . . . 94

56 -Plot of M1 area in Bighorn Basin omomyids ............. 94

57-Changes in morphology of $\mathrm{p} 4$ and proportions of $\mathrm{m} 1$ in Teilhardina

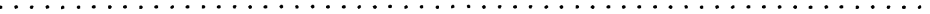

58-Upper cheek teeth of Teilhardina ................... 96

59-Stratigraphic distribution of $\mathrm{m} 1$ and $\mathrm{m} 2$ sizes in the Teilhardina and Tetonius-Pseudotetonius lineages $\ldots \ldots \ldots \ldots \ldots \ldots \ldots \ldots \ldots \ldots$

$60-$ Plot of p4 area in Clark's Fork Basin omomyids $\ldots \ldots \ldots \ldots \ldots$

61 -Plot of $\mathrm{m} 1$ area in Clark's Fork Basin omomyids $\ldots \ldots \ldots \ldots \ldots \ldots$

62-Plot of $\mathrm{m} 1$ area in Clark's Fork Basin omomyids with vertical scale

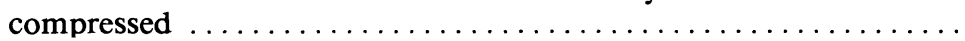

63-Interrelationships of Anemorhysis and Teilhardina ........... 101 
64-Morphological stages of evolution between Teilhardina and Tetonius

65-Histograms of $\mathrm{p} 4$ and $\mathrm{m} 1$ size in Teilhardina americana and Tetonius

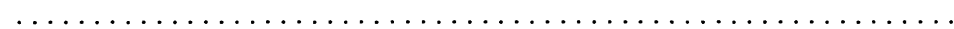

66-Shape of p4 in Bighorn Basin omomyids, 180-190 m interval ....

67-Morphologic stages in the Tetonius-Pseudotetonius lineage .......

68-Stratigraphic distribution of lower premolar traits in the TetoniusPseudotetonius lineage, central and southern Bighorn Basin ......

69-Stratigraphic distribution of lower premolar traits in the TetoniusPseudotetonius lineage, Clark's Fork Basin ...............

70-Comparisons of lower fourth premolar crown distention in Absarokius

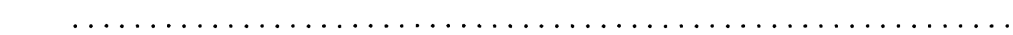

71-Dental variation in $\mathrm{p} 4-\mathrm{m} 1$ of Absarokius abbotti (Loomis) .......

72-Dental variation in $\mathrm{p} 4-\mathrm{m} 1$ of Absarokius metoecus $\mathrm{n}$. $\mathrm{sp}$. . ..........

73-Dental variation in M1-2 of Absarokius abbotti (Loomis) .........

74-Dental variation in M1-2 of Absarokius metoecus n. sp. and Strigorhysis

75-Evolutionary interrelationships of Bighorn Basin Anaptomorphinae

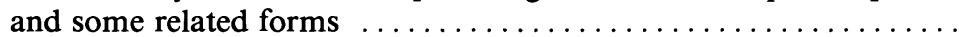

76-Temporally-stratified morphology, morphologic breadth, and some possible species groupings in Tetonius-Pseudotetonius lineage .....

TABLES 1-Summary of recent systematic treatment of anaptomorphine primates

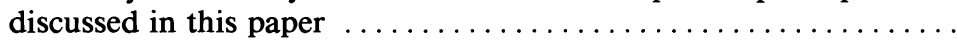

2-Stratigraphic distribution of localities yielding anaptomorphine primates in the southern Bighorn Basin $\ldots \ldots \ldots \ldots \ldots \ldots \ldots \ldots$

3-Comparative statistics for lower teeth of Teilhardina ...........

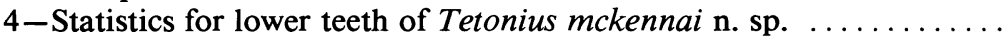

5-Comparative statistics for lower teeth of Tetonius matthewi $\mathrm{n}$. sp. and Pseudotetonius ambiguus (Matthew)

6-Statistics for lower teeth of Tetonius sp.

7-Comparative statistics for lower teeth of Tetonius-Pseudotetonius in-

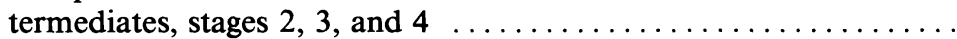

8-Comparative statistics for cheek teeth of Absarokius ............

9-Estimates of evolutionary rates for some early anaptomorphine primates from the Willwood Formation 


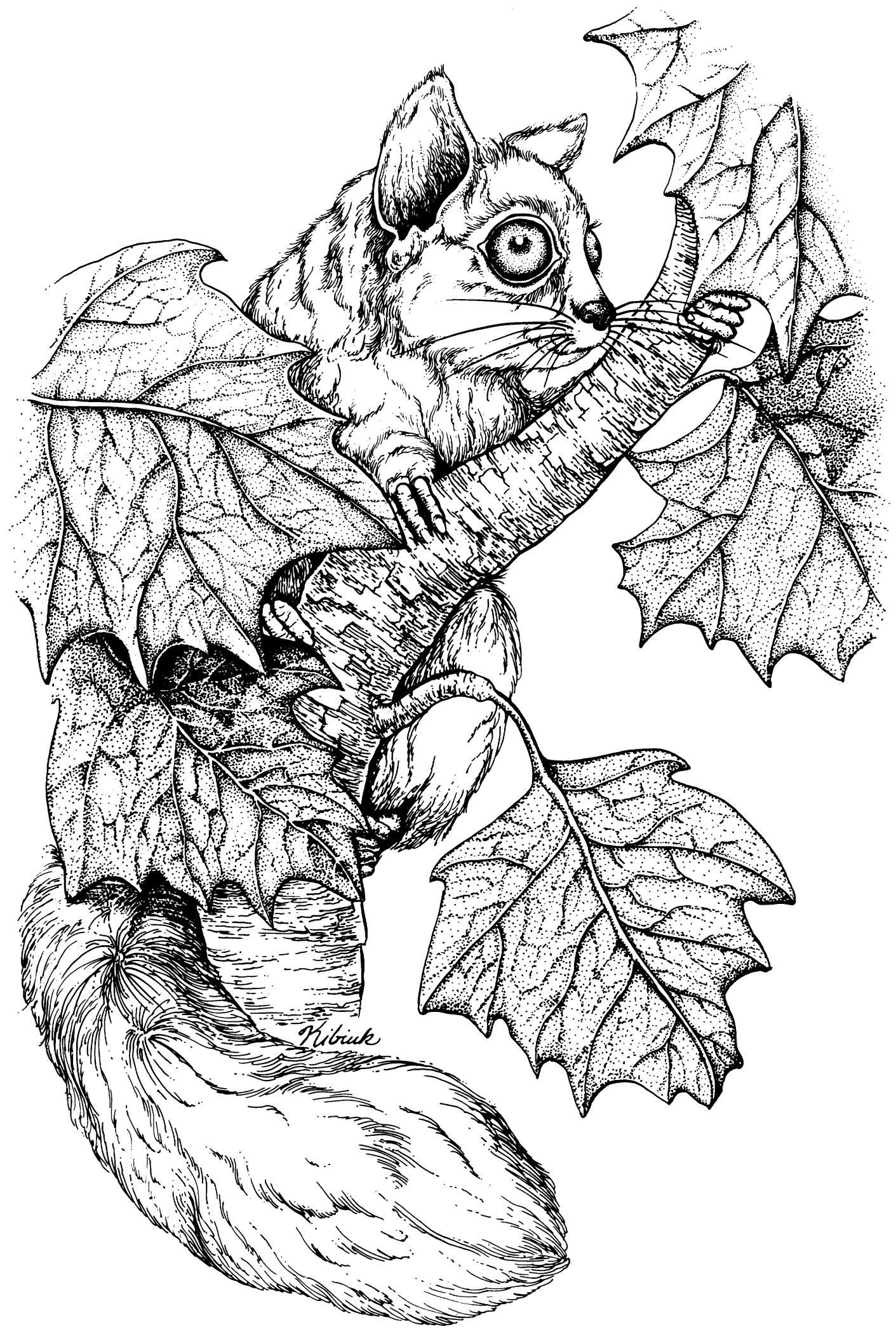

FRONTISPIECE-Restoration of the early Eocene anaptomorphine Tetonius. 


\title{
PATTERNS OF DENTAL EVOLUTION IN EARLY EOCENE ANAPTOMORPHINE PRIMATES (OMOMYIDAE) FROM THE BIGHORN BASIN, WYOMING
}

\author{
THOMAS M. BOWN AND KENNETH D. ROSE \\ U.S. Geological Survey, Denver, Colorado 80225 and \\ Department of Cell Biology and Anatomy, The Johns Hopkins University, \\ Baltimore, Maryland 21205
}

\begin{abstract}
The subfamily Anaptomorphinae contains the oldest and most generalized members of the tarsier-like primates and is the basal group of the extinct family Omomyidae. The best and most continuous record of anaptomorphine history is from rocks of early Eocene (Wasatchian) age in the Bighorn Basin of northwest Wyoming where eight genera and 14 species are recognized. Three of these species are new (Teilhardina crassidens, Tetonius matthewi, Absarokius metoecus), and four other new species are described from elsewhere (Tetonius mckennai, Absarokius gazini, A. australis, Strigorhysis huerfanensis). Teilhardina tenuicula and Absarokius nocerai are new combined forms. Absarokius noctivagus is considered to be a synonym of A. abbotti, and Mckennamorphus is a synonym of Pseudotetonius.

The evolution of dental characters in three principal morphologic clades of anaptomorphines from the Bighorn Basin is documented with the aid of numerous new specimens ( $75 \%$ of the sample is new) and with precise stratigraphic data. These major clades are Teilhardina-Anemorhysis, Tetonius-Pseudotetonius, and Absarokius. In each of these clades, evolution appears to have occurred gradually. In the first two clades it was mainly anagenetic, although each one included a minor branching event. In Absarokius, evolution was instead characterized by cladogenesis followed by continued (and continual) anagenetic change in each of the new lines. Anagenetic gradual evolution produced the new genus Pseudotetonius (from Tetonius) and possibly Anemorhysis (from Teilhardina). Similarly, the Absarokius metoecus lineage probably gave rise to late Wasatchianearly Bridgerian Strigorhysis. Evolution from Tetonius to Pseudotetonius has been clarified by establishment of five arbitrary stages of evolution (Tetonius-Pseudotetonius intermediates). Estimates of relative proportions of time represented by paleosols in different parts of the Willwood section suggest that cladogenetic speciation in Absarokius was almost certainly more rapid than anagenesis in Tetonius-Pseudotetonius.

Anagenetic character evolution and speciation in the anaptomorphine primates was typified first by increase, then decrease in variability, which resulted in measurable apomorphic morphologic change. Cumulation of changes of this sort created more extensive differences of importance at the species and genus levels. Introduction of changing character states and their tempo was staggered temporally, and new characters (and new taxa) are least separable from their antecedent states when they first appear. This evidence is in sharp contrast to predictions of the punctuated equilibria model of evolution. Because the emergence of diagnostic characters occurs gradually (in evolutionary terms) and not all at once (in temporal terms), and because diagnostic characters are the essence of the diagnosis (and thereby taxonomy), the implications of gradual evolution for both systematic paleontology and biostratigraphy are profound. Stasis exists in the evolution of individual characters over certain periods, but this study offers no evidence supporting either organismic stasis or even stasis in the dental evolution of the Anaptomorphinae over a period of about 4.8 million years.
\end{abstract}

\section{INTRODUCTION}

THE ANAPTOMORPHINAE are an early group of tarsier-like primates belonging to the family Omomyidae. While most diversified in North America, anaptomorphines are also known from Europe (e.g., Simpson, 1940) and probably from Asia (Kohatius; Russell and Gingerich, 1980). Another proposed Asian anaptomorphine genus, Altanius (Dashzeveg and McKenna, 1977), may actually belong in the Plesiadapiformes (Rose and Krause, 1984).
Two additional subfamilies are generally included within the Omomyidae. The Omomyinae are apparently exclusively North American, whereas the Microchoerinae (traditionally including Nannopithex, Necrolemur, Microchoerus, and perhaps Pseudoloris) have been believed to be European in both origin and dispersion (Nannopithex may be an anaptomorphine). Szalay (1976) named the new omomyid subfamily Ekgmowechashalinae to accommodate Macdonald's (1963) Ekgmowechashala, otherwise includ- 
ed in Omomyinae. Krishtalka and Schwartz (1978) placed Wilson's (1966) Rooneyia in the Microchoeridae, recognizing the extinct tarsiiform families Omomyidae, Anaptomorphidae, and Microchoeridae. The only other certain fossil records of tarsier-like primates are Afrotarsius (?Tarsiidae) and an unnamed omomyid from the early Oligocene of Egypt (Simons and Bown, 1985; Simons et al., 1986). However, Szalay and Li (1986) suggested that middle Paleocene Decoredon (Xu, 1977) from China might be the earliest tarsier-like primate.

The first specimen of an anaptomorphine primate, the type skull of Tetonius homunculus (=Anaptomorphus homunculus of Cope, $1882 \mathrm{a}, 1882 \mathrm{~b})$ was described more than a century ago from an unknown locality in the so-called "Gray Bull" beds of the lower Eocene Willwood Formation (then called the "Bighorn Wasatch"). Since that time, more than 850 specimens of anaptomorphines have been collected from the Willwood Formation of the Bighorn Basin, Wyoming (where they make up less than $1.5 \%$ of the Wasatchian fauna), and perhaps as many as 250 others are known from lower Eocene rocks elsewhere in Wyoming, Colorado, Utah, New Mexico, and North Dakota. A significant number of the Willwood Formation specimens in the Yale (YPM) collection that were examined for this study have been available for more than a decade but remained undescribed. The remainder (probably exceeding 500 specimens) were collected on expeditions by the authors from 1975 to date, and by $P$. D. Gingerich at the University of Michigan during the same interval.

Only recently have stratigraphic studies of lower Eocene fluvial rocks progressed to where approximately coeval samples of omomyid primates and other fossil mammals can be identified and compared, with the goals of establishing species variability and accurate, temporally-controlled faunal compositions and evolutionary records. By far, the best published biostratigraphic control for continental lower Eocene rocks anywhere in the world is that of the Willwood Formation of the Bighorn Basin, Wyoming (Gingerich, 1974a, 1976, 1982; Bown, 1979a, 1980a; Schankler, 1980; Rose, 1981b). This is also the source of the largest lower Eocene sample of anaptomorphine primates (more than 850 specimens, largely jaws with two or more teeth, from 229 localities).

It is the intent of this study to document anaptomorphine dental evolution and diversity in the lower Eocene of the Bighorn Basin (Figure 1) in the context of the now well established Willwood Formation biostratigraphy, and to discuss closely related forms from elsewhere in the Rocky Mountain region. The information and evolutionary patterns that have emerged from this research can be used as a working base for study of anaptomorphine evolution in other lower Eocene intermontane basins, where exposures are less extensive but for which biostratigraphy relative to that in the Bighorn Basin can be independently established by examination of the nonprimate mammalian record.

A preliminary account of part of this research was published by Rose and Bown (1984). Stanley's (1985) dismissal of that carefully documented study by parenthetical reference to a personal communication regarding questionable unpublished data was an inadequate response. As Branscomb (1985, p. 423) astutely observed: "Information that is wrong is not useful. And information lacking evidence revealing whether it is right or wrong is scarcely more so."

Earlier detailed reviews of anaptomorphine primates and of their interrelationships were published by Matthew (1915), Simpson (1940), Gazin (1958), Szalay (1976), Krishtalka and Schwartz (1978), and Gingerich (1981). Each of these has contributed to knowledge of these animals as well as to perspectives in methodology for studying them. It might well be asked, in view of the three quite recent studies of the group, why paleontologists need yet another study of the Anaptomorphinae?

Prior to the present work, most knowledge of anaptomorphines was based on small numbers of fragmentary (often inadequate) dental remains, almost invariably lacking good stratigraphic data. This applies particularly to many type specimens. Though large samples of Bighorn Basin anaptomorphine dentitions were available by 1975 , Szalay (1976) and Krishtalka and Schwartz (1978) did not make use of the vast majority of this material; and Gingerich (1980a) based his study only on materials from the Clark's Fork Basin (northern Bighorn Basin), restricting 


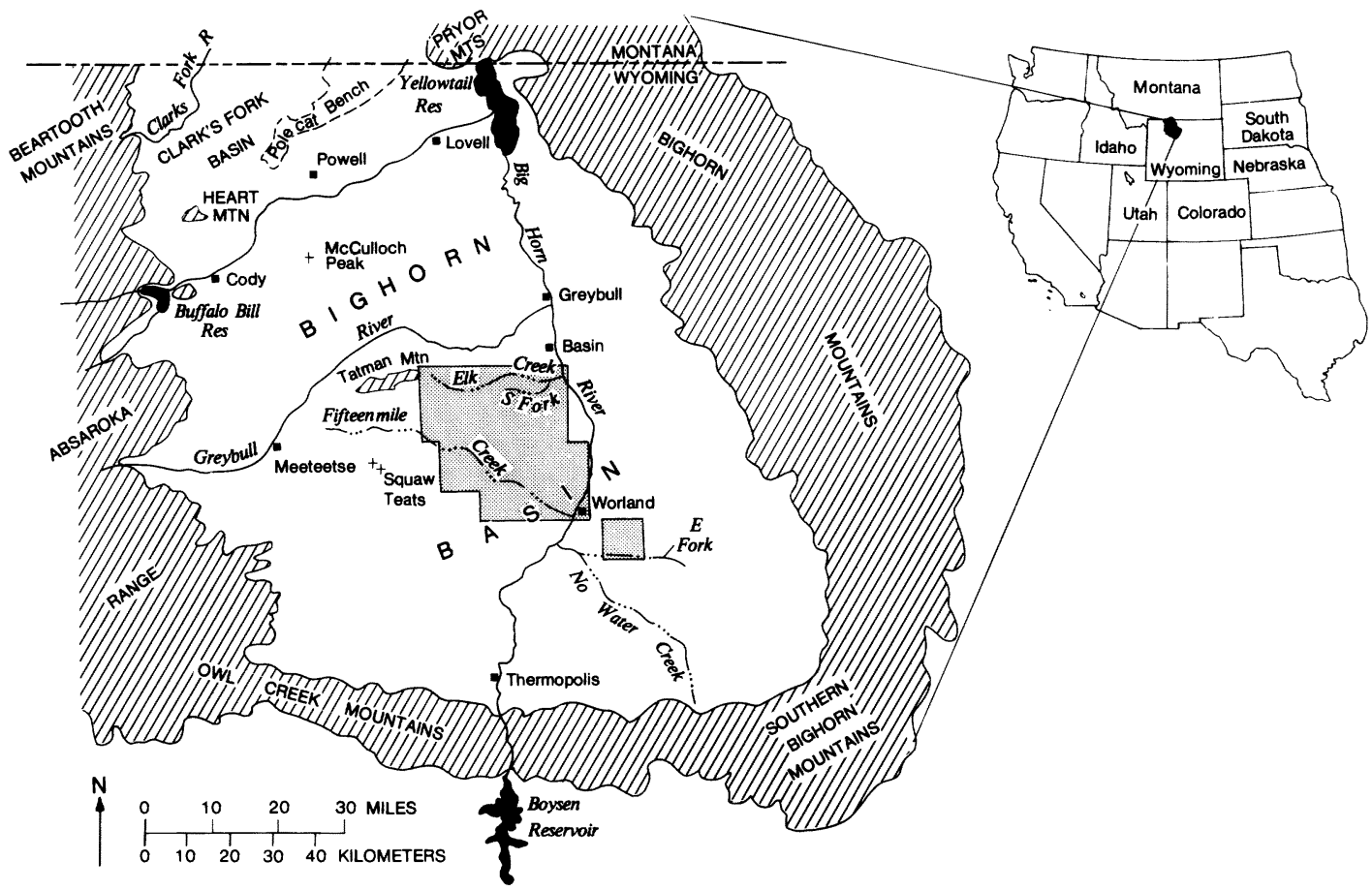

FIGURE 1-Map of the Bighorn Basin, northwest Wyoming, showing major physiographic features and shaded study area in lower Eocene Willwood Formation (see also Figures 2 and 3).

his analysis to lower first molar size. Neither of the first two studies made any use of detailed stratigraphic information, used to considerable advantage by Gingerich (1974a, 1976) in his seminal studies of evolution in the Bighorn Basin condylarth Hyopsodus and the adapid primate Cantius (then included in Pelycodus). The collections utilized in the present study include at least 700 specimens (many recently collected) not examined by Szalay (1976), Krishtalka and Schwartz (1978), and Gingerich (1980a). This material constitutes at least $75 \%$ of all known North American lower Eocene anaptomorphine jaws, and includes the most complete known dental remains of Teilhardina, Anemorhysis, Pseudotetonius, and Steinius.

The study by Krishtalka and Schwartz (1978) was thoroughly cladistic in philosophy and based on too few characters for each taxon to assist very much in deciphering anaptomorphine interrelationships. Moreover, many of their nodal characters are common to both their established sister groups and/or to outgroup taxa. Some characters do not occur consistently within the specified clade, or are not fully distinguished or defended as synapomorphous. Krishtalka and Schwartz's study is also founded on their unorthodox and cumbersome interpretations of primate dental formulae (partly based on the sequence of dental development and eruption in extant Tarsius); namely, the presumed loss of all incisors and retention of five premolars as the ancestral condition of tarsiiforms. Although the presence of five lower premolars may well be primitive for therian mammals (McKenna, 1975; Novacek, 1986), the dental homologies inferred by Krishtalka and Schwartz (1978) and Schwartz (1978) cannot be established for any fossil primate, and have been challenged for Tarsius as well (Luckett and Maier, 1982). Therefore, it is premature to extend these homologies to primates.

Szalay's (1976) review of the Omomyidae is the most comprehensive ever published and is largely founded on traditional viewpoints. Although the authors disagree with him on some of these, Szalay clarified many points of anaptomorphine systematics. Nonetheless, there are problems in using Szalay's work as a reliable handbook on the 
TABLE 1-Recent systematic treatment of various parts of the hypodigms of anaptomorphine primates discussed in this paper $(*=$ not known from the Bighorn Basin; $+=$ not known outside the Bighorn Basin).

\begin{tabular}{|c|c|c|}
\hline This paper & Szalay $(1976,1982)$ & Gingerich (1980a, 1981) \\
\hline Teilhardina americana+ & $\begin{array}{l}\text { not available in 1976; placed in Ane- } \\
\text { morhysis tenuiculus in } 1982\end{array}$ & Tetonoides sp. \\
\hline Teilhardina crassidens + & Anemorhysis tenuiculus & Tetonoides tenuiculus \\
\hline Teilhardina tenuicula + & Anemorhysis tenuiculus & Tetonoides tenuiculus \\
\hline Tetonius matthewi & $T$. homunculus & T. steini \\
\hline Tetonius homunculus + & T. homunculus & T. homunculus \\
\hline Tetonius mckennai* & Tetonius sp. & not discussed \\
\hline Tetonius sp. + & not available & not discussed \\
\hline Pseudotetonius ambiguus & $\begin{array}{l}\text { Tetonius? ambiguus, Mckennamorphus } \\
\text { despairensis }\end{array}$ & Tetonius homunculus \\
\hline Steinius vespertinus & Uintanius vespertinus & Omomys? vespertinus \\
\hline Anemorhysis pattersoni+ & not available & not available \\
\hline Anemorhysis wortmani+ & not available & not available \\
\hline Chlororhysis incomptus + & not available & not available \\
\hline Absarokius abbotti & A. abotti (sic), $A$. noctivagus & $\begin{array}{l}\text { A. abbotti, possibly also } \\
\text { A. noctivagus }\end{array}$ \\
\hline Absarokius metoecus & A. abotti (sic), A. noctivagus & $\begin{array}{l}\text { A. abbotti, possibly also } \\
\text { A. noctivagus }\end{array}$ \\
\hline Absarokius gazini* & A. abotti (sic) & not discussed \\
\hline Absarokius australis* & A. noctivagus & not discussed \\
\hline Strigorhysis bridgerensis & Absarokius sp. & Anaptomorphus aemulus \\
\hline Strigorhysis huerfanensis* & Absarokius noctivagus & not discussed \\
\hline
\end{tabular}

Omomyidae (e.g., see reviews by Krishtalka, 1978; Kay, 1980; Cartmill, 1980; Bown, 1981; Rose, 1981a).

Consequently, it is timely to present an upto-date account of anaptomorphine evolution in the light of an enormous body of unpublished material. The authors recognize eight genera and 14 species of anaptomorphine primates in the Willwood Formation of the Bighorn Basin (13 species are named). The original citations of these taxa and the taxonomic names assigned to them by Szalay (1976, 1982), Gingerich (1980a, 1981), and the authors (this study) are depicted in Table 1 .

It has always been tacitly or explicitly believed by proponents of gradual evolution that paleontologic species would be more difficult to discriminate once series of intermediates were found (e.g., Simpson, 1943; Gingerich, 1974a; Rose and Bown, 1986). Evidence from this study shows that enough intermediates are now known in at least three lineages of omomyid primates to render specific and even generic diagnoses exceptionally difficult to construct. The problems that this information poses are relevant and far-reaching for traditional taxonomy as applied to fossil organisms, as well as for the biostratigraphy derived from the examination of temporallystratified lineages in stratigraphic context. The assignment of specimens to evolutionary stages is very useful in evolutionary studies (Rose and Bown, 1984, 1986; see also Maglio, 1973; Krishtalka and Stucky, 1985). These stages are established by fiat for the purposes of discussing fossils in stratigraphic context. It should be apparent that, far from destroying established practice in biostratigraphy, recognition of stages in evolutionary sequences adds appreciably to biostratigraphic resolution.

Evidence is presented here for directional evolution from species to species and genus to genus in a single line (anagenesis), as well as for sympatric divergence of evolutionary lineages (cladogenesis). For taxonomists, the recognition of separate though evolving taxa in an anagenetic line must be accomplished more or less arbitrarily, though tempered by recognition of significantly, if not fundamentally, different adaptations. Where the fossil record is sufficiently dense there are simply no longer any convenient points of chronologic, sedimentologic, or morphologic origin at which many of the anaptomorphine taxa discussed herein can be neatly and consistently separated.

At this point it is necessary to define some terms as used here and to provide a brief overview of some of the conclusions reached in this study. This will aid in understanding the organization of the evidence. In this paper, taxa that arise by anagenesis (resulting 
in no diversification) and those arising by cladogenesis (resulting in multiplication of taxa) are both termed "species." The authors are aware that many authors consider anagenesis to be simply phyletic change. However, because the sum of morphologic change by either cladogenesis or anagenesis does not differ in number or quality (i.e., the end products of one are as morphologically different as the end products of the other), nothing is served by considering one end product a different "species" but failing to recognize the other as a distinct "species." All taxa herein discussed as "species" are paleontologic morphospecies. The relationship between these "species" and species as defined biologically and neontologically is imperfectly known, but the approximation is probably close (Gould, 1983). Some critics have argued that the lineages presented here are oversplit, whereas others suggested that each morphospecies described herein may actually represent more than one biologic species.

In this study, three major lineages of anaptomorphine primates in the Bighorn Basin of Wyoming are recognized that show evidence of gradual evolution through time. Each apparently originated from a common "primitive" anaptomorphine with a morphology near that of Bighorn Basin Teilhardina americana. The first lineage, that of Teilhardina, exhibits evolutionary tendencies toward enlarging the lower central incisors and developing short, squat, more molarized lower posterior premolars in a dental array that remained more-or-less evenly spaced and was accompanied by minimal loss of teeth ( $\mathrm{p} 1$ only). The Teilhardina-Tetonius-Pseudotetonius lineage exemplifies trends toward great enlargement of the central incisor, accompanied by reduction in size and number of the other teeth anterior to the lower fourth premolar and consequent shortening of the anterior portion of the jaw. The principal evolution in both of these lineages appears to have been accomplished by anagenetic speciation, although each one contains an apparent branching event.

Genus Absarokius (Absarokius metoecus$A$. abbotti) evinces cladogenetic rather than anagenetic speciation, as well as intraspecific anagenesis. Absarokius metoecus was an immigrant to the Bighorn Basin where it gave rise to $A$. abbotti. Yet $A$. metoecus persisted sympatrically with $A$. abbotti and retained its generalized lower fourth premolar but underwent progressive morphologic changes in molar anatomy, including reduction in molar size. In contrast, the evolution of $A$. abbotti was typified by slight increase in overall size of the lower fourth premolar and the first and second molars, accompanied by increase in height of the lower fourth premolar and progressive distinctive posterobuccal distention of its crown. The $A$. metoecus lineage was probably related to the ancestries of Bridgerian Aycrossia and Strigorhysis (almost certainly the latter genus), and the $A$. abbott $i$ line might be related to the ancestries of $A b s a$ rokius nocerai and perhaps some other $A b$ sarokius species occurring outside the Bighorn Basin. The data at hand, including those from other basins, are not sufficient to substantiate these possibilities.

\section{PHILOSOPHY}

It appears probable that the geographic dispersion and biostratigraphic occurrences of some, if not many, Willwood mammals are subject to poorly understood paleoecologic controls (see, e.g., Bown, 1979a, 1987; Schankler, 1981; Wing and Bown, 1985; Beard et al., 1986; Bown and Kraus, 1987). Though hardly surprising, the effect of these controls is that true stratigraphic points of origination, immigration, and extinction of certain taxa may not exactly coincide with stratigraphic points of first or last occurrence as inferred from field data or the biostratigraphic record of the Willwood Formation. Nevertheless, the established biostratigraphy of the Willwood Formation is a real record of these biologic events that must be considered if time plays an important role in evolutionary studies and phylogeny reconstruction.

The authors have proceeded from the viewpoint that the paleontologist has three essential tools with which to reconstruct phylogenies: 1) time (in this case, stratigraphy), because without it evolution cannot occur; 2) morphology, because without it evolution through time cannot be documented; and 3) paleoecologic studies, because they are the only method by which to determine paleoenvironments and thereby reconstruct ancient habitats. Though seemingly prosaic, the tools cited above have been neglected by many 
workers, especially in the last decade, due to the advent of the cladistic approach to phylogenetic reconstruction. Cladistic analyses appear to be especially appealing to workers not engaged in field oriented studies and to those who have many specimens but little in the way of obtainable stratigraphic controls. Though cladistic analyses can be very valuable by virtue of their methodological rigor (particularly where the density of the fossil record is poor), they must not be substituted for field research or for stratigraphic control.

In this study considerable emphasis is placed on the stratophenetic approach to phylogeny reconstruction, developed in several works by Gingerich (e.g., 1974a, 1976, $1979,1980 \mathrm{a}$ ). This is not to say that time (or biostratigraphy) in combination with biometric data alone are the only requisite evidence for phylogeny reconstruction. Rather, the stratigraphic arrangement of tooth dimensions or a function of their dimensions is an easy and succinct way to depict how these dimensions exist in time and the fact that they have changed through time (observable and testable), if not why they have changed (interpretive). When consistently occurring morphologic attributes are studied and displayed graphically in like manner, what results is a summary of empirical observations (size, structure, and stratigraphic position) that constitutes a data base for more heuristic interpretation.

Graphic representations of tooth size alone, as used here in several figures, are means of arranging data, not of interpreting it. All of the parameters used in constructing this graphic data base (tooth size, morphology, and stratigraphic position) are observable and testable data that can be and have been established independently of one another, and that can be rechecked and reassessed as often as necessary. For cases in which a good stratigraphic data base exists, it is more efficient to begin studies by utilizing all of the available data from the outset, rather than by repeated examination of character states, setting up possible morphologic clades or pivots, and then testing these against biostratigraphy. Although many cladistically-oriented students philosophically acknowledge the importance of testing their cladograms with known biostratigraphy and the fossil record, few actually reach this stage, preferring in- stead to present cladistic representations as faits accomplis.

Any systematic or phylogenetic scheme that is not tested by, or is not consistent with, the fossil record is either incomplete or spurious, because the fossil record is the only real record and thereby our only means of testing conclusions with facts. An unfortunate aspect of many cladistically-oriented studies is that actual specimens of fossils are only rarely mentioned. How, then, are these studies to be evaluated or tested again by other workers, if not by the specimens they purport to evaluate? Thus, it is rather distressing in the light of the foregoing that several authors appear to believe that evolutionary studies need no longer be encumbered by the fossil and/or biostratigraphic evidence (e.g., Schaeffer et al., 1972; Patterson, 1981; Rosen et al., 1981).

The stratophenetic approach must, however, be undertaken with the realization that the antiquity of a character state does not by itself determine its primitiveness, even though it can certainly be helpful in establishing character polarities, as even Hennig (1966) acknowledged. With a dense stratigraphic record of specimens it is, indeed, the only method by which character polarities can be tested without a great many a priori assumptions that may or may not be grounded in empirical data. The stratophenetic approach appears to be especially parsimonious in this regard because it allows consideration of only those character states that are known from specimens whose time contexts can be established; that is, it makes use of only real data, and all conclusions drawn from those data must conform with what is known from the fossil record.

For example, concerning this study, it is fruitless to speculate that the morphology of middle and late early Eocene Absarokius might be ancestral to the morphology of early early Eocene Tetonius. The morphology of Tetonius is such that derivation of Absarokius from it is a very likely possibility, and one that is supported by biostratigraphic occurrences. However, the polarities of the Omomyidae are such that Tetonius could be regarded to be a descendant of Absarokius if the stratigraphic record were ignored. Though no one can say positively that no early early Eocene species of Absarokius existed to give rise to Tetonius, stratophenetic methodology 
excludes this possibility until fossils of such an animal are found. In other words, the stratophenetic approach ideally utilizes only evidence and, if used properly, all of that evidence.

The authors' adhesion to the stratophenetic philosophy has its roots in the unusually dense and stratigraphically continuous fossil record of anaptomorphine primates and other mammals in the Willwood Formation, but it has also been enhanced by the clarification of their evolution afforded by studying several groups of these mammals in stratigraphic context. It is extremely unlikely that thisthe best record of early Eocene mammals anywhere in the world-is misleading; i.e., that the true relations of these mammals will never be known, can only be documented by as yet undiscovered specimens, or can be corroborated only by collections from other nearby basins or more outlying areas. Nothing found in another geographic area or in another temporal sequence can alter the record of anaptomorphine evolution in the Bighorn Basin, even though new records from elsewhere could certainly clarify knowledge of origins and broader interrelationships of the Bighorn Basin anaptomorphines. Significantly, existing collections of early Eocene anaptomorphines from other areas in no way contradict any part of this interpretation of the Bighorn Basin record and, in several noteworthy instances, supplement and support it admirably.

It cannot be emphasized too strongly that a clear knowledge of the stratigraphic provenance of samples is essential in sorting out variable characters of taxonomic weight from those that have directional (temporal) importance in evolving lineages. Stratigraphic data have therefore been of nonpareil importance in identifying morphologic trends and in elucidating phylogenetic relationships of closely related taxa. Similarly, Lazarus and Prothero (1984, p. 163) believed stratigraphic information to be essential in the phylogenetic analysis of some deep-sea microfossils that "... lack a sufficient number of hierarchically nested sets of characters for cladistic analysis." Whatever the cladistic merit of the dental characters of the Bighorn Basin anaptomorphine primates, the results of this study are owed chiefly to precise stratigraphic controls. Solely cladistic analyses of the specimens at hand are unlikely to achieve a more internally consistent or comprehensive picture of the dental evolution of this group.

In a few instances, character trends in Bighorn Basin anaptomorphine lineages are interrupted, or a distinctive morphology makes a first appearance with no apparent intrabasin progenitor. In these examples, cases are made for local or paleoecological extinction, organismic extinction, or immigration from an extraneous area. There is no evidence of "punctuation" in the evolution of the Bighorn Basin anaptomorphines that cannot be equally well or better explained by means other than the punctuated equilibria model.

Certain taxa are known to have occupied several intermontane basins simultaneously during parts of the early Eocene: e.g., Tetonius in the Bighorn, Powder River, Sand Wash (Four Mile Creek area), ?Washakie, and Laramie Basins; Teilhardina in the Bighorn, Williston, ?Sand Wash, and ?Powder River Basins; Anemorhysis in the Bighorn, Wind River, Green River, and Washakie Basins; Absarokius in the Bighorn, Wind River, Piceance, Huerfano, and greater Green River Basins. Therefore, opportunities for immigration resulting in apparently "punctuated" evolutionary records abound. Following the establishment of a species in several basins at about the same time, evolution appears to have proceeded more or less independently in each of these basins, with the record further complicated by sporadic dispersals of evolving populations to other basins. To the extent that the mechanism of evolution outlined by the punctuated equilibria school is correct, identifying the temporal and geographic points of origin of these taxa is technically impossible (and therefore untestable); however, these points might be identified in densely sampled sections if some or all of these taxa originated gradually (by either anagenesis or cladogenesis). The point is that stratigraphic relations of samples are necessary to establish phyletic relationships with confidence. Evidence is offered here supporting the gradual origination of anaptomorphine taxa by both anagenesis and cladogenesis, as well as a clear example of immigration of an anaptomorphine species into the Bighorn Basin.

At some advanced stage of phylogenetic 
analysis, it is instructive to leave philosophical proclivities behind and simply speculate: "if, indeed, these organisms evolved gradually or, on the other hand, in a manner more consistent with punctuated equilibria, how would the sum of the biometric and morphologic information look when arranged stratigraphically?" The picture revealed by anaptomorphine primate evolution in the Bighorn Basin is, as far as the evidence reaches, wholly consonant with gradual evolution. The authors do not, however, champion "gradualism" as the only mechanism of tempo in evolution; it is simply the one that best explains the evidence at hand.

It may be that some proponents of the punctuated equilibria school of evolution will be left unconvinced, and that they will coin new terminologies to bring the picture of anaptomorphine evolution offered here into their philosophy. As with Gould and Eldredge's (1977) evocation of "species selection" (Stanley, 1985) to explain evolution of tooth size in Hyopsodus (Gingerich, 1974a, 1976), this vacillation is a revisionist merging of the two schools of evolutionary thought; to wit, the gradual evolution of the theory of punctuated equilibria into that of gradualism.

\section{PUNCTUATED EQUILIBRIA AND GRADUALISM}

Considerable debate traditionally attends articles purporting to clarify understanding of the mode and tempo of organic evolution. In paleontology in recent years, this debate has crystallized into two broad views of the mechanisms of speciation as they appear to be documented by data derived from field studies. The traditional Darwinian viewpoint that species can and commonly do originate gradually (and continue to evolve gradually) by means of phyletic evolution (anagenesis) and/or division of lineages (cladogenesis) is best expounded in the recent works of Gingerich and his co-workers on fossil mammals, largely from the Bighorn Basin (e.g., Gingerich, 1974a, 1976, 1977a, 1980a, 1980b; Gingerich and Schoeninger, 1977; Gingerich and Simons, 1977; Bookstein et al., 1978; Gingerich and Gunnell, 1979).

Origin of species by a strictly allopatric model known as punctuated equilibria is a second widely-held concept and, to judge from prevailing publication trends (including the newspapers), the one that currently enjoys the upper hand. This model, championed by Eldredge and Gould (1971, 1974), Gould (e.g., 1977, 1982, 1983), and Gould and Eldredge (1977), among many others, advocates that most gaps in the fossil record are probably real in paleontologic terms; they "punctuate" periods of evolutionary stasis and probably result from relatively rapid episodes of allopatric speciation. New characteristics arise in isolated populations, in some sense peripheral to a central population and, after successful genetic invasion of the central population, they become dominant in it. Thus the much older concepts of genetic drift (Wright, 1948) and "founder principle" (Mayr, 1942) are salient components of punctuated equilibria. Yet, the theory of punctuated equilibria differs appreciably from them in that: 1) the proposed nature of the origination of new characteristics is entirely different (and not of importance to this discussion); 2) the allopatric "drift" of genetic materials is given preeminent stature in organization of new taxa; and 3) dissemination and dominance of the new characteristics are postulated to occur so rapidly (geologically speaking) in both the peripheral isolate and in the central population that the chance of finding fossils documenting intermediate stages of development is, except in extraordinary cases, virtually nonexistent.

It is not the intent of this paper to offer evidence favoring one or the other model as the single or the most realistic mechanism of speciation. Such speculation is well in advance of the paleontologic evidence. Indeed, both schools of thought now admit the possibility, albeit small, that both processes could be operative in the same or different groups, at different times in their histories, or in different places (Bookstein et al., 1978; Gould and Eldredge, 1977). However, the latter two authors consistently aver that actual cases of gradualism must be very rare and operate too slowly to have had much significance in evolution.

Eldredge and Gould correctly point out that for studies of evolutionary processes to make any headway we must divorce ourselves thoroughly from incunabula that prove to be unworkable. Gingerich's work demonstrates that new empirical data and new interpretations logically require the reevaluation of the old. 
It is not important in this study to recognize whether gradualism or punctuated equilibria might have had the major impact on evolution (a subject that cannot be resolved by any single contribution); rather, explanations for well documented transitions should be sought as the best evidence for them becomes available. Once numerous transitions are well documented from the fossil record, one may expect to see continued vacillation in both schools of thought.

The current "contest" between punctuated equilibria and phyletic gradualism is largely ". . . one that reduces to an issue of scale. The more one aggregates temporally stratified data, the more difficult it is to read the consequences of differential reproductive success among individuals" (Bookstein et al., 1978, p. 133; see also Penny, 1985). Though this seems prosaic, it is an idea that cannot be emphasized too strongly. In order to discuss morphological differences between samples of temporally disjunct fossils that are believed to be closely related members of a higher order taxon (for example, Tetonius and Pseudotetonius as members of the Anaptomorphinae), the different samples are distinguished, at one level or another, as separate taxa based on discrete character states. This distinction is traditionally expressed as a diagnosis. However, if these character states in fact evolved gradually, it would be impossible to refer intermediate morphologies (when they become known) to one taxon or the other (e.g., Simpson, 1943; Rose and Bown, 1986). One reason that so many taxa described from relatively poorly known areas (that are geographically and/or temporally disparate from better sampled areas) remain valid is that, because of this disparity, they are de facto geographic and stratigraphic end members of lineages. They do not possess the baggage of temporally-stratified morphologic variability that makes their taxonomy more difficult to establish. In a conversation many years ago with T.M.B., M. C. McKenna referred to these taxonomically valid isolates as "sagebrush species"; i.e., one or at best a few specimens surrounded by miles of sagebrush.

In a typical graphic portrayal of the biostratigraphic ranges of a group of closely related taxa through time, the aggregation of character states (determined from temporally-stratified morphologic data) used in originally diagnosing these taxa necessarily produces a picture of what appears to be the somewhat abrupt replacement of one form by another. In other words, classification tends to obscure our ability to view process. This must be kept in mind by all who overemphasize the perceived paucity of morphological intermediates, between lower and higher taxonomic categories alike.

Evolutionary mechanisms have, at times, been improperly inferred from non-evolutionary data. For example, Stanley (1982, p. $462-464 ; 1985)$ interpreted Schankler's (1980) simple depictions of the stratigraphic ranges of early Eocene mammals from the Willwood Formation as "ranges for 69 lineages" (the authors' emphasis), and he asserted that "any one of the well documented segments of lineages could exhibit significant evolution over the span of time represented, but none does." He further concluded that "at least two species of Hyracotherium lasted for several million years without appreciable change." The latter rather sweeping interpretation was offered despite the lack of any review of Hyracotherium for three decades (Kitts, 1956). Even Kitts' study was accomplished with no stratigraphic base and less than $10 \%$ of the specimens now available. It is emphasized that Schankler's (1980) study, so widely quoted by Stanley $(1982,1985)$, is wholly biostratigraphic in nature and presents no information, either explicit or implicit, about species variability or evolution. Schankler's study, by itself, does not support any theory of evolutionary mechanisms.

There is also a tendency to use dense, temporally-stratified variability as evidence that only one, highly variable species is present. Once this variability is "lumped" by assigning a single taxonomic name, it is lost, and what remains appears to be a temporal succession of rather clearly defined species without any transitory links between them. Because the names do not overlap, the morphology is no longer seen to overlap, and the record of these "species" appears to be punctuated.

With some qualification, Gould and Eldredge $(1977$, p. 121) observed that the tenets of punctuated equilibria need not deny that allopatric speciation occurs gradually in ecologic time. It certainly must (even though "gradual" might be very rapid in the geologic 
sense), because time is required for genetic replacement in a large population with a broad range. Within this context of change through time, it is important to recall that taxa are normally established on end member character complexes - end members that owed (at the time of their naming) their recognition as something distinct from what came before or after to data gaps in which an appreciable number of structural intermediates were unknown. It is only by attempting to fill in these temporal data gaps that the nature of the evolutionary change across them can best be evaluated.

The "absence" of structurally intermediate forms in the fossil record has been somewhat overemphasized by Eldredge and Gould and, as they would surely recognize, is far from total. It is true that for many important evolutionary transitions one cannot point to direct ancestor-descendant pairs with any confidence, and that several (if not all) of the intermediate forms appear to be divergently specialized away from the direct line of succession. Nonetheless, it is important to recognize that the density and continuity of sampling for all of the more spectacular vertebrate transitions (i.e., amphibians to reptiles, reptiles to birds, and even reptiles to mammals) are orders of magnitude less than those for the fossil mammal transitions documented by Gingerich and his co-workers, and those in the current study.

For many groups, the "absence" of intermediate forms in the fossil record is at least as much the result of taxonomic procedures (the typologic concept of "missing link" species) and, perhaps more importantly, the lack of a good, dense record of fossils, as it may be due to rapid allopatric speciation. Recognition of precisely which of these factors affects the interpretation of specific cases must await equally dense data bases. In view of the fact that the record of many Paleozoic and Mesozoic sections (as well as some Tertiary sections) has almost certainly been severely compromised by time-averaging, a suitably dense record for many important evolutionary transitions may never be obtained.

In sum, the lack of recognition of intermediate forms can arise from: 1) the lumping of a broad range of morphologies into one taxon as a classificatory convenience; 2 ) the recognition of what appear to be discrete taxa due to data gaps (of whatever origin), which tend not only to emphasize these discrete morphologies recognized as taxa but also to limit the ability to adduce what, if any, changes might have taken place during a temporal hiatus; and 3) instances in which intermediate forms cannot be found in a densely sampled and continuous stratigraphic record because they never existed. Good examples of the third case are extremely rare, if they occur at all, and the authors know of no compelling evidence for them in the fossil record of mammals from the Willwood Formation. In that sequence, it is clear that records of many mammals for which good ancestors are not known, e.g., Absarokius, have not resulted from "punctuations" in the evolution of their lineage, but rather from their immigration into the Bighorn Basin from elsewhere.

Problems posed for evolutionary studies by the lumping of intermediate forms for the purposes of taxonomy can be eliminated procedurally by making no effort initially to link character states with a taxon. That is, specimens, including type materials, are not tied to names until the analytical part of a study is completed, thus preventing the tendency to associate unidentified materials with established taxa early on in the research. Names only provide an easy way to refer to a group of animals and to distinguish "landmarks" in a graded sequence of morphology. If many taxa actually did evolve gradually, as the authors believe, this methodological approach is essential because it becomes clear that the names, and even those names applied to type materials, constitute the artificial imposition of a controlled, hierarchy on what may actually be a fluid, everchanging system. It is therefore important to separate process (i.e., evolution) from the inherent obfuscation of taxonomy.

One of the principal criticisms anticipated in this study hinges on the significance of the overlap of characters seen in specimens forming parts of temporally stratified sequences. Some colleagues feel that overlap is an indication of sameness in the taxonomic sense; i.e., if sample $A$ at stratigraphic position 1 is really distinct from sample $B$ at stratigraphic position 4 , this distinction should be a measure of the degree to which they do not over- 
lap. The authors agree to the extent one's aim is to classify. If instead the object is to view process, the nature and extent of overlap of characters in time succcessive samples is critical to understanding in what sequence, and how fast, distinctions of taxonomic import have arisen. The taxonomic pigeonholing of variable characters distributed in time inevitably leads the worker to conclude, in agreement with Eldredge and Gould (1972, p. 96), that two species ". . . will display their greatest difference when the descendant first appears." Although this contention is one that should be retained as a possibility, it is not one that should be arrived at by ignoring whatever directional temporal variability does exist for the sake of a taxonomy set up prior to evolutionary analyses.

As is defended at some length in the sections to follow, the temporally-stratified continuum of directional or diverging character states in the lines leading from Tetonius to Pseudotetonius and from Absarokius metoecus to A. abbotti is such that taxa of consistently varying morphologies could be recognized at any of a number of stratigraphic points in the biostratigraphic continuum of the Willwood Formation (i.e., taxonomy is a sliding-scale). However, wherever these taxa are recognized, there are no great morphological differences separating them from specimens of what came immediately below or immediately above.

Another difficult problem posed for evolutionary studies is what Eldredge and Gould (1972) rightly identified as the long-standing apology by students of phyletic evolution for the "lack" of intermediate forms in the fossil record; to wit, that this paucity is the result of gaps. Gaps deserve special attention because they are central to the concept of punctuated equilibria, which maintains that many, if not most, appearances of new characters are sudden (not the result of gaps in the geologic record), and that they accurately reflect rapid, step-wise evolutionary transitions.

No one will deny that real gaps in the sedimentary and fossil records exist and that in many instances more advanced fossils of the same level taxon or a higher taxon succeed (above the gaps) less advanced forms distributed lower in the geologic column. The geologic literature is riddled with instances of this sort, in which no paleontological data exist through a considerable time period and over a considerable region; both probably within the ranges of several evolving groups of organisms. These gaps may be ecologic and/or taphonomic as well as temporal in origin, and may be represented by rock sequences barren of fossils as well as by a variety of unconformable relations. By their nature, such gaps neither support nor refute a particular theory of evolutionary process because they owe their recognition to an absence of data, and thereby an absence of evidence (see also Hecht, 1983; Gingerich, 1984). The fallacy of incorporating large geographic areas and temporal sequences devoid of fossils into theories of mammalian evolution and paleogeography was superbly underscored by Clemens et al. (1979) who addressed these problems as they apply to mammalian evolution in the Mesozoic. This reasoning must also be applied to evaluation of the significance of gaps in the geologic record.

In the light of Sadler's (1981) innovative studies on time-averaged sedimentary sequences, it seems likely that a great many Paleozoic and early Mesozoic sequences do not represent enough time (or enough reasonably continuous time) to adequately document evolutionary patterns. If, for whatever reason, there is no fossil record for any time interval, no assessment of evolutionary patterns or rates across this interval is more reasonable than any other (see also Maglio, 1973).

On a smaller scale, that of the local section rich in fossils, the problem of gaps (i.e., exactly what constitutes a gap to different paleontologists, and the significance of these gaps) must be resolved before deciding whether a measurable amount of change through time occurred "gradually" or as the result of rapid transition between essentially static populations. A gap is simply that: a sequence of rocks or an unconformity representing some time interval for which no data exist.

It can be argued that any gap in a dense stratigraphic record of fossils, however seemingly insignificant, introduces the possibility (to some, even the likelihood) that evolutionary change across some part of it was very rapid and, therefore, consonant with the model of punctuated equilibria. When ap- 
plied to the record of fossil mammals from the Willwood Formation, however, acceptance of this argument is tantamount to reasoning that empirical data almost never portray real relationships. This is not a realistic or workable concept from which to entertain scientific inquiry. Whether a data gap of 1 $\mathrm{cm}, 1 \mathrm{~m}, 10 \mathrm{~m}$, or $20 \mathrm{~m}$ is significant to a particular transition in a local section must be evaluated from both the nature of the section (by recourse to sedimentology) and the nature of the paleontologic evidence partitioned by the gap.

Evidence from the evolutionary transitions documented in this study suggests that if evolutionary mechanisms consistent with punctuated equilibria were operative, there must have been very numerous introductions of new genetic material from "peripheral" populations, all of which were so trivial in nature that they cannot be visualized, much less analyzed, for their morphological or biometric evolutionary import. Moreover, these introductions would have had to have been, coincidentally, both chronologically and morphologically conformable with a gradual pattern of evolution. The hypothesis that such coincidence is possible (e.g., Lillegraven et al., 1981, fig. 55) is not evidence that it is fact.

The problem of data gaps in the densely fossiliferous Willwood section and some interpretations that can be drawn from them were illustrated recently by Bookstein et al. (1978) in their analyses of stratigraphically successive samples of teeth of early Eocene mammals, particularly those of the condylarth Hyopsodus. Using their figure 8 , it is seen that gaps of a few to several meters separate stratigraphically successive samples of the first lower molar in Hyopsodus. For any one of these gaps (including those within very closely spaced stratigraphic data) it is possible to interpolate hypothetical data in a temporal framework that would alter the empirical record so as to favor a more rapid, "punctuated" transition between apparently static populations or, alternatively, a relatively slow, "gradual" rate of change. Neither exercise solves any problems and it should be assumed that the relatively dense and continuous parts of the empirical records accurately document the nature of transitions. Several very dense transitions are currently represented by the Hyopsodus data and those records provide evidence apparently supporting both phyletic evolution and intervals of stasis in first lower molar size. Key to the identification of supposed intervals of stasis in Hyopsodus tooth size, as outlined by Bookstein et al. (1978), is that only biometric data are presented. There is no evidence presented for or against evolutionary trends or stasis in any other morphologic characters of the dentition.

Unfortunately, presentation of such limited data can be misleading. For example, Stanley (1985, p. 18) claimed: "In fact, within the Hyopsodus clade there was apparently little morphologic evolution other than size change, which may have been punctuational ..." and, citing West (1979), "As currently defined (Gazin, 1968) species of Hyopsodus are virtually indistinguishable from one another except for size differences." "This information is presented in spite of the fact that no significant morphologic information, apart from size, was presented by Gingerich (1974a, 1976), Bookstein et al. (1977), West (1979), or Schankler (1980). Moreover, there has been no published study of dental morphology and dental variability in Hyopsodus since Gazin's (1968) work, and very little there. What "stasis" exists in the evolution of Hyopsodus has been demonstrated only in lower molar size, not the more important evolutionary stasis in the organism as a whole (that is proposed by the tenets of punctuated equilibria), nor even in the available morphology.

If punctuated equilibria represents the true mode of species succession, then one should be able to document long periods without significant (i.e., observable) change in morphology, aside from oscillation about a mean, even if punctuations cannot be detected. Where known, the empirical evidence does not support this. Analyses of morphologic variability and its evolution in Hyopsodus will have to be assessed after detailed studies of dental morphology in that taxon have been made; for the time being it falls in the realm of no data.

In examining the evolutionary record of anaptomorphine primates from the Willwood Formation, it was found that one or several aspects of the dental and gnathic anatomy were changing during any given time interval, even though others (in analogy with 
tooth size in the case of the condylarth Hyopsodus) may not have changed at the same time or during another time. Because much of the anatomy of fossil organisms can never be known due to preservation potentials, it will always be impossible to test for total evolutionary stasis in any fossil organism (see also Schopf, 1982; Gingerich, 1984; Martin, 1984; Krishtalka and Stucky, 1985; Rose and Bown, 1986). From the foregoing, it seems that organismic stasis is rarely if ever testable and cannot, therefore, be given much weight in scientific arguments of evolutionary processes.

In summary, more or less continuous stratigraphic sequences rich in fossils are relatively rare. This is unfortunate because clearly they are the most important for evaluating evolutionary successions and processes. One such relatively continuous sequence is the early Eocene Willwood Formation in the central Bighorn Basin, which yields abundant fossil mammals through about $770 \mathrm{~m}$ of section. The evidence of the fossil record combined with the foregoing discussion suggests a somewhat startling fact. If one accepts that empirical evidence is generally realistic as a function of the quality of the available data base, and even if one admits the possibility that populations of organisms might have remained totally static in their evolution for long or short intervals of time, it appears that actual documentation of a punctuated record of evolution requires a somewhat denser data base than does documentation of phyletic evolution. It is not inferred that a greater density of data will "capture" the picture of evolution in "peripheral" groups (one of the central concepts of punctuated equilibria). It is simply necessary to have extremely dense sampling across an interval to document that an actual "punctuation" (rather than relatively rapid gradual evolution) took place.

The concept of evolution by the mechanism of punctuated equilibria implies that rock sequences with many, commonly profound fossil data gaps are important in evaluating evolutionary processes. These sequences are not only implied to be equally significant as those with fewer and less profound gaps, they are fundamental to the concept of punctuated equilibria and are believed to serve as our guidon bearer to evolutionary process. The conceptual and methodological difference in pursuing studies of evolution with the two different philosophies is that the theory of punctuated equilibria relies on gaps (i.e., no paleontologic data) and on typological concepts of species to evaluate evolutionary processes. Darwinian gradualism simply requires the best available fossil record.

\section{GEOLOGIC SETTING OF BIGHORN BASIN ANAPTOMORPHINE PRIMATES}

The Bighorn Basin is a yoked intermontane basin in northwest Wyoming (Figure 1) that is structurally bounded by several distinct uplifted areas. In clockwise succession, these include the Pryor Mountains on the north, the Bighorn Mountains on the east and southeast, the Owl Creek Mountains on the south, the Absaroka Range on the southwest and west, and the Beartooth Mountains on the northwest. The basin is open today, as it was in Eocene times, in a narrow region to the north between the Beartooth and Pryor Mountains. The Pryor, Bighorn, Owl Creek, and Beartooth Mountains are later Laramide fold mountains, all of which are complicated by thrust faulting on their margins (east, west, south, and east margins, respectively).

The Beartooth and Pryor Mountains and the northern part of the Bighorn Mountains appear to have been elevated by late Paleocene time. In contrast, the southern Bighorn Mountains and the Owl Creek Mountains arose somewhat later; the most appreciable structural elevation of them having probably been accomplished in late early Wasatchian through early late Wasatchian time (Love, 1939; Bown, 1979a, 1980b; Bown and Kraus, 1981a; Wing and Bown, 1985). The Absaroka Range is a partly dissected pile of volcanic and volcaniclastic rocks, largely of middle and late Eocene age (Love, 1939; Bown, 1982), although volcanic activity in the Wyoming Absaroka region began in the latest early Eocene (Smedes and Prostka, 1972). Thus, during the earliest period of omomyid evolution discussed herein, the Bighorn Basin was structurally and probably topographically open to the north, southeast, south, and southwest.

The advent of the early Eocene in the Bighorn Basin was typified by somewhat warmer climate than the Paleocene. This is reflected 
in the compositions of the Paleocene Fort Union and lower Eocene Willwood floras (Hickey, 1980; Wing, 1980, 1984) and faunas (Rose, 1981b), as well as in the morphologies of Fort Union and Willwood paleosols (Bown and Kraus, 1981a). In the later part of the early Wasatchian, easy faunal access to the Powder River and Wind River Basins was lost due to rapid structural elevation of the southern Bighorn and Owl Creek Mountains. Evidence of the succession of later Wasatchian Willwood paleosols (Bown, 1979a; Bown and Kraus, 1981a, 1987) and later Wasatchian floras (Wing, 1980) indicates that structural closure of the Bighorn Basin was accompanied by trends toward a general climatic drying, perhaps due to the progressive development of a basinward rain shadow (Bown, 1979a, 1980b; Bown and Kraus, 1981a).

Each of the bounding uplifted areas contributed sediment to the alluvial Willwood Formation at different times and in different areas throughout the early Eocene. These sediments are dominated by sandstone and mudstone, and nearly all were deposited by alluvial mechanisms. Willwood sandstones are of channel, levee, and crevasse-splay origins, whereas the mudstones were deposited both on levees (where they are generally very sandy) and on more distal parts of stream floodplains. All of these sediments underwent varying degrees of pedogenesis during the early Eocene (Bown and Kraus, 1981a), and analyses of the pedofacies relations of these soils (Bown and Kraus, 1987) allow assessment of their relative stages of maturity.

Willwood paleosols are classified in the entisols, alfisols, and spodosols (Bown, 1985; Bown and Kraus, 1987) and, by analogy with comparable stages of development in analogous modern soils, they appear to have formed over periods of approximately 1,00024,000 years (Kraus and Bown, 1986). The most important fossil vertebrate sites in the Willwood Formation, as well as the vast majority of all of these sites, contain attritional assemblages of fossils that accumulated in the upper parts (commonly in A horizons) of Willwood soils during their times of formation (Bown and Kraus, 1981b; Bown, 1987). Therefore, approximate isochroneity can be established for the paleosol assemblages of fossils. The temporal resolution of the sam- ples of anaptomorphine primates is the same as that for the paleosols, i.e., on the order of $1,000-24,000$ years - among the best for any samples of fossil vertebrates anywhere in the world (see also Bell et al., 1985; see Kraus and Bown, 1986, for fuller treatment of time resolution in the alluvial stratigraphy of the Willwood Formation).

A combination of faunal and sedimentologic evidence indicates that no appreciable temporal gaps exist anywhere in the central Bighorn Basin Willwood section, with the exception of a widespread intraformational erosional unconformity that locally separates rocks and faunas of early Wasatchian age from those of later Wasatchian age at Biohorizon C of Schankler (1980). This unconformity records an episode of lowered local baselevels and gullying, followed by a return to aggradational conditions (Bown, 1984).

Much if not all of the faunal distinctiveness on either side of Biohorizon $\mathrm{C}$ is linked to the erosion of more than $100 \mathrm{~m}$ of Willwood sediment during early Eocene gullying. The basal gully-fill deposits are largely levee, crevasse channel, and proximal floodplain in origin and contain a fauna that is significantly younger than found in the enclosing truncated sediments. Nonetheless, faunal continuity has, where possible, been maintained across Biohorizon $\mathrm{C}$ by collection of fossils from temporally more complete sections lateral to the intraformational unconformity. In the central Bighorn Basin, Biohorizon $\mathrm{C}$ appears to be variously developed within the 425$530 \mathrm{~m}$ interval above the base of the Willwood Formation; the lower figure reflects areas of deepest gullying, and the higher figure records the approximate stratigraphic level of the edge of the late early Wasatchian gully system, where the temporal record of fossils is again more or less continuous.

In summary, careful and detailed stratigraphic, sedimentologic, paleopedologic, and taphonomic studies of the Willwood Formation have been as essential to unravelling the geologic overprint on the evolutionary relations of the Bighorn Basin Anaptomorphinae as have the dense, temporally-stratified records of Willwood anaptomorphines themselves. Not only do the geologic studies establish acceptable controls on contemporaneity of anaptomorphine samples over wide geographic areas, they permit realistic ap- 
praisals of the tempo of evolution of mammals in the Bighorn Basin. The geologic evidence is sufficient to explain the origin of a significant biostratigraphic boundary (Biohorizon $\mathrm{C}$ ) in the best documented Wasatchian sequence in the world and offers insights on the possible nature of other sedimentologically-controlled faunal breaks elsewhere in alluvial sequences. Even more important, the causal relation of the structural closure of the Bighorn Basin to climatic drying in later Wasatchian time, afforded by a combination of independent sedimentologic, paleopedologic, and paleobotanical evidence, provides a backdrop of gradually changing climatic conditions against which Bighorn Basin mammalian evolution can be evaluated.

\section{STRATIGRAPHIC AND LOCALITY DATA FOR BIGHORN BASIN ANAPTOMORPHINE PRIMATES}

As outlined above, much of the confusion attending earlier studies of anaptomorphines from the Bighorn Basin and other areas has resulted from inadequate samples, inadequate stratigraphic data, and/or inadequate locality data. Of the 13 named species of Bighorn Basin anaptomorphines here recognized as valid, good locality and stratigraphic data are available for the holotypes of only seven of these, three of which are described here for the first time; the others are Teilhardina americana (Bown, 1976) and Anemorhysis pattersoni, $A$. wortmani, and Chlororhysis incomptus (Bown and Rose, 1984).

Of all lower Eocene anaptomorphine materials collected outside the Bighorn Basin, only materials of Arapahovius gazini (Savage and Waters, 1978) and some associated primates are tied to a detailed measured (though unpublished) stratigraphic section (Savage and Hutchison, 1972). Published sectioncontrolled biostratigraphic data do not exist for any other samples of North American anaptomorphines, though most of these are associated with large faunas of other mammals. Lack of stratigraphic control makes it very difficult to establish whether these occurrences are typical for the time in which they are represented in local sections, or if they are paleoecological anomalies. Likewise, lack of stratigraphic control makes it impossible to distinguish immigration from origination. It is therefore to the superb record of anaptomorphine primates from the Bighorn Basin that one must turn to analyze the evolutionary succession in these animals, acknowledging that somewhat different successions are likely in other basins.

All Wasatchian lower Eocene rocks in the Bighorn Basin belong to the about $770 \mathrm{~m}$ thick Willwood Formation (Van Houten, 1944), excepting the lower 100-150 m of the conformably overlying Tatman Formation (Bown, 1982) and about $300 \mathrm{~m}$ of Wasatchian rocks near Basin, Wyoming, which belong to the Fort Union Formation (Wing and Bown, 1985). The most recent estimate of the duration of the Wasatchian (about 6 m.y.) was by Berggren et al. (1985), and is used here. Anaptomorphine primates have been found from $25 \mathrm{~m}$ to about $700 \mathrm{~m}$ in the Willwood Formation.

The Willwood (then the "Bighorn Wasatch") was divided from bottom to top, on the basis of its faunas, into the Sand Coulee "local fauna," the Gray Bull "member," the Lysite "equivalent," and the Lost Cabin "equivalent" by Wood et al. (1941). This was a confused view of time- and rock-stratigraphy, and implemented (though in different form) the earlier concepts of Loomis (1907), Sinclair and Granger (1911, 1912), and Granger (1914). The term Sand Coulee (Granger, 1914; Jepsen, 1930) is no longer used in its original sense (Bown, 1979a) and the "Gray Bull," "Lysite," and "Lost Cabin" have always been utilized strictly as faunal horizons in the Bighorn Basin - the latter two terms having been borrowed from the Wind River Formation of the Wind River Basin, where they have rock-stratigraphic meaning as members of the Wind River Formation. Traditionally, the "Gray Bull," "Lysite," and "Lost Cabin" faunas (as "Graybullian," "Lysitean," and "Lostcabinian") have been used as informal subdivisions of the Wasatchian Land Mammal Age, even though as such they have not been adequately documented anywhere by a section-controlled biostratigraphy.

Section-controlled biostratigraphic studies of the Willwood Formation and/or Willwood mammals were accomplished by Neasham (1970), Gingerich (1974a, 1976, 1977a, 1980a), Gingerich and Simons (1977), Gin- 
gerich and Gunnell (1979), Bown (1979a, 1980a), Schankler (1980), Rose (1981b), Krause (1982), and Bown and Schankler (1982), to name a few. The most useful of these publications for central Bighorn Basin mammalian faunas is the biostratigraphic zonation of the Willwood Formation by Schankler (1980), in which all of the then known mammal fauna from stratigraphically identifiable horizons was utilized.

Since Schankler's study, 582 fossil vertebrate localities that have produced about 28,000 new specimens (U.S. Geological Survey collection, Denver, Colorado) have been established in the central Bighorn Basin by the authors. Of these, 243 localities are now tied to the authors' measured sections and 78 have yielded specimens of anaptomorphine primates (Table 2). The Willwood section measured by Schankler (1980) contains 242 Yale Peabody Museum (YPM) localities and has been tied to the authors' own section. With the addition of 21 Duke University Primate Center (DPC) localities and the 80 University of Wyoming (UW) localities published by Bown (1979a), a total of 586 localities in the central and southeast Bighorn Basin have good stratigraphic control; 239 localities yield anaptomorphine primates (Table 2), and 199 of those have as precise stratigraphic resolution as is obtainable for surface-measured sections. These correlated sections enable samples from the Bown (1979a; see Figure 2) and Schankler (1980) sections to be compared directly with those from the authors' new section in the southcentral Bighorn Basin.

The section from the Clark's Fork Basin in the northern Bighorn Basin (Rose, 1981b; Gingerich, 1982; see Figure 1) has not been related directly to the sections farther south. Nonetheless, it contains a significant sample of stratigraphically-documented anaptomorphines whose record of evolution in that part of the basin can be compared indirectly by means of the associated faunas. It is emphasized that the Clark's Fork Basin sample was studied independently from the bulk of the Bighorn Basin anaptomorphines and therefore acts as an independent intrabasinal check on the evolutionary interrelationships documented here. It is clear that the Willwood section in the Clark's Fork Basin is thicker than that in the central Bighorn Basin; how- ever, less Wasatchian time is represented by the Clark's Fork Basin section. Therefore, sediment accumulation rates were somewhat greater in the Clark's Fork Basin, obviating the direct correlation of that section with the central Bighorn Basin sections on the basis of corresponding meter levels.

At the outset of this study, the stratigraphic distributions of the Bighorn Basin anaptomorphine samples were examined for any undesirably large gaps in the stratigraphic density of localities. Collecting operations were directed over three seasons with the motive of filling in these gaps to the extent allowable by the vagaries of exposure and fossil concentrations. Considerable effort was also expended in increasing the sample sizes of anaptomorphine specimens, from sites unusually rich in them as well as from sites yielding only a few specimens. These efforts were rewarded by the recovery of about 180 additional specimens, bringing the total sample of Bighorn Basin anaptomorphines studied to its current representation of about 850 specimens, largely upper and lower jaws with two or more teeth. Specimens collected through the 1986 field season were utilized in this study.

Stratigraphic sections of Willwood rocks were measured by the senior author and several assistants in 1975 and 1980-1986 and encompass about $740 \mathrm{~km}^{2}\left(288 \mathrm{mi}^{2}\right)$ in the southeast and south-central Bighorn Basin. They comprise more than $1,500 \mathrm{~m}$ of detailed spur sections tied to a detailed $560 \mathrm{~m}$ master section that begins in the Sand Creek area (Figure 2) and continues up section along the superb exposures developed in the valley of Fifteenmile Creek (Figure 3). Control for crossing the extensive Quaternary alluvium in the Bighorn River valley is provided by the $\log$ of Gulf Oil Corporation \#1 Teeters well in sec. 28, T47N, R93W (Wyoming Geological Association, 1968).

\section{MATERIALS AND METHODS}

In addition to the approximately 850 specimens of anaptomorphine primates from the Willwood Formation, more than 200 specimens from other areas were examined, including representative and type materials of all other named anaptomorphine taxa. Though moderate to relatively large samples of Bighorn Basin species identified as Teil- 
R 92 W R 91 W

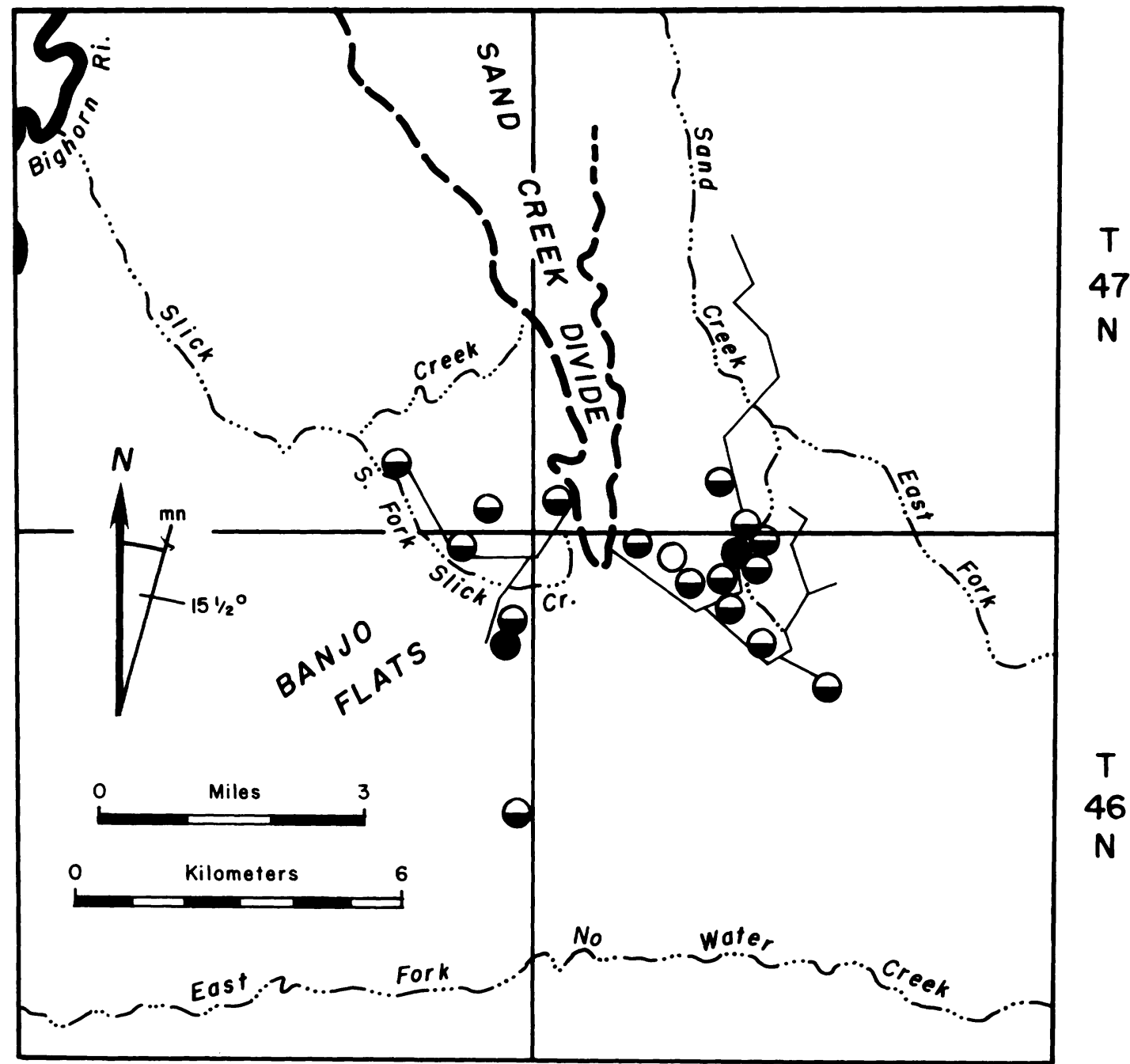

Figure 2-Map of a portion of the Sand Creek-No Water Creek area of the southeastern Bighorn Basin (Bown, 1979a), showing major physiographic features, lines of measured sections, and fossil vertebrate localities that have specimens of anaptomorphine primates. Open circles = YPM localities; black circles = USGS localities; half-filled circles = UW localities.

hardina americana, T. crassidens n. sp., Tetonius matthewi n. sp., T. homunculus, Pseudotetonius ambiguus, Absarokius abbotti, $A$. metoecus n. sp., and numerous intermediates not allocated to species are now known, small sample sizes are still the rule for all of the other species of early Eocene anaptomorphines. Several species of anaptomorphines from outside the Bighorn Basin are known only from the type specimens.

No complete serial upper or lower crown dentition of any age is known, and only two nearly complete (though damaged) serial lower dentitions of anaptomorphines have ever been collected (one of these, CM 12190, Tetonius matthewi $\mathrm{n}$. sp., is now lost). However, the number and disposition of all lower antemolar teeth can be reconstructed for Teilhardina crassidens n. sp., Anemorhysis wortmani, Tetonius matthewi n. sp., Pseudotetonius ambiguus, Absarokius metoecus n. sp., and Absarokius abbotti. Chlororhysis incomptus and Anemorhysis wortmani are known with certainty only from lower jaws, 
TABLE 2-Stratigraphic distribution of anaptomorphine primate-bearing localities in the Willwood Formation of the southern Bighorn Basin, Wyoming (data from Bown, 1979a, and unpublished sections; Schankler, 1980, and personal commun.). D = U.S. Geological Survey (Denver) localities; $\mathrm{Y}=$ Yale Peabody $\mathrm{Mu}$ seum localities; $\mathrm{V}=$ University of Wyoming Geological Museum localities; DPC = Duke University Primate Center (Durham, North Carolina) localities. Localities yielding specimens of anaptomorphines that have not been correlated to this section are as follows: D-1214, D-1236, D-1345, D-1476, D-1504, D-1506, D-1511, D-1528, D-1572, D-1596, D-1607, D-1608, D-1647, D-1651, D-1696, D-1704; Y-38, Y-44, Y-49, $\mathrm{Y}-80, \mathrm{Y}-102, \mathrm{Y}-123, \mathrm{Y}-124, \mathrm{Y}-129, \mathrm{Y}-158, \mathrm{Y}-159$, Y-182, Y-229, Y-255, Y-258, Y-290, Y-303, Y-313, Y-331b, Y-333, Y-390; V-73040; Iowa State University localities ISU \#1, ISU \#4. Localities followed by an asterisk $\left(^{*}\right)$ are at estimated positions but occur within $10 \mathrm{~m}$ of the meter levels depicted. Meter levels are above contact of Willwood Formation with Fort Union Formation in the SW 1/4, sec. 16, T47N, R91W, Washakie County, Wyoming.

\begin{tabular}{|c|c|}
\hline $\begin{array}{l}\text { Meter } \\
\text { level }\end{array}$ & Localities \\
\hline $\begin{array}{l}690 \\
680 \\
670 \\
660\end{array}$ & $\begin{array}{l}\text { Y-32 } \\
\text { Y-3, Y-31, Y-195 } \\
\text { Y-160, Y-162 } \\
\text { Top of middle Heptodon Range Zone } \\
\text { (Schankler. 1980) }\end{array}$ \\
\hline 650 & Y-1, Y-2, Y-161, D-1566 \\
\hline $\begin{array}{l}638 \\
635\end{array}$ & D-1473, D-1558 \\
\hline 630 & Y-187, D-1583 \\
\hline $\begin{array}{l}625 \\
620\end{array}$ & $\begin{array}{l}Y-192, Y-193, D-1256, D-1467, D P C-15 \\
Y-16, Y-167, Y-181, Y-184\end{array}$ \\
\hline $\begin{array}{l}610 \\
600\end{array}$ & $\mathrm{Y}-174, \mathrm{Y}-175, \mathrm{Y}-176, \mathrm{Y}-185, \mathrm{D}-1567$ \\
\hline 595 & D-1625 \\
\hline 590 & Y-314, D-1175, D-1573 \\
\hline 585 & D-1436 \\
\hline 580 & $\begin{array}{l}\text { Y-21, Y-25, Y-39, Y-55, Y-77, Y-168, } \\
\text { D-1337, D-1346, D-1431, D-1435, D- } \\
1468\end{array}$ \\
\hline 575 & D-1474 \\
\hline 575 & $\begin{array}{l}\text { Top of lower Heptodon Range Zone } \\
\text { (Schankler, 1980) }\end{array}$ \\
\hline 570 & $\begin{array}{l}\text { Y-18a, Y-27, Y-28, Y-56, D-1 163, D-1338, } \\
\text { D-1345, D-1346* }\end{array}$ \\
\hline 565 & D-1469 \\
\hline 560 & $\begin{array}{l}\mathrm{Y}-34, \mathrm{Y}-40, \mathrm{Y}-42, \mathrm{Y}-61, \mathrm{Y}-318, \mathrm{D}-1162 \\
\mathrm{D}-1229\end{array}$ \\
\hline 550 & $Y-100$ \\
\hline 535 & D-1507*, D-1508* \\
\hline 530 & $\mathrm{Y}-126, \mathrm{Y}-228, \mathrm{D}-1157^{*}, \mathrm{D}-1230^{*}, \mathrm{D}-1510^{*}$ \\
\hline $\begin{array}{l}519 \\
516\end{array}$ & $\begin{array}{l}D-1304 \\
D-1438\end{array}$ \\
\hline $\begin{array}{l}510 \\
490\end{array}$ & $\begin{array}{l}\text { D- } 1438 \\
Y-49^{*}\end{array}$ \\
\hline 485 & D-1552* \\
\hline 481 & D-1177 \\
\hline 480 & D-1602*, D-1603*, D-1604* \\
\hline 480 & Y-249* \\
\hline 470 & Y-45, Y-45-S, Y-45-E, D-1198, D-1662 \\
\hline 470 & $\begin{array}{l}\text { Local level of Biohorizon C ( }=\text { top of Buno- } \\
\text { phorus Interval Zone; Schankler, 1980) }\end{array}$ \\
\hline 464 & D-1495, D-1676 \\
\hline 463 & D-1699 \\
\hline 457 & Y-227 \\
\hline 455 & D-1698 \\
\hline 450 & $\mathrm{Y}-340-\mathrm{S}^{*}$ \\
\hline 449 & D-1599 \\
\hline
\end{tabular}

TABLE 2-Continued.

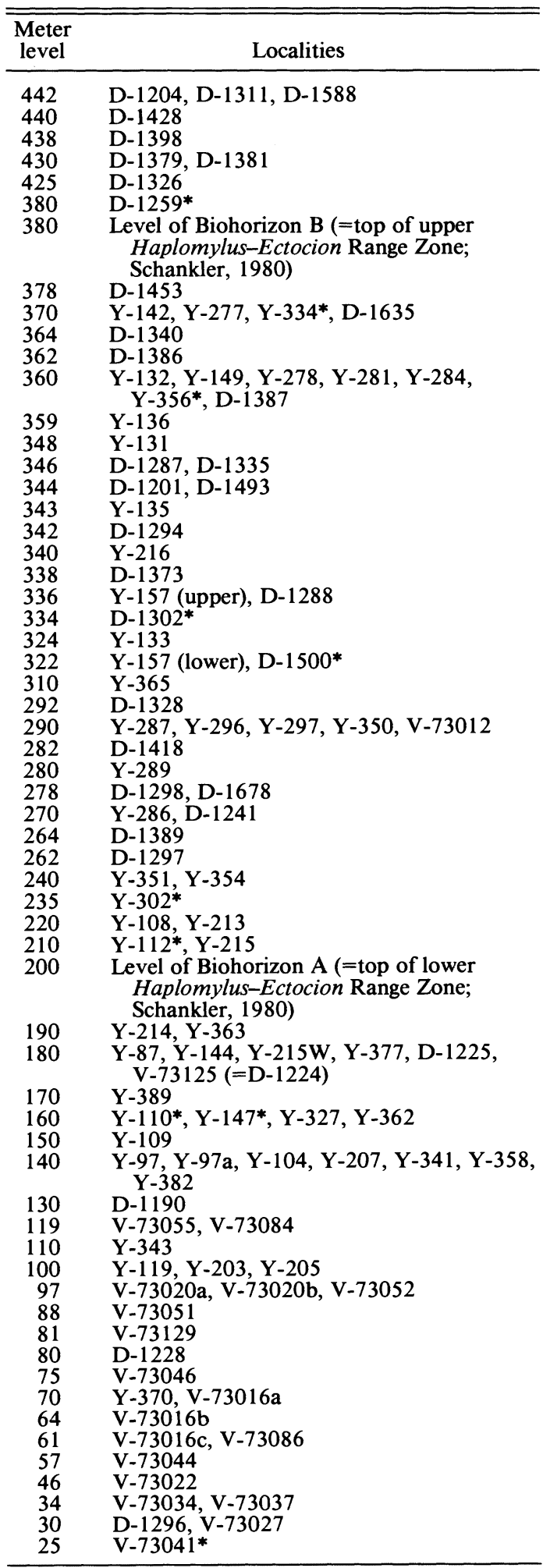


as are Anemorhysis sublettensis, Chlororhysis knightensis, and Absarokius nocerai (n. comb.)-all species extraneous to the Bighorn Basin. Teilhardina tenuicula, from the Bighorn Basin, is positively known only from the holotype upper jaw, and Tetonius homunculus (for reasons discussed below) only from the holotype skull. "Tetonius" musculus (Matthew, 1915 = Anemorhysis musculus of Szalay, 1976) is based on an inadequate type lower jaw preserving only the third lower molar. The holotypes of Paratetonius steini (Seton, 1940) and Uintalacus nettingi (=Anemorhysis sp.) are now lost, as are the best published maxillary of European Teilhardina belgica (Simons, 1972, fig. 58) and the best lower jaw (the holotype) of Tetonius matthewi $\mathrm{n}$. sp.

The paucity of specimens preserving the anterior dentition is probably the most vexing obstacle to the interpretation of anaptomorphine systematics. This is especially true because the evidence of this study has been that the most appreciable evolutionary change in the dentitions of these animals has been in the antemolar dentition. The molars are conservative in their morphologic evolution, even though in some cases they underwent changes in dimensions through time. For example, as will be demonstrated below, comparisons of dentitions of Tetonius, TetoniusPseudotetonius intermediates, and Pseudotetonius reveal that (aside from minor size differences) the fourth premolar and the molars alone are inadequate to determine specializations and evolutionary patterns in these animals and, ironically, even to determine which specimens comprise a reasonable hypodigm for Tetonius homunculus.

It is fortunate that evidence of il-2, c, and p1-3, in cases where these teeth are not preserved, can commonly be obtained from alveoli or roots. However, the numbers, proclivities, relative sizes, and number of roots of these teeth cannot be ascertained for many specimens. The results of this study, then, are based on the best evidence and on all specimens of any provenance for which the parameters under consideration can be determined.

As observed above, this study is based principally on the large undescribed samples of central Bighorn Basin anaptomorphines in the U.S. Geological Survey (USGS) and Yale
Peabody Museum (YPM) collections, but the authors attempted to collect information on all anaptomorphine specimens from this basin in other collections, even though the stratigraphic and locality documentation for most of these is inadequate by itself to pursue detailed evolutionary studies. For some of them, probable stratigraphic occurrences can be confidently reconstructed.

The large and important collection of stratigraphically documented anaptomorphines from the Clark's Fork Basin in the northern Bighorn Basin (housed at the University of Michigan) has special significance because, as observed above, it allows an independent check on the evolutionary patterns of these primates from a geographically disparate part of the same intermontane basin. Relatively small samples of approximately coeval anaptomorphines have been recovered from the Wind River, Powder River, greater Green River, and Laramie Basins of Wyoming, the Piceance and Huerfano Basins of Colorado, the Green River and Uinta Basins of Utah, and the San Juan Basin of New Mexico. When possible, these specimens were examined as well. Specimen data for materials most important to this study are given in the Appendices.

Nearly all of the anaptomorphine specimens used in this study were surface-collected, with the exception of small parts of the sample obtained by excavation and/or screen-washing from Banjo Quarry (UW locality V-73016a), Slick Creek Quarry (UW V-73022), Supersite Quarry (UW V-73037), and a few other sites.

Tooth dimensions and morphologic traits were assessed independently in stratigraphic context (and divorced from taxonomic names as far as possible) to determine if trends, patterns of change, stasis, or punctuational events could be discerned. Only in this way has it been possible to make sense of the broad range of intergrading morphologies observed. The limited stratigraphic (temporal) occurrence of specific morphologies, together with the temporal distribution of these morphologies, has been indispensible to our interpretations of relationships, evolving lineages, and character changes through time.

There is probably no reliable way to orient teeth in a manner allowing for fully consistent measurements. This is especially true for 


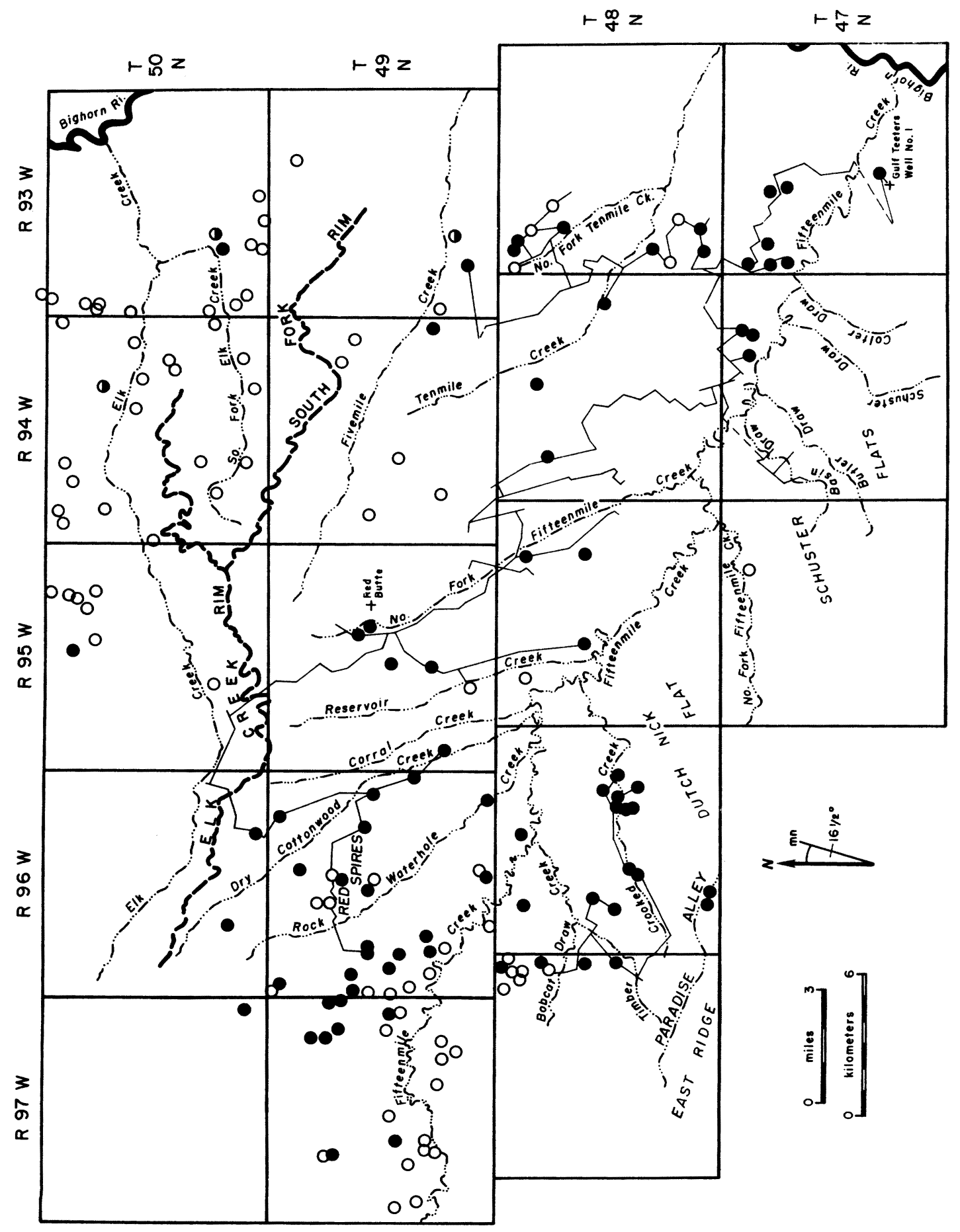


comparisons of measurements of isolated teeth with tooth dimensions obtained from serial dentitions. It is obvious that tooth shape variability adversely affects consistent measurements and that tilting of the teeth or jaw even slightly forward or side-to-side exposes more of one lingual, labial, anterior, or posterior margin and less of another in a fashion that affects consistency of the dimensions to be measured. However, if care is taken to orient teeth similarly for each measurement, the resulting discrepancies of measurement are negligible and do not affect appreciably the observed range of measurements or the temporally distributed evolutionary patterns for a large sample of teeth.

Tooth dimensions used in this study were taken with an ocular micrometer attachment calibrated to $0.05 \mathrm{~mm}$ fitted to Bausch and Lomb and Nikon stereozoom binocular microscopes with the object of obtaining the maximum anteroposterior and transverse dimensions (including cingula) of the tooth crowns oriented in occlusal view (Figure 4). Isolated teeth were oriented so as to conform as closely as possible to their orientations in jaws. The whole anaptomorphine sample was measured at least three times. The maximum variability observed for any tooth was about $10 \%$; more commonly measurements varied by about $0.05-0.10 \mathrm{~mm}(<5 \%)$. Measurements were rounded off to the nearest 0.05 $\mathrm{mm}$.

Teeth and jaws were compared directly using a binocular microscope and these comparisons were supplemented for nearly all specimens by enlarged camera lucida tracings which, for purposes of morphologic comparisons, were standardized to eliminate size differences. Digitized drawings of many features of crown morphology were used to great advantage in assessing amounts of total morphologic change in teeth through different stratigraphic intervals of the Willwood Formation.

All stratigraphic section measurements were accomplished directly with a tape and with a Jacob's staff and Brunton compass. Structural dip generally varies from about $0-6$ degrees in the research area and was calculated using the three point dip solution described by Billings (1965). In areas of rapid dip change, direct thicknesses were measured with the Jacob's staff and compass, whereas in broader areas controlled by constant dips, direct apparent thickness measurements were adjusted trigonometrically by adding the components of true dips obtained from three point problems.

Abbreviations of institutions housing specimens discussed in this paper are: AC, Amherst College Museum, Amherst, Massachusetts; AMNH, American Museum of Natural History, New York, New York; CM, Carnegie Museum of Natural History, Pittsburgh, Pennsylvania; DPC, Duke University Primate Center, Durham, North Carolina; JHU, Johns Hopkins University, Baltimore, Maryland; MCZ, Museum of Comparative Zoology, Harvard University, Cambridge, Massachusetts; RAM, Raymond M. Alf Museum, Claremont, California; UCMP, University of California Museum of Paleontology, Berkeley, California; UKMNH, University of Kansas Museum of Natural History, Lawrence, Kansas; UM, University of Michigan Museum of Paleontology, Ann Arbor, Michigan; USGS, United States Geological Survey, Denver, Colorado; USNM, United States National Museum, Washington, D.C.; UW, The Geological Museum, The University of Wyoming, Laramie, Wyoming; YPM, Yale Peabody Museum of Natural History, New Haven, Connecticut; YPM-PU, Princeton University collection (at YPM), New Haven, Connecticut.

Abbreviations for teeth follow standard terminology; however, lower case letters are used for lower teeth and upper case letters refer to upper teeth, such that il and P3 refer to the lower first incisor and the upper third premolar, respectively. Abbreviations used for tooth measurements and statistics used are: L, maximum anteroposterior measure-

FIGURE 3-Map of a portion of the south-central Bighorn Basin (largely the Fifteenmile Creek region), showing major physiographic features, lines of measured sections, and fossil vertebrate localities that have yielded specimens of anaptomorphine primates. Open circles = YPM localities; black circles = USGS localities; half-filled circles = UW localities. 

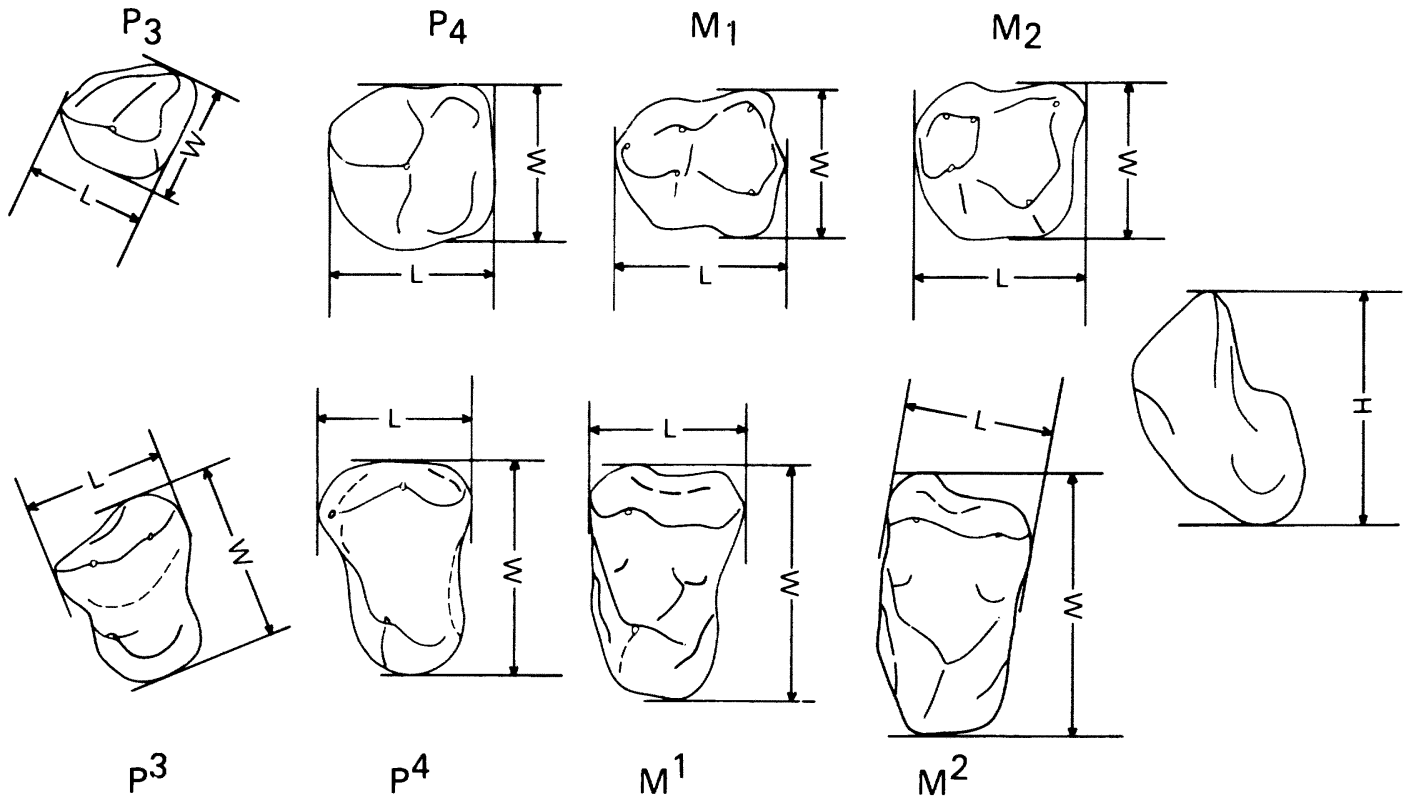

$p^{3}$

$P^{4}$

$M^{1}$

$\mathrm{M}^{2}$

Posterior $\longrightarrow$

FIGURE 4-Camera lucida drawings of teeth of the anaptomorphine primate Tetonius (Tetonius-Pseudotetonius intermediate), showing axes of orientation of teeth utilized in obtaining tooth measurements. Tooth at far right of illustration is a labial view of p4; all other views are occlusal.

ment (length); Ln, natural logarithm; n, number in sample; OR, observed range; S, standard deviation; $\mathbf{W}$, maximum transverse measurement (width); $\bar{x}$, mean. Tooth measurements are in millimeters $(\mathrm{mm})$, the stratigraphic section is in meters $(\mathrm{m})$.

\section{SYSTEMATIC PALEONTOLOGY}

"What's the use of their having names," the Gnat said, "if they won't answer to them?" "No use to them," said Alice; "but it's useful to the people that name them, I suppose. If not, why do things have names at all?"

Lewis Carroll, 1872 -Through the Looking-Glass

Alice's perceptive comment to the Gnat underscores the views of the authors, and the views of many others, on the one utility of taxonomy; that is, to provide names and hierarchies of names for landmarks in evolutionary lines in order that they can be discussed with a minimum of supplementary identifying characters. In other words, taxonomic names are simply a part of the terminology of biology just as other fields of endeavor have accumulated their useful terminologies. The binomial Absarokius abbotti for an early Eocene anaptomorphine primate is analogous to "muddy sandstone"; Absarokius and "sandstone" being generic terms and abbotti and "muddy" are qualifiers, leading us to their more specific attributes.

In the first application of binomina to organisms, Linnaeus dealt largely with extant end members of evolutionary lineages and had to contend less with the profound geographically and temporally-intergraded variability between taxa that is now known to exist in both living and fossil organisms. Sometime in the last two centuries, many biologists acquired the idea that taxa were something other than just names, that taxa (especially species) evolve. New definitions, especially of the "species," arose and incorporated more in the way of biological and evolutionary restrictions and less purely descriptive information. New viewpoints on 
species were popular with typologists because they appeared to provide necessary links not only between physiology/behavior and anatomy, but also between "fossil species" and "extant species."

Belief that taxonomic diagnoses distinguish between different kinds of organisms is, with reservation, sound if we are diagnosing taxa that exist or existed at a single point in time. The species is sometimes considered a more "real" biological category than higher taxa, since living organisms recognize their own "species" when it is time to reproduce. But behavioral and physiological responses during the mating period cannot be quantified or qualified for their recognition in the fossil record (nor can species be recognized genetically in the fossil record). Nonetheless, firm ground is held if analyses are restricted to living organisms or to fossil ones for which an acceptable limit of contemporaneity can be established.

However, introduction of a series of temporally-stratified, closely related fossil organisms into taxonomic analyses immensely complicates the picture. This is because the species concept is no longer one of a static, coeval system, but rather part of a continuum. As Gingerich (1985, p. 29) observed, "species are in many cases objective evolutionary units on a time plane and at the same time arbitrary units crossing time planes." The continuum itself is underscored profoundly if gradual evolution (anagenetic, cladogenetic, or both) actually played an important role in the origin of new species or even, by compounding this evolutionary "interest" through time, new superspecific taxa.

This study indicates that nearly all of the evolutionary change documented for the origin of taxa of anaptomorphine primates in the Bighorn Basin (both at the species and generic levels) was accomplished gradually; i.e., that the characters studied evolved in mosaic fashion at different times and different rates. Three kinds of morphologic characters were observed: 1) those present in part of the sample but absent in the remainder (here termed absolute characters, the evolution of which is identified by their presence, followed in time by their absence); 2) characters typified by multiple morphologies (transient characters, the evolution of which is identified by replacement of the earliest character state by succeeding, younger, different character states); and 3) characters that show no appreciable evolutionary change through a particular stratigraphic interval (static characters).

Absolute characters are recognized as those invariably present in samples from lower in the section, present in some specimens but absent in others higher in the section, and invariably absent in the highest samples. In general, the density of the acquired character state increases up section, whereas that for the original character state decreases in importance. For transient characters, evolution is documented by: 1) older samples in which only character state " $A$ " is present; 2) later samples in which, successively, character states " $A$ " and " $B$ ", " $A$ ", " $B$ ", and " $C$ ", and " $B$ " and " $C$ " are present; and 3 ) youngest samples in which only character state " $C$ " survives. It is emphasized that the evolution of the different absolute, transient, and static characters was neither begun nor completed at the same time, and that at no point in any lineage do only static characters exist.

This picture of evolutionary change for only a few of the characters in a single anaptomorphine lineage in the Bighorn Basin is instructive by virtue of its implications for taxonomy (and thereby biostratigraphy). The fossil record is now so dense and continuous in the Bighorn Basin that several of the taxa recognized here no longer have discrete morphologic or stratigraphic boundaries. There is no point at which the evolving complex of temporally-stratified diagnostic characters is clearly distinctive from those occurring immediately above or below, although the end points are decidedly different. Evolution proceeded by increased, then decreased, variability in character states, with the more derived character states eventually predominating in younger samples. As a result, diagnoses at generic and specific levels have become very difficult to construct.

Some workers prefer to consider that if a diagnosis cannot be drawn, taxonomic distinction cannot be made and the entire sample belongs to the same species. This is an easy way out when the sample belongs to somebody else, but it solves no problems, obscures the significance of temporally-stratified morphologic changes, and thereby obscures the record of actual evolutionary re- 
lationships. A species (or genus) that has been considered valid by virtue of its distinctive and diagnostic morphology is no less valid simply because more temporally-stratified morphologic information (i.e., a more complete record) now makes its diagnosis difficult. The purpose of taxonomy being to identify morphologic difference, it is important to recognize that morphologic difference is in no way diminished simply because the diagnostic differences might have accumulated gradually. The systematic arrangement should reflect these factors; consequently, a substantial number of specimens are designated as "intermediates," without specific assignment. Although this taxonomic scheme will be unpopular with some paleontologists, it is the most accurate reflection of the taxonomic status of these fossil samples. No scheme would meet with universal acceptance.

As mentioned earlier, the species discussed in this report are, obviously, paleontological (or morphological) species. How closely they approximate biological species is not (and cannot be) known and, as discussed above, the temporal component and gradual morphological evolution add new dimensions to the problem. However, size variation in samples here assigned to a single fossil species generally conforms closely to observations for single species of living and other fossil mammals (e.g., Gingerich, 1974b; Gingerich and Winkler, 1979). Moreover, size differences (or overlap) between these fossil taxa are similar to those between closely allied taxa of extant primates (e.g., Swindler, 1976; Musser and Dagosto, 1987). Basic statistics are presented to demonstrate some of the significant as well as nonsignificant metric differences between closely allied taxa. The principal distinctions between closely related anaptomorphines, however, are in premolar and molar crown morphology and configuration of antemolar teeth-aspects that are at present very difficult to quantify and, therefore, to assess statistically (significance levels indicated by $t$-tests). Variation in such morphologic characters, and the extent of such differences between extant closely allied species, is not well understood. But the fossil taxa recognized in this report appear to be comparable in these respects with extant and other fossil taxa of similar rank.

Linnaean systematics is an artificial system imposed on a natural one. In pursuing evolutionary studies with an increasingly dense record of temporally-stratified fossil data (and its unique contribution of the time element), one cannot expect the Linnaean system to continue to be useful without considerable modification. In dealing with the same problem, many earlier workers have found it of utility to use appellations for groups of fossils that do not conform to Linnaean systematics (e.g., lineage segments, stage "intermediates," etc.; see Van Hinte, 1969; Krishtalka and Stucky, 1985). These are arbitrary subdivisions of lineages that are perceived through the context of excellent temporallystratified collections of fossils. Applying formal Linnaean binomina to these subdivisions (e.g., Krishtalka and Stucky, 1985) can lead to considerable confusion by contributing unnecessary new names to an already ponderous terminology. Moreover, terms introduced to define lineages in one basin might very well not be applicable to records of somewhat different evolution of the same group in other basins, and a separate terminology for each basin would become necessary. Here, the authors introduce informal stages that are distinguished by a combination of stratigraphic occurrence and morphologic criteria. They are essentially arbitrary and are given numbers to facilitate discussion of fossils in a lineage; however, they also reflect cumulative morphologic change. Existing valid taxa are discussed using Linnaean binomina but their diagnoses, of necessity, are strongly influenced by stratigraphic data. As observed above, it is impossible to place them neatly and consistently in binomia as typically utilized in less well understood groups.

In the following systematic revision, the synonymies listed are not exhaustive, but include the most important references to taxaparticularly those differing from the taxonomic scheme used here. Diagnoses have been constructed to differentiate a given taxon from its closest relatives or from other taxa with which it is most likely to be (or in fact has been) confused.

The hypodigms below include all Bighorn Basin specimens with diagnostic morphology, as well as many specimens from elsewhere. They also include a large number of specimens (e.g., fragmentary lower dentitions and upper teeth not associated with diagnos- 
tic lowers) that are assigned solely by their stratigraphic association with specimens that do contain diagnostic teeth; these are indicated where appropriate. Many specimens that lack adequate data for assignment to species or stage are not listed. Where possible, the best material from outside the Bighorn Basin is included, but hypodigms are not necessarily complete with regard to specimens from other basins, some of which were not available for this study (e.g., the Golden Valley, North Dakota, sample).

The systematic revision that follows is an integral part of this work, and taxonomy of pertinent anaptomorphines is discussed there in some detail. However, the principal focus of this study is the evolutionary patterns that emerged-not the systematics of the Anaptomorphinae. The systematic revision is presented to enable discussion of evolution in Bighorn Basin anaptomorphines, and this revision resulted directly from (and was impossible before) analyses of these samples in their stratigraphic contexts.

Dimensions for all measurable specimens are listed in Appendices 1-21.

Order Primates Linnaeus, 1758

Suborder HAPLORHINI Pocock, 1918

Infraorder TARSIIFORMES Gregory, 1915

Family OMOMYIDAE Trouessart, 1879

Subfamily ANAPTOMORPHINAE Cope, 1883

Type genus. - Anaptomorphus Cope, 1872.

Diagnosis. -(In contrast to Omomyinae): 1) first incisor generally much larger than second and slightly procumbent; 2) tendency to reduce antemolar teeth between first incisor and fourth premolar in size and number; 3) third premolar never taller than fourth and fourth premolar generally with inflated appearance; 4) molar cusps more internal in occlusal view due to inflation of bases of molars; 5) molar paraconids more lingual and generally progressively appressed to metaconids from $\mathrm{ml}$ through $\mathrm{m} 3$; 6) $\mathrm{ml-2}$ talonids anteroposteriorly shorter and hypoconid and entoconid less peripheral; 7) trigons generally more constricted and with better developed Nannopithex-fold; 8) M3/m3 generally smaller with respect to $\mathrm{M} 2 / \mathrm{m} 2$.

(In contrast to Microchoerinae): 1) lower medial incisor relatively less enlarged in all members, except in Pseudotetonius, Nannopithex, and Trogolemur; 2) p2 sometimes re- tained; 3) molar paraconids remaining lingual on m1-3 (not increasingly buccal, except in Uintanius and Nannopithex - which lies at base of microchoerine radiation, see below); 4) upper molars less squared, M2 especially transverse; 6) upper molars lacking nearly continuous cingulum, well-defined talon, and prominent conules; 7) $\mathrm{M} 3 / \mathrm{m} 3$ relatively reduced with respect to $\mathrm{M} 2 / \mathrm{m} 2$.

Included genera. - Teilhardina, Anemorhysis, Arapahovius, Trogolemur, Chlororhysis, Steinius, Tetonius, Pseudotetonius, Nannopithex, Absarokius, Anaptomorphus, Uintanius, Aycrossia, Strigorhysis, Gazinius, Kohatius, and, probably, the unnamed Oligocene omomyid from Egypt described by Simons et al. (1986).

Discussion.-Although it is beyond the scope of this paper to revise the entire subfamily Anaptomorphinae, it is impossible to complete a study of this evolutionary and systematic scope without forming opinions about the broader composition of the group under study. Although there is no room in this work to document the above assignments, it was thought best to provide perspective by outlining the current beliefs of the authors regarding the composition of the Anaptomorphinae. These assignments are made on the basis of structural similarity of presumed derived features of the dentition and largely ignore broader phylogenetic considerations, some of which are discussed below and would affect principally the genera Steinius and Nannopithex. Several genera belonging here, but not treated in this paper, are: Arapahovius (one species), Anaptomorphus (two species), Trogolemur (one species), Nannopithex (possibly four species), Uintanius (three species), Gazinius (one species), Aycrossia (one species), and Kohatius (one species).

As observed above, this study was undertaken to document evolutionary patterns in the densest known record of the Anaptomorphinae-that in the Bighorn Basin of Wyoming. What systematic revision is contained herein was dependent upon the density of the Bighorn Basin evolutionary record for its completion. Certain forms from other areas described or revised here represent important coeval early Eocene samples necessarily included in order to place the Bighorn Basin lineages in their geographic and phy- 
logenetic perspective. Most of the last eight genera are represented by only a few specimens; none have dense enough stratigraphic records to assist in elucidating their phylogenetic histories beyond what has been inferred by other workers.

Since the classification of Gazin (1958), who gave family status to the Anaptomorphinae and Omomyinae, there has been general agreement on which genera belong in each group, with a few exceptions. Gazin included Uintasorex in the Anaptomorphidae, but most authors now place it in the Microsyopidae (e.g., Szalay, 1969; Bown and Gingerich, 1972). Russell et al. (1967) transferred Gazin's Chlororhysis to the anaptomorphines, and Szalay (1976) subsequently recognized its close relationship to Euramerican Teilhardina. Regardless of how authorities regard the validity of several other genera named after Gazin's (1958) study (e.g., Pseudotetonius, Mckennamorphus, Arapahovius, Kohatius, Aycrossia, Strigorhysis, Gazinius), there seems to be agreement that they are anaptomorphines. The affinities of Uintanius and Steinius are more controversial.

Uintanius was placed in the Anaptomorphidae by Gazin but in the Omomyinae by Szalay. It is returned to the Anaptomorphinae here because its premolar structure seems to have been derived from that in early $A b$ sarokius, a genus that appears to have evolved after the presumed stem genera of the tribes Omomyini (Steinius) and Washakiini (Loveina) were established. Although the relatively buccal molar paraconids in Uintanius vaguely resemble those in some omomyines, they are constructed somewhat differently and were probably derived convergently.

Steinius was earlier included in the Omomyidae, as ?Omomys (Gazin, 1958), and in the Omomyinae, as Uintanius (Szalay, 1976). Here it is considered to be an anaptomorphine, as judged from its lingual paraconids and the morphology of its molar basins. Nonetheless, Steinius is phylogenetically near the base of Szalay's tribe Omomyini. Loveina (Simpson, 1940) is, as Szalay (1976) stated, an omomyine at the base of his tribe Washakiini.

Similarly, European middle Eocene Nannopithex is morphologically most similar to North American Pseudotetonius and thereby probably also belongs in the Anaptomor- phinae; however, it also apparently gave rise to the Microchoerinae. Teilhardina belgica (early Sparnacian of western Europe), the only other European anaptomorphine, appears to lie at the base of the omomyid radiation. Teilhardina is the only known Euramerican omomyid, just as Cantius, the stem genus of the Adapidae, is the only known member of that family common to both continents.

\section{Genus Teilhardina Simpson, 1940}

Tetonius MATTHEW, 1915, p. 463 (part); JEPSEN, 1930, p. 126; DELSON, 1971, p. 338 (part).

Omomys TeIlHARD DE CHARdIN, 1927, p. 16 (part).

Protomomys TeIlHARD DE CHARDIN, 1927, p. 25 (name suppressed by ICZN).

Teilhardina SIMPSON, 1940, p. 190; QUINET, 1966, p. 2; SimONS, 1972, p. 153; SzAlay, 1976, p. 176; Savage, Russell, AND Waters, 1977, p. 163 (part); Bown, 1979a, p. 11; SzALAY AND DELSON, 1979, p. 210; GINGERICH, 1981, p. 358; ROSE AND BOWN, 1984, p. 250; 1986, p. 123.

Anemorhysis Bown, 1974, p. 24 (A. cf. tenuiculus from Bighorn Basin only); SzALAY, 1976, p. 220 (part); 1982, p. 154; SzALAY AND DELSON, 1979, p. 221 (part).

Tetonoides GAZIN, 1962, p. 35 (part); JEPSEN, 1963, p. 679; BOWN, 1979a, p. 75; GINGERICH, 1981, p. 358 (part); RoSE AND Bown, 1984, p. 250.

Type species. - Omomys belgicus Teilhard de Chardin, 1927, p. 16.

Included species. $-T$. belgica, $T$. americana, $T$. crassidens $\mathrm{n}$. sp., T. tenuicula $\mathrm{n}$. comb.

Distribution. - Early Wasatchian (early Eocene) of Wyoming and North Dakota; early Sparnacian (early Eocene) of western Europe.

Revised diagnosis. -Small, primitive omomyids with cheek teeth similar in size to Anemorhysis; smaller than in Chlororhysis, Tetonius homunculus, and T. matthewi. Lower dental formula least reduced of all omomyids; 2.1 .4 .3 or 2.1.3.3. Lower third premolar and p4 simple or with small paraconid and metaconid; $\mathrm{p} 3$ not markedly reduced and $\mathrm{p} 4$ not relatively enlarged. Talonid of $\mathrm{p} 4$ short and not basined, and p4 cristid obliqua more lingual than in Anemorhysis, resulting in deeper hypoflexid.

Discussion. - Simpson (1940) proposed the name Teilhardina for Teilhard's (1927) Omomys belgicus, now known from a large sample from Dormaal, Belgium. The genus was first recognized in North America by 

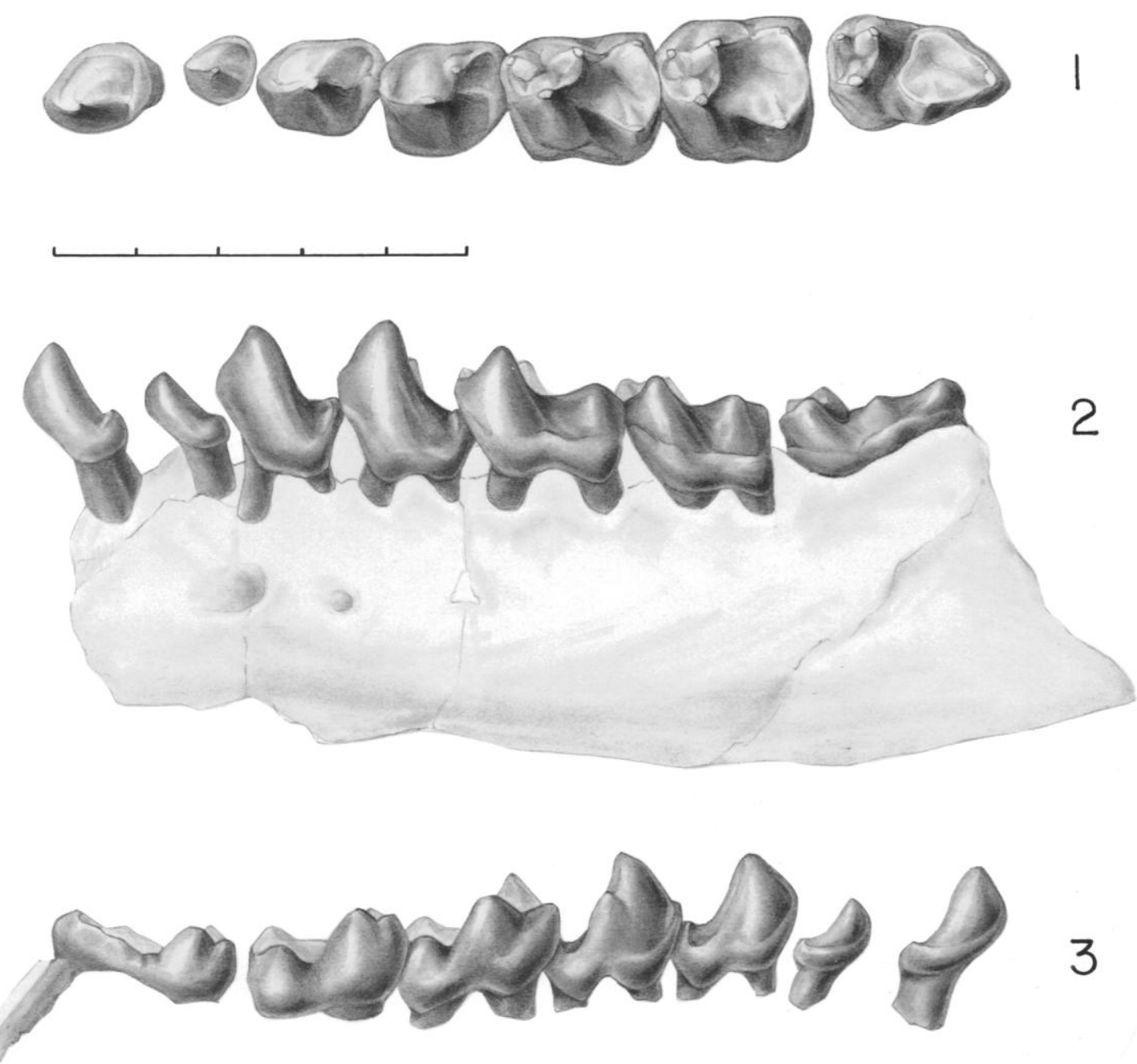

FIGURE 5-Teilhardina americana Bown, holotype UW 6896, left dentary with c, p2-m3 (46 m). 13 , occlusal, lateral, and medial views, respectively. Scale is $5 \mathrm{~mm}$.

Bown (1976), but its prevalence in the earliest Wasatchian of the Bighorn Basin was not realized until this study. Teilhardina includes the only anaptomorphines (and indeed the only omomyids) known to retain $\mathrm{p} 1$. This and other aspects of its morphology indicate that the genus includes the most primitive known members of the Omomyidae (see also Szalay, 1976; Savage et al., 1977). It was probably the basal omomyid, almost certainly directly ancestral to Tetonius, Chlororhysis, and Anemorhysis, and is plausibly the common ancestor of all omomyids.

This study indicates that the most diagnostic teeth of Teilhardina are p3 and especially $\mathrm{p} 4$. Although lower and upper molars are somewhat distinctive, they are usually insufficient by themselves to allow specific identification and, in the absence of stratigraphic data, may be easily confused with molars of Anemorhysis. Unfortunately, relatively few specimens preserve antemolar teeth, so many specimens can be assigned only by stratigraphic association with individuals that are diagnostic. These assignments can be made confidently, however, since all well preserved specimens indicate directional trends without reversal to earlier morphologies; i.e., all specimens fitting the description of $T$. americana come from a restricted interval very low in the section, and this morphology never occurs higher in the 
section. Similarly, $T$. crassidens $\mathrm{n}$. sp. occurs only in a limited stratigraphic interval somewhat higher in the section. The two are linked by many specimens that are intermediate in morphology, but do not clearly belong to one species or the other, nor do they seem sufficiently distinct to be given a new name.

European Teilhardina belgica (earliest Sparnacian) is the most generalized species and, based on its morphology and faunal association, probably predates North American Teilhardina (Godinot, 1982). Teilhardina americana shows slight advances over $T$. belgica and, in most characters, is morphologically closer to the latter than it is to $T$. crassidens $\mathrm{n}$. sp. or T. tenuicula $\mathrm{n}$. comb. The latter two species are the youngest and most derived, displaying certain characters that bridge the gap between primitive Teilhardina and the still more derived Anemorhysis (see discussion of Anemorhysis below).

TeIlHardina Americana Bown, 1976

Figures 5, 6.1, 6.3, 7.3

Teilhardina americana Bown, 1976, p. 63, figs. lc, d; 1979a, p. 77; SAVAGE, RUSSELL, AND WATERS, 1977, p. 163; GINGERICH, 1981, p. 358; ROSE AND BOwN, 1984 , p. $250 ; 1986$, p. 123 , figs. 2, 3.

Tetonoides tenuiculus Bown, 1979a, p. 76 (part), fig. 48d, f.

Anemorhysis tenuiculus Szalay AND Delson, 1979, p. 223; Szalay, 1982, p. 154.

Tetonius homunculus Bown, 1979a, p. 78 (part), fig. 49a (UW 7165 only), 49d.

Holotype. - UW 6896, left dentary with c, possible alveolus for p1, p2-m3; UW locality V-73022 (Slick Creek Quarry), $46 \mathrm{~m}$ level of Willwood Formation, Washakie County, Wyoming.

Hypodigm. - The holotype and USGS 2428, 2509, 2523?, 3849, 3863, 3864, 5991, 7195, 7196, 8882, 8886, 9037, 10503, 12193, 12194, 15405, 15406, 15450; UW 6917, 6965, 7095-7098, 7140-7142, 7144, 7164, $7165,7170,7171,7175,7179,7181,7217$, $7281,7295,7329,7912,7915,8812,8870$, 8871, 8961, 10247; DPC 2973, 2979, all from the southern Bighorn Basin; UM 76600 from Foster Gulch, northeastern Bighorn Basin; UM 65770, 67424?, 72105, 72251, 72268, 75610 from the Clark's Fork Basin.

Distribution. - Lower part of Willwood Formation, lower Eocene (early Wasatchian; lower part of lower Haplomylus-Ectocion
Range Zone of Schankler, 1980), 25-46 m interval in southern Bighorn Basin, and 50$125 \mathrm{~m}$ interval $(1,570-1,645 \mathrm{~m}$ of Gingerich's 1982 section) in Clark's Fork Basin.

Revised diagnosis. - Larger than T. belgica; p3 10-20\% larger in mean length and breadth; $\mathrm{p} 4, \mathrm{~m} 1$, and $\mathrm{m} 2$ slightly longer and $10-15 \%$ broader (mean dimensions). Metaconid of $\mathrm{p} 4$ slightly higher than in $T$. belgica. Cheek teeth narrower than in $T$. crassidens $\mathrm{n}$. sp.; $\mathrm{p} 3$ lacking paraconid and metaconid, and p4 with more open trigonid, weaker paraconid, and lower and smaller metaconid than in $T$. crassidens $\mathrm{n}$. sp.

Discussion. - Teilhardina americana is very similar to European T. belgica, differing chiefly in having slightly larger (mainly broader) cheek teeth (Table 3) and a relatively slightly higher metaconid on $\mathrm{p} 4$. There appear to be minor differences in the anterior dentition but existing evidence is too weak to be conclusive.

The incisors are unknown, and what remains of the front of the jaw in the holotype gives no indication of significant hypertrophy of $i 1$, as is characteristic of many anaptomorphines. However, USGS 2523, a dentary fragment questionably referred here, preserves part of the incisor alveoli and indicates a moderately enlarged il. Even if the medial incisor was larger than in $T$. belgica (in which both incisors evidently were small), it was apparently smaller than in $T$. crassidens $\mathrm{n}$. sp. The canine, preserved only in the holotype, is smaller than that of $T$. belgica (as indicated by its alveolus), but larger than in later Teilhardina.

Bown (1976) could not establish the presence of $\mathrm{p} 1$ in $T$. americana (otherwise only known in $T$. belgica among omomyids), but he observed that there is space between the canine and p2 in the holotype. Subsequent preparation of this region exposed a pit that may be the $\mathrm{p} 1$ alveolus, but poor preservation of this region renders this determination inconclusive. With one exception, the few other specimens preserving any of the dentary anterior to $\mathrm{p} 2$ show definitive or suggestive evidence of a vestigial p1 (root of p1 in USGS 3849 , alveolus in UM 75610, possible alveolus in UM 65770, 72105, 72268). In all of these, p1 was laterally displaced, as in $T$. belgica, and was consistently very small. USGS 2523, however, apparently lacked p1. In $T$. 

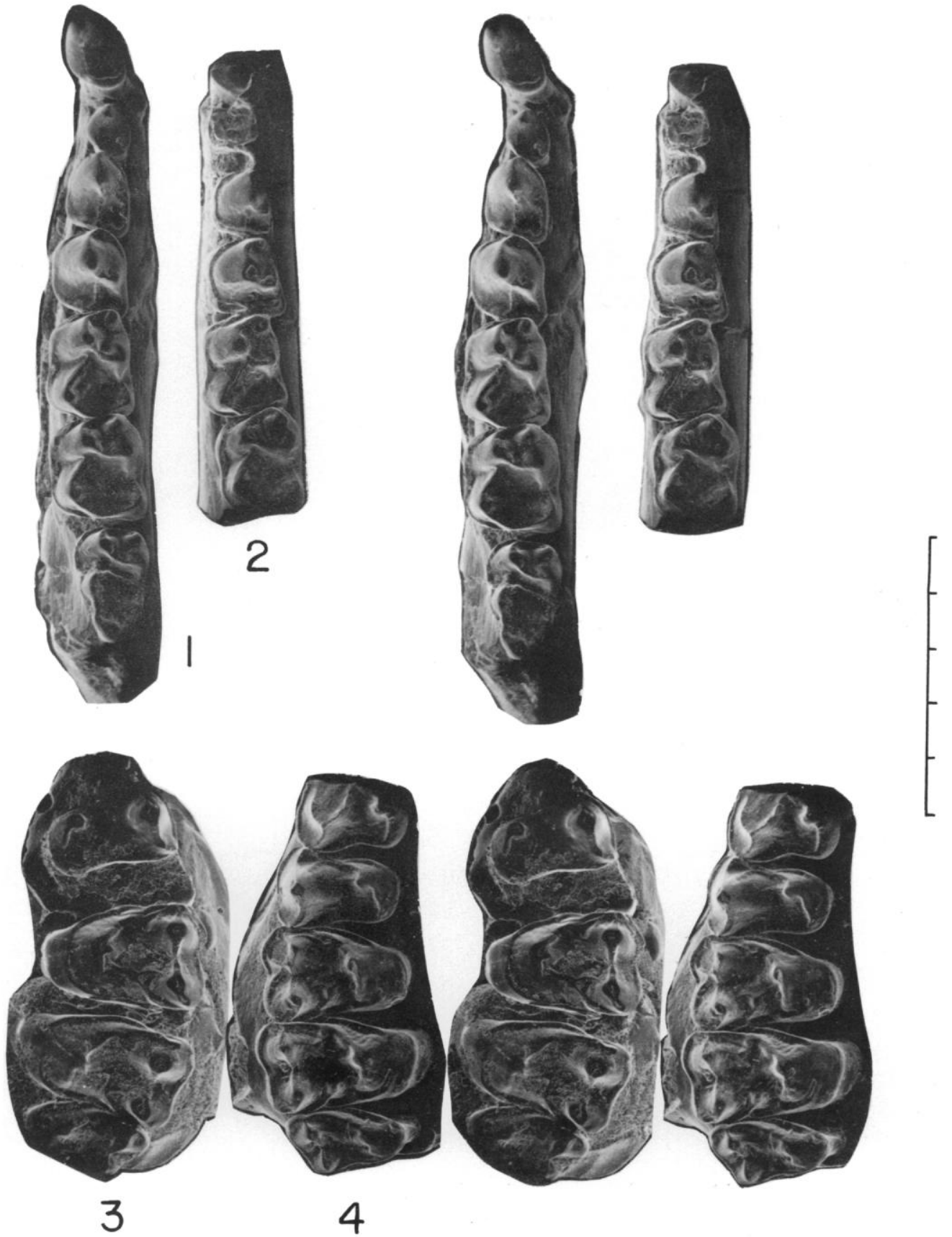

FIGURE 6-Teilhardina, SEM stereographs, occlusal views. 1, T. americana Bown, holotype, UW 6896, left c, p2-m3 $(46 \mathrm{~m}) .2, T$. crassidens n. sp., holotype, UW 8959, left p3-m2 and roots or alveoli of i1-2, c, p2 (180 m). 3, T. americana, UW 8961, left P4-M3 (46 m). 4, T. crassidens, YPM 24626, right P3-M3 (180 m). Scale is $5 \mathrm{~mm}$. 

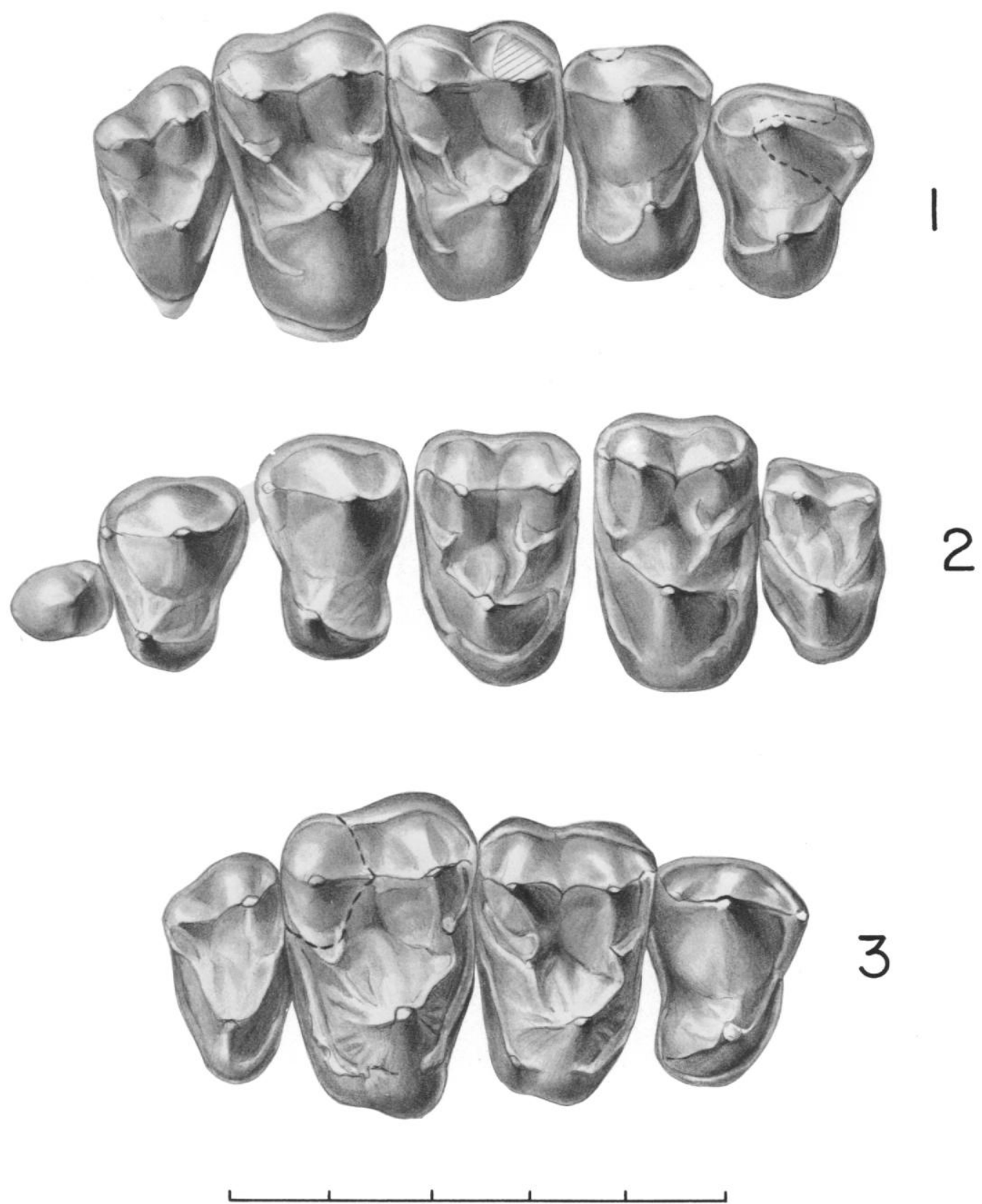

FIGURE 7-Upper teeth of Teilhardina. 1, T. crassidens $\mathrm{n}$. sp., YPM 24626, right P3-M3 (180 m, P3 restored from USGS 7204). 2, Teilhardina intermediate, UM 69783, left P2-M3 (Clark's Fork Basin, $240 \mathrm{~m}$ ). 3, T. americana Bown, UW 8871, P4-M3 (34 m, M3 restored from UW 8961). Scale is 5 $\mathrm{mm}$.

belgica, $\mathrm{p} 1$ was variable in size and absent in at least one specimen (Gingerich, 1977b).

The most salient difference in the upper teeth (known from relatively few specimens) is the consistent presence of a "Nannopithexfold" on the molars of $T$. americana (Figures $6.3,7.3)$; this crest is very weak or absent on molars of $T$. belgica. Upper molars of $T$. 
TABLE 3-Comparative statistics for lower teeth of Teilhardina. Significant differences between $T$. crassidens $\mathbf{n}$. sp. and $T$. americana Bown are indicated by ${ }^{*}(P<0.01)$ and ${ }^{* *}(P<0.001)$. All data from appendices except $T$. belgica (Teilhard de Chardin).

\begin{tabular}{|c|c|c|c|c|c|}
\hline Dimension & & T. belgica ${ }^{1}$ & T. americana & $\begin{array}{c}\text { Teilhardina } \\
\text { intermediates }\end{array}$ & T. crassidens \\
\hline p3 L & $\begin{array}{l}\mathrm{n} \\
\text { OR } \\
\bar{x} \\
s\end{array}$ & $\begin{array}{c}6 \\
1.20-1.40 \\
1.30 \\
0.071\end{array}$ & $\begin{array}{c}11 \\
1.20-1.55 \\
1.42 \\
0.110\end{array}$ & $\begin{array}{c}9 \\
1.15-1.40 \\
1.29 \\
0.074\end{array}$ & $\begin{array}{c}4 \\
1.30-1.40 \\
1.34 \\
0.048\end{array}$ \\
\hline p3 W & $\begin{array}{l}\mathrm{n} \\
\text { OR } \\
\bar{x} \\
s\end{array}$ & $\begin{array}{c}6 \\
0.90-1.00 \\
0.93 \\
0.052\end{array}$ & $\begin{array}{c}11 \\
1.05-1.15 \\
1.10 \\
0.027\end{array}$ & $\begin{array}{c}9 \\
1.05-1.20 \\
1.13 \\
0.071\end{array}$ & $\begin{array}{c}4 \\
1.15-1.20 \\
1.19^{* *} \\
0.025\end{array}$ \\
\hline p4 L & $\begin{array}{l}\mathrm{n} \\
\text { OR } \\
\bar{x} \\
s\end{array}$ & $\begin{array}{c}9 \\
1.40-1.70 \\
1.54 \\
0.105\end{array}$ & $\begin{array}{c}18 \\
1.45-1.75 \\
1.60 \\
0.070\end{array}$ & $\begin{array}{c}23 \\
1.30-1.70 \\
1.47 \\
0.108\end{array}$ & $\begin{array}{c}11 \\
1.30-1.65 \\
1.54 \\
0.104\end{array}$ \\
\hline p4 W & $\begin{array}{l}\mathrm{n} \\
\text { OR } \\
\bar{x} \\
s\end{array}$ & $\begin{array}{c}9 \\
1.10-1.30 \\
1.18 \\
0.061\end{array}$ & $\begin{array}{c}18 \\
1.25-1.55 \\
1.39 \\
0.085\end{array}$ & $\begin{array}{c}25 \\
1.2 G-1.50 \\
1.34 \\
0.088\end{array}$ & $\begin{array}{c}11 \\
1.35-1.60 \\
1.48(P<0.02) \\
0.087\end{array}$ \\
\hline $\mathrm{p} 4 \mathrm{~W} / \mathrm{L}$ & $\begin{array}{l}\text { n } \\
\text { OR } \\
\bar{x} \\
s\end{array}$ & $\begin{array}{c}9 \\
0.73-0.86 \\
0.77 \\
0.041\end{array}$ & $\begin{array}{c}18 \\
0.78-1.00 \\
0.87 \\
0.057\end{array}$ & $\begin{array}{c}23 \\
0.77-1.15 \\
0.92 \\
0.080\end{array}$ & $\begin{array}{c}11 \\
0.84-1.08 \\
0.96^{* *} \\
0.063\end{array}$ \\
\hline $\mathrm{m} 1 \mathrm{~L}$ & $\begin{array}{l}\mathrm{n} \\
\text { OR } \\
\bar{x} \\
s\end{array}$ & $\begin{array}{c}9 \\
1.80-2.00 \\
1.90 \\
0.071\end{array}$ & $\begin{array}{c}26 \\
1.80-2.10 \\
1.96 \\
0.089\end{array}$ & $\begin{array}{c}47 \\
1.65-2.00 \\
1.85 \\
0.106\end{array}$ & $\begin{array}{c}13 \\
1.70-2.00 \\
1.84^{* *} \\
0.089\end{array}$ \\
\hline $\mathrm{m} 1 \mathrm{~W}$ & $\begin{array}{l}\mathrm{n} \\
\text { OR } \\
\bar{x} \\
s\end{array}$ & $\begin{array}{c}9 \\
1.35-1.60 \\
1.43 \\
0.071\end{array}$ & $\begin{array}{c}26 \\
1.40-1.80 \\
1.61 \\
0.101\end{array}$ & $\begin{array}{c}47 \\
1.40-1.90 \\
1.61 \\
0.108\end{array}$ & $\begin{array}{c}13 \\
1.55-1.75 \\
1.64 \\
0.079\end{array}$ \\
\hline $\mathrm{m} 2 \mathrm{~L}$ & $\begin{array}{l}\mathrm{n} \\
\text { OR } \\
\bar{x} \\
s\end{array}$ & $\begin{array}{c}8 \\
1.80-1.90 \\
1.85 \\
0.046\end{array}$ & $\begin{array}{c}27 \\
1.80-2.10 \\
1.91 \\
0.092\end{array}$ & $\begin{array}{c}48 \\
1.65-2.00 \\
1.81 \\
0.097\end{array}$ & $\begin{array}{c}10 \\
1.65-1.90 \\
1.79^{*} \\
0.078\end{array}$ \\
\hline $\mathrm{m} 2 \mathrm{~W}$ & $\begin{array}{l}\mathrm{n} \\
\text { OR } \\
\bar{x} \\
s\end{array}$ & $\begin{array}{c}8 \\
1.45-1.70 \\
1.56 \\
0.078\end{array}$ & $\begin{array}{c}27 \\
1.40-1.85 \\
1.68 \\
0.103\end{array}$ & $\begin{array}{c}49 \\
1.50-1.90 \\
1.68 \\
0.106\end{array}$ & $\begin{array}{c}10 \\
1.60-1.75 \\
1.69 \\
0.058\end{array}$ \\
\hline
\end{tabular}

${ }^{1}$ Sample used includes CtM 64 (lectotype), CL 182, CL 188, CL 192, CL 246, CL 455, CL 457, WL 128, WL 259, WL 1052, WL 1060, WL 1180-all in the Institut Royal d'Histoire Naturelle de Belgique; casts supplied by M. Godinot.

americana typically have stronger pre- and postcingula and wider stylar shelves than in T. belgica.

All of these characters of the dentition in $T$. americana indicate that it is slightly derived with respect to $T$. belgica and support its direct descent from the latter species. Only one feature is possibly in conflict with this hypothesis. In $T$. americana, $\mathrm{m} 3$ is slightly longer than $\mathrm{m} 2$, whereas in $T$. belgica $\mathrm{m} 3$ is about the same length as $\mathrm{m} 2$ or very slightly shorter. Although an unreduced $\mathrm{m} 3$ has been considered to be a more primitive condition, the difference between the two species in this respect seems insufficient to preclude their direct relationship.

See Appendices 1 and 2 for measurements.
TeILHARDINA CRASSIDENS $\mathrm{n}$. sp.

Figures 6.2, 6.4, 7.1, 7.8, 7.9, 8, 9

?Tetonius musculus MATTHEw, 1915, p. 463 (part), fig. 34 .

Tetonoides tenuiculus GAZIN, 1962, p. 35 (part), Pl. 3, fig. 6; ROSE AND BOWN, 1984, p. 250.

Tetonoides pearcei Bown, 1979a, p. 77, fig. 48e.

Teilhardina sp. nov. RoSE AND BOwn, 1986, p. 123, fig. 3.

Holotype. - UW 8959, left dentary with p3$\mathrm{m} 2$, roots of $\mathrm{i} 1$ and $\mathrm{c}$, and alveoli for $\mathrm{i} 2$ and p2; UW locality V-73125 (=USGS locality D-1224), $180 \mathrm{~m}$ level of Willwood Formation, secs. 27 and 28, T47N, R93W, Bighorn Basin, Wyoming.

Hypodigm. - The holotype and USGS 482, 7203, 7204, 15409; UW 6583; DPC 1317; 

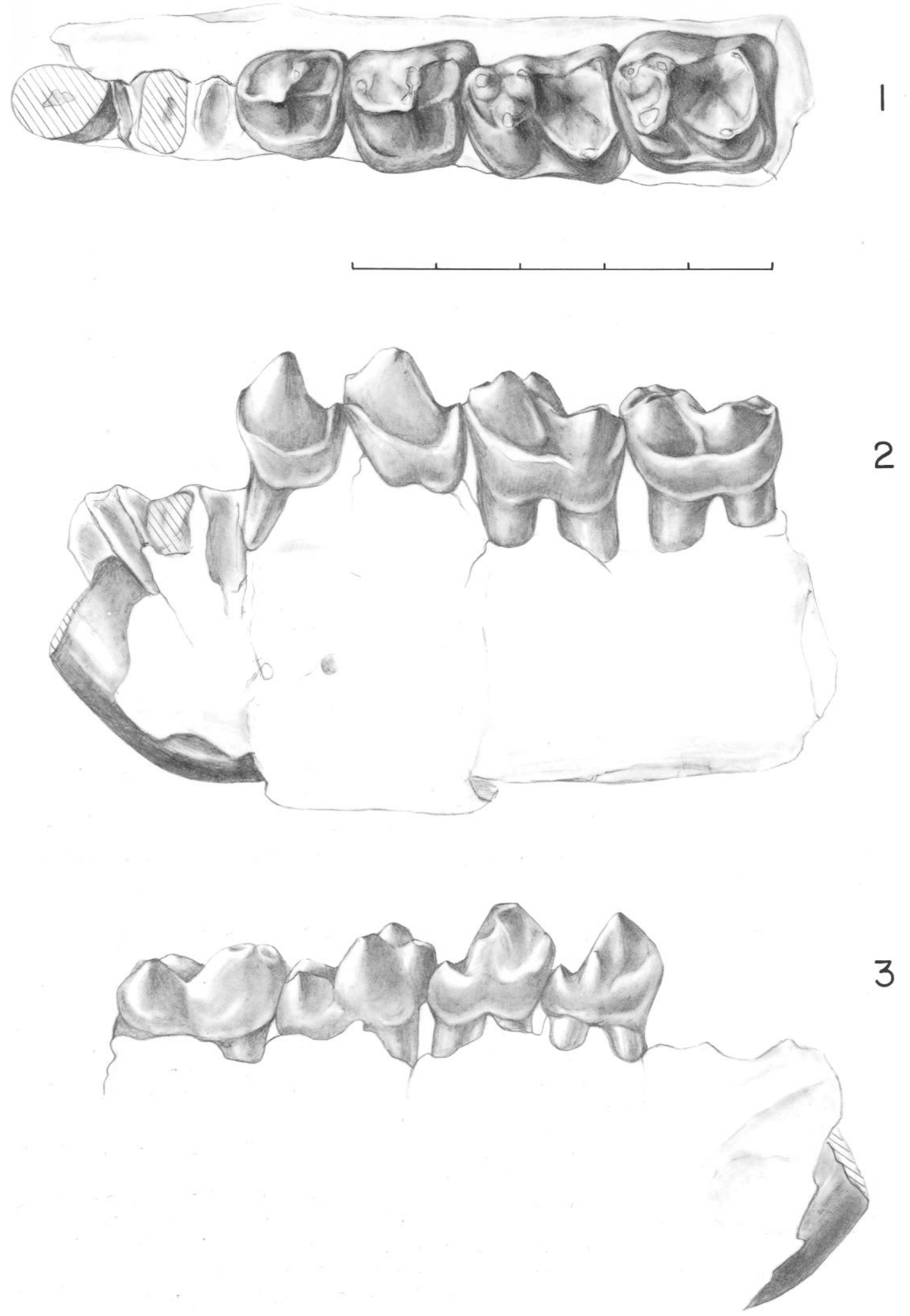
YPM 24626, 30721, 30723, 30725, 30731, 30733; ?AMNH 15066, from the Bighorn Basin; UM 66276, 71071, 73908, 75005, 79498, 79824, 85516, 85525, from the Clark's Fork Basin.

Distribution. - Willwood Formation, lower Eocene (Wasatchian; upper part of lower Haplomylus-Ectocion Range Zone of Schankler, 1980), 180-190 m interval, Bighorn Basin, and 240-330 m interval (1,7601,850 m of Gingerich's 1982 section), Clark's Fork Basin, Wyoming.

Etymology. - Latin crassus, stout, and dens, tooth; in allusion to the broader p4 in this species compared to that in T. americana.

Diagnosis. - Differs from $T$. belgica and $T$. americana in having relatively broader mandibular cheek teeth (p3-m3), p3-4 lower crowned, p3 with small metaconid and variable paraconid, $\mathrm{p} 4$ trigonid broader and more anteroposteriorly compressed and with higher and larger paraconid and metaconid cusps. Third lower premolar and p4 higher crowned, p4 with broader trigonid, and $\mathrm{m} 1$ with more closed trigonid than in $T$. tenuicula $\mathrm{n}$. comb. Lower and upper molars about $10 \%$ smaller (mean size) than in T. americana. Lower dental formula 2.1.3.3. Upper molars generally with more inflated stylar shelf than in $T$. americana; small mesostyle present on $\mathrm{M} 1$, variable on $\mathbf{M} 2$.

Discussion. - The specimens here included in Teilhardina crassidens constitute part of the sample previously called Tetonoides tenuiculus (e.g., Rose and Bown, 1984). Because there is now a series of transitional specimens linking this sample to the older and more primitive T. americana, it is included in Teilhardina. But $T$. crassidens differs from $T$. americana in having more molarized p3-4 and relatively broader (or relatively shorter) cheek teeth (Table 3). Although $T$. crassidens closely resembles $T$. tenuicula $\mathrm{n}$. comb. (here placed in Teilhardina) and Anemorhysis pearcei, subtle morphologic differences (mainly pertaining to $\mathrm{p3}-4$ ), together with different stratigraphic occurrences, indicate that these are three distinct species. Teilhardina
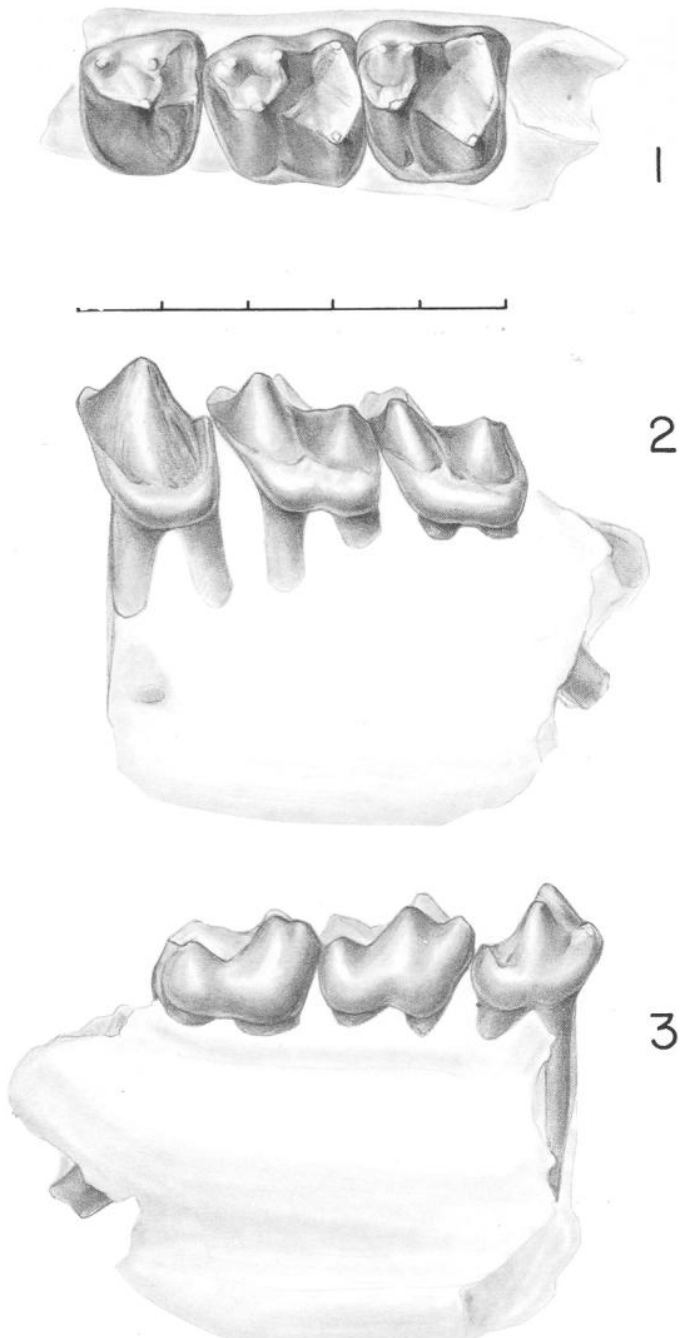

FIGURE 9-Teilhardina crassidens n. sp., YPM 30721 , left dentary with p4-m2 (190 m). 1-3, occlusal, lateral, and medial views, respectively. Scale is $5 \mathrm{~mm}$.

crassidens can be distinguished from $A$. pearce $i$ by its shorter and unbasined p4 talonid, the deep constriction (hypoflexid) between trigonid and talonid of $\mathrm{p} 4$, and the presence of a metaconid on $\mathrm{p} 3$ (see further discussion under Anemorhysis and T. tenuicula).

FIGURE 8-Teilhardina crassidens n. sp., holotype, UW 8959, left dentary with p3-m2 and roots or alveoli of $\mathrm{i} 1-2$, c, p2 $(180 \mathrm{~m})$. 1-3, occlusal, lateral, and medial views, respectively. Scale is $5 \mathrm{~mm}$. 

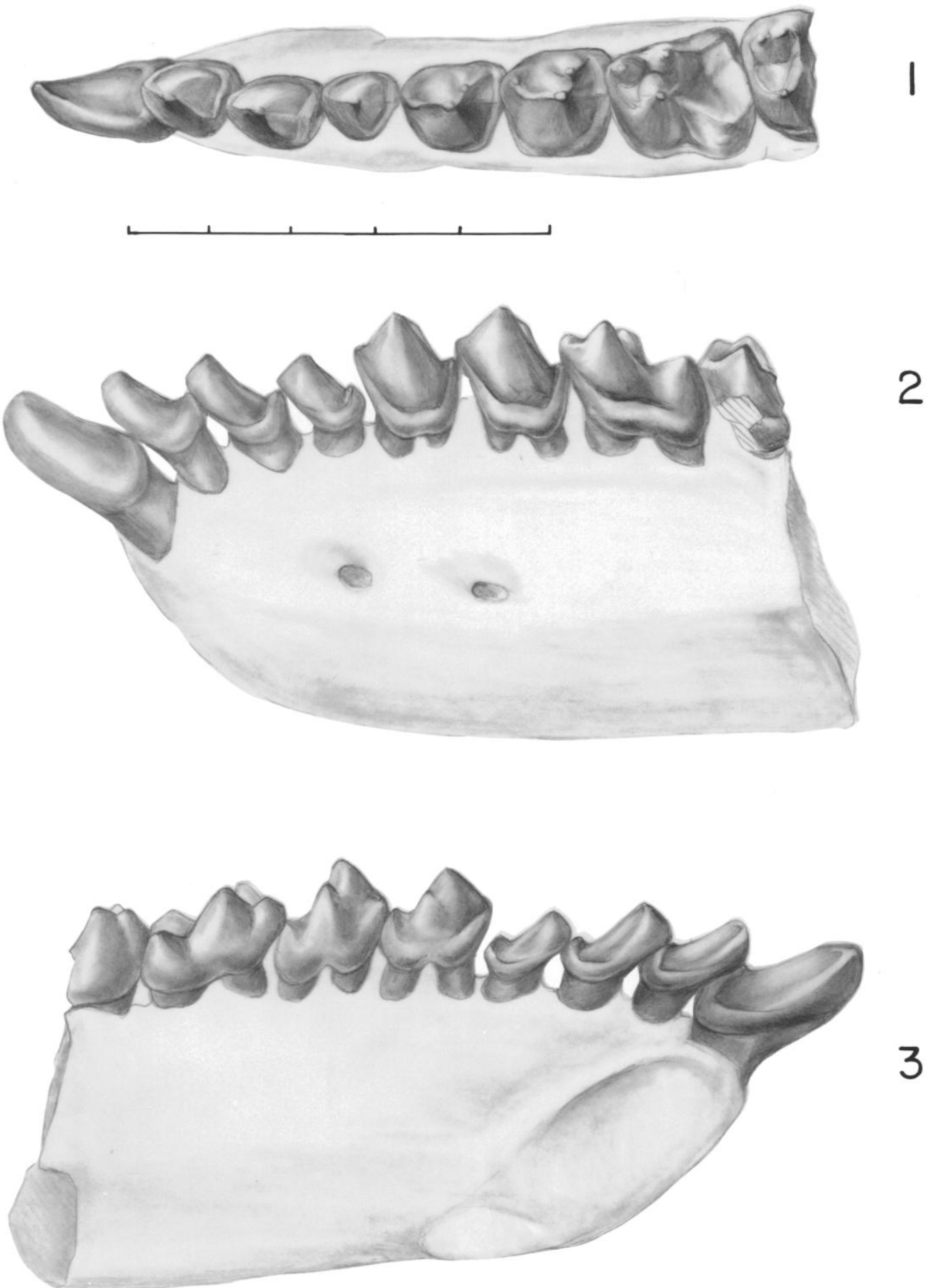

FIGURE 10-Teilhardina intermediate, USGS 512, left dentary with i1-2, c, p2-m1, m2 trigonid (140 m). $1-3$, occlusal, lateral, and medial views, respectively. Scale is $5 \mathrm{~mm}$. 
Szalay (1976) tentatively referred a few specimens (AMNH 59600, 59601, 59641, 59682, and 80956) from East Alheit Pocket, Four Mile fauna, to Anemorhysis tenuiculus. AMNH 59600 may belong to the insectivore Talpavus. Of the others, the authors have seen only AMNH 59682 (maxilla with M1-3); it has an incipient mesostylar fold on M1. This feature and the co-occurrence of these specimens with advanced Tetonius matthewi suggest that they may instead represent Teilhardina crassidens.

See Appendices 3 and 4 for measurements.

TEILHARDINA AMERICANA-

TEILHARDINA CRASSIDENS INTERMEDIATES

Figures 7.2, 10, 11, 12.1-12.3, 13

Discussion. - Several specimens exhibit morphology intermediate between Teilhardina americana and $T$. crassidens and come from the stratigraphic interval between them. As detailed later, these are interpreted as representing transitional populations in a gradually evolving lineage. Consequently, the limits of $T$. americana and $T$. crassidens are necessarily arbitrary and are here drawn stratigraphically. There is, however, no discrete break between either species and the intermediates from immediately above or below; rather, there is a morphological continuum from $T$. americana through a series of stratigraphically ascending transitional specimens to $T$. crassidens. Indeed, it was impossible to draw even a discrete lower stratigraphic boundary for $T$. crassidens in the Clark's Fork Basin, and it was necessary, on morphological grounds, to assign part of the sample from $240 \mathrm{~m}(=1,760 \mathrm{~m}$ of Gingerich, 1982 ) to $T$. crassidens and to designate the remainder as intermediates. (Specimens of Teilhardina from $240 \mathrm{~m}$ that lack diagnostic teeth are arbitrarily included as intermediates, but some or all could represent $T$. crassidens.)

This transitional sample, which occurs through about $100 \mathrm{~m}$ in the central and southern Bighorn Basin, exhibits greater variability in size and morphology than either $T$. americana or $T$. crassidens and includes many specimens that are smaller than either of those species. This may be related to the trend toward increasing relative breadth of the cheek teeth, achieved in some specimens by reducing tooth length. It may also reflect the probability that this transitional sample gave rise not only to $T$. crassidens but also to $T$. tenuicula n. comb., i.e., the sample may record the initial phase of divergence of these two species.

Workers who prefer a neater taxonomy might advocate a new species name for the intermediates or broader definitions of the three Bighorn Basin species that would permit all specimens to be assigned to one of them. These alternatives are less satisfactory than the procedure adopted here because either one would still require arbitrary species boundaries and would obscure the gradual, temporally stratified morphological transition between them.

The specimens included here are intermediate between $T$. americana and $T$. crassidens in relative breadth of cheek teeth (p3$\mathrm{m} 3$; Table 3), expression of the paraconid and metaconid of p3 and p4 (especially size and elevation of the $\mathrm{p} 4$ metaconid relative to the protoconid), crown height of $\mathrm{p} 3$ and $\mathrm{p} 4$, and apparently (where known) relative size of lower incisors and canine. Presence of $\mathrm{p} 1$ is variable. Although upper teeth are assigned here principally by their intermediate stratigraphic positions (as are lower dentitions that lack diagnostic teeth), they also appear transitional in the increasing breadth of the stylar shelf and the variable presence of a small mesostyle on M1.

The sample from Hackberry Hollow (UM locality SC-192) in the Clark's Fork Basin is included here but these specimens differ slightly from other intermediates in ways that foreshadow Teilhardina tenuicula n. comb. (Figures 12.3, 13). They are perhaps better regarded as $T$. americana-T. tenuicula intermediates. The paraconid of p4 is slightly stronger and more lingually placed, the p4 metaconid is closer to the protoconid, and the trigonid of $\mathrm{m} 1$ is slightly more open than in other intermediates. They are perhaps related to (or descended from) the smaller intermediates in the sample from the southern and central Bighorn Basin.

YPMPU 17232 and 17357 from the early Wasatchian Golden Valley Formation of North Dakota appear to represent advanced Teilhardina intermediates, or possibly $T$. crassidens.

See Appendices 5 and 6 for measurements. Referred specimens. - Bighorn Basin- 

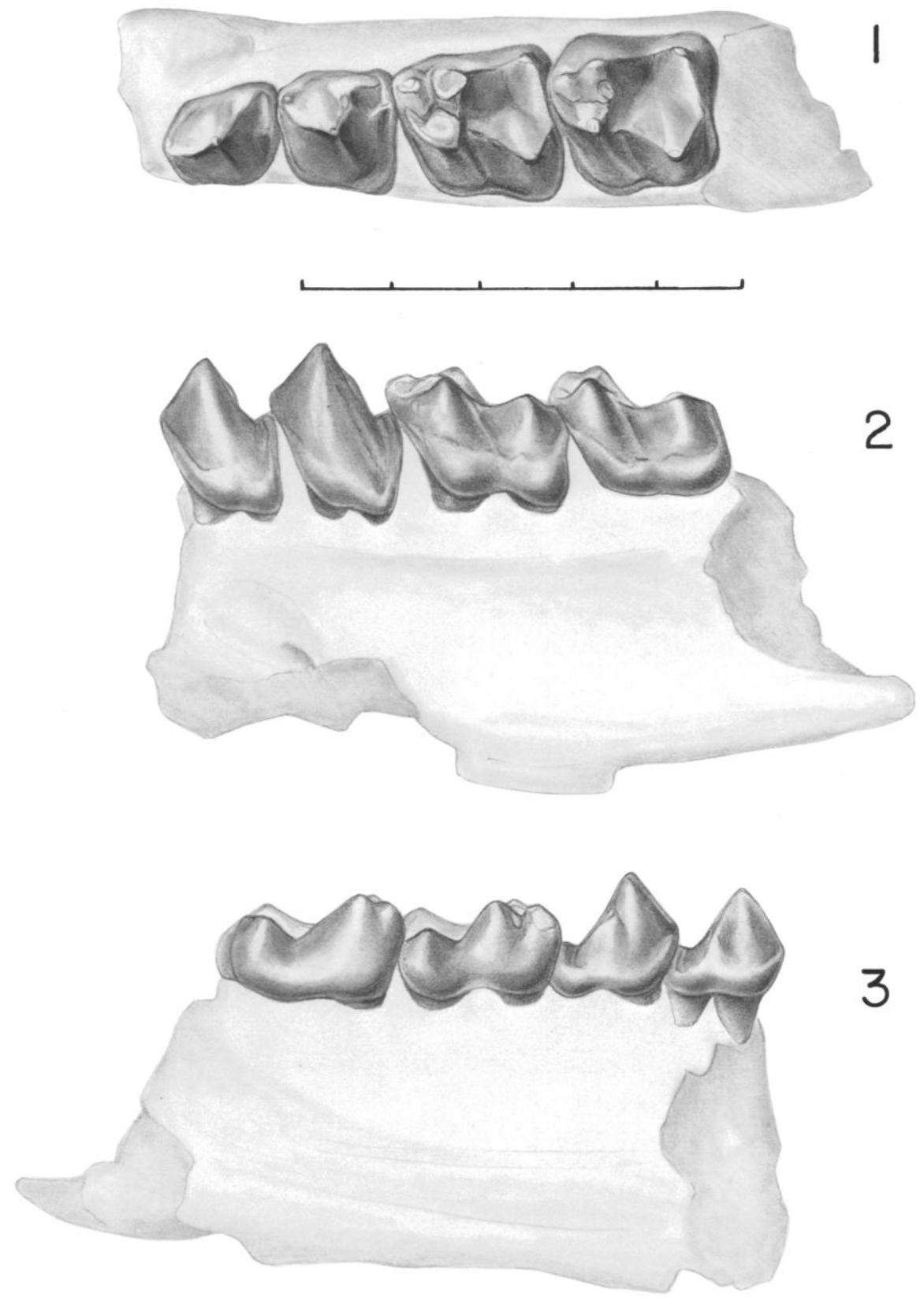

FIGURE 11-Teilhardina americana-T. crassidens intermediate, YPM 30720, left dentary with p3-m2 $(140 \mathrm{~m}) .1-3$, occlusal, lateral, and medial views, respectively. Scale is $5 \mathrm{~mm}$.

FIGURE 12-Teilhardina, SEM stereophotographs, occlusal views. $1, T$. americana-T. crassidens intermediate, UM 77391, right p2-3 and roots of c and p1 (Clark's Fork Basin, $205 \mathrm{~m}$ ); 2, T. americanaT. crassidens intermediate, USGS 512 , left i1 $-\mathrm{m} 2(140 \mathrm{~m}) ; 3, T$. americana-T. tenuicula intermediate, YPMPU 17418, left p2-m3 (Hackberry Hollow locality); 4, T. tenuicula (Jepsen) n. comb., YPM 33273 , right $\mathrm{p} 3-\mathrm{m} 1(240 \mathrm{~m})$. Scale is $5 \mathrm{~mm}$ except for 1 . 
EOCENE PRIMATES FROM WYOMING
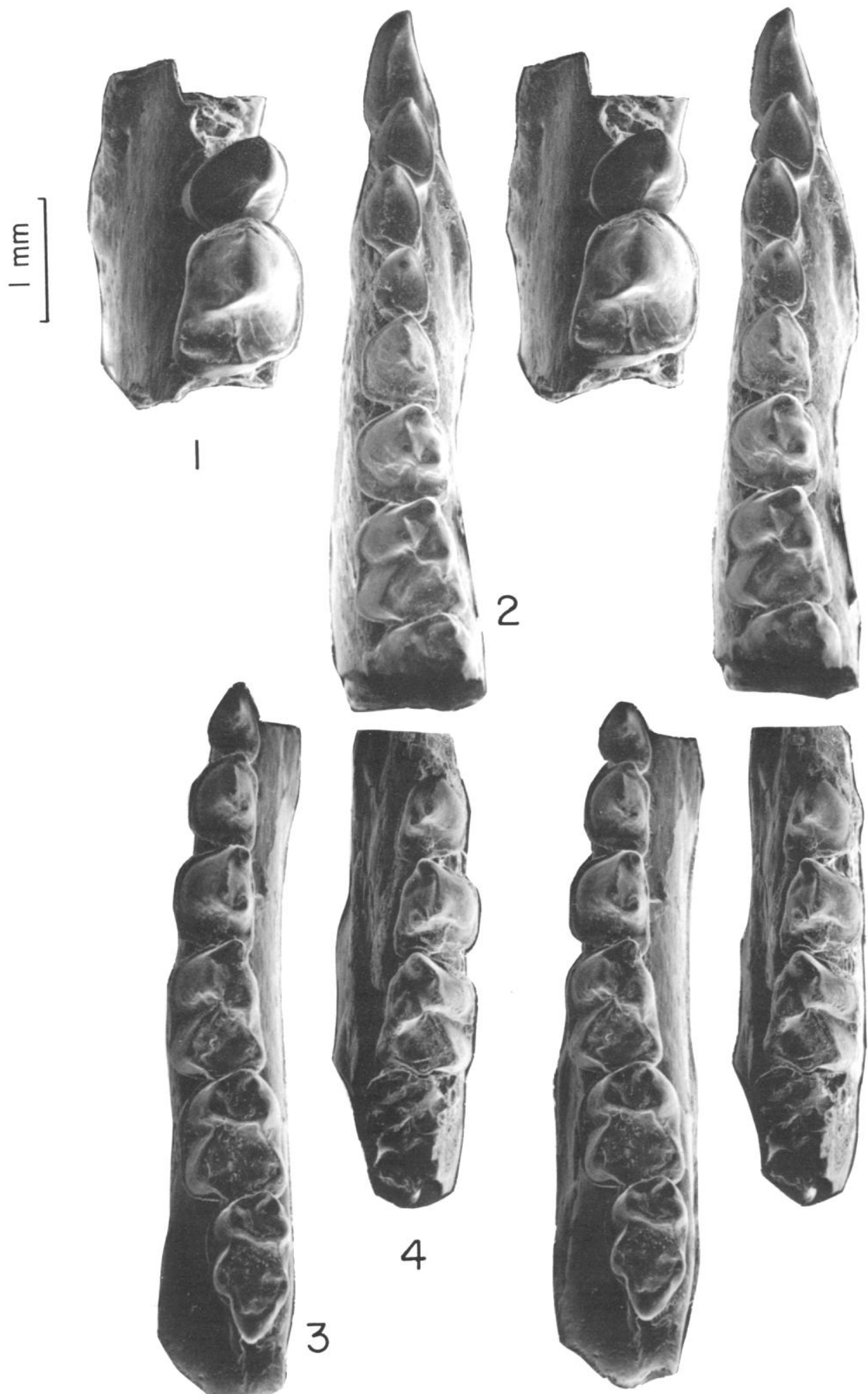

3 

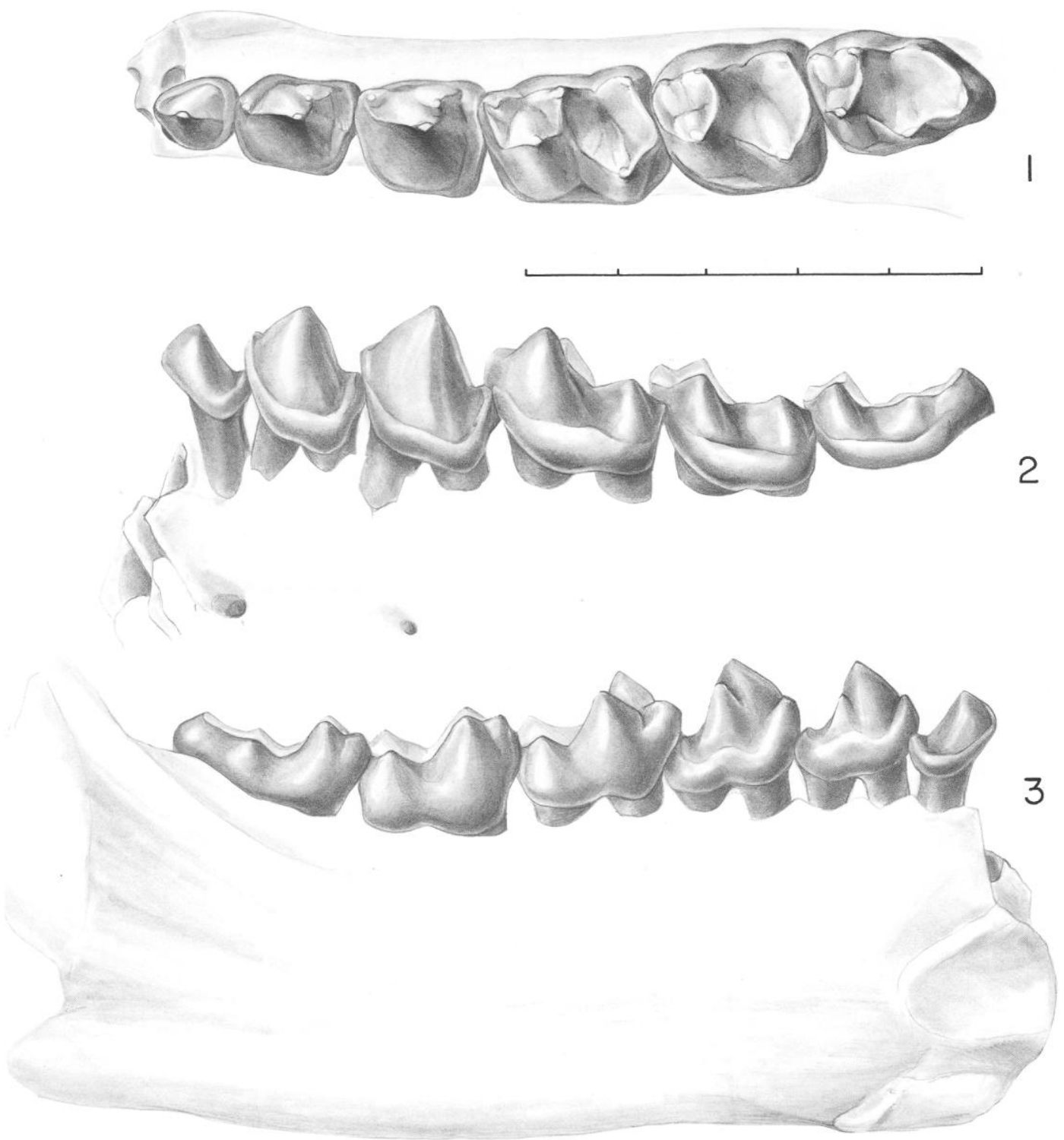

FIGURE 13-Teilhardina americana-T. tenuicula intermediate, YPMPU 17418, left dentary with p2$\mathrm{m} 3$ and alveoli of i1-2 and c (Hackberry Hollow locality, meter level unknown). 1-3, occlusal, lateral, and medial views, respectively. Scale is $5 \mathrm{~mm}$.

USGS 477, 478, 488, 512, 2562, 3650?, 7192$7194,9142,9152,9156,9203,9211,9212$, $9215,9216,9223,9610,13926,14730$, 15893, 15894?; YPM 23172, 24356, 24358, 27204, 30705, 30719, 30720, 30726-30730, 30732, 33231; UW 6618, 6907, 7139, 7199, 7201, 7212, 7214, 7224, 7225, 7227, 7246, 7694, 7707, 8819, 8835, 8922, 10424. Clark's Fork Basin-UM 64760, 66222, 66483, 68538, 69493, 69754, 69783, 71091, 71095, 71126, 71147, 71386, 71398, 75246, 76492,
76501, 76519, 77361, 77391, 79549, 85823. Hackberry Hollow-YPMPU 17418, 17683, 23064, 23083, 23301, 23302; UM 69147, 69198, 69646, 73876.

\section{TEILHARDINA TENUICULA} (Jepsen, 1930) n. comb. Figures $12.4,14,15.1$

Tetonius tenuiculus JePSEN, 1930, p. 126, Pl. 2, fig. 9.

Paratetonius? tenuiculus GaZIN, 1952, p. 25. 

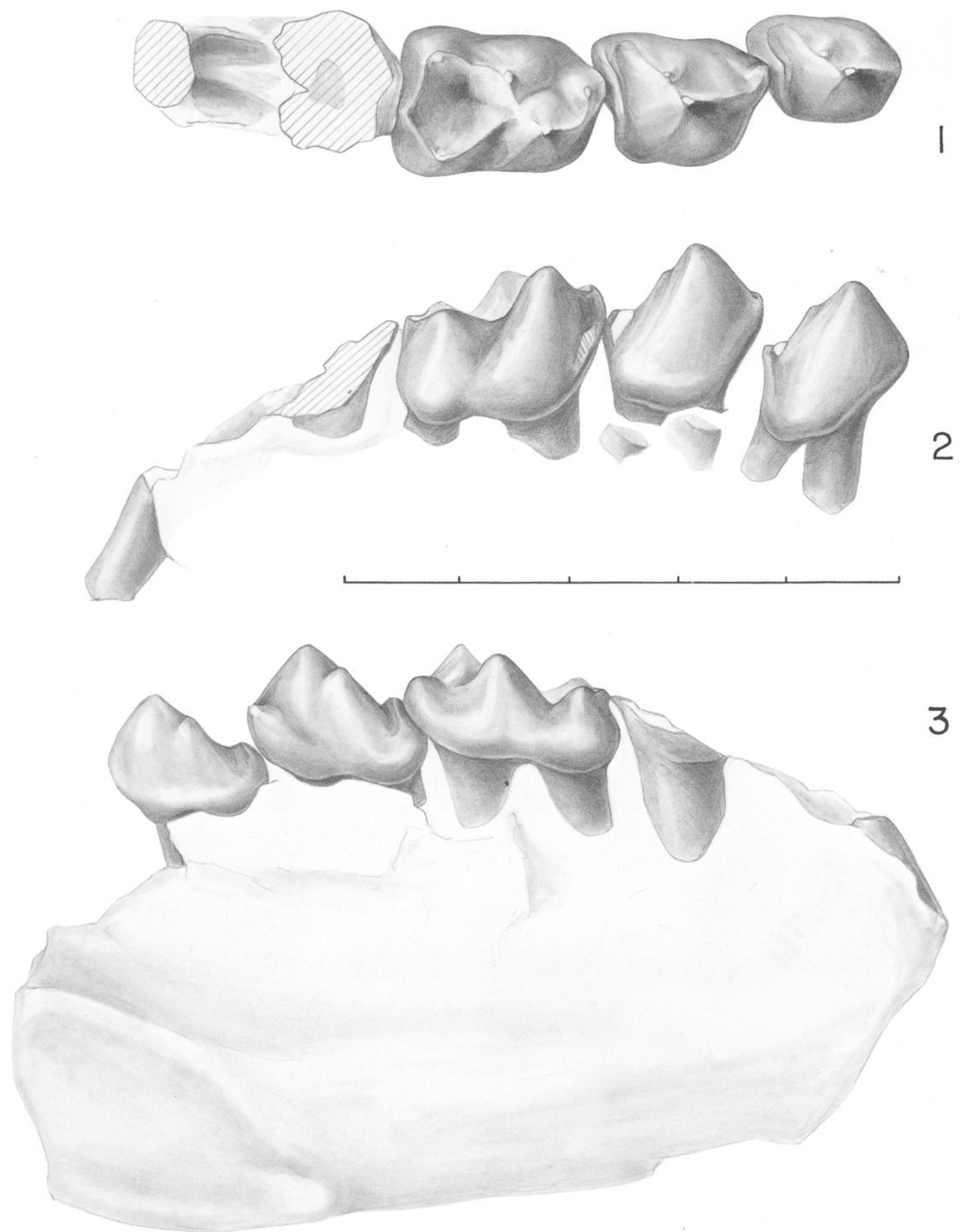

FIGURE 14-Teilhardina tenuicula (Jepsen) n. comb., YPM 33273, right dentary with p3-m1 (240 m). $1-3$, occlusal, lateral, and medial views, respectively. Scale is $5 \mathrm{~mm}$. 

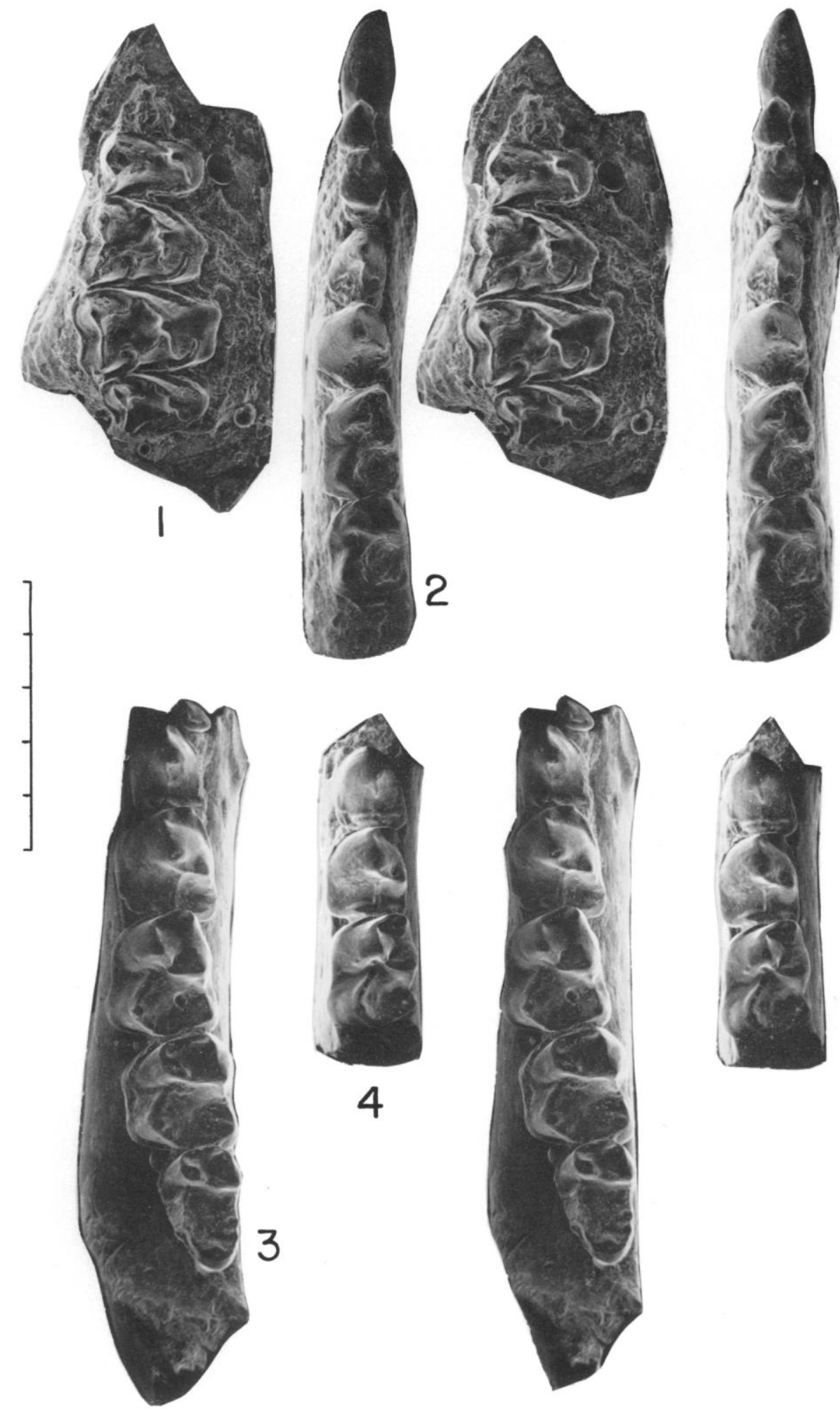
Tetonoides tenuiculus GAZIN, 1962, p. 35. Tetonius musculus Delson, 1971, p. 338 (part). Anemorhysis tenuiculus SzALAY, 1976, p. 220 (holotype only), fig. 35; SZALAY AND DELSON, 1979, p. 223 (part).

Holotype. - YPMPU 13027, right maxilla with P4-M3, from Willwood Formation, "about two miles east of the old Otto-Basin road crossing on Dorsey Creek and well south of the road" (Jepsen, 1930, p. 126), Bighorn Basin. The precise locality clearly cannot be determined, but the approximate region must be within a mile or two of Yale localities 302 and 351 (which produced the referred specimens), suggesting a level of about 230-300 m.

Hypodigm. - The holotype and tentatively USGS 12192 (right $\mathrm{m} 1$ from Yale locality 302, about $235 \mathrm{~m}$ ) and YPM 33273 (right p3-m 1, from Yale locality 351 at $240 \mathrm{~m}$ ).

Distribution. - Lower part of Willwood Formation, lower Eocene (Wasatchian), Bighorn Basin, Wyoming.

Revised diagnosis. - Smaller than T. americana and $T$. crassidens; upper molars with no trace of a mesostyle. Third and fourth lower premolars relatively broad, lowercrowned, and with smaller and shorter talonid than in other species of Teilhardina; $\mathrm{p} 4$ trigonid relatively open with metaconid close to relatively low protoconid. Trigonid of $\mathrm{ml}$ more extended anteroposteriorly than in other species.

Discussion. - Previous authors have considered this species to belong to Tetonius, Tetonoides, or Anemorhysis, and to include specimens here placed in Anemorhysis pearcei, Teilhardina americana, and T. crassidens. Teilhardina tenuicula is restricted here to the holotype and two tentatively allocated lower jaw fragments; there is no convincing evidence that any other known specimens belong to this species (see further discussion under Anemorhysis). Teilhardina tenuicula as here defined comes from at least $200 \mathrm{~m}$ stratigraphically above the last occurrence of $T$. americana and $50 \mathrm{~m}$ above $T$. crassidens.
The two referred specimens are lower teeth (Figures 12.4, 14) and cannot be directly compared with the type. Their assignment here is justified because both are also relatively small, they come from the same general area and stratigraphic interval as the type and occlude perfectly with it, and they do not resemble any of the other very small Bighorn Basin anaptomorphines whose assignments are less problematical; i.e., they are clearly distinct from other Teilhardina and from Anemorhysis (which is characterized by enlargement of the $\mathrm{p} 4$ talonid) and must belong to $T$. tenuicula or to a new, otherwise unknown species.

The status of $T$. tenuicula, as with certain other omomyids, is in doubt because the holotype itself is problematical; it is an upper dentition of uncertain provenance. Upper teeth (particularly of Anemorhysis) are too poorly known to establish diagnostic differences between Teilhardina and Anemorhysis. We assign this species to Teilhardina rather than to Anemorhysis based on the referred lower teeth (especially p4), which bear detailed resemblances to those of Teilhardina americana-T. crassidens intermediates (see discussion in Evolution section) and differ from those of Anemorhysis. The species is considered to be valid because of the minor structural differences noted in the diagnosis and the probable temporal separation from other North American Teilhardina and Anemorhysis.

See Appendices 7 and 8 for measurements.

\section{Genus ANEMORHysis Gazin, 1958}

Paratetonius? GazIN, 1952, p. 24 (P.? sublettensis only).

Anemorhysis GazIN, 1958, p. 25; 1962, p. 34; SZALAY, 1976, p. 211 (part); SZALAY AND DELSON, 1979, p. 221 (part); GINGERICH, 1981, p. 358; BOWN AND ROSE, 1984, p. 106.

Uintalacus GazIN, 1958, p. 28 , Pl. 14, fig. 5.

Tetonoides GAZIN, 1962, p. 34; GINGERICH, 1981, p. 358 ( $T$. pearcei only).

Tetonius Delson, 1971, p. 338 (part).

$\leftarrow$

FIGURE 15-Tetonius and Teilhardina, SEM stereophotographs, occlusal views. 1, Teilhardina tenuicula (Jepsen) n. comb., holotype, YPMPU 13027, right P4-M3 (meter level unknown). 2, Tetonius mckennai n. sp., holotype, UCMP 46192, left i1-2, c, p3-m2 (Alheit Pocket, Four Mile fauna). 3, Tetonius matthewi n. sp. (stage 1), YPM 23031, left p2-m3 (meter level unknown). 4, Tetonius species (stage 1), USGS 5936, left p3-m 1 and alveoli of c and p2 (180 m). Scale is $5 \mathrm{~mm}$. 
Type species. - Paratetonius? sublettensis Gazin, 1952, p. 24.

Included species. - A. sublettensis, $A$. pearcei, $A$. pattersoni, and $A$. wortmani.

Distribution. - Late early through late Wasatchian (early Eocene) of Wyoming.

Revised diagnosis. - Small anaptomorphines of similar size to Teilhardina and smaller than Tetonius. Lower third premolar and p4 lower crowned and relatively shorter and broader than in most species of those genera; and p4 more molariform, with stronger paraconid and moderately high and prominent metaconid (except in A. pattersoni). Lower fourth premolar with short but distinct cristid obliqua, more buccally oriented than in Teilhardina (resulting in shallower hypoflexid), and moderate to well developed talonid basin with distinct hypoconid and weaker entoconid. First lower molar and $\mathrm{m} 2$ with relatively broad talonids and talonid basins, but molars less inflated basally than in Tetonius, so cusps appear peripheral in occlusal view. Postcristid of m1-2 almost straight, not markedly convex posteriorly as in Tetonius and Teilhardina.

Discussion.-Gazin's (1958) original diagnosis of this genus, though based only on Anemorhysis sublettensis, is basically accurate and, with slight modifications (Bown and Rose, 1984), is followed here. In addition to A. sublettensis, the following are valid species of Anemorhysis: A. pearcei, A. pattersoni, and A. wortmani. "Tetonius" musculus (Matthew, 1915), based on a dentary fragment with $\mathrm{m} 3$ from the Lysite Member of the Wind River Formation, may belong to this genus (based on its foreshortened dentary and bilobed p3 root), but it lacks more definitive features, leaving its assignment in doubt.

There has been much confusion concerning the composition and recognition of this genus, largely stemming from the previous tendency to identify most small Wasatchian anaptomorphines (including those here allocated to North American Teilhardina) as either Tetonoides pearcei or Anemorhysis tenuiculus. This was not an unreasonable practice in view of the scarcity of specimens and their fragmentary nature. However, the considerable new material of small Wasatchian anaptomorphines from the Bighorn Basin permits substantial clarification of the taxa involved.
When Gazin (1962) named Tetonoides (for the new species $T$. pearcei), he transferred Jepsen's (1930) "Tetonius" tenuiculus to Tetonoides. Szalay (1976) subsequently regarded $T$. pearcei as a junior synonym of " $T e$ tonius" tenuiculus and reallocated it to Anemorhysis, thereby placing most small early Wasatchian anaptomorphines in Anemorhysis tenuiculus. As discussed above, the latter species is here restricted to Jepsen's holotype (a maxilla) and two lower dentitions, and is assigned to Teilhardina. The authors concur with Szalay that Tetonoides is a junior synonym of Anemorhysis-A. pearcei and $A$. pattersoni being the most generalized species of the genus.

In view of the revision of North American Teilhardina presented above, Anemorhysis is a rare genus; none of its four species is represented with certainty by more than a few fragmentary jaws. Therefore, relationships between these species cannot yet be confidently established. However, the genus seems to be most closely allied to Teilhardina and was almost certainly descended from it. This conclusion is strengthened by new material of both Anemorhysis and Teilhardina described here and earlier (Bown and Rose, 1984). However, the potential for confusion between the two genera has increased because the new samples have begun to fill some of the morphologic and temporal gaps that formerly existed. In particular, $A$. pearcei and $A$. wortmani are similar to $T$. crassidens, and $A$. pattersoni closely resembles $T$. americana.

The most consistent distinction between Teilhardina and Anemorhysis is seen in p4, all Anemorhysis having a relatively larger, usually basined talonid, a more buccal cristid obliqua, and a shallower hypoflexid. Except in $A$. pattersoni, the paraconid of p4 is higher and more prominent than in Teilhardina $(T$. crassidens has a well developed p4 trigonid resembling that of Anemorhysis, but its short talonid heel and deep hypoflexid contrast with Anemorhysis). There is no metaconid on $\mathrm{p} 3$ in $A$. pearcei or $A$. wortmani (the only two species in which this tooth is known), in contrast to $T$. crassidens. The molar cusps in Anemorhysis tend to be more peripherally placed, the paraconids more lingual, and the postcristid more squared than in Teilhardina. Anemorhysis pattersoni and $A$. wortmani are more derived than Teilhardina in having a 
more foreshortened jaw (i.e., show greater compression of anterior teeth), and the latter has a larger il than in any Teilhardina ( $A$. pearce $i$ appears somewhat comparable to $T$. crassidens in this regard). The anterior part of the jaw is unknown in A. sublettensis.

Based on these characters, Anemorhysis can be defended as a clade whose species share the derived character of $\mathrm{p} 4$ talonid structure. If this is accepted, present evidence suggests that $A$. pattersoni is a side branch in which the p4 paraconid was reduced (thus resembling Teilhardina americana in this feature). Alternatively, $A$. pattersoni might be considered to be a late species of Teilhardina that independently acquired Anemorhysis-like p4 talonid structure-a possibility that cannot be eliminated until all these taxa are better known. The differences between Anemorhysis and Teilhardina are subtle but they are illustrative of the problems posed for systematics once lineages become better known.

\section{ANEMORHYSIS PATTERSONI \\ Bown and Rose, 1984 \\ (not figured)}

?Anemorhysis musculus SzAlay, 1976; p. 226 (YPM 18695 only), fig. 39.

Anemorhysis pattersoni BOwN AND ROSE, 1984, p. 108, fig. 5 .

Holotype.-USGS 476, left dentary fragment with p4-m2; YPM locality 45-S, 470 meter level of Willwood Formation.

Hypodigm. - The type and, tentatively, USGS 15403 and YPM 18695.

Distribution - Willwood Formation, lower Eocene (late early-earliest middle Wasatchian-middle Bunophorus Interval Zone through base of lower Heptodon Range Zone of Schankler, 1980), 382-470 m interval, southern Bighorn Basin, Wyoming.

Revised diagnosis. - About the size of Anemorhysis wortmani; larger than $A$. sublettensis and slightly larger than $A$. pearcei. Teeth and dentary anterior to p3 shorter (more compressed) than in $A$. pearcei, longer than in $A$. wortmani; p3 clearly two-rooted as in $A$. pearcei, unlike $A$. wortmani. Lower fourth premolar less basally inflated on the buccal side than in $A$. wortmani, and differing from all other species of Anemorhysis in having much weaker and lower paraconid. Talonid basin of $\mathrm{p} 4$ about the same size as in $A$. wort- mani, larger than in $A$. pearcei, and shorter than in $A$. sublettensis.

Discussion. - This species is known only from the holotype dentary (USGS 476), a second lower jaw fragment discovered during the 1986 field season, and one tentatively referred upper dentition. Bown and Rose (1984) included this species in Anemorhysis because of its small size, squared molars, and p4 talonid construction, but acknowledged that it differs from other species of the genus in having a much weaker paraconid and a somewhat lower metaconid on p4. In the latter characters, it resembles Teilhardina americana, the probable direct ancestor of Anemorhysis.

The probable absence of $\mathrm{p} 2$ in the holotype of $A$. pattersoni (Bown and Rose, 1984), upon restudy, seems equivocal. It is just as likely that the two small compressed alveoli anterior to the two roots of $\mathrm{p} 3$ contained $\mathrm{c}$ and $\mathrm{p} 2$, and that damage at the back of the i1 alveolus has obliterated a diminutive i2 alveolus. Despite this ambiguity, the anterior lower dentition of $A$. pattersoni is clearly more compressed than in $A$. pearcei but less compressed than in $A$. wortmani.

A specimen recovered early in the 1986 field season appears to be referable to this species and, if so, underlines its close affinity to Teilhardina. USGS 15403, a right dentary with $\mathrm{p} 4-\mathrm{m} 2$ from USGS locality D-1652 (382 $\mathrm{m}$ level of Willwood Formation, Bighorn Basin, about $85 \mathrm{~m}$ below the level of the holotype), is significant because it is more similar to Teilhardina americana than is the holotype and may represent a transitional form between them, although it is somewhat larger than either. As in the holotype of $A$. pattersoni (and other Anemorhysis), p4 has a buccal cristid obliqua and a shallow hypoflexid; but its entoconid is less lingually situated and less distinct and its paraconid, though very small, is more distinct, features resembling Teilhardina americana. A few other subtle characters support allocation of USGS 15403 to Anemorhysis pattersoni. As in the holotype, p4 lacks a buccal cingulid (present in all known p4's of $T$. americana) and displays a distinct crest on the posterior wall of the trigonid (postvallid), joining the protoconid and the hypoconid. Such a crest is conspicuously absent in $T$. americana, although some specimens have a short, faint 
crest directed toward the area between the protoconid and metaconid and terminating halfway up the postvallid. Although the significance of such subtle differences is unknown, the sum of features in USGS 15403 together with its stratigraphic occurrence (>300 m higher and 2-3 m.y. younger than the latest $T$. americana) support its assignment to $A$. pattersoni.

Two other specimens that include only molars (USGS 3988, $384 \mathrm{~m}$; YPM 24984, $370 \mathrm{~m}$ ) may also belong here based on stratigraphic occurrence, but they lack diagnostic characters.

See measurements in Appendices 7 and 8.

\section{ANEMORHYSIS WORTMANI \\ Bown and Rose, 1984 \\ (not figured)}

Anemorhysis wortmani Bown AND ROSE, 1984, p. 107, fig. 4.

Holotype. - USGS 6554, fragment of right ramus with $\mathrm{p} 3-\mathrm{m} 2$ and root of i1; USGS locality D-1473, $635 \mathrm{~m}$ level of Willwood Formation, Bighorn Basin, Wyoming.

Hypodigm. - The type specimen and USGS 12218.

Distribution. - Willwood Formation, lower Eocene (middle Wasatchian-middle part of Heptodon Range Zone of Schankler, 1980), 630-635 m interval, southern Bighorn Basin, Wyoming.

Revised diagnosis. - Larger than A. sublettensis, slightly larger than $A$. pearcei. Lower second premolar absent, in contrast to $A$. pearcei; p3 anteroposteriorly compressed, with one root, in contrast to $A$. pearcei and $A$. pattersoni. Lower fourth premolar broader than in $A$. pearcei and $A$. sublettensis and relatively more distended buccally than in other Anemorhysis species, but with strong paraconid as in $A$. pearcei and $A$. sublettensis and in contrast to $A$. pattersoni. Talonid of $\mathrm{p} 4$ with well developed hypoconid and entoconid; talonid basin wider than in $A$. pearcei, about as wide as in $A$. pattersoni and $A$. sublettensis but shorter than in $A$. sublettensis. Molar talonid basins slightly narrower than in $A$. pattersoni.

Discussion. - In addition to the holotype, only USGS 12218 from USGS locality $\mathrm{D}-1583$ (about $630 \mathrm{~m}$ level) is referred to this taxon. USGS 12218 is a left dentary fragment with p4-m2. It is slightly larger than the holotype, and the paraconid on $\mathrm{ml}$ is not as fully lingual in position as in the holotype. In other respects, the two specimens are essentially identical.

See Appendix 7 for measurements.

Genus Steinius Bown and Rose, 1984

?Omomys MatThew, 1915, p. 450 (part).

?Loveina SIMPSON, 1940, p. 188 (?L. vespertina only).

Omomys Gazin, 1962, p. 32.

Uintanius SZALAY, 1976, p. 337 (part).

Steinius BOWN AND Rose, 1984, p. 98.

Type species. -? Omomys vespertinus Matthew, 1915 , p. 450 , only known species.

Diagnosis. - Lower molars differ from those of most other anaptomorphines (e.g., Tetonius, Absarokius) in lacking marked basal inflation and in having cusps set near periphery of crowns; $m 3$ larger than in those genera. Differs from Omomys in having smaller molar paraconids, $\mathrm{m} 1$ paraconid slightly less lingual and $\mathrm{m} 2-3$ paraconids more lingual than in Omomys carteri. Trigonids of m 1-2 more compressed anteroposteriorly than in $\mathrm{Omo}$ mys; paraconid and metaconid on $\mathrm{m} 2-3$ closely appressed and not separated by a notch, in contrast to Omomys, Uintanius, and Loveina. Differs from Uintanius in having $\mathrm{m} 1$ with much more compressed trigonid (not tilted backward), and broader talonid, and in having more lingual paraconids on $\mathrm{m} 2-3$. First two lower molars differ from those of Loveina in having broader trigonids and talonids; $\mathrm{m} 2$ trigonid more compressed anteroposteriorly than in Loveina, with paraconid more lingually situated and close to metaconid. Lower fourth premolar, judging from alveoli, longer than in Loveina, about same size as in Omomys.

\section{STEINIUS VESPERTINUS \\ (Matthew, 1915) \\ (not figured)}

?Omomys vespertinus MATTHEw, 1915, p. 450 (holotype only), fig. 22; GINGERICH, 1981, p. 358.

?Loveina vespertina SIMPSON, 1940, p. 188.

Omomys cf. vespertinus GazIN, 1962, p. 32, Pl. 5, fig. 2.

Omomys vespertinus RUSSELl, LoUIS, AND SAVAGE, 1967, p. 3.

Uintanius vespertinus SzALAY, 1976, p. 337 (holotype only), figs. 117 (part), 118 (part). 
Steinius vespertinus Bown AND Rose, 1984, p. 99, figs. $1,2$.

Holotype.-AMNH 16835, fragment of left ramus with m 1-3; Willwood Formation, Bighorn Basin, Wyoming.

Hypodigm. - The type specimen and UW 1647, 15675; USGS 502, 3854, 5995, 6623, 16454; YPM 24982.

Distribution. - Willwood Formation, lower Eocene (late early Wasatchian-lower and middle Bunophorus Interval Zone of Schankler, 1980), at least 438-463 m interval, southern Bighorn Basin, Wyoming; Indian Meadows Formation (near base-see Winterfeld, 1986), lower Eocene (early Wasatchian), Green River and western Wind River Basins, Wyoming.

Diagnosis. - Only known species; as for genus.

Discussion. - To the hypodigm of Steinius vespertinus recognized by Bown and Rose (1984) two specimens are added: UW 15675, a left dentary fragment with $\mathrm{m} 2-3$ from UW locality V-80027 near the base of the Indian Meadows Formation of the Wind River Basin, and USGS 16454, from locality D-1699 at the $463 \mathrm{~m}$ level of the Willwood Formation. These specimens conform in every way with other teeth of Steinius from the Willwood Formation.

See Appendices 7 and 8 for measurements.

\section{Genus CHLORORHYSIS Gazin, 1958}

Chlororhysis GazIN, 1958, p. 27; 1962, p. 32; SzAlay, 1976, p. 177; BOWN AND ROSE, 1984, p. 105.

Type species. - Chlororhysis knightensis Gazin, 1958, p. 27.

Included species. $-C$. knightensis and $C$. incomptus.

Distribution. - Late early through late Wasatchian (early Eocene) of Wyoming.

Diagnosis. -Canine relatively large as in primitive Teilhardina, relatively larger than in Anemorhysis or Tetonius. Second lower premolar relatively large as in Absarokius and Loveina, not small as in Tetonius. Last two lower premolars relatively narrow and uninflated, in contrast to Tetonius and $\mathrm{Absa}$ rokius, and proportionately narrower than in Teilhardina and Loveina. Metaconid on p4 lacking or very small and lower in position than in either Teilhardina or Anemorhysis. Heel of p4 not basined as in Anemorhysis.

\section{CHLORORHYSIS INCOMPTUS \\ Bown and Rose, 1984 \\ (not figured)}

Chlororhysis incomptus Bown AND Rose, 1984, p. 105, fig. 3.

Holotype. -YPM 24997, fragment of right dentary with p3-4 and root of p2 (Bown and Rose, 1984, fig. 3).

Hypodigm. - The type specimen only.

Distribution. - Type locality only; Willwood Formation, lower Eocene (late early Wasatchian-probably from upper part of Bunophorus Interval Zone of Schankler, 1980), near $450 \mathrm{~m}$ level, southern Bighorn Basin, Wyoming.

Diagnosis. -Differs from Chlororhysis knightensis in having narrower $\mathrm{p} 3-4$ with less pronounced buccal distension of crown; p34 with shorter, weaker paracristids and with no paraconid or metaconid (from Bown and Rose, 1984).

Discussion. - No additional specimens of this rare species have come to light since its description by Bown and Rose (1984). Given its unique occurrence and the absence of any known Teilhardina-Chlororhysis intermediates in the Bighorn Basin, it is likely that $C$. incomptus was another in a wave of immigrant mammals into the Bighorn Basin during the time represented by the $425-490 \mathrm{~m}$ interval.

See measurements in Appendix 7.

Genus Tetonius Matthew, 1915

Anaptomorphus CoPE, 1882a, p. 152 (A. homunculus only); 1882b, p. 73; 1884, p. 249; OsBORN, 1902 , p. 200 (part).

Tetonius MATTHEw, 1915, p. 457 (T. homunculus only); Szalay, 1976, p. 196 (part); Bown, 1979a, p. 78 (part).

cf. Anemorhysis McKennA, 1960, p. 65 (cf. $A$. minutus only).

?Tetonoides RoBINSON, 1967, p. 187.

Type species. - Anaptomorphus homunculus Cope, 1882, p. 152.

Included species. - The type species and $T$. matthewi n. sp., T. mckennai n. sp., and Tetonius sp.

Distribution. - Early Wasatchian (early Eocene) of Wyoming and Colorado.

Revised diagnosis.-Primitive omomyid 
with lower dental formula 2.1.2.3. or 2.1.3.3. Lower third premolar relatively unreduced and with two roots; anterior teeth evenly spaced and anterior of dentary not foreshortened as in Pseudotetonius. Larger than Teilhardina and with relatively broader (basally more inflated) cheek teeth, taller p4, and relatively more reduced $\mathrm{c}$ and $\mathrm{p} 2$. Lower fourth premolar generally not as tall or as ventrobuccally distended as in Absarokius, and p2 smaller than in Absarokius; il always much larger than i2 and i1-2 larger and more procumbent than in Absarokius.

Discussion. - The revised concept of $T e$ tonius employed here allows discrimination of this genus from its close relatives Teilhardina, Pseudotetonius, and Absarokius. Tetonius is one of the most familiar generic names in the literature on fossil primates, yet the precise taxonomic position of the type species is uncertain (see discussion on $T$. homunculus). Despite this technical problem, the concept of Tetonius used here coincides for the most part with that of previous authors.

Tetonius homunculus (Cope, 1882) (not figured)

Anaptomorphus homunculus CoPE, 1882a, p. 152; 1882b, p. 73; 1884, p. 249, Pl. 24e, fig. 1; OSBORN, 1902, p. 200 (holotype only), fig. 24.

Tetonius homunculus MATTHEW, 1915, p. 459 (holotype only), fig. 30; GREGORY, 1920, Pl. 51; SzALAY, 1976, p. 197 (holotype only), fig. 15.

Holotype. - AMNH 4194, nearly complete skull with right P3-M3 and left C, P3-M3 (Szalay, 1976, fig. 15).

Hypodigm. - The type specimen only.

Distribution. - Type locality only. Unknown level of Willwood Formation (lower Eocene), Bighorn Basin, Wyoming.

Diagnosis. -See discussion.

Discussion. - Only the type specimen is referred to Tetonius homunculus. By virtue of the antiquity of the species name homunculus, the type skull of Tetonius homunculus clearly has priority, not only as a valid species but also as the earliest generic name for this long recognized but poorly understood taxon. Nonetheless, in view of a most peculiar and even amusing taxonomic dilemma that surfaced in the course of this study, only Cope's type specimen (AMNH 4194) can be assigned with certainty to this unquestionably valid species.
As will be shown below, P4-M3 in the Tetonius-Pseudotetonius lineage remained conservative in both size and morphology. That lineage is instead characterized by gradual but obvious evolution of the lower antemolar dentition, il-p3. It is most likely that similar transformations occurred in corresponding parts of the upper dentition; however, the preserved crown dentition in the type skull is restricted to the left canine and left and right P3-M3; and no other known maxillary specimens in the lineage preserve crowns anterior to P3.

The priorities of taxonomic names aside, it would be absurd to contend that a well preserved skull with most of the dentition is an inadequate type specimen; it almost certainly is adequate to diagnose Tetonius homunculus on skull morphology, but it is the only known North American anaptomorphine skull and has proven to be inadequate to assist in assigning the majority of specimens potentially referable to it (largely lower jaws) to its hypodigm (there is no lower dentition associated with the type skull). Because P4 and the upper molars are virtually identical in Tetonius and Pseudotetonius, it has proven impossible to assign any upper dentitions to either genus using tooth size or morphology alone. The stratigraphic position of the type of Tetonius homunculus is unknown (see discussion below). Stratigraphic data are known for good, diagnostic lower dentitions of Pseudotetonius, however, and upper dentitions have been assigned to it on the basis of stratigraphic position. In view of the large sample available, it is extremely unlikely that either taxon is represented by only upper or lower dentitions.

To complicate matters even further, the taxonomy of Tetonius and different authors' constructs of the genus have had a long and checkered history. Matthew (1915) originally distinguished Tetonius from Anaptomorphus on differences in their lower dentitions. He based the lower dentition of $T$. homunculus on referred specimens that he believed to be conspecific with the type, and that of Anaptomorphus on the (then) only known specimen, a lower jaw with p4-m2. In the same paper, Matthew also distinguished his new genus Absarokius from Tetonius principally on characters of the lower dentition, even though he figured a good maxillary of $A b$ - 
sarokius. Thus, even as early as 1915 (when Tetonius was proposed) the type skull was not used in diagnosing the genus.

Matthew used characters of the lower antemolar dentition to distinguish not only $T e$ tonius homunculus from Absarokius, but also $T$. homunculus from what he perceived to be a second new Tetonius species, T. ambiguus. Because in Matthew's day the dentition of $T$. homunculus anterior to $\mathrm{p} 3$ was unknown, the lower dental formula of Tetonius was derived from Matthew's interpretation of the better preserved type lower jaw of $T$. ambiguus (=Pseudotetonius of Bown, 1974). This, Matthew believed, was 0.1.2.3 and that formula, or one similarly reduced, was believed to characterize the lower dentition of Tetonius for more than half a century.

In 1967, Robinson described a nearly complete anaptomorphine lower jaw (CM 12190) from the lower Willwood Formation that he ascribed to ?Tetonoides. Simons (1972, p. 144, fig. 52) assigned this specimen to Tetonius, an assessment also reached by Bown and Gingerich (1972). In 1974, Bown named Pseudotetonius, basing his new genus on Matthew's (1915) type of Tetonius ambiguus. Szalay (1976) described materials that he referred to Tetonius homunculus from northwestern Colorado, observing that some specimens retained a tiny $\mathrm{p} 2$ (like that in $\mathrm{CM}$ 12190), whereas others did not. Since that time, the lower dental formula of Tetonius homunculus has generally been regarded to be 2.1.2.3 or 2.1.3.3. The type of Pseudotetonius ambiguus, on the other hand, has been variably placed in ?Tetonius ambiguus (Szalay, 1976), Tetonius homunculus (Gingerich, 1980a, 1981), or accepted as valid (Schwartz, 1978; Krishtalka and Schwartz, 1978; Rose and Bown, 1984). Gingerich (1980a) placed Tetonius-like lower jaws retaining $\mathrm{p} 2$ in $\mathrm{Te}$ tonius steini (Seton, 1940) and those lacking $\mathrm{p} 2$ in $T$. homunculus. Unfortunately, although Seton provided an available name, the type of his "Paratetonius" steini is now lost and it is impossible to ascertain from his figures and description whether or not $\mathrm{p} 2$ was present in the lower jaw. Hence, Paratetonius steini is a nomen dubium.

What is significant from the foregoing is that nearly all treatments of Tetonius and its close relatives have been based principally or exclusively on lower dentitions. Superb as it is, the type skull has played little or no role in the taxonomic assessment of the genus except to serve as the type specimen of its type species. A logical and defensible explanation for the varying lower dental morphology and lower dental formulae of Tetonius-like anaptomorphines has emerged from examination of relevant specimens in their stratigraphic and evolutionary contexts (Rose and Bown, 1984, and herein). But the dilemma of what names to apply to different parts of this sample (though parenthetical to the evolution discussed here) has proven to be considerably more difficult.

Accepting Tetonius homunculus as a valid taxon, the problem becomes: which of the numerous specimens of lower jaws with differing dental features belong to that species? The possibilities are: 1) specimens typified by CM 12190 (i.e., with a moderately large i1-2, large c, p2 present, and a large doublerooted $\mathrm{p} 3$, here designated as stage 1 ); 2) specimens exemplified by Matthew's species ambiguus (with a very large i1, very small i 2 and $\mathrm{c}$, no $\mathrm{p} 2$, and a small crowned and single- or bilobed-rooted p3, here designated stages 4 and 5 , respectively); or 3 ) jaws with one of several temporally intergrading morphologies intermediate between those of CM 12190 and Pseudotetonius ambiguus (here included in stages 2,3 , or 4 ; see further discussion of stages under the systematic headings Tetonius matthewi, Pseudotetonius ambiguus, and Tetonius-Pseudotetonius intermediates, and in the Evolution section).

In an attempt to discover where in the Tetonius-Pseudotetonius lineage the type of $T$. homunculus belongs, the authors examined the available data pertaining to lower canine size, presence of $\mathrm{p} 2$ and $\mathrm{P} 2$, size of $\mathrm{p} 3$ and $\mathrm{P} 3$, occlusal relations of upper and lower dentitions, and what provenance data of the type skull might suggest about its possible stratigraphic position.

To the extent that the decrease in the lower canine size seen in the Tetonius-Pseudotetonius lineage occurred concomitantly in the upper canines (represented in the type skull by the crown on the left side and the root on the right), the evidence suggests that the roots in the skull supported crowns somewhat smaller than appropriate for occlusion with c in CM 12190 (stage 1), and certainly much too large to occlude properly with the tiny 
lower canines in Pseudotetonius ambiguus (stage 5 and some stage 4). A single small P2 alveolus appears to be present in the right maxillary of the type skull but the authors cannot agree on whether an alveolus (lacking the root) is present in the $\mathrm{P} 2$ position on the left side. Presence of P2, however, does not demonstrate that $\mathrm{p} 2$ existed in lower jaws, because $\mathrm{P} 2 / \mathrm{p} 2$ are too small to have occluded; hence p2 might have been lost but its counterpart retained in either or both maxillaries.

The crown of $\mathrm{p} 3$ became rapidly smaller with respect to $\mathrm{p} 4$ crown size from early stage 3 through stage 5 , as the roots first conjoin and then finally fuse into a single small root. Thus one might expect that P3 which, at least early in the lineage, occluded with p3 also became progressively smaller. Plots of relative length of $\mathrm{P} 3$, or relative area of $\mathrm{P} 3$ (Figure 16) show only a slight trend toward a smaller P3, and suggest that the holotype of $T$. homunculus represents an intermediate (stage 2, 3, or 4) between $T$. matthewi and Pseudotetonius ambiguus. But the data are too limited for assignment of the skull on this criterion to be very compelling. The type skull clearly has longer tooth rows than do upper dentitions of Pseudotetonius (stage 5 and some stage 4), consequently lower dentitions of Pseudotetonius do not occlude well with either of the type maxillary dentitions. Even so, the type left P3-M3 appears to be a bit too short to occlude properly with CM 12190 (stage 1). Therefore, a stage $2-4$ position for the type of Tetonius homunculus is supported by this evidence.

Szalay (1976, p. 201) indicated that AMNH 41, a lower jaw and associated maxillae, was collected from the same horizon and locality as the type skull of Tetonius homunculus. Could this be established, it would provide an important clue to the evolutionary position of the type with respect to the TetoniusPseudotetonius lineage, if its morphology is adequate to determine the species or stage it represents, and if convincing evidence exists that it indeed comes from the same horizon as the type skull. Unfortunately, however, both of these factors are questionable.

The anterior part of the lower jaw of AMNH 41 is relatively complete and includes the root of a small tooth anterior to p3, interpreted by Szalay as $\mathrm{p} 2$. If this were demonstrable, the specimen would represent $T$. matthewi (stage 1) in the terminology presented here. However, the root in question is larger than that for $\mathrm{p} 2$ in stage 1 specimens and similar in size to that of the canine in specimens that lack p2. Although the jaw is complete anteriorly, it is poorly preserved and appears to have room only for i1-2 anterior to the small root, supporting interpretation of the small root as that of the canine and not $p 2$. The $p 3$ is damaged but appears to have two coalesced roots most typical of stage 3 intermediates in the Tetonius-Pseudotetonius lineage. Because the other evidence suggests a post-stage 1 and pre-stage 5 position for the type of $T$. homunculus, and because all existing names could be accommodated by demonstrating that the type of $T$. homunculus represents stage 3, AMNH 41, if actually from the same locality, is a critical specimen. Unfortunately, as will be shown now, even a respectable degree of synchroneity cannot be verified on the existing evidence.

Matthew (1915, p. 460 , caption to his fig. 30) noted that the type skull is from "?Gray Bull beds, Bighorn Basin, Wyoming," and that the lower jaw (AMNH 41, figured with the skull) is from ". . . the same horizon and locality." However, a passage by Wortman (1904, p. 212), who actually collected both specimens, illustrates the imprecision of the provenance data:

\begin{abstract}
"A second species, A. homunculus, was described by Cope from the now famous cranium found by me in the Basin of the Big Horn, in 1881. This cranium, together with a second specimen (No. 41 of the American Museum collection) which I also discovered in 1891, in the same region [our emphasis] ...."
\end{abstract}

The literal reading of the statements by Matthew and by Wortman is critically important. In view of the nature of locality information accompanying fossils from the Bighorn Basin from 1880-1913, it is most probable that by ". . . the same horizon and locality" Matthew meant only "?Gray Bull beds, Bighorn Basin, Wyoming." The label with AMNH 41 does not add any new information and, unless Matthew had precise information from Wortman regarding the locality of the skull (and this information does not survive), AMNH 41 does not assist at all in elucidating the geographic (and thereby the 
TABLE 4-Statistics for lower teeth of Tetonius mckennai n. sp. Significant differences from Tetonius sp. are indicated by $*(P<0.01)$ and $* *(P<0.001)$. All means are significantly smaller than in Tetonius matthewi $\mathrm{n}$. sp. $(P<0.001)$. Data from Appendix 7 .

\begin{tabular}{ccccc}
\hline $\begin{array}{c}\text { Dimen- } \\
\text { sion }\end{array}$ & $\mathrm{n}$ & \multicolumn{1}{c}{ OR } & \multicolumn{1}{c}{} & \multicolumn{1}{c}{} \\
\hline p3 L & 3 & $1.35-1.50$ & $1.43^{*}$ & 0.076 \\
p3 W & 3 & $1.10-1.30$ & $1.17^{*}$ & 0.115 \\
p4 L & 5 & $1.60-1.80$ & 1.70 & 0.079 \\
p4 W & 5 & $1.40-1.60$ & $1.51^{*}$ & 0.074 \\
m1 L & 5 & $2.00-2.10$ & 2.06 & 0.055 \\
m1 W & 5 & $1.60-1.75$ & $1.64^{* *}$ & 0.065 \\
m2 L & 2 & $1.90-2.00$ & $1.95^{* *}$ & 0.070 \\
m2 W & 2 & $1.65-1.70$ & $1.68^{*}$ & 0.035 \\
\hline
\end{tabular}

approximate stratigraphic) position of the type of Tetonius homunculus. Nonetheless, there is some circumstantial evidence of the probable general locality of the type skull that could bear on its identity.

In a detailed recapitulation of Wortman's probable progress across the Bighorn Basin in 1881 , Gingerich $(1980 \mathrm{~b}$, p. 10) cogently reasoned that the majority of his collection (including the type skull) was obtained “... in the extensive badlands just south of where the main road through the basin crossed the Greybull River, i.e., in the vicinity of Dorsey Creek south of Otto." The skull was found in a "limestone" nodule (Cope, 1882a), structures (calcrete glaebules) that do not occur in the extensive Willwood badlands south and east of the town of Worland (Bown, 1979a). If, as Gingerich opines, Wortman moved generally northward following the Bridger Trail and stayed near sources of water, the next major area of Willwood badlands is indeed the Dorsey Creek area. There, fossils are found commonly in calcrete nodules and the best exposed and most accessible Willwood section is that in the 260-360 meter interval, yielding fossils of stages $2-5$ in the Tetonius-Pseudotetonius lineage.

Admittedly, all of the evidence outlined above is circumstantial. It is concluded that the type of Tetonius homunculus is almost certainly more advanced than stage 1 ( $T$. matthewi). It is probably more advanced than stage 2 and less advanced than stage 5 (Pseudotetonius ambiguus), and most probably represents stage 3 or 4 . However, because of the great uncertainties remaining, and because putting the name Tetonius homunculus on many specimens does not add to the evo-

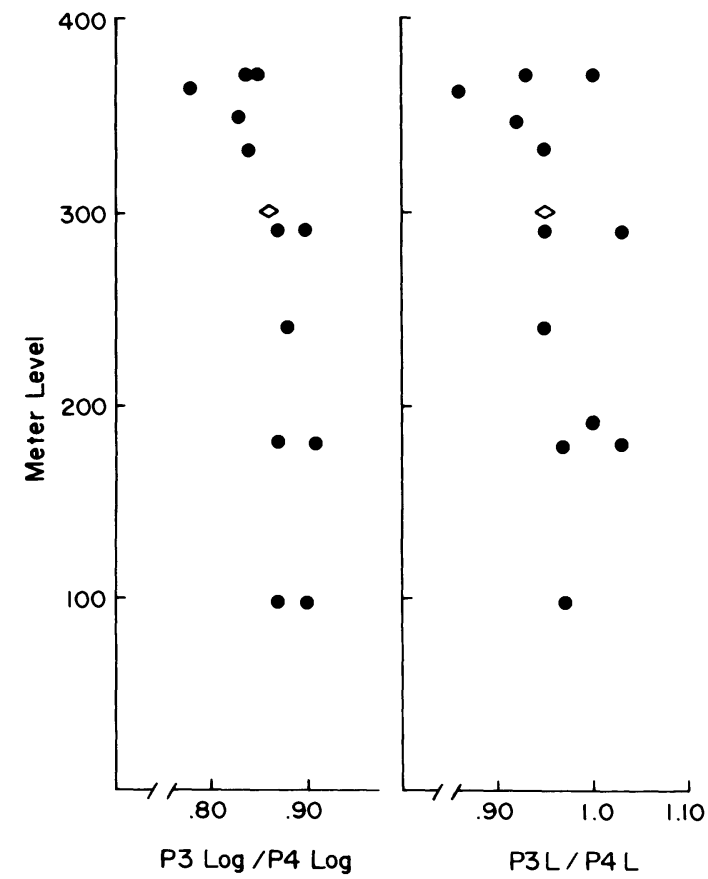

FIgURE 16-Relative size of P3 in the TetoniusPseudotetonius lineage from the Bighorn Basin, showing equivocal position of the holotype of Tetonius homunculus (Cope) (indicated by open diamond arbitrarily placed at $300 \mathrm{~m}$; stratigraphic level unknown). Left graph depicts the ratio of the natural logarithms of P3 area (length $\times$ breadth) to P4 area; right graph depicts ratio of $\mathrm{P} 3$ length to $\mathrm{P} 4$ length.

lutionary picture, the hypodigm of $T$. homunculus is restricted to the type specimen. Even if one prefers to place stage 3 and/or stage 4 anaptomorphines in $T$. homunculus, that species could still only be distinguished from the older $T$. matthewi or the younger Pseudotetonius ambiguus on a purely arbitrary stratigraphic basis (see discussion of this lineage in Evolution section).

See Appendix 8 for measurements.

TETONIUS MCKENNAI $\mathrm{n}$. $\mathbf{s p}$. Figure 16.2

Anemorhysis minutus McKenNA, 1960, p. 65, figs. 32, 33.

Tetonius sp. Szalay, 1976, p. 207 (part), fig. 29.

Holotype. - UCMP 46192, left dentary with i1-2, c, p3-m2, and alveolus for p2; Alheit Pocket, Sand Wash Basin, northwest Colorado. 

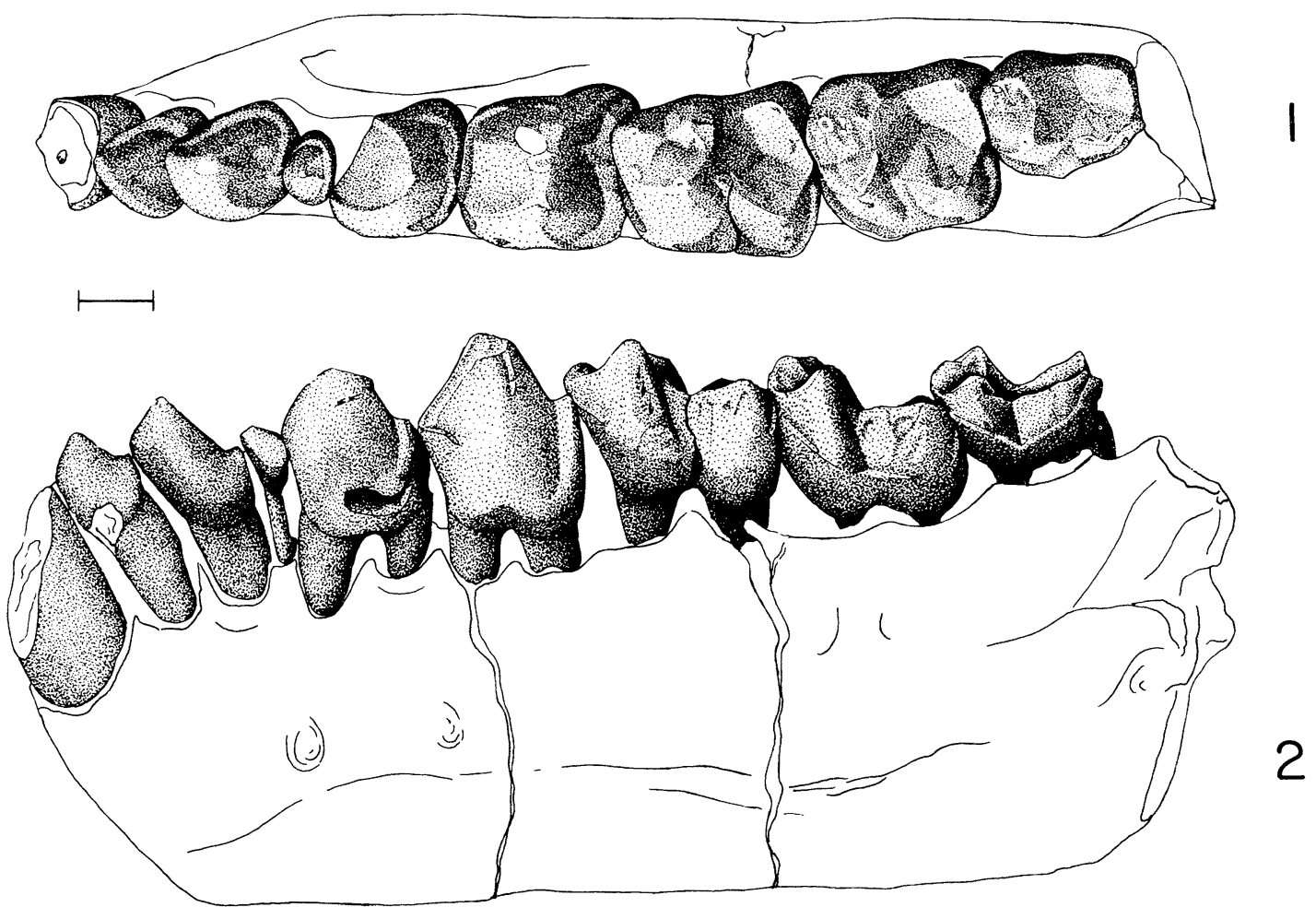

FIGURE 17-Tetonius matthewi n. sp. (stage 1), holotype, CM 12190, left dentary with i1 (crown missing)-i2, c, p2-4, m1-3 (about $180 \mathrm{~m}$ ). 1 , 2, occlusal and lateral views. From Robinson (1968), published with permission of $\mathrm{P}$. Robinson and the Carnegie Museum. Scale is $5 \mathrm{~mm}$.

Hypodigm. - The holotype and UCMP 44158, 46194, 47159 (all from Alheit Pocket), and questionably AMNH 80078 (from East Alheit Pocket).

Distribution. - Alheit Pocket and East Alheit Pocket, Hiawatha Member of Wasatch Formation (lower Eocene), Sand Wash Basin, northwest Colorado.

Etymology. - For Malcolm C. McKenna, who collected and first described these specimens, and in acknowledgment of his many important contributions to the paleontology of Eocene mammals.

Diagnosis. - Smallest species of Tetonius, intermediate in size between Teilhardina americana and Tetonius sp. (see below); canine relatively smaller, $\mathrm{p} 4$ taller, and $\mathrm{p} 4$ and $\mathrm{m} 1$ slightly longer and broader than in Teilhardina americana, but smaller, especially narrower, than in all other Tetonius species. Lower dental formula 2.1.3.3., as in T. matthewi, with $\mathrm{p} 2$ present in contrast to other species of Tetonius.
Discussion. - Szalay (1976) correctly allocated these specimens to Tetonius and considered them either a distinct species or a smaller, gracile variant of $T$. homunculus (samples here referred to T. matthewi n. sp.). All five specimens appear to be severely abraded or chemically eroded, but this cannot fully account for their small size. Morphologically, they are perfectly intermediate between Teilhardina americana (from which they probably descended) and the small specimens designated below as Tetonius sp., from the Bighorn Basin (the resemblance of these specimens to Teilhardina was first noted by Russell et al., 1967). They are significantly smaller than Tetonius matthewi in all dimensions (Table 4), thus T. mckennai strengthens the probability that Tetonius descended directly from Teilhardina americana.

The known sample of $T$. mckennai cannot represent the ancestral population that gave rise to $T$. matthewi and Tetonius sp. (since all three occur at East or West Alheit Pocket 

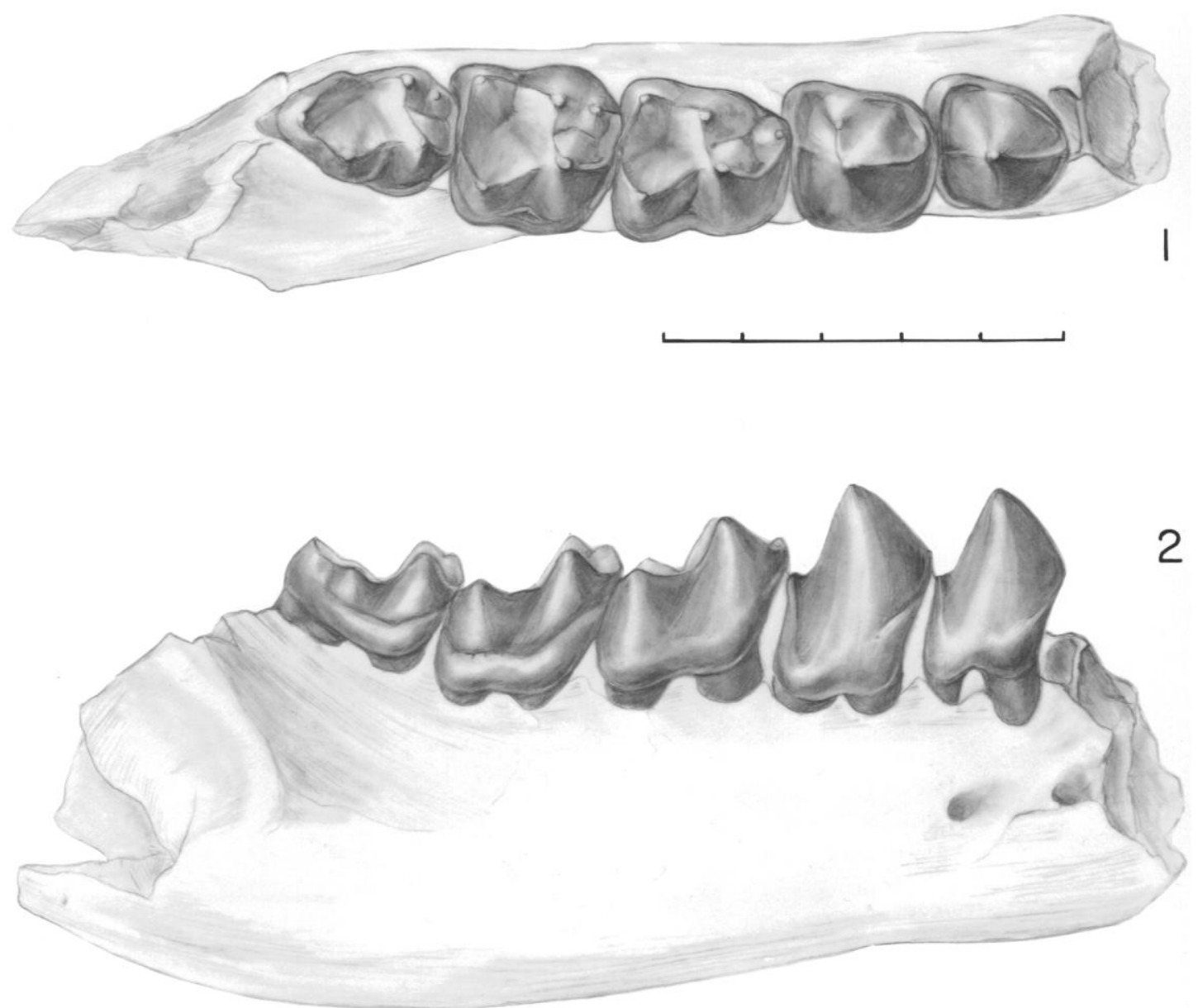

FIGURE 18-Tetonius matthewi $\mathrm{n}$. sp. (stage 1), YPM 35016, right dentary with p3-m3 and alveoli of c and p2 $(140 \mathrm{~m}) .1,2$, occlusal and lateral views, respectively. Scale is $5 \mathrm{~mm}$.

quarries), but an older sample of T. mckennai may have been the ancestor.

See Appendix 7 for measurements.

TETONIUS MATTHEWI $\mathbf{n}$. sp.

Figures 15.3, 17-20, 25.3

?Tetonoides sp. RoBINson, 1967, p. 187, fig. 1.

Tetonius homunculus? McKeNNA, 1960, p. 72 (UCMP 44159, 44290, 44769 only).

Tetonius homunculus Bown, 1974, figs. 4, 5a; 1979a, p. 78 (part), fig. 49c; SzAlay, 1976, p. 197 (part), figs. 22, 24, 26 (part); ROSE AND BOWN, 1984 , p. 250 , fig. 2 ; 1986 , p. 125 , fig. 5.

Tetonius steini GINGERICH, 1980a, fig. 4 (part).

Holotype.-CM 12190 (Figure 17), left dentary with nearly complete dentition - il (crown broken)-m 3 (hypoconulid of $\mathrm{m} 3$ missing)-representing stage 1; from Section
10 or 11, T50N, R94W, Big Horn County, Wyoming. A more precise location is unknown; however, this area is surrounded by sites tied into the stratigraphic section. Hence, its stratigraphic position can be confidently estimated as about $180 \mathrm{~m} \pm 10 \mathrm{~m}$. CM 12190 now appears to be lost, but its use as the holotype is justified because it is unequivocally the best specimen whose locality and stratigraphic level are reasonably precise, it has been well illustrated in the previous literature (e.g., Robinson, 1967; Szalay, 1976), and many high-resolution epoxy casts of it are available at several museums.

Hypodigm. - The holotype, and the following specimens; the latter are assigned by morphology (M) and/or stratigraphic occurrence (S); for specimens followed by a query 

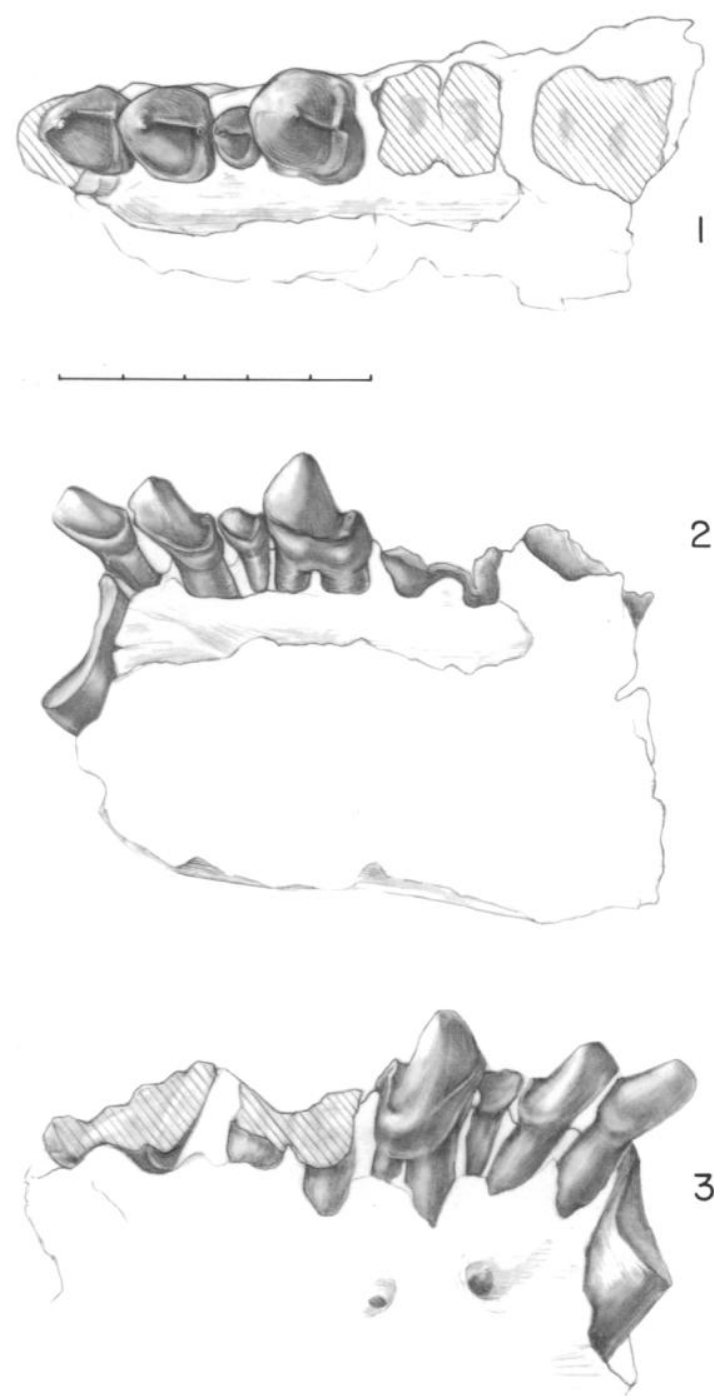

FIGURE 19-Tetonius matthewi n. sp. (stage 1), RAM 575, right dentary with i2, c, p2-3, and roots of i1, p4-m1 (meter level unknown). 1-3, occlusal, medial, and lateral views, respectively. Scale is $5 \mathrm{~mm}$.

(?), stage assignment (to either stage 1 or stage 2) is uncertain, but these specimens can be confidently assigned to $T$. matthewi (see diagnosis and following discussion for explanation of stages). It is emphasized that all assigned specimens conform well with the holotype and other positively referred specimens, but some are not well enough preserved to have many diagnostic characters.

1) Central and southern Bighorn Basin, stage 1: USGS 483, 7198; YPM 23167,
30676?, 33223?, 33246, 35016; DPC 1263?; UKMNH 8662 (all M, S). YPMPU 17687, 17693; DPC 2976; RAM 575; UM 85970; YPM 23031 (all M). USGS 481, 490, 3649, 7191, 7265, 9151, 9154, 9221, 9225; UW $7110,7188,7204,7223,7228,7271,7325$, 8830, 9412, 10246; YPM 23169, 23568, 23618, 30709, 30722 (all S).

2) Central and southern Bighorn Basin, stage 2: USGS 499?, 1643?, 3857; YPM 30524; UW 6532? (all M, S).

3) Central and southern Bighorn Basin, stage 1 or 2: USGS 497, 501, 508, 509, 3856, 5937, 5938, 5941, 6634, 7197, 7205, 8992, 15408; UW 8901, 8910, 10356, 10357; YPM 23182, 24366, 26621, 30486, 30542, 30674, 30677, 30682-30685, 30688, 30690, 3069330695, 30702, 30704, 30707, 30710-30712, 30714, 30718, 31379, 33261 (all S). USNM 19146 (M).

4) Clark's Fork Basin, stage 1: USGS 2326; UM 69787, 69817, 71393, 79540 (all M, S). UM 79232 (M).

5) Clark's Fork Basin, stage 2: UM 76767 (M, S). USGS 479; UM 79332 (both M).

6) Clark's Fork Basin, stage 1 or 2: USGS 2333; YPMPU 18139; UM 66219, 69611, 73913, 76771, 78969, 79335, 83122, 85777 (all M, S). UM 79371?; USGS 5985 (M). USGS 480, 2252, 2334, 2335; MCZ 20853; YPMPU 23088; UM 71135, 71229, 71383, 71537, 71546, 73911, 75006, 76675 (all S).

7) Laramie Basin, stage 1: UW $11382(\mathrm{M})$.

8) Laramie Basin, stage 2: UW 10053?(M).

9) Sand Wash Basin, stage 1: AMNH 59619, 80077?, 80086, 80951? (all M, East Alheit Pocket).

10) Sand Wash Basin, stage 2: AMNH 80075, 88888; UCMP 44159 (all M, East Alheit Pocket). UCMP 1 18542?, 118543 ? (both M, Sand Quarry).

11) Sand Wash Basin, stage 1 or 2: AMNH 59634 (M, East Alheit Pocket); UCMP 44290 (M, West Alheit Pocket); UCMP 44769? (M, Sand Quarry); UCMP 59422? (M, Timberlake Quarry).

Distribution. - Willwood Formation, 64 $190 \mathrm{~m}$ interval in the central and southern Bighorn Basin (lower Haplomylus-Ectocion Range Zone of Schankler, 1980); approximately 230-330 m interval in the Clark's Fork Basin (1,750-1,850 m interval of Gingerich's 1982 section). "Wind River" Formation, Laramie Basin, Wyoming; Wasatch Forma- 

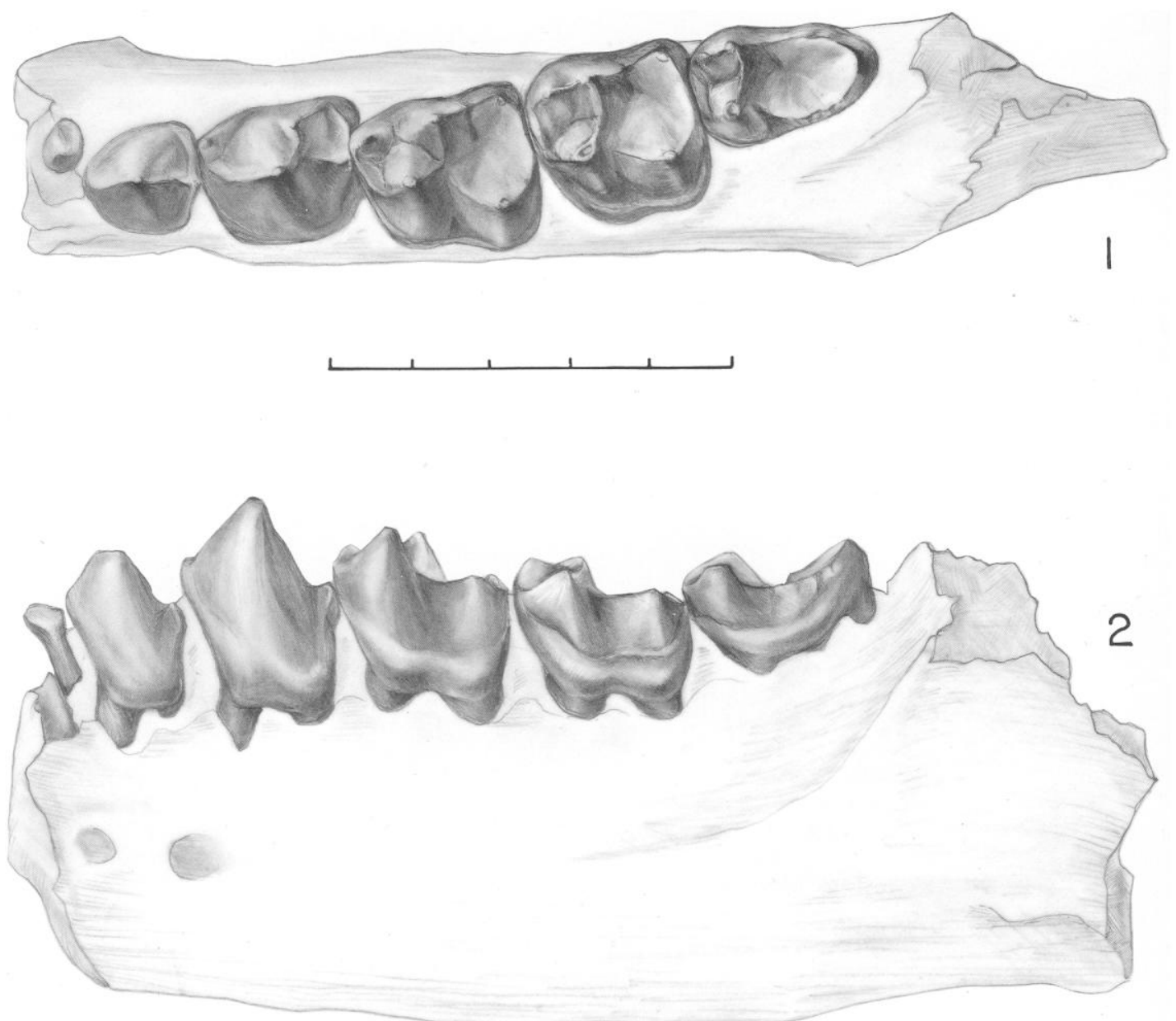

FIGURE 20-Tetonius matthewi $\mathrm{n}$. sp. (stage 1), YPM 23031, left dentary with p2-m3 (meter level unknown). 1, 2, occlusal and lateral views, respectively. Scale is $5 \mathrm{~mm}$.

tion, Sand Wash Basin (Four Mile area of McKenna, 1960), northwest Colorado.

Etymology. - For W. D. Matthew, in recognition of his pioneering contributions to Eocene mammals of the Bighorn Basin in general, and to the omomyid primates in particular.

Diagnosis. - Larger than T. mckennai; p2 either present but very reduced (stage 1) or absent in some latest-occurring individuals (stage 2). Third lower premolar relatively unreduced and always with two roots, in contrast to stage 3 and 4 Tetonius and Pseudotetonius. Antemolar teeth evenly spaced, not compressed together as in latter two stages of Tetonius and Pseudotetonius.

Discussion.-Specimens referred here to
Tetonius matthewi constitute much of the sample considered to be $T$. homunculus by previous workers-specifically, larger stage 1 and contemporaneous primitive stage 2 specimens of Tetonius. Stage 2 specimens assigned here occur only in the latest part of the range of $T$. matthewi $(180-190 \mathrm{~m}$ in the Bighorn Basin, $330 \mathrm{~m}$ in the Clark's Fork Basin) and are identical to stage 1 except that they lack p2 (see further discussion of stages in Evolution section). Smaller stage 1 and stage 2 specimens are considered under the next heading, whereas stage 2 specimens from stratigraphically above the last occurrence of stage 1 (>190 $\mathrm{m}$ in the central Bighorn Basin) are designated as Tetonius-Pseudotetonius intermediates (see below). Although it is pos- 
TABLE 5-Comparative statistics for lower teeth of Tetonius matthewi $\mathrm{n}$. sp. and Pseudotetonius ambiguus (Matthew). Significant differences are indicated by * $(P<0.01)$ and ** $(P<0.001)$.

\begin{tabular}{lcccc}
\hline \hline Dimension & $\mathrm{n}$ & OR & $\tilde{x}$ & $s$ \\
\hline \multicolumn{5}{c}{ Tetonius matthewi } \\
p3 L & 55 & $1.50-1.90$ & 1.72 & 0.091 \\
p3 W & 54 & $1.40-1.80$ & 1.58 & 0.109 \\
p4 L & 72 & $1.85-2.35$ & 2.05 & 0.122 \\
p4 W & 70 & $1.70-2.25$ & 1.93 & 0.127 \\
p4 L/m1 L & 51 & $0.79-1.04$ & 0.91 & 0.047 \\
m1 L & 72 & $2.00-2.50$ & 2.27 & 0.096 \\
m1 W & 70 & $1.75-2.50$ & 2.10 & 0.119 \\
m2 L & 49 & $2.00-2.35$ & 2.19 & 0.086 \\
m2 W & 48 & $1.85-2.30$ & 2.07 & 0.103 \\
\multicolumn{5}{c}{} \\
p3 L & Pseudotetonius ambiguus & \\
p3 W & 11 & $1.20-1.70$ & $1.43^{* *}$ & 0.154 \\
p4 L & 11 & $1.20-1.65$ & 1.49 & 0.161 \\
p4 W & 23 & $1.90-2.30$ & 2.09 & 0.116 \\
m1 L & 23 & $1.70-2.30$ & $2.03^{*}$ & 0.164 \\
m1 W & 29 & $2.00-2.40$ & $2.18^{* *}$ & 0.100 \\
m2 L & 28 & $1.80-2.30$ & 2.04 & 0.122 \\
m2 W & 27 & $1.95-2.30$ & $2.09^{* *}$ & 0.094 \\
\hline
\end{tabular}

sible that $T$. matthewi is synonymous with $T$. homunculus, this is unlikely and cannot be demonstrated; consequently, a new name is required (see previous remarks concerning Tetonius homunculus).

Gingerich $(1980 b, 1981)$ used the name Tetonius steini (without explanation) for earlier specimens of Tetonius that retained p2, while maintaining $T$. homunculus for later specimens lacking p2 (including those here placed in Pseudotetonius ambiguus). The holotype and only known material of "Tetonius" steini (originally described as Paratetonius steini by Seton, 1940) apparently lacked diagnostic parts of the dentition and is now lost. Its recorded locality, "south Elk Creek, Bighorn Basin," is too vague to indicate stratigraphic level (exposures there span about the 130-370 m interval). Although it clearly belongs to the Tetonius-Pseudotetonius lineage, it is impossible to determine with certainty either the species represented or its stratigraphic occurrence. Therefore, Paratetonius steini is here considered to be a nomen dubium.

See Appendices 9 and 10 for measurements, and Table 5 for basic statistics.

\section{Tetonius sp.}

\section{Figure 15.4}

Tetonius homunculus? McKenNA, 1960, p. 72 (UCMP 44934 only).
TABLE 6-Statistics for lower teeth of Tetonius sp. Significant differences from $T$. matthewi $\mathrm{n}$. sp. are indicated by $*(P<0.01)$ and $* *(P<0.001)$. See Table 4 for statistical differences from $T$. mckennai $\mathrm{n}$. sp. Data from Appendix 11.

\begin{tabular}{lrccc}
\hline \hline Dimension & $\mathrm{n}$ & OR & $\bar{x}$ & $s$ \\
\hline p3 L & 9 & $1.50-1.70$ & $1.58^{* *}$ & 0.062 \\
p3 W & 9 & $1.20-1.50$ & $1.37^{* *}$ & 0.087 \\
p4 L & 17 & $1.70-1.95$ & $1.81^{* *}$ & 0.088 \\
p4 W & 17 & $1.50-1.80$ & $1.66^{* *}$ & 0.097 \\
p4 L/m1 L & 13 & $0.74-0.93$ & $0.84^{* *}$ & 0.058 \\
m1 L & 18 & $2.00-2.30$ & $2.15^{* *}$ & 0.087 \\
m1 W & 18 & $1.70-2.10$ & $1.89^{* *}$ & 0.137 \\
m2 L & 10 & $2.10-2.20$ & 2.13 & 0.035 \\
m2 W & 10 & $1.80-2.10$ & $1.97^{*}$ & 0.097 \\
\hline
\end{tabular}

Tetonius homunculus SZALAY, 1976, p. 197 (UCMP 44934 and AMNH 59671 only); Bown, 1979a, p. 78 (part), fig. 49a (UW 8960), 49b.

Referred specimens.-USGS 495, 1644, 5936, 5940, 9208, 15884; UW 6584, 7210, 7216, 7910, 7919, 8960, 10355; YPM 30691, 30697, 33226 (all from the central Bighorn Basin); UM 71379, 76674, 79537, 83394, 86219 (all from the Clark's Fork Basin); UCMP 44934; AMNH 59671 (all from East Alheit Pocket, Sand Wash Basin).

Discussion. - Specimens clearly referable to the genus Tetonius first occur at $64 \mathrm{~m}$ in the Bighorn Basin Willwood Formation, but whether or not they all belong to Tetonius matthewi is uncertain. Although many teeth of Tetonius in the 64-190 m interval fall within the size range of subsequent samples in this lineage, the specimens listed above have significantly smaller teeth than in $T$. matthewi (Table 6) and in later samples in the Tetonius matthewi-Pseudotetonius ambiguus lineage. Moreover, the size range of $\mathrm{m} 1$ in the $100-190 \mathrm{~m}$ interval $(0.35-0.40 \mathrm{log}$ units) and of $\mathrm{p} 4$ in the $180-190 \mathrm{~m}$ interval (nearly $0.60 \mathrm{log}$ units) exceeds that typical of a single lineage at any other stratigraphic level by about $50 \%$. For these reasons, it is likely that two species of Tetonius (perhaps sibling species) coexisted at least in the upper part of the $64-190 \mathrm{~m}$ interval in the Willwood Formation, and at comparable levels in the Clark's Fork and Sand Wash Basins.

In the specimens referred to Tetonius sp., p3 and p4 are smaller than $\mathrm{m} 1$ and are relatively much smaller than p3 and p4 in $T$. matthewi (Tables 5, 6) and stage 2-3 Tetonius-Pseudotetonius intermediates. The first molar is at the extreme small end of the size 

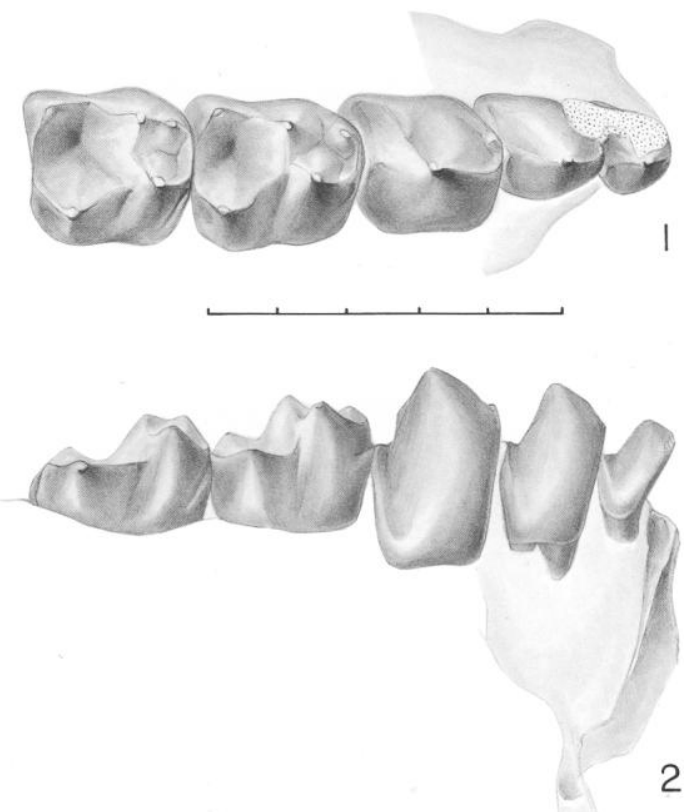

FIGURE 21-Tetonius matthewi-Pseudotetonius ambiguus intermediate (stage 2), YPM 25026, right dentary with c, p3-m2, and edges of alveoli of i1-2 (290 m). 1, 2, occlusal and lateral views, respectively. Scale is $5 \mathrm{~mm}$.

range for $T$. matthewi and stage 2-3 Tetonius-Pseudotetonius intermediates, or falls beneath this range. Hence, these specimens bridge the gap in size between the smaller $T$. mckennai and $T$. matthewi and might represent a transitional stage between them. All those for which the anterior portion of the dentition is suitably preserved possess $\mathrm{p} 2$ (as in stage $1=T$. matthewi, as defined here), except UCMP 44934, which appears to lack p2.

Despite suggestive evidence that two species of Tetonius coexisted in the lower Willwood Formation, clear differentiation of Tetonius sp. from T. matthewi is no easy task, for size and morphology intergrade imperceptibly. It is not impossible that some specimens listed here are small individuals of $T$. matthewi, while some listed under that species might instead be large representatives of $T e$ tonius sp. Indeed, upper teeth at hand do not reveal as broad a range of size as lowers, and no attempt was made to separate them; hence, some of the smaller specimens of upper teeth here assigned to $T$. matthewi may belong to this sample. Critics may claim that if the two
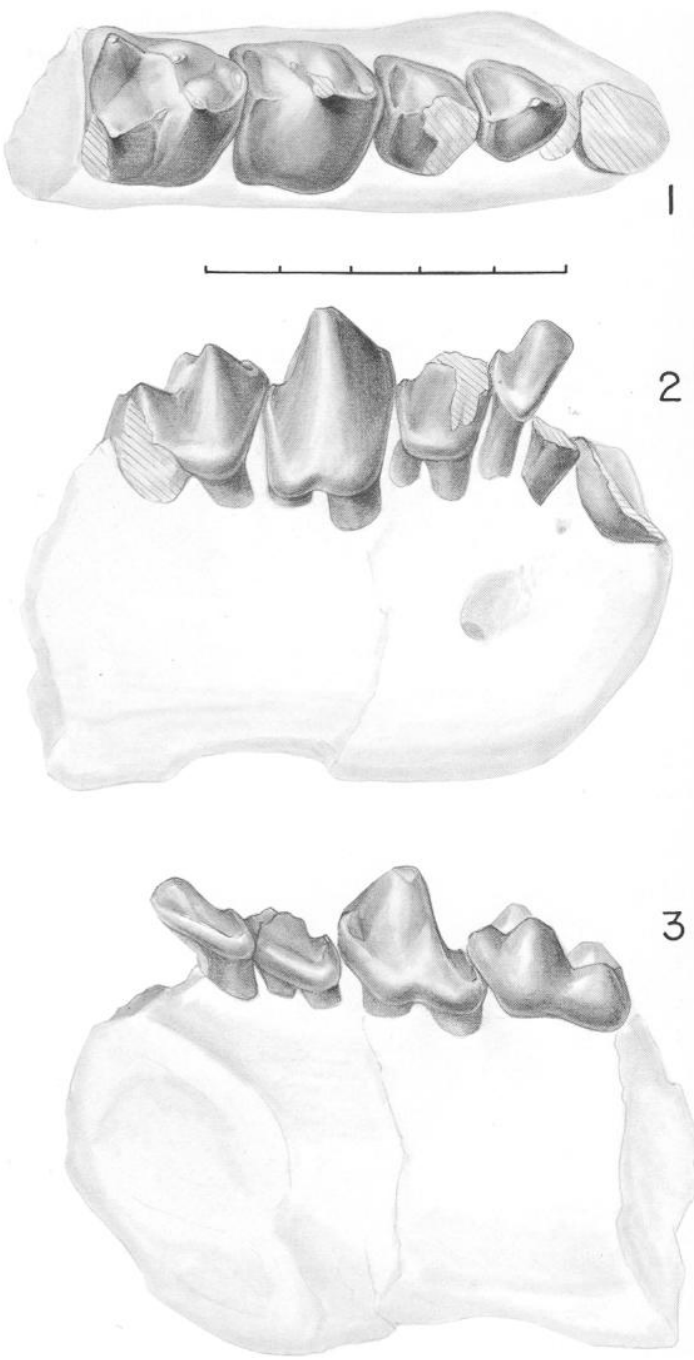

FIGURE 22-Tetonius matthewi-Pseudotetonius ambiguus intermediate, USGS 6555, right dentary with c, p3-m1, and roots of i1-2 (344 m). $1-3$, occlusal, lateral, and medial views, respectively. This specimen is stage 2 in p3 roots but about stage 4 in size of p 3 and compaction of anterior teeth. Scale is $5 \mathrm{~mm}$.

samples cannot be consistently distinguished, then all specimens should be allocated to the same species. However, if two very similar species were present (as inferred here) the importance of recognizing this probability outweighs the drawback that some specimens may be improperly allocated. Because the combined Tetonius matthewi-Tetonius sp. sample exemplifies greater biometric breadth than that seen in any other anaptomorphine 

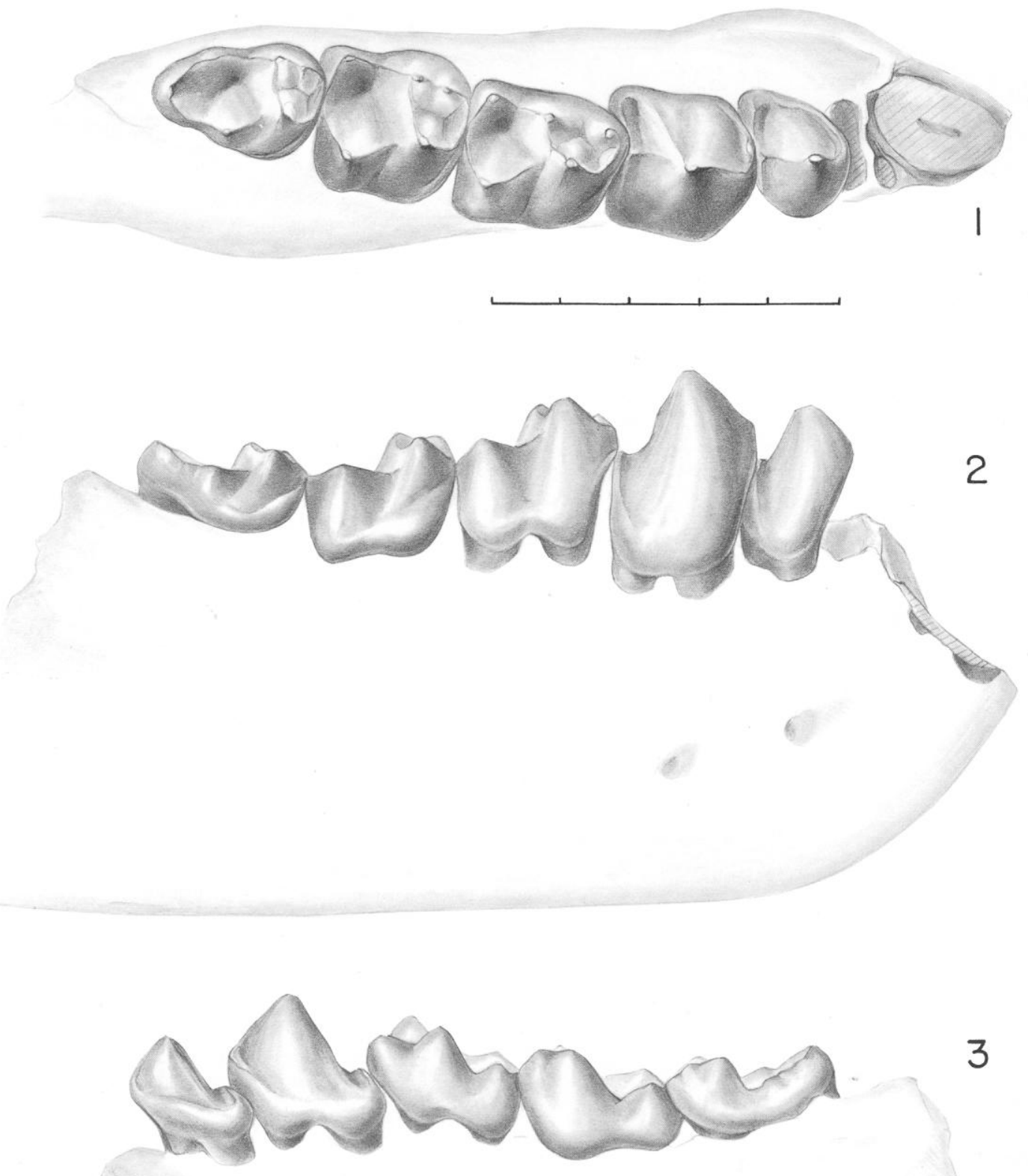

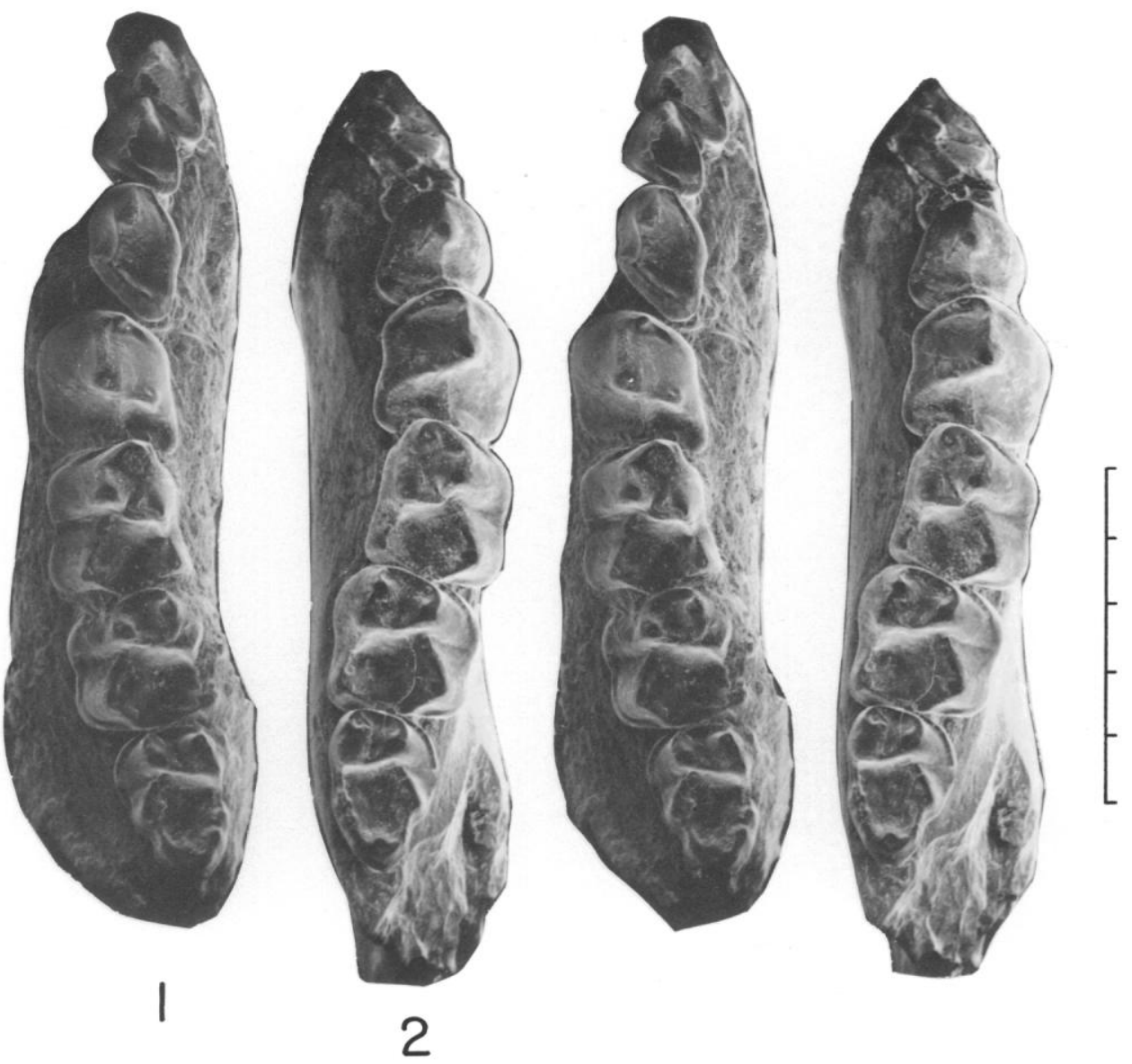

FIGURE 24-Tetonius matthewi-Pseudotetonius ambiguus intermediates, SEM stereophotographs, occlusal views. 1, USGS 3841 (stage 2), left i2, c, p3-m3, and root of il (264 m); 2, UW 10212 (stage $3)$, right p3-m3, alveolus for c, and roots of il-2 (322 m). Scale is $5 \mathrm{~mm}$.

species studied here, the requirements of artificial diagnoses regarding how to discern different species may be inadequate to express potential species differences between closely related species.

The position that Tetonius sp. holds with respect to $T$. matthewi is tantalizingly similar to that which obtains between coeval samples of Absarokius abbotti and A. metoecus n. sp. at a much higher interval in the Willwood section (see discussion of evolution in genus Absarokius below). The signal difference is that in the case of Absarokius much more of the lineage is preserved. A case is made below for the gradual cladogenetic splitting of the Absarokius lineage, coupled with an initial profound increase in the biometric variability of the ancestral species, $A$. metoecus $\mathrm{n}$. sp. It seems likely, in view of this evidence, that coeval Tetonius matthewi and Tetonius sp. also document an increase in biometric variability around the time of gradual cladogenesis in the Tetonius lineage. However, in the case of the Tetonius lineage, Tetonius sp. ap-

FIGURE 23-Tetonius matthewi-Pseudotetonius ambiguus intermediate (stage 3), UW 10212, right dentary with p3-m3, alveolus for c, and roots of i1-2 (322 m). 1-3, occlusal, lateral, and medial views, respectively. Scale is $5 \mathrm{~mm}$. 

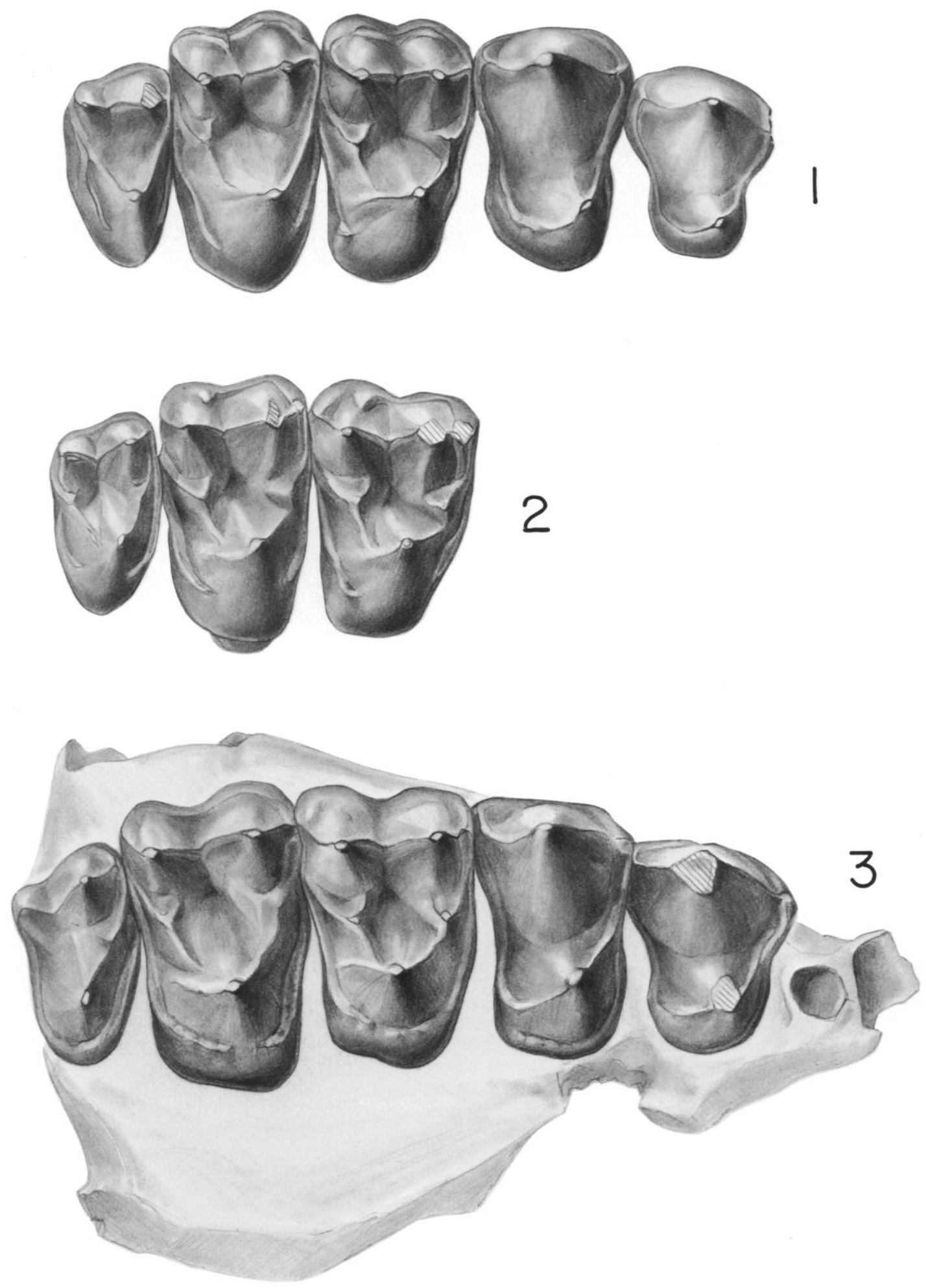
pears to have gone extinct in the Bighorn Basin before consolidation of the variability was effected in the two lines.

See Appendices 10 and 11 for measurements.

\section{Tetonius-PsEUdotetonius INTERMEDIATES \\ Figures 21-24, 25.2}

Discussion. - A large number of specimens are both stratigraphically and morphologically intermediate between Tetonius matthewi and Pseudotetonius ambiguus, making their taxonomic assignment problematical. Were they allocated arbitrarily to one or the other species, their critical attributes as evolutionary intermediates might well be overlooked. All of them belong to stage 2, stage 3 , or stage 4 (but not all stage 2 and stage 4 individuals are classified as intermediates). Morphologically, these stages intergrade imperceptibly from one to the next, with $T$. matthewi and $P$. ambiguus simply constituting, respectively, the stratigraphically lowest and highest end members. As observed above, even the distinction of these two species from their bounding intermediates is wholly arbitrary in the morphological sense because of this temporally intergraded morphology. Thus stage 2 specimens from within the stratigraphic range of stage 1 are assigned to $T$. matthewi, while stage 4 specimens coincident with stage 5 are allocated to $P$. ambiguus.

The intermediate nature of these samples is underscored not only by the gradual acquisition of various morphologic traits (see Evolution section), but also by biometric analysis. Tetonius matthewi and Pseudotetonius ambiguus are demonstrably different in antemolar morphology and configuration, and in length of $\mathrm{p} 3, \mathrm{~m} 1$, and $\mathrm{m} 2(P<0.001$, Table 5). However, in no case does any of these tooth lengths show a significant difference (of $P<0.01$ ) between successive samples in the sequence of Tetonius matthewi
TABLE 7-Comparative statistics for lengths of $\mathrm{p} 3, \mathrm{~m} 1$, and $\mathrm{m} 2$ in Tetonius matthewi-Pseudotetonius ambiguus intermediates of stages 2,3 , and 4 . These dimensions display the most significant differences between $T$. matthewi $\mathrm{n}$. sp. and $P$. ambiguus (Matthew) (see Table 5). None of the means for successive stagesincluding $T$. matthewi vs. stage 2 intermediates, and stage 4 intermediates vs. $P$. ambiguus - is significantly different at $P<0.01$. The greatest difference is in p3 $\mathrm{L}$ in stage 2 vs. stage $3(P<0.02)$.

\begin{tabular}{|c|c|c|c|c|}
\hline Dimension & $\mathrm{n}$ & OR & $\overline{\bar{x}}$ & $s$ \\
\hline \multicolumn{5}{|c|}{ Stage 2} \\
\hline $\begin{array}{l}\text { p3 L } \\
\text { m1 L } \\
\text { m2 L }\end{array}$ & $\begin{array}{l}24 \\
19 \\
15\end{array}$ & $\begin{array}{l}1.45-1.80 \\
2.10-2.40 \\
2.00-2.30\end{array}$ & $\begin{array}{l}1.69 \\
2.24 \\
2.16\end{array}$ & $\begin{array}{l}0.096 \\
0.098 \\
0.096\end{array}$ \\
\hline $\begin{array}{l}\text { p3 L } \\
\text { m1 L } \\
\text { m2 L }\end{array}$ & $\begin{array}{r}11 \\
11 \\
9\end{array}$ & $\begin{array}{c}\text { Stage } 3 \\
1.45-1.70 \\
2.10-2.35 \\
1.90-2.40\end{array}$ & $\begin{array}{l}1.60 \\
2.20 \\
2.14\end{array}$ & $\begin{array}{l}0.096 \\
0.096 \\
0.145\end{array}$ \\
\hline $\begin{array}{l}\text { p3 L } \\
\text { m1 L } \\
\text { m2 L }\end{array}$ & $\begin{array}{l}2 \\
1 \\
2\end{array}$ & $\begin{array}{c}\text { Stage } 4 \\
1.30-1.60 \\
- \\
2.15-2.20\end{array}$ & $\begin{array}{l}1.45 \\
2.20 \\
2.18\end{array}$ & $\begin{array}{c}0.212 \\
\overline{-} \\
0.035\end{array}$ \\
\hline
\end{tabular}

intermediates of stages 2, 3, 4, and Pseudotetonius ambiguus (Table 7).

A convenient stratigraphic gap in the temporal distribution of specimens in the Tetonius-Pseudotetonius lineage (above $190 \mathrm{~m}$ in the central Bighorn Basin and above Gingerich's (1982) 1,850 m level in the Clark's Fork Basin) was used to demarcate $T$. matthewi from subsequent intermediates. Similarly, stage 4 and stage 5 specimens from above $345 \mathrm{~m}(2,050 \mathrm{~m}$ in the Clark's Fork Basin)-again an arbitrary datum-are assigned to Pseudotetonius ambiguus.

Because the proposed stages themselves are, like the species $T$. matthewi and P. ambiguus, selected from a temporally and morphologically graded continuum, many of the intermediates do not fit neatly into one or another of these stages (e.g., p3 in USGS 6555 (Figure 22 ) is nearly as reduced as in stage 4 but retains two distinct roots, as in stage 2 ), and there is substantial overlap in their stratigraphic occurrences. Nonetheless, the mor-

FIGURE 25-Upper teeth of Tetonius and Pseudotetonius. 1, composite right P3-M3 based on $P$. ambiguus (Matthew), USGS 3860, P3-4 (364 m), and advanced $T$. matthewi-P. ambiguus intermediate, USGS 9202, M1-3 (344 m); 2, T. matthewi-P. ambiguus intermediate, USGS 5992, right M1-3 (262 m): note incipient mesostyles on M1-2; 3, T. matthewi n. sp., UM 76675, right P3-M3 and alveoli for C and P2 (Clark's Fork Basin, $240 \mathrm{~m}$ ). Scale is $5 \mathrm{~mm}$. 
phologic trend is clearly directional in the stratigraphic sense from the earlier $T$. matthewi to the younger P. ambiguus. In the following list, specimens that are more progressive than typical for one stage but less so for the next stage are indicated by a slash (e.g., stage $2 / 3$ ). An asterisk $\left({ }^{*}\right)$ denotes specimens assigned by morphology but lacking stratigraphic data, and a query (?) marks specimens whose stage assignment is probable but not certain due to ambiguous or obscured morphology. No consistent, reliable differences have been discerned in upper cheek teeth from one stage to another. Consequently, upper dentitions are assigned to species or stage based on association with diagnostic lower dentitions and/or stratigraphic occurrence (where only one species or stage is present at a given level).

See Appendices 12 and 13 for measurements.

Referred specimens. -Stage 2 (Figures 21, $22,24.1)-\mathrm{p} 2$ absent, $\mathrm{p} 3$ relatively unreduced and with two roots, or somewhat reduced with two roots progressively more compressed in younger samples (advanced stage 2 , indicated by $a$ ); anterior teeth otherwise showing little compression: 1) Central Bighorn Basin-USGS 3841?, 3853 (a), 3879, 6555 (a), 9148 (a), 15415 (a); CM 11471, 12345, 12391; MCZ 19986*(a), 20826*(2/ 3), 20863* (2/3); YPM 24980?, 25015B, 25017?, 25026, 25034 (2/3), 25044 (a), 25585 (a), 28203*, 30686?, 30708. USGS 504, 3843, and 5934 represent stage 2 or stage 3 , more likely stage 2 judging from their low stratigraphic levels; 2) Clark's Fork Basin-USGS 2457 (a); UM 66695, 66807, 66821 (2/3), 66832, 72937, 72966, $73151(2 / 3), 73206(2 /$ 3), $73231(a), 80152$.

Stage 3 (Figures 23, 24.2)-p3 somewhat reduced with roots fused but bilobed or U-shaped in occlusal view (one buccal root, two apparent lingual roots); moderate compression of spacing of antemolar teeth and consequent shortening of anterior part of dentary: 1) Central Bighorn Basin-USGS 3865 (3/4), 3873, 3874, 3882?, 5994 (3/4), 9140, 9147, 15407, 15412; YPMPU 13218*, 17686*, 17692*?; USNM 19151, 19152; UW 6192, 10212; YPM 25028, 25592?, 26022; 2) Clark's Fork Basin-UM 67306 (3/4), 67318, $69700(3 / 4), 73264$.
Stage $4-\mathrm{p} 3$ noticeably reduced relative to $\mathrm{p} 4$, with root weakly bilobed lingually and very faintly bilobed or single-rooted buccally; anterior teeth closely spaced and anterior part of dentary distinctively short: Central Bighorn Basin-USGS 3868, 5997; YPM 27219*.

The following specimens are in stages 2-4 of the Tetonius-Pseudotetonius transition, based on stratigraphic occurrence, but they lack stage-diagnostic lower antemolar morphology: 1) Central Bighorn Basin-USGS 505, 507, 510, 511, 3840, 3842, 3844, 3845, 3861,3862 , 3866, 3875-3878, 3967, 5953, 5960, 5992, 5993, 6754, 6975, 7201, 7202, $9143,9201,9202,13760,15413,15414$, 15416; YPM 23184, 23185, 23189, 23614, 24349, 24976, 24985, 24999, 25006, 25019, 25021-25025, 25027, 25029-25033, 2503525038, 25041, 25043, 25497, 25550, 27167 , 30503, 30504, 30519, 30525, 30675, 30678, 30679, 30681, 30687, 30696, 30699, 30700, 30715, 30716, 33272; AMNH 41; DPC 1407; 2) Clark's Fork Basin-UM 65735, 66655, 66805, 72815, 72816, 72927, 72936, 72951, 72964, 72966, 72983, 73007, 73071, 73072, 73195, 73243, 74065, 76780.

The following specimens belong to the Tetonius-Pseudotetonius lineage but non-diagnostic morphology and lack of good stratigraphic data preclude stage identification: USGS 1738, 2467, 7200; AMNH 15064B, 15065; CM 12189, 12225; MCZ 17947, 19003, 19004, 20395, 20827, 20837; YPM 23095, 24371, 24374, 25016, 25020, 25705, 26043, 30465, 30713; UM 67329, 73125, $73150,75687,75697$.

Genus PSEudotetonius Bown, 1974

Tetonius MATTHEw, 1915, p. 457 (part); MCKENNA, 1960, p. 72 (part); SZALAY AND DELSON, 1979, p. 215 (part); GINGERICH, 1980a, p. 415 (part); 1981, p. 358 (part).

Trogolemur MCKENNA, 1960, p. 69.

Pseudotetonius Bown, 1974, p. 20; ROSE AND Bown, 1984, p. 250; 1986, p. 125.

Tetonius? Szalay, 1976, p. 207.

Mckennamorphus SZALAY, 1976, p. 249.

Type species. - Tetonius? ambiguus Matthew, 1915, p. 462; only known species.

Diagnosis. - As for species. 

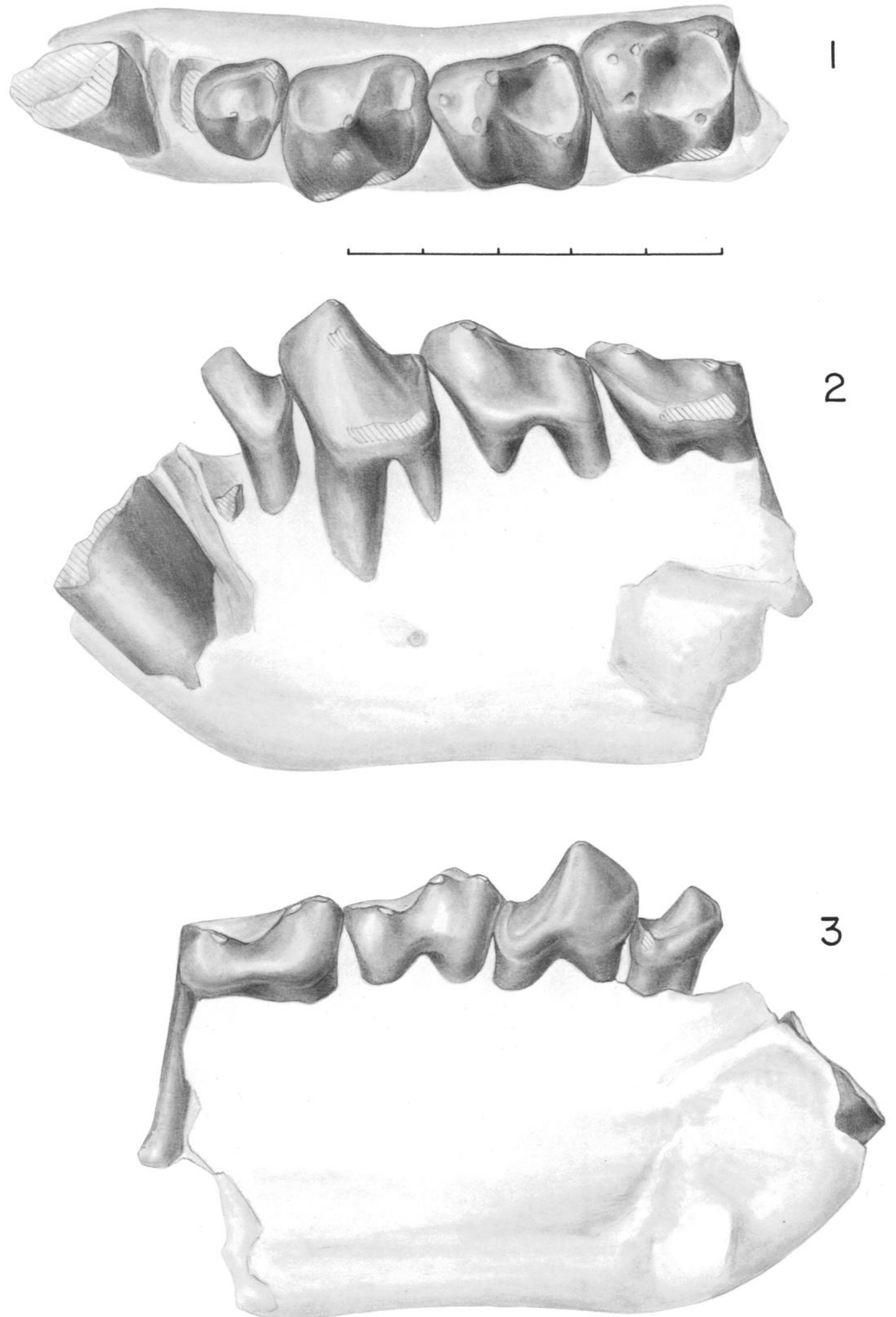

FIGURE 26-Pseudotetonius ambiguus (Matthew) (stage 4/5), holotype, AMNH 15072, left dentary with p3-m2 and roots or alveoli of i1-2 and c (?about $350 \mathrm{~m}$ ). 1-3, occlusal, lateral, and medial views, respectively. Scale is $5 \mathrm{~mm}$. 

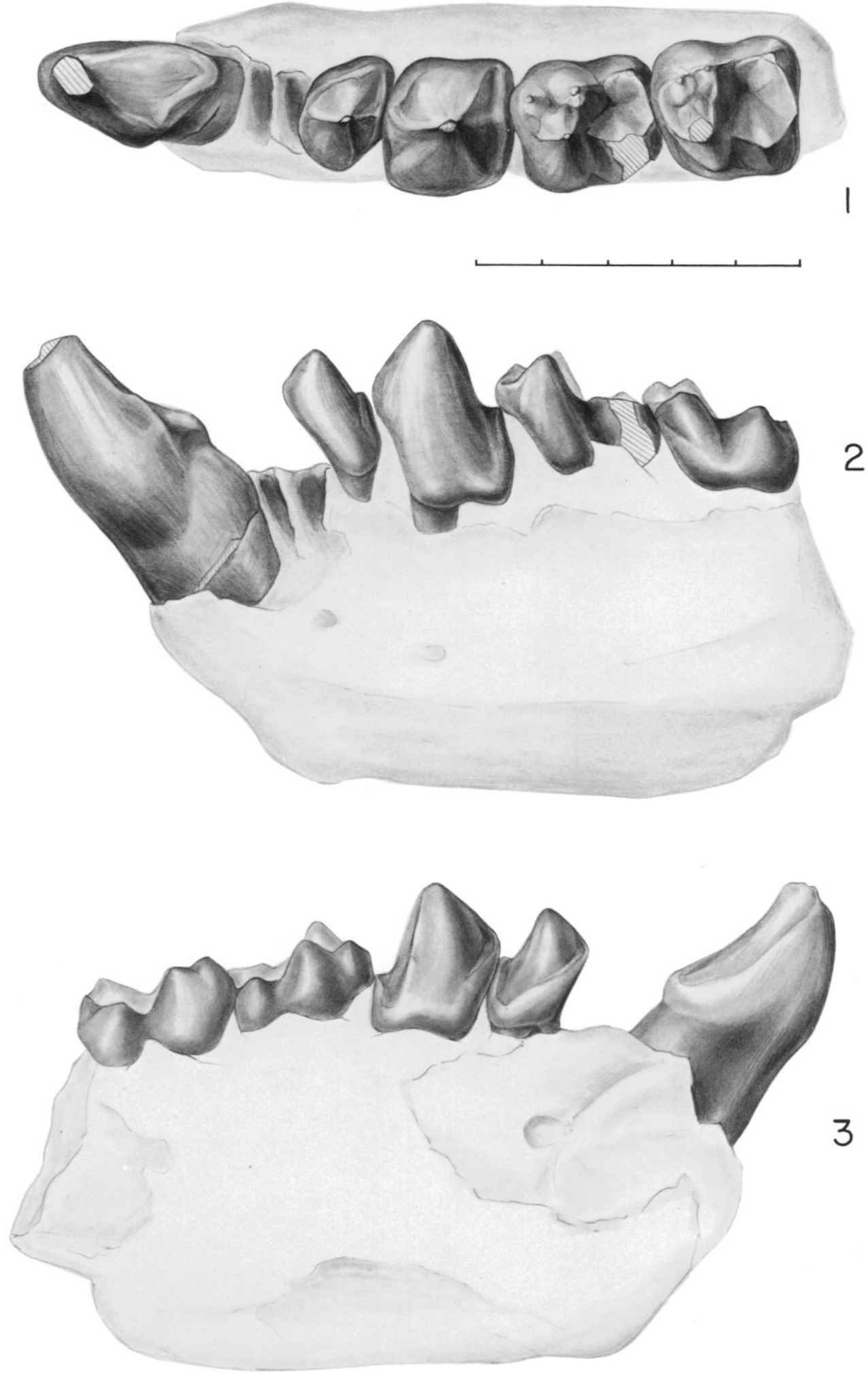

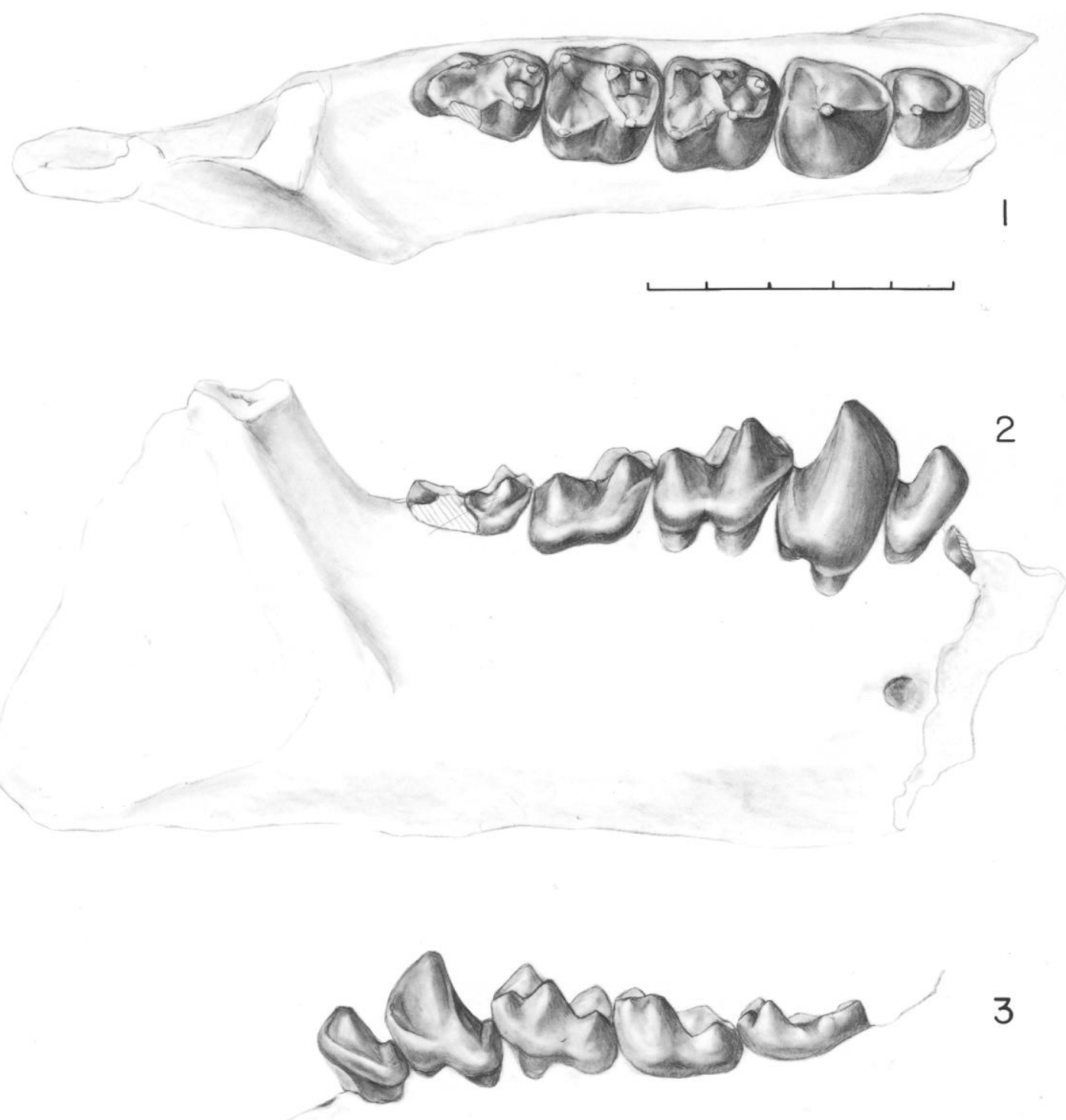

FIGURE 28-Pseudotetonius ambiguus (Matthew) (stage 4/5), USGS 5973, right dentary with p3-m3, root of c, and edges of incisor alveoli $(346 \mathrm{~m}) .1-3$, occlusal, lateral, and medial views, respectively. Scale is $5 \mathrm{~mm}$.

FIGURE 27-Pseudotetonius ambiguus (Matthew) (stage 4), MCZ 19010, left dentary with i1, p3-m2, and alveoli of $i 2$ and c (about $350 \mathrm{~m}$ ). 1-3, occlusal, lateral, and medial views, respectively. Scale is $5 \mathrm{~mm}$. 

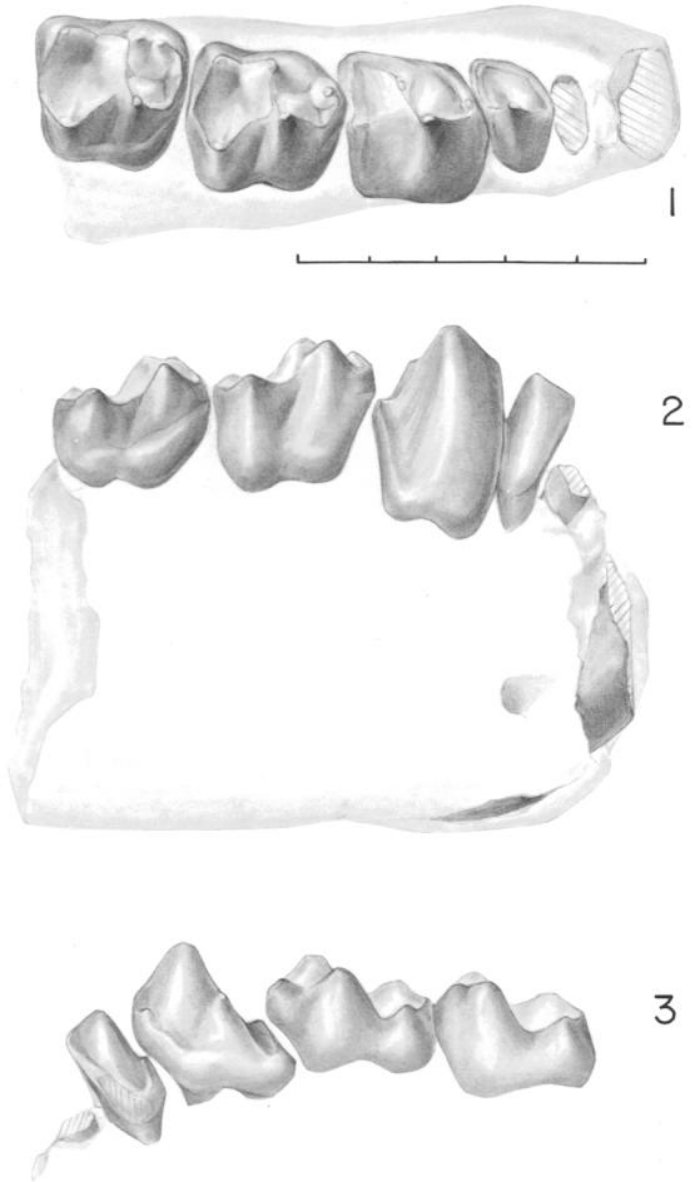

FIGURE 29-Pseudotetonius ambiguus (Matthew) (stage 5), YPM 30698, right dentary with p3$\mathrm{m} 2$ and roots or alveoli of $\mathrm{i} 1-2$ and $\mathrm{c}(370 \mathrm{~m})$. $1-3$, occlusal, lateral, and medial views, respectively. Scale is $5 \mathrm{~mm}$.

\section{PSEUdoteTONIUS AMBIGUUS (Matthew, 1915)}

Figures 25.1, 26-29, 30.1

Tetonius ambiguus MATTHEw, 1915, p. 462, fig. 32; SZALAY AND Delson, 1979, p. 215.

Trogolemur sp. McKenNA, 1960, p. 69, fig. 34.

Tetonius homunculus? MCKenNA, 1960, p. 72 (UCMP 44029, 44052, 44054 only), fig. 38.

Pseudotetonius ambiguus Bown, 1974, p. 20, figs. 1-3; ROSE AND BOWN, 1984, p. 250, fig. 2; 1986, p. 125 , fig. 5 .

Tetonius? ambiguus Szalay, 1976, p. 207, figs. 26-28.

Mckennamorphus despairensis SZALAY, 1976, p. 251, figs. 26, 28, 57; SzALAY AND DELSON, 1979, p. 226, fig. 113 .

Tetonius homunculus GiNGERICH, 1980a, fig. 4 (part); 1981, p. 358 (part).
Holotype.-AMNH 15072, left dentary with p3-m2, roots of il and c, and alveolus for i2 (Figure 26); Willwood Formation (lower Eocene), "5 miles south of Otto, Bighorn Basin, Wyoming."

Hypodigm. - The holotype (stage 4/5) and the following specimens assigned by morphology (M) and/or stratigraphic position (S); specimens in which the configuration of $\mathrm{p} 3$ is ambiguous are followed by a query (?) and are assigned to their most probable stage.

1) Central Bighorn Basin, stage 4: USGS 3881, 3883?, 6752; MCZ 19010; YPM 24981, 25042, 30689? (all M, S). AMNH 15064A, YPM 23183 (both M).

2) Central Bighorn Basin, stage 5 ( $\mathrm{p} 3$ very reduced and with a single root, not bilobed): USGS 3867, 5973 (4/5), 7199?, 9144; JHU 66, 699; YPM 30698 (all M, S).

3) Central Bighorn Basin, stage 4 or 5 : USGS 3858-3860, 3884, 8842, 9087, 9141, 9155; JHU 156, 695; YPM 23181, 23187, 24992, 24994, 25040, 27933, 30673, 30703 (all S).

4) Clark's Fork Basin, stage 4: UM 73453 (M, S).

5) Clark's Fork Basin, stage 5: UM 67329?, 73224?, 75037 (M, S).

6) Clark's Fork Basin, stage 4 or 5: UM 75036? (M, S). UM 73462, 73484, 73452, and probably (not seen) UM 73485, 75728, 76427, 80740, 83674, 83692, 83699, 83704, 83707, 83726, 83738 (all S).

7) Sand Wash Basin, Colorado, Despair Quarry: UCMP 44055 (M) and probably (not seen) UCMP 44029, 44052, 44054; AMNH 80060.

Distribution. - Willwood Formation (lower Eocene, Wasatchian), upper part of upper Haplomylus-Ectocion Range Zone of Schankler (1980), about 346-375 m interval in the central Bighorn Basin and about 530$590 \mathrm{~m}$ interval $(2,050-2,110 \mathrm{~m}$ interval in Gingerich's 1982 section) in the Clark's Fork Basin. Despair Quarry, Hiawatha Member of Wasatch Formation (lower Eocene), Sand Wash Basin, northwest Colorado.

Revised diagnosis. - Anaptomorphine generally similar in size and morphology to $\mathrm{Te}$ tonius, but differing from that genus in the combination of the following characters: lower dental formula 2.1.2.3, p3 reduced relative to $\mathrm{p} 4, \mathrm{p} 3$ with single anteroposteriorly compressed root sometimes weakly bilobed 

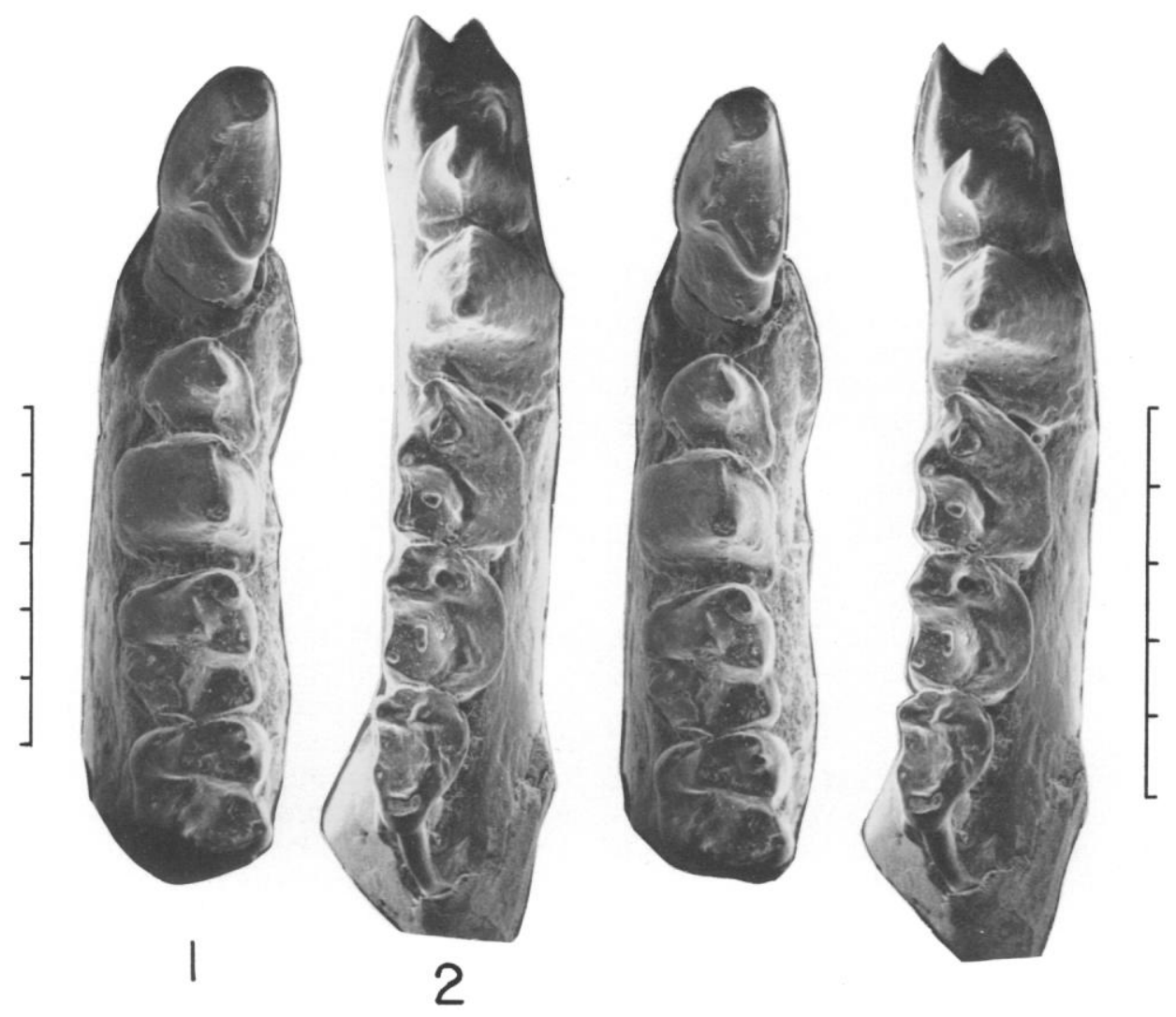

FIGURE 30-Pseudotetonius and Absarokius, SEM stereophotographs. 1, Pseudotetonius ambiguus (Matthew) (stage 4), MCZ 19010, left i1, p3-m2, and alveoli of i2 and c (about $350 \mathrm{~m}$ ). 2, Absarokius gazini n. sp., holotype, UW 1644, right p3-m3 and alveoli of i1-2, c, and p2 (late Wasatchian, Sweetwater County, Wyoming). Scale is $5 \mathrm{~mm}$.

lingually, c and i2 much smaller and more compressed, il more robust, and antemolar portion of dentary shorter.

Discussion. - Matthew (1915) recognized the distinctiveness of this taxon (which he assigned to Tetonius) long before its stratigraphic separation from more primitive $T e$ tonius was known. In fact, he used the type of $P$. ambiguus in first evaluating the lower dental formula of genus Tetonius. Although maintaining ambiguus as a valid species, Szalay (1976) questioned its allocation to Tetonius (overlooking Bown's (1974) proposal of the genus Pseudotetonius). Gingerich (1980a, 1981), however, subsumed $P$. ambiguus within Tetonius homunculus. Allocation of the species to a separate genus, Pseudotetonius, is defended by the conspicuous contrast in the lower antemolar dentition. This reflects a significant adaptive shift in the dentition from that characterizing Tetonius.
Although specimens here assigned to Pseudotetonius ambiguus are readily distinguished from the stratigraphically disparate Tetonius matthewi (see also Table 5), the transition between these forms is so gradual and continuous that no discrete stratigraphic boundaries or morphologic diagnoses can be drawn (at either the generic or specific levels) between either species and the series of intermediates that link them. Nor are such boundaries evident between the intermediates themselves. An arbitrary boundary is therefore proposed, one drawn stratigraphically to include all stage 5 specimens in the Tetonius-Pseudotetonius transition, as well as contemporaneous stage 4 specimens.

See Appendices 14 and 15 for measurements.

\section{Genus ABSAROKIUS Matthew, 1915}

Anaptomorphus LoOMIs, 1906, p. 278. 
Absarokius MATTHEw, 1915, p. 463; MORRIS, 1954, p. 199; GUTHRIE, 1967, p. 17; 1971, p. 64; GAZIN, 1952, p. 24; 1962, p. 37; SIMONS, 1972, p. 144; Szalay, 1976, p. 229; Szalay AND DELSON, 1979, p. 219.

Type species. - Anaptomorphus abbotti Loomis, 1906, p. 278.

Included species. - The type species and $A$. metoecus n. sp., $A$. gazini n. sp., $A$. australis n. sp., $A$. nocerai n. comb., $A$. witteri.

Distribution.-Latest early through late Wasatchian (middle and late early Eocene) and early Bridgerian (early middle Eocene) of Wyoming; late Wasatchian of Colorado.

Revised diagnosis. - Teeth larger in mean size than in Tetonius and Pseudotetonius; mean $\mathrm{p} 3 / \mathrm{p} 4$ and $\mathrm{m} 3 / \mathrm{m} 2$ ratios smaller than in Tetonius. Lower medial incisor much smaller and canine much larger than in Pseudotetonius; i1-2 much smaller and p2 much larger than in Tetonius.

Discussion. - Matthew (1915) named $A b$ sarokius for Loomis's (1906) Wind River Basin Anaptomorphus abbotti and erected $A$. noctivagus for a more derived specimen from the Bighorn Basin. Morris (1954) based the last previously described species, $A$. witteri, on a single lower jaw that clearly belongs to a distinct and advanced species of Absarokius. Robinson (1966) proposed the subspecies $A$. noctivagus nocerai for additional distinctive Absarokius materials from the Huerfano Formation of southern Colorado.

The large Absarokius sample from the Bighorn Basin (more than 250 upper and lower jaws with two or more teeth) is marked both by considerable variability and intergradation of characters. Although the size ranges of teeth in this sample are beyond those expected for a single species (see, e.g., Gingerich, 1974b), there is no clear bimodal or polymodal distribution, nor any other clear size separation at any level throughout the lower half of the stratigraphic range. Nonetheless, these Willwood specimens are unified taxonomically in Absarokius by virtue of the number, size, and configuration of the lower antemolar teeth.

Only Absarokius abbotti and the new species $A$. metoecus represent Absarokius in the Bighorn Basin. Although the type specimen of $A$. noctivagus is from the Willwood Formation as well, in the pooled Willwood $A b s a-$ rokius sample there is clear stratigraphically- controlled overlap of all characters formerly used to distinguish $A$. noctivagus from $A$. $a b$ botti. Until larger samples of Absarokius are known from the upper part of the Willwood Formation, the holotype of $A$. noctivagus (from the highest part of the range of $A b s a$ rokius) and several other similar specimens from lower levels are best regarded as relatively large, advanced end members of the Absarokius abbotti lineage (see discussion un$\operatorname{der} A$. abbotti below).

Robinson's (1966) hypodigm of Absarokius noctivagus nocerai from southern Colorado contains several species; the type of $A$. noctivagus nocerai is specifically distinct from $A$. abbotti (including those specimens earlier referred to $A$. noctivagus), and is here elevated to specific rank.

Absarokius metoecus is in some ways morphologically generalized and in other ways morphologically advanced. It includes specimens in the smallest part of the size range for the pooled sample of Willwood Absarokius, as well as many of those from the stratigraphically lowest part of the range for the genus in the Willwood Formation (at least 30 $\mathrm{m}$ beneath the occurrence of the lowest specimens typical of $A$. abbotti). Nonetheless, in spite of considerable and pervasive morphologic overlap throughout most of the shared stratigraphic ranges of the new species and $A$. $a b b o t t i$, the $A$. metoecus line gradually diverged morphologically from that of $A$. $a b$ botti, apparently in the direction of early Bridgerian Strigorhysis. Absarokius gazini n. $\mathrm{sp}$. is another divergently specialized species from southwestern Wyoming, and $A$. australis $\mathrm{n}$. $\mathrm{sp}$. is a new and distinct species from southern Colorado.

Morphologic trends in Bighorn Basin $A b$ sarokius abbotti include tendencies toward larger mean cheek tooth size (excluding $\mathrm{m} 3$ ), increased hypertrophy of $\mathrm{p} 4$, and progressive ventral distension of the posterobuccal part of $\mathrm{p} 4$ to a point markedly ventral to the level of the anterobasal margin of the crown of $\mathrm{m} 1$. In some Absarokius species from outside the Bighorn Basin, $\mathrm{p} 2$ is lost (A. nocerai, $A$. australis $\mathrm{n}$. sp., and $A$. witteri), and $\mathrm{p} 3$ becomes very small ( $A$. gazini n. sp., $A$. witteri, and $A$. australis $\mathrm{n}$. sp.) or is single-rooted ( $A$. nocerai and $A$. australis $\mathrm{n}$. sp. - double rooted in all other species). There is a tendency toward even greater hypertrophy and buccal disten- 
sion of p4 (A. nocerai and $A$. witteri), in two cases coupled with minor crenulation of the enamel of the lower molar talonids ( $A$. witteri and $A$. australis n. sp.). Absarokius metoecus n. sp., on the other hand, shows trends toward enlargement of the upper molar trigon basins, transverse narrowing of $\mathrm{M} 1-2$, and crenulation of the enamel of the upper molars, as well as buccolingual compression of the trigonid of $\mathrm{m} 1$ (effected by the extreme anterior placement of the $\mathrm{ml}$ paraconid). This $\mathrm{ml}$ morphology is also developed in A. gazini n. sp., a species that has also divergently developed markedly narrow lower molars and somewhat enlarged incisors.

AbSAROKIUS ABbotTI (Loomis, 1906)

Figures 31, 32, 33.1, 34.4, 44.3

Anaptomorphus abbotti LoomIs, 1906, p. 278, fig. 2.

Absarokius abbotti MATTHEw, 1915, p. 463, fig. 35; Kelley AND WoOD, 1954, p. 343, fig. 4; GUTHRIE, 1967, p. 17, fig. 9; Bown AND GINGERICH, 1972, p. 5, figs. 3, 4.

Absarokius abotti (sic) SzALAY, 1976, p. 231, figs. 42-45; Szalay and Delson, 1979, p. 219, fig. 109.

Absarokius, near A. abbotti GAZIN, 1962, p. 37, Pl. 5, fig. 3.

Absarokius noctivagus MatTHEw, 1915, p. 465, figs. 36, 37; GAZIN, 1952, p. 24; GAZIN, 1962, p. 38, Pl. 4, fig. 1; GUTHRIE, 1971, p. 64; SZALAY, 1976 , p. 238 , figs. 48-51 (part); SzALAY AND DELSON, 1979, p. 219.

Holotype. - ACM 3479, right p3-m3 (Figure 44.3) and right M2-3; Cottonwood Creek, Lysite Member of Wind River Formation, Wind River Basin, Wyoming.

Hypodigm. - The holotype and the following specimens:

1) Willwood Formation, Bighorn Basin, Wyoming-USGS 322, 475, 485, 489, 493, 494, 503, 990, 991, 992, 1598, 1798, 1826, 1827,2302 , 3847, 3850-3852, 3869-3872, 3885-3890, 5944, 5945, 5947, 5949, 5954, 5956-5958, 5961, 5964, 5968, 5969, 5981, 5984, 6005, 6006, 6117, 6556, 6566, 6568, $6569,6629,6632,6753,7696-7699,7701$, $7702,7786,8030,8133,8305,8322,8634$, $8682,8933,9138,9139,9145,9149,9150$, $9161,9162,9163,9165-9167,9169,9172$, 9173, 9174, 9176, 9177, 9180, 9181, 9183, 9184, 9189-9192, 9200, 9885, 9898, 9907, $9911,9971,9994,10038,10055,10111$, 10153-10155, 12204, 12205, ?12206,

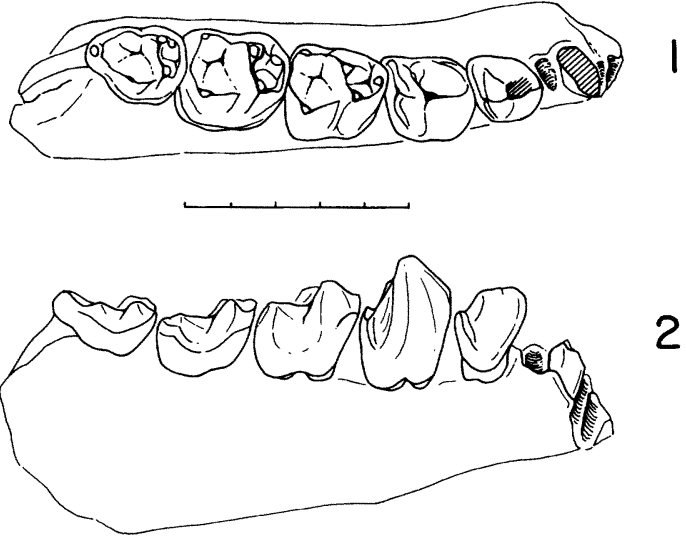

FIGURE 31-Absarokius abbotti (Loomis), USGS 1598 , right dentary with $\mathrm{p} 3-\mathrm{m} 3$, root of $\mathrm{c}$, and alveoli of i1-2 and p2 $(570 \mathrm{~m})$. 1, 2, occlusal and lateral views, respectively. Scale is $5 \mathrm{~mm}$.

?12207, 12209-12214, ?12215, ?12216, 12217,12219 , ?12220, ?12221, 12224, $12225,12227,12228$, ?12229, 12230, 16431 ?, 16442, 16443, 16444, 16446, 16449, 16450, 16452, 16457; YPM 17465, 17471, 17473, 17476, 17478, 17482, ?17485 (now lost), 17486, 18577, ?18639 (now lost), 18684, 18686, 18687-18691, ?18693 (now lost), 18698, 18699, ?23176 (now lost), 23177, 23195-23198, 23203, 23204, ?26352 (now lost), 26651, 26969, 27790, 27791, 27795, 27797, 27798, 27817, 27818, 27833, 27867, 27873, 27874, 27878, 27887, 27890, 27892, 27896, 27901, 27906, 27909, 27910, 27915, 27925, 27930, 27932, 27944, 27945, 27946, 28202, 28204, 28205, 28206, 28229, 28230, 28276, ?28278 (now lost), 35082 35083, 35084, 35091, 35097, 35238; AMNH 15601, 15628; MCZ 18950; DPC 1215, 1225, 1318, 1468, 1581, 1583, 2956, 2974, 2975, 2978.

2) Wind River Formation, Wind River Basin, Wyoming-CM 19861, 19862, 20907, 22126, 22127; UW 14749-14751, 15679.

3) Wasatch Formation, greater Green River Basin, Wyoming-USNM 19198 is Absarokius cf. abbotti.

4) Many of the other specimens referred by Szalay $(1976$, p. 231,238$)$ to $A$. abbotti and $A$. noctivagus probably belong in $A$. $a b$ botti but were not examined. This excludes Absarokius from the Huerfano Formation, which belong in $A$. nocerai n. comb. (Robinson, 1966), $A$. metoecus n. sp., $A$. australis n. sp., and Strigorhysis huerfanensis n. sp. All 

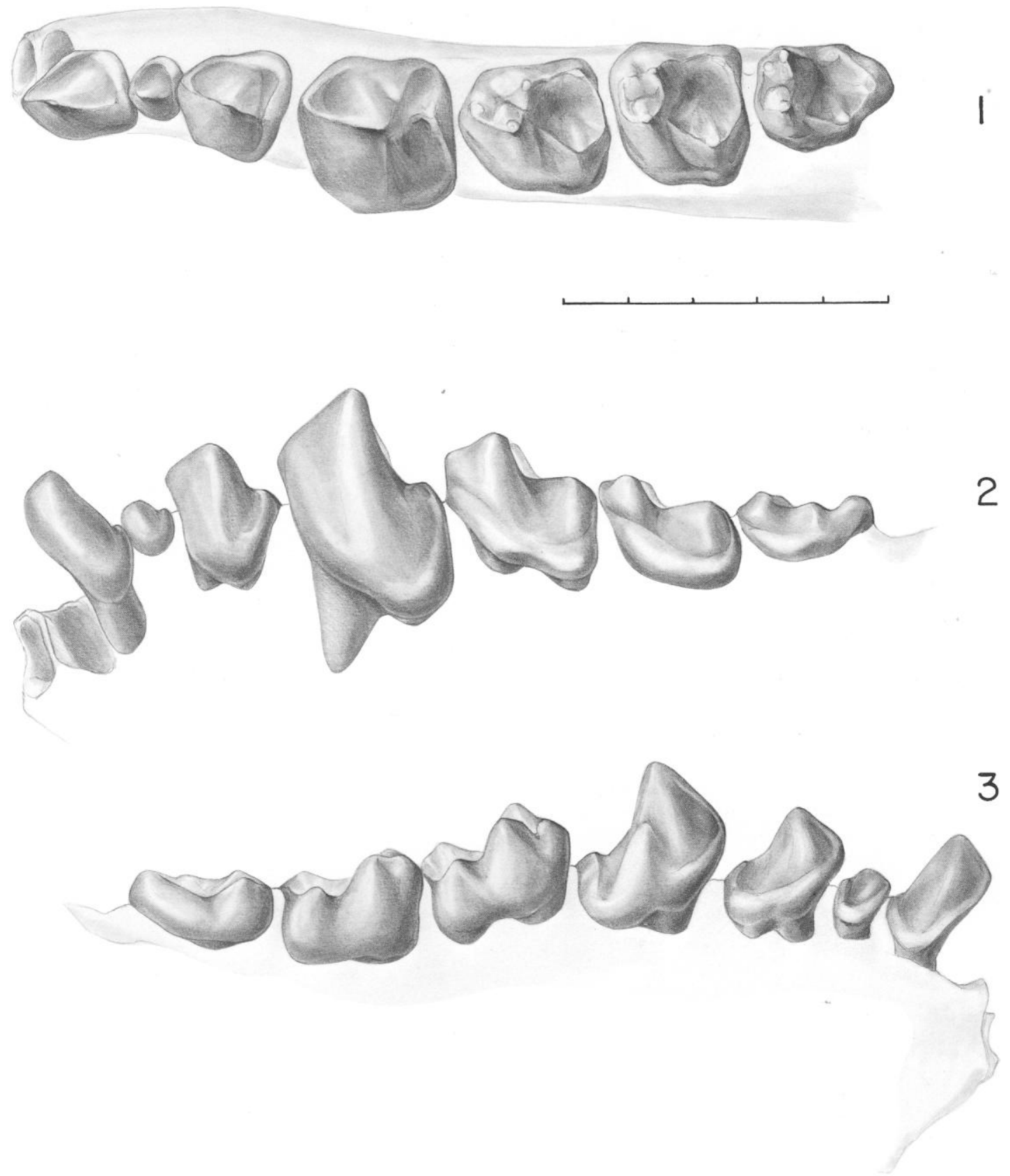

FIGURE 32-Absarokius abbotti (Loomis), YPM 27791, left dentary with c, p2-m3, and alveoli of i1$2(610 \mathrm{~m}) .1-3$, occlusal, lateral, and medial views, respectively. Scale is $5 \mathrm{~mm}$.

YPM specimens referred by Szalay (1976) to $A$. abbotti or $A$. noctivagus are from the Willwood Formation of the Bighorn Basin, not from the Wind River Basin. Of those specimens, YPM 18639 (unknown species), 18685
(A. metoecus n. sp.), and 18693 (unknown species) are now apparently lost.

Distribution. - Middle and late Wasatchian (middle and late early Eocene) of Wyoming and Colorado; 455 to $690+$ meter levels 


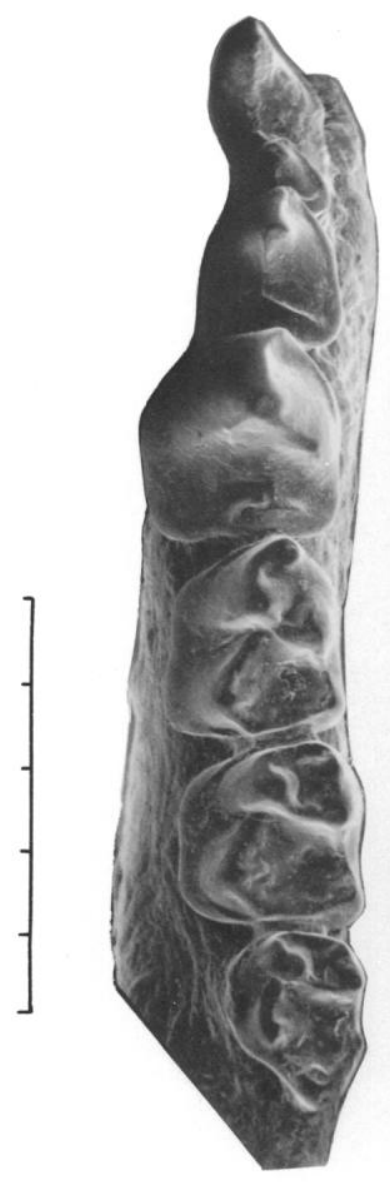

|

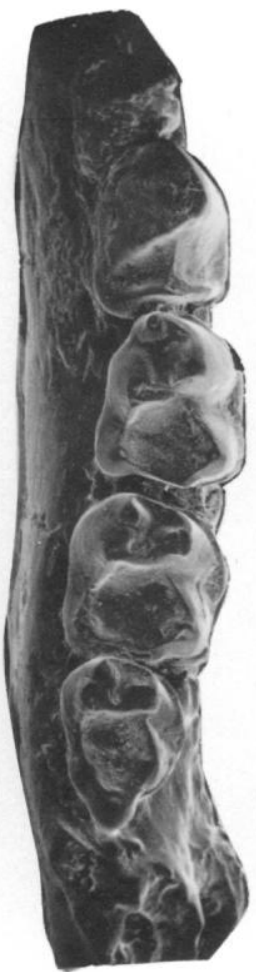

2
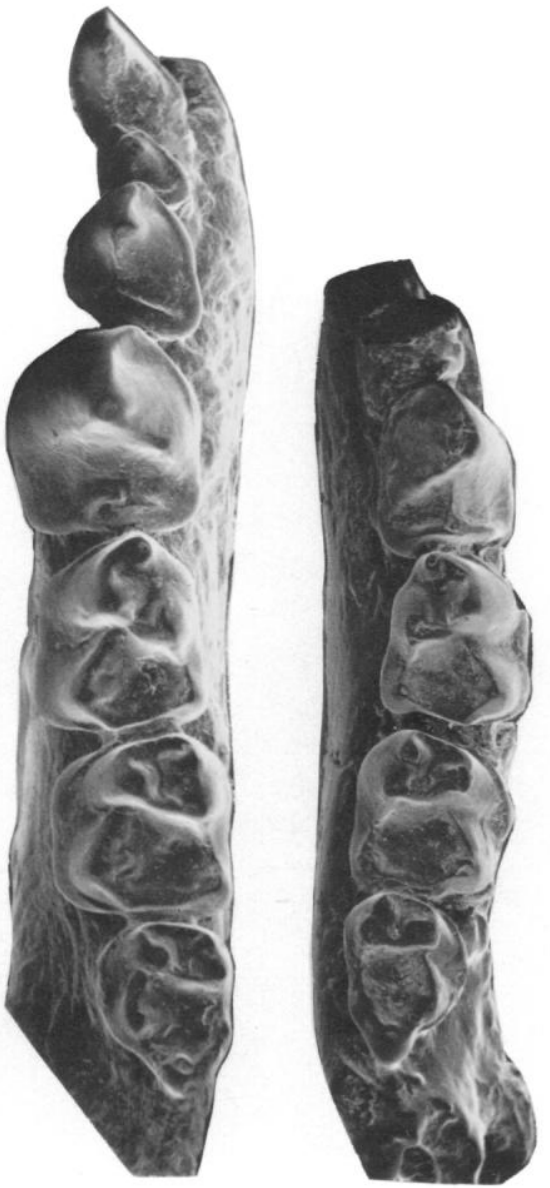

FIGURE 33-Absarokius, SEM stereophotographs. 1, A. abbotti (Loomis), YPM 27791, left c-m3 and alveoli of il-2 (610 m). 2, A. metoecus n. sp., holotype, USGS 492, right dentary with p4-m3 and part of p3 $(470 \mathrm{~m})$. Scale is $5 \mathrm{~mm}$.

of Willwood Formation (lower Eocene; upper Bunophorus Interval Zone through lower part of upper Heptodon Range Zone of Schankler, 1980); Bighorn Basin, Wyoming.

Revised diagnosis.-Differs from $A$. metoecus n. sp. and $A$. gazini n. sp. in larger mean tooth size, from $A$. metoecus $\mathrm{n}$. sp. in larger and more hypertrophied p4 and in greater ventrobuccal distension of $\mathrm{p} 4$ crown. M1-2 more transverse than in later $A$. $m e-$ toecus n. sp., M2 with relatively smaller trigon basin, and molars without crenulation or joining of postprotocrista to postcingulum as seen in $A$. metoecus $\mathrm{n}$. sp. Lower second premolar present and p3 with two roots, both in contrast to $A$. nocerai n. comb. and $A$. aus- tralis n. sp. Differs from $A$. witteri and $A$. australis $\mathrm{n}$. sp. in retention of $\mathrm{p} 2$, and from $A$. gazini n. sp. and $A$. witteri in greater p3/ p4 size ratio, smaller and more trenchant but less hypertrophied $\mathrm{p} 4$, absence of enamel crenulation of molar talonids, and smaller m3. Differs from $A$. gazini n. sp. in having larger incisors and $\mathrm{p} 3$ and from $A$. gazini n. sp. and later $A$. metoecus $\mathrm{n}$. sp. in having paraconid of $\mathrm{m} 1$ relatively close to metaconid, not greatly removed anteriorly as in those species.

Discussion. - The Absarokius abbotti-A. "noctivagus" group is complex. Successively younger samples of Bighorn Basin Absarokius abbotti show a clear trend only toward 
T. M. BOWN AND K. D. ROSE
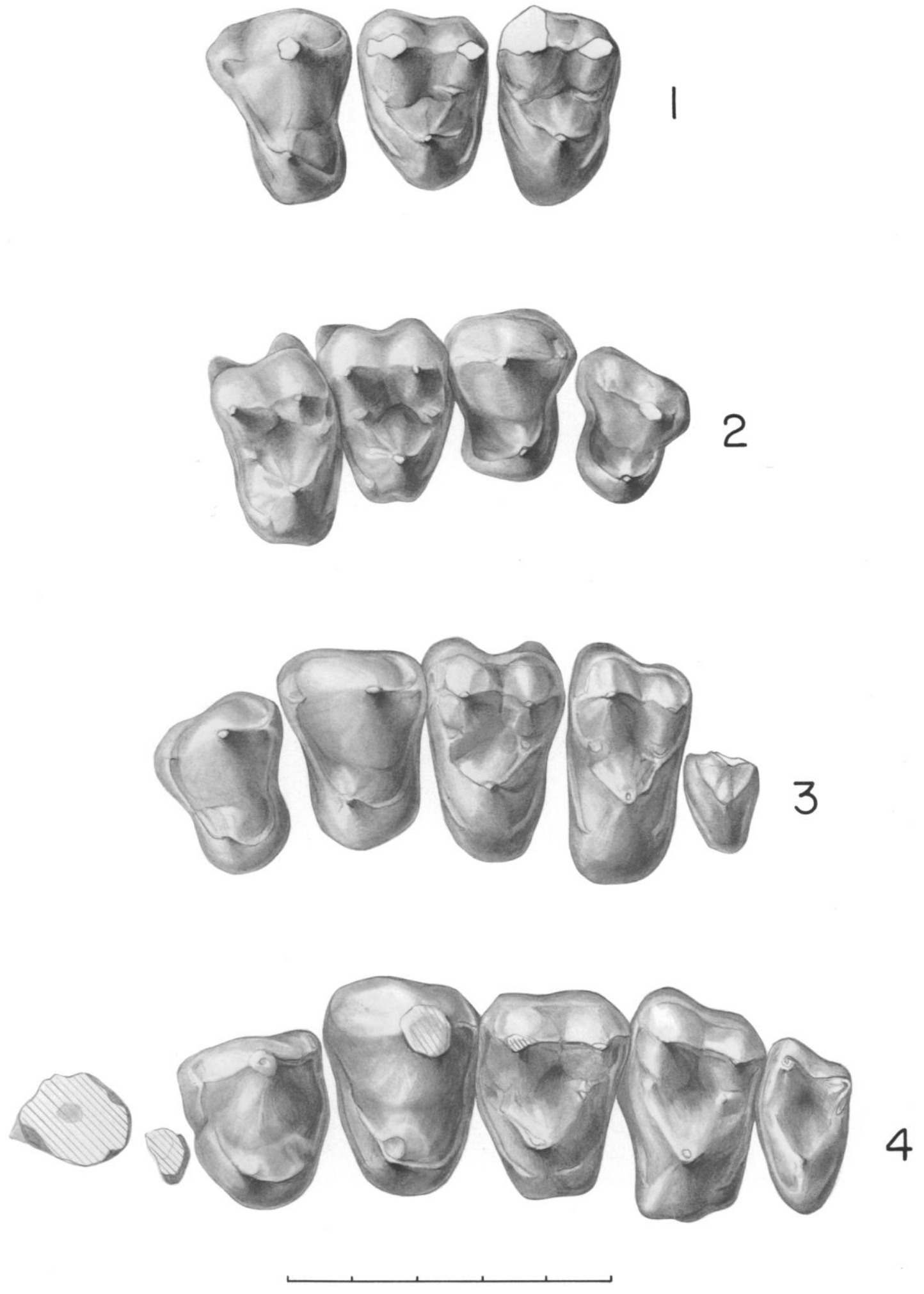
greater posterobuccal and ventral distension of the crown of $p 4$, culminating in the advanced condition seen in the type specimen of Absarokius noctivagus (AMNH 15601; Matthew, 1915; Szalay, 1976, fig. 48). Length and crown height of $\mathrm{p} 4$ as well as the size of the upper and lower molars, are established early in this lineage and remain more or less stable throughout its duration in the Bighorn Basin.

Absarokius noctivagus is considered a junior synonym of $A$. abbotti. Matthew (1915, p. 465) originally distinguished the type of $A$. noctivagus from that of $A$. abbotti on the "... somewhat more progressive ..." dentition. Guthrie (1967) recorded that $A$. noctivagus possesses a larger $\mathrm{p} 4$ than $A$. abbotti, an observation also endorsed by Szalay (1976). Szalay (1976, p. 239) also mentioned the buccal distension of the $\mathrm{p} 4$ crown, noting that this feature is developed "... to a greater degree than this is seen in $A$. abotti [sic]." Specimens referred by other workers to $A$. noctivagus have been recorded from later Wasatchian rocks of the Bighorn Basin (Matthew, 1915; Szalay, 1976), the Wind River Basin (Matthew, 1915; Kelley and Wood, 1954; Guthrie, 1971; Szalay, 1976; Stucky, 1982), and the greater Green River Basin (Gazin, 1952, 1958, 1962; Szalay, 1976).

Among the difficulties in assigning samples of $A$ bsarokius to $A$. abbotti or $A$. noctivagus have been the lack of large samples clearly referable to either species, with which specimens might be compared, and the absence of detailed stratigraphic information. Stratigraphic control would establish relative contemporaneity of samples as well as the morphologic and size variability expected for species of Absarokius at successive stratigraphic levels. In the absence of stratigraphic information, Szalay assigned some of the Bighorn Basin materials to $A$. abbotti and others to $A$. noctivagus. However, when the very large samples of Bighorn Basin Absarokius are placed in stratigraphic context, $A$. abbotti and $A$. noctivagus are not nearly as distinct as previously believed.

The holotype of Absarokius noctivagus (AMNH 15601) is from the Willwood Formation of the Bighorn Basin (not the Wind River Basin as reported by Szalay, 1976, p. 238) and it can therefore be compared in context with other Willwood Absarokius. In this context, it is clear that the type specimen of $A$. noctivagus differs from the remainder of the $A$. abbotti sample only in the relative development of p3 and p4, especially p3-4 width. Although this tooth in AMNH 15601 is overall larger than in most other Willwood specimens, there is no bimodal or polymodal distribution of $\ln (\mathrm{L} \times \mathrm{W})$ in $\mathrm{p} 4$ in the sample, even though the observed range in this parameter is relatively great at and above the $560 \mathrm{~m}$ level of the Willwood Formation. The type specimen of $A$. noctivagus is matched in p4 crown length by 34 other specimens of Bighorn Basin Absarokius (Figure 35) and is greatly exceeded in this dimension by both DPC 1225 and YPM 28230. In crown height, p4 in AMNH 15601 is matched only by USGS 5956, 12219, and YPM 27795 (Figures 36, 37). Considering stratigraphically controlled trends in these characters, the value for $\mathrm{p} 4$ height is unusual only in USGS 5956 at the $585 \mathrm{~m}$ level of the Willwood Formation. The values for $\mathrm{p} 4$ length are distinct only in DPC 1225 and YPM 28230. The type specimen of $A$. noctivagus, on the other hand, conforms well with trends in the remainder of the sample of $A$. abbotti. In AMNH 15601, p4 W is indeed great but its potential significance in the light of the diminished differences between the $A$. noctivagus type and the remainder of the $A$. abbotti sample cannot be evaluated without additional specimens from near the top of the Willwood Formation.

Although there are several specimens of Absarokius from the Willwood Formation in which p4 is comparable in size to that in Matthew's type of Absarokius noctivagus, p3 and $\mathrm{m} 1-2$ in those specimens have wide size

$\leftarrow$

Figure 34-Upper teeth of Absarokius. 1, A. metoecus n. sp., YPM 28317, left P4-M2 (625 m); 2, USGS 1437, right P3-M2 (530 m); 3, DPC 1257, left P3-M2 and part of M3 (470 m). 4, A. abbotti (Loomis), YPM 18686, left P3-M3 and roots of C and P2 $(560 \mathrm{~m})$. Scale is $5 \mathrm{~mm}$. 
distributions that do not correlate well with p4 size and morphology. To the extent that large and advanced lower fourth premolars might be considered useful in substantiating Matthew's $A$. noctivagus, at least DPC 1225 , USGS 5956, and YPM 27795 and 28230 would qualify for assignment there, even though the first and last of these specimens have molars much larger than those in the type specimen of $A$. noctivagus. In the type of Absarokius noctivagus, p3 falls at the large end of the size range of the pooled Willwood Absarokius sample, but it is exceeded in size by that tooth in both YPM 17476 and YPM 27817 , both of which (especially YPM 17476) possess small p4. The molars of AMNH 15601 fall evenly into the middle of the size range for the pooled Absarokius sample and cannot be distinguished from it morphologically. Of the seven specimens with p4 approximating the large size of that in the type of A. noctivagus (DPC 1225; USGS 5956, 6005; YPM 27795, 27798, 27817, and 28230), p3 is not preserved in USGS 6005 and YPM 27798 and 28230. In DPC 1225, p3 size falls into the middle of the combined range for this tooth and in YPM 27817 it is slightly larger than in the $A$. noctivagus type specimen. The first lower molar is missing in USGS 6005 and in YPM 27798. In YPM $27817 \mathrm{ml}$ falls in the middle of the size range for the combined sample, and in DPC 1225 and YPM 28230 the ml's are by far the largest in the entire sample. The second lower molar is missing in USGS 6005, YPM 27798 and 28230 , and it falls in the middle of the range for the whole sample in DPC 1225 and YPM 27817. In USGS 5981 and YPM 18691 at the $560 \mathrm{~m}$ level of the Willwood Formation, $\mathrm{m} 2$ is unusually large (both of these specimens also have relatively large $\mathrm{ml}$ ); however, their p4's, though large, are clearly smaller than in any of the seven above specimens in which $\mathrm{p} 4$ approximates the size of that in AMNH 15601.

Szalay (1976, p. 238), perhaps influenced by the condition in Absarokius nocerai (see below), diagnosed $A$. noctivagus from $A$. $a b$ botti by the presumed lack of $\mathrm{p} 2$ in the former. However, all of the lower jaw anterior to the front root of $\mathrm{p} 3$ is missing in the holotype of $A$. noctivagus and, therefore, using Szalay's criteria, this specimen is nondiagnostic. Of the seven Willwood specimens of Absarokius in which p4 is close to the size of that in AMNH 15601, only DPC 1225 retains the region of the lower jaw anterior to p3. In that specimen, as well as in every other specimen of Bighorn Basin Absarokius in which this character is determinable, the crown, root, or alveolus of the single-rooted p2 is present.

Though very large, p4 in the type of $A b$ sarokius noctivagus is not abnormal in size (except in width) when compared with others in the Bighorn Basin Absarokius sample at and above the $620 \mathrm{~m}$ level of the Willwood Formation (Figures 35-37). As observed above, when viewed in stratigraphic perspective, AMNH 15601 is considerably less distinctive and puzzling than are DPC 1225, USGS 5956, and YPM 28230. Aside from these last three specimens, p4 size generally increased upward through the Willwood section. The large p4 in the type specimen of $A$. noctivagus would fit well with this general trend were it known that the specimen came from a locality at or above the meter level of the highest of the remainder of the Willwood Absarokius sample.

Locality data on the label accompanying the type specimen of Absarokius noctivagus states that it was collected " $5 \mathrm{~m}$. N. of Parker Spr." Parker Springs are situated in the NE $1 / 4$ sec. 26, T49N, R99W, Park County, Wyoming. Five miles due north of the springs is a large tract of badlands in the upper drainage of Blackstone Gulch, in the only Willwood exposures in the region that could accurately fit the locality description. These rocks are developed between the 680 and $720 \mathrm{~m}$ levels of the Willwood Formation and yield Lambdotherium, a palaeothere confined to the Upper Heptodon Range Zone in the Bighorn Ba-

FIGURE 35-Stratigraphic plots of lower fourth premolar lengths in Absarokius metoecus n. sp., A. abbotti (Loomis), and for the type specimens of other species of Absarokius whose approximate relative stratigraphic positions are interpolated on faunal evidence. Note that $\mathrm{p} 4 \mathrm{~L}$ in $A$. metoecus and $A$. abbotti are quite similar at their earliest co-occurrence and do not change appreciably up section. 
A. witteri

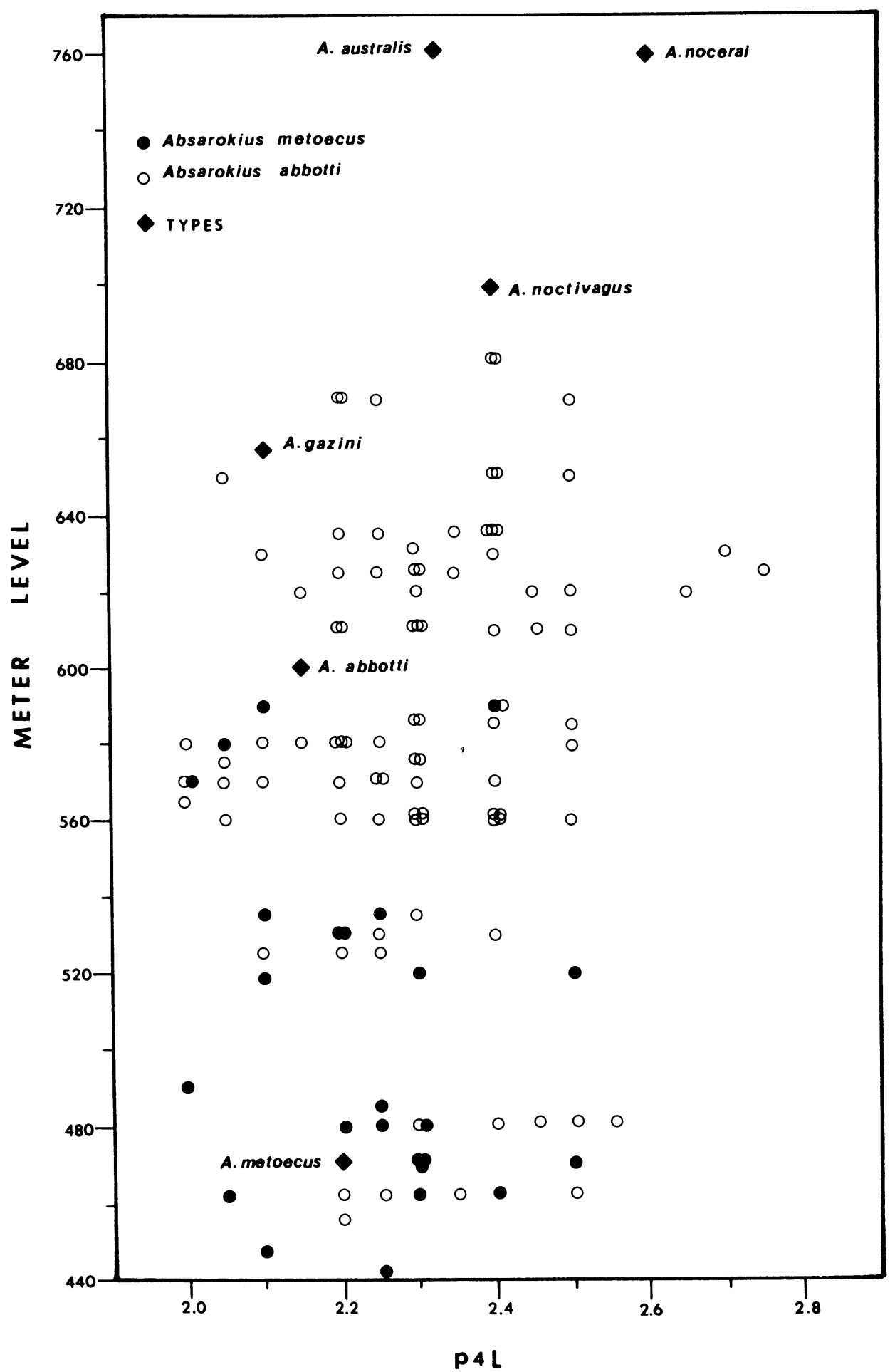




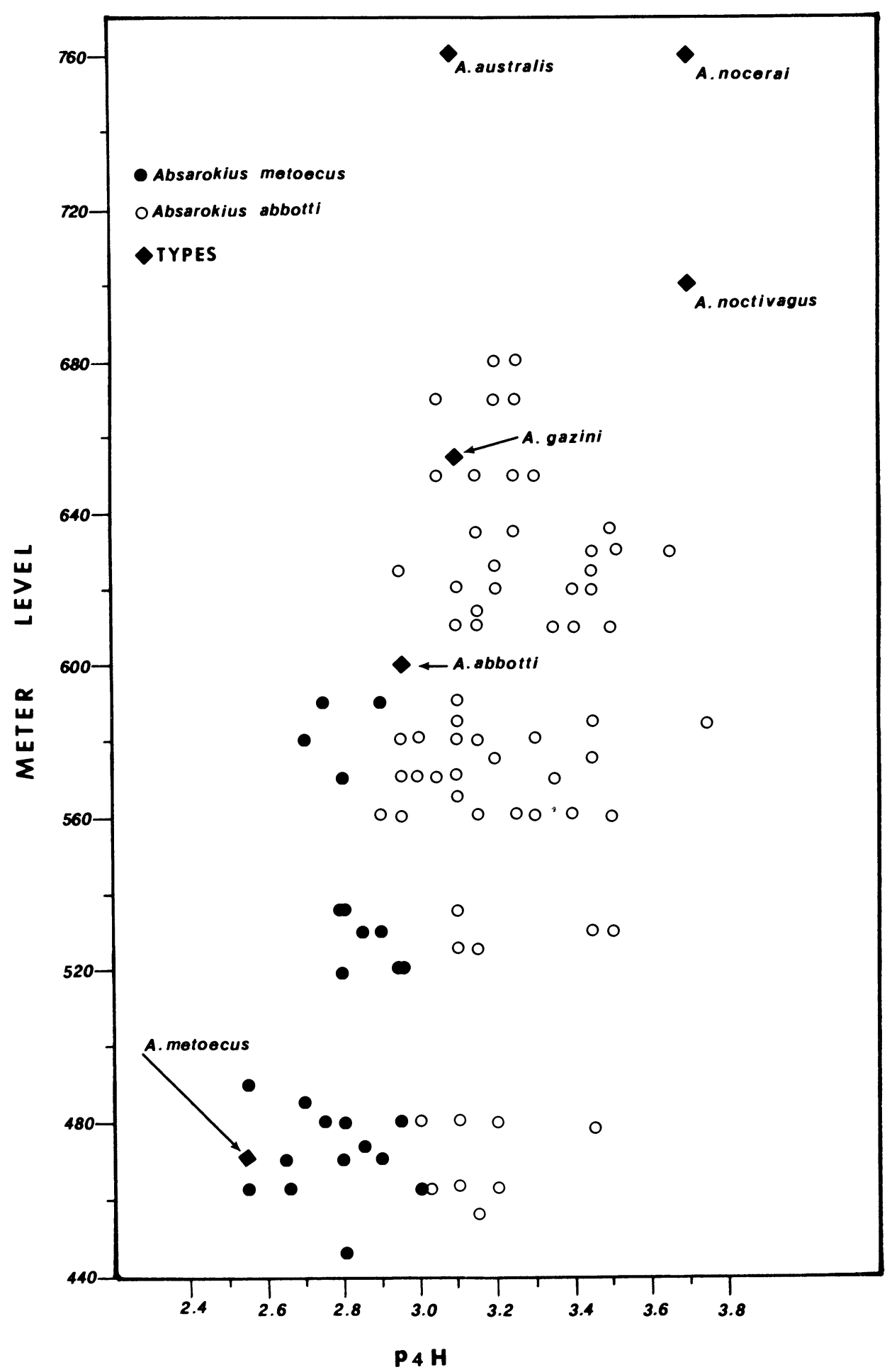

FIGURE 36-Stratigraphic plots of crown heights of lower fourth premolars of Absarokius metoecus $\mathrm{n}$. sp., A. abbotti (Loomis), and for the type specimens of other species of Absarokius whose approximate relative stratigraphic positions are interpolated on faunal evidence. Note that $\mathrm{p} 4 \mathrm{H}$ in $A$. metoecus 


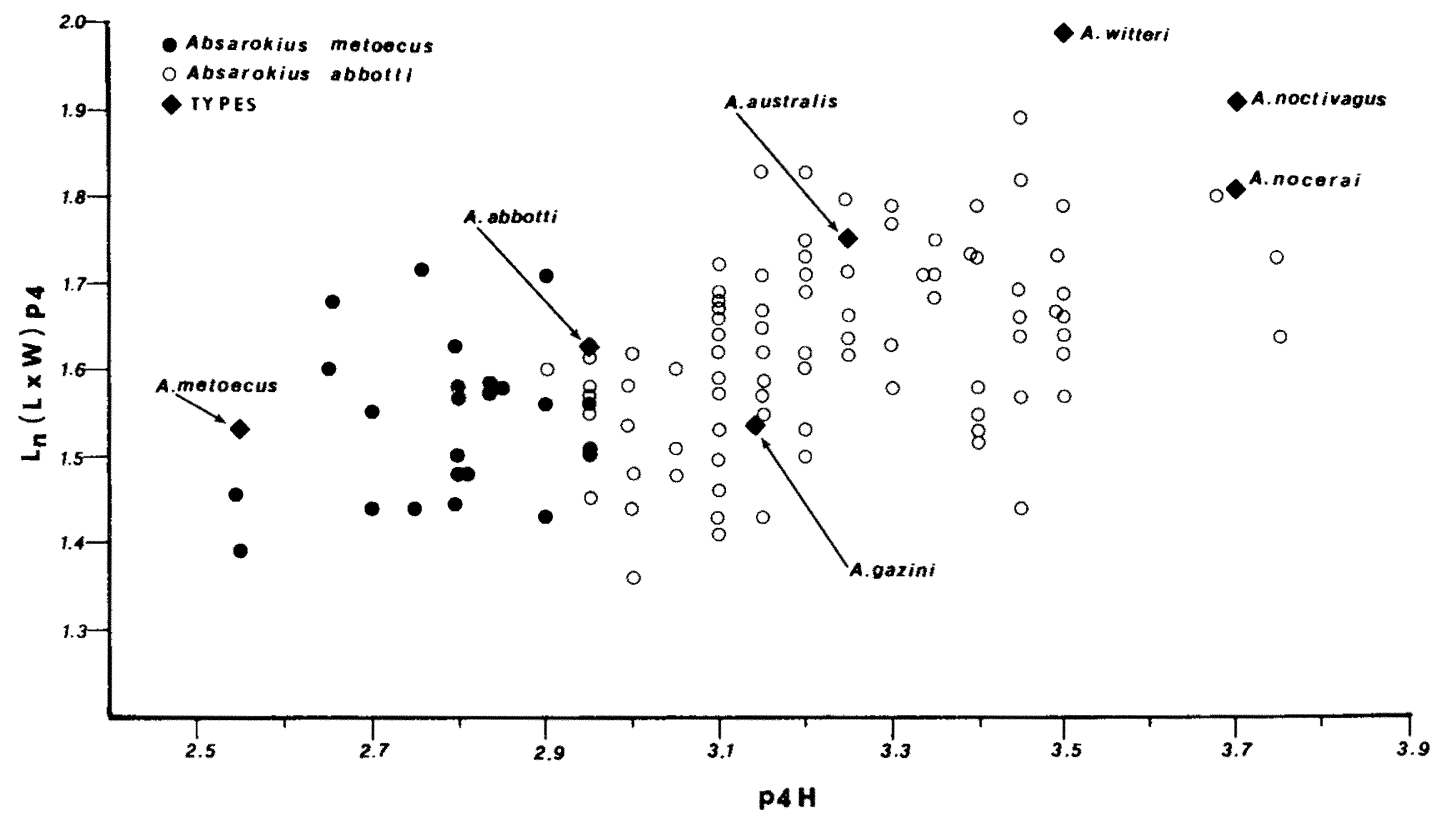

FIGURE 37 -Scatter diagram showing correlation between crown height of $\mathrm{p} 4$ and natural log of area of $\mathrm{p} 4$ in Absarokius metoecus n. sp., A. abbotti (Loomis), and type specimens of other species of Absarokius. Although these two variables correlate reasonably well, they do not depict the crown shape differences that also exist between these Absarokius species.

$\sin$ (Schankler, 1980). If the locality data are accurate, the type specimen of $A$. noctivagus was collected at or above the highest occurrence of the Bighorn Basin Absarokius sample. Because AMNH 15601 cannot be consistently distinguished from the Absarokius abbotti sample on any known character, $A$. noctivagus is regarded as a junior synonym of $A$. abbotti, within which it is one of several relatively large variants. This interpretation can only be tested by recovery of additional Absarokius material from the upper $100 \mathrm{~m}$ of the Willwood Formation.

Synonymy of Absarokius noctivagus with A. abbotti embraces several specimens from the Lost Cabin Member of the Wind River Formation that were earlier assigned to the former species (Guthrie, 1971; Szalay, 1976; Stucky, 1982). Although it was not possible to examine all of these specimens (several are now apparently lost), there appears to be no evidence of $\mathrm{p} 2$ loss in any of these lower jaws.

See Table 8 for basic statistics and Appendices 16 and 17 for measurements.

ABSAROKIUS METOECUS n. $\mathrm{sp}$. Figures 34.1-34.3, 38-42, 43.3-43.4, 44.2 Absarokius noctivagus nocerai RoBINson, 1966, p. 33 (part).

Absarokius abotti (sic) SzALAY, 1976, p. 231 (part). Absarokius noctivagus SZALAY, 1976, p. 238, fig. 49 (part).

Holotype. -USGS 492 (Figures 38, 44.2), right mandibular fragment with part of $\mathrm{p} 3$, $\mathrm{p} 4-\mathrm{m} 3$, partially resorbed alveolus for $\mathrm{p} 2$, and posterior part of alveolus for canine; USGS locality D-1198-B, $470 \mathrm{~m}$ level of Willwood Formation (lower Eocene), sec. 33, T49N, R95W, Big Horn County, Wyoming.

is invariably less than that in coeval $A$. abbotti. This difference in crown height correlates with lesser development of posterobuccal distention of the $\mathrm{p} 4$ crown as well as with actual height of the p4 protoconid with respect to the trigonid height of $\mathrm{ml}$. 
TABLE 8-Comparative statistics for cheek teeth of Absarokius abbotti (Loomis) and $A$. metoecus $\mathbf{n}$. sp. Significant differences between them are indicated by ${ }^{*}(P<0.01)$ and ${ }^{* *}(P<0.001)$.

\begin{tabular}{|c|c|c|c|c|c|c|c|c|}
\hline \multirow[b]{2}{*}{ Dimension } & \multicolumn{4}{|c|}{ A. abbotti } & \multicolumn{4}{|c|}{ A. metoecus } \\
\hline & $\mathbf{n}$ & OR & $\bar{x}$ & $s$ & $\mathbf{n}$ & OR & $\bar{x}$ & $s$ \\
\hline p3 L & 57 & $1.50-2.10$ & 1.74 & 0.137 & 11 & $1.60-2.00$ & 1.76 & 0.109 \\
\hline p3 W & 57 & $1.40-2.20$ & 1.73 & 0.146 & 11 & $1.50-1.90$ & 1.69 & 0.132 \\
\hline p4 L & 113 & $2.00-2.75$ & 2.32 & 0.146 & 31 & $2.00-2.50$ & $2.23^{*}$ & 0.129 \\
\hline $\mathrm{p} 4 \mathrm{~W}$ & 111 & $1.90-2.80$ & 2.22 & 0.169 & 31 & $1.90-2.40$ & $2.12^{*}$ & 0.146 \\
\hline p4 H & 104 & $2.90-3.75$ & 3.24 & 0.197 & 29 & $2.50-3.00$ & $2.79^{* *}$ & 0.135 \\
\hline $\mathrm{m} 1 \mathrm{~L}$ & 132 & $2.10-2.70$ & 2.39 & 0.107 & 50 & $2.10-2.50$ & $2.33^{*}$ & 0.118 \\
\hline $\mathrm{ml} \mathrm{W}$ & 132 & $1.85-2.50$ & 2.16 & 0.117 & 49 & $1.70-2.45$ & 2.12 & 0.134 \\
\hline $\mathrm{m} 2 \mathrm{~L}$ & 136 & $2.10-2.65$ & 2.33 & 0.117 & 56 & $2.10-2.60$ & 2.32 & 0.121 \\
\hline $\mathrm{m} 2 \mathrm{~W}$ & 133 & $1.90-2.45$ & 2.16 & 0.106 & 56 & $1.80-2.40$ & 2.14 & 0.127 \\
\hline P3 L & 14 & $1.80-2.40$ & 2.05 & 0.160 & 9 & $1.95-2.50$ & 2.19 & 0.204 \\
\hline P3 W & 15 & $2.20-2.90$ & 2.45 & 0.235 & 9 & $2.30-2.90$ & 2.58 & 0.245 \\
\hline P4 L & 27 & $2.10-2.60$ & 2.37 & 0.160 & 20 & $2.10-2.70$ & 2.33 & 0.162 \\
\hline P4 W & 27 & $3.00-3.80$ & 3.36 & 0.216 & 19 & $2.85-3.60$ & 3.28 & 0.186 \\
\hline M1 L & 34 & $2.00-2.40$ & 2.23 & 0.099 & 26 & $2.00-2.45$ & 2.22 & 0.120 \\
\hline M1 W & 34 & $3.10-3.80$ & 3.39 & 0.190 & 25 & $3.00-3.70$ & 3.33 & 0.196 \\
\hline M2 L & 40 & $1.90-2.20$ & 2.07 & 0.079 & 23 & $1.85-2.40$ & 2.06 & 0.126 \\
\hline M2 W & 39 & $3.50-4.30$ & 3.83 & 0.231 & 23 & $3.30-4.20$ & 3.77 & 0.215 \\
\hline
\end{tabular}

Hypodigm. - The holotype and the following specimens:

1) Willwood Formation, Bighorn Basin, Wyoming-USGS 484, 486, 491, 496, 498, $506,1195,1437,3846,3848,3855,3880$, 5951, 5952, 5963, 5980, 5987, 8256, 9146, 9164, 9171, 9175, 9176, 9182, 9197, 9199, $9213,9214,9910,10054,10061,12195-$ $12198,12199,12200,12201, ? 12202$, ?12203, 12208, ?12222, ?12223, 12226, $12231,15410,15416,16432-16435,16436$, $16437,16441,16445,16447,16448,16451$, $16453,16455,16456,16458-16461$; YPM $17483,17484,17485,17488,18685,18692$, $18693,18710,19861,23178,24415,26218$, 27796, 27868, 28232, 28248, 28317, 35098; DPC 1257, 1342, 1413, 2985.

2) Wind River Formation, Wind River Basin, Wyoming-USNM 22267.

3) Huerfano Formation, Huerfano Basin, Colorado-AMNH 55154, 55155.

Distribution. -425-680 m levels of Willwood Formation (middle and upper lower Eocene; middle Bunophorus Interval Zone through lower part of Upper Heptodon Range Zone of Schankler, 1980); Bighorn Basin, Wyoming. Wind River Formation (middle or upper lower Eocene), Wind River Basin, Wyoming. Huerfano Formation locality III (upper lower Eocene), Huerfano Basin, Colorado.

Etymology.-Latin metoecus, stranger, resident alien; in allusion to the probably im- migrant status of this species in the Bighorn Basin.

Diagnosis. -P3-M2 and p4-m2 smaller in mean size than in $A$. abbotti and all other species of Absarokius except for smaller molars of $A$. gazini n. sp. Second lower premolar present in contrast to advanced Tetonius, Pseudotetonius, $A$. nocerai n. comb., $A$. australis $\mathrm{n}$. sp., and $A$. witteri, and $\mathrm{p} 2$ relatively large in contrast to Tetonius matthewi. Ratio of p3/p4 size relatively large in contrast to $A$. witteri, $A$. gazini n. sp., $A$. australis n. sp., and Pseudotetonius, and $\mathrm{p} 3$ with two distinct roots in contrast to advanced Tetonius, Pseudotetonius, $A$. australis n. sp., and Absarokius nocerai $\mathrm{n}$. comb. Lower fourth premolar lower crowned than in all other $A$ bsarokius species and with less pronounced posterobuccal ventral distension of crown. First lower molar with paraconid relatively close to metaconid in early samples; paraconid becoming anteriorly removed in later samples, as occurs in $A$. nocerai n. comb. and $A$. gazini n. sp. M12 of geologically younger specimens less transverse than in $A$. abbotti and with somewhat enlarged trigon basins, and tendency toward crenulated enamel and confluence of postprotocrista with postcingulum.

Discussion. - Absarokius metoecus includes parts of samples referred by earlier workers to $A$. abbotti and by Szalay (1976) to both $A$. abotti (sic) and $A$. noctivagus. Recognition of a new species is justified by the 
wide size distribution in $\mathrm{p} 4$ and $\mathrm{m} 1$ and, especially in $\mathrm{p} 4$ height. The latter character is significantly less in Absarokius metoecus than in $A$. abbotti (Table 8). Recognition of two species of Bighorn Basin Absarokius is also warranted by evolutionary trends indicating that the sample here called $A$. metoecus diverged morphologically through time from that of the more conservative $A$. abbotti; the $A$. metoecus line eventually producing a new form, Strigorhysis.

See additional discussion in section on Evolution in genus Absarokius. See Appendices 18 and 19 for measurements.

\section{AbSAROKIUS GAZINI n. sp.}

Figures 30.2, 44.1

Absarokius, near $A$. abbotti GAZIN, 1962, p. 37, Pl. 5, fig. 3.

Absarokius abotti (sic) Szalay, 1976, p. 231, fig. 48 (part).

Holotype.-UW 1644, right mandibular fragment with $\mathrm{p} 3-\mathrm{m} 3$ and alveoli anterior to p3; Wasatch Formation (late Wasatchian); University of Wyoming locality V-58003, $\mathrm{SW}^{1 / 4}, \mathrm{NE}^{1 / 4}$, sec. 10, T24N, R100W, Sweetwater County, Wyoming.

Hypodigm. - The holotype and'UW 11372 , $11373,21521,21522,21523,21524 ;$ AMNH 14672.

Distribution. - Wasatch Formation (late Wasatchian), type locality and UW locality V-58004, Sweetwater County, Wyoming; Wind River Formation (late Wasatchian), Cottonwood Draw.

Etymology.-For C. L. Gazin, who first recognized the unusual attributes of UW 1644 , and in acknowledgment of his many contributions to our understanding of early primates in general and the Omomyidae in particular.

Diagnosis. - Size of $\mathrm{p} 3$ and $\mathrm{m} 1$ similar to that of very small $A$. metoecus or smaller; much smaller than in $A$. abbotti. Lower fourth premolar tall and large as in $A$. abbotti and with posterobuccal ventral enamel distension as seen in that species; all in contrast to $A$. metoecus. Lower fourth premolar smaller than in $A$. nocerai n. comb. and $A$. witteri. Lower second premolar present in contrast to $A$. nocerai n. comb., $A$. witteri, and $A$. australis n. sp., and p3 with two roots in contrast to $A$. nocerai $\mathrm{n}$. comb. and $A$. australis n. sp. Sec- ond lower molar much smaller than in $A$. metoecus and all other species, and $\mathrm{m} 1$ trigonid buccolingually compressed, with median paraconid far in advance of other trigonid cusps, as in $A$. nocerai $\mathrm{n}$. comb. and advanced $A$. metoecus, but in contrast to all other Absarokius species.

Discussion. - Seven of these specimens are from two nearby localities and, together with AMNH 14672 from the Wind River Basin, certainly represent a single new species of $A b$ sarokius. Szalay (1976, p. 238, fig. 48) hesitantly assigned UW 1644 to Absarokius $a b$ botti. Gazin (1962, p. 37) earlier described his specimen, commenting (as did Szalay) on its abnormally small molars. In UW 1644, m1-2 are indeed exceedingly small (especially narrow), and fall far outside the small end of the size range for molars in the smallest Bighorn Basin species, $A$. metoecus. The molars are slightly larger in the UW referred material.

In length of p3 and p4, UW 1644 and AMNH 14672 could be assigned to $A$. $m e$ toecus; however, the diagnostic p4 crown height in UW 1644 and the morphology of the labial margin of that tooth in both specimens are more typical of that observed for $A$. abbotti. In AMNH 14672, p4 is relatively short as in $A$. metoecus but the remainder of its morphology conforms to that in UW 1644. The p3 is small in Absarokius gazini, and in UW 11373 it is unusually so, the smallest seen in any Absarokius. This tooth is also quite small in Aycrossia and Strigorhysis (e.g., USGS 2021 and 2027, and in UCM 42809, Stucky, 1982). In addition, the $\mathrm{m} 1$ trigonid in both UW 1644 and 11372 appears to be divergently specialized away from the conditions in all other $A$ bsarokius, except $A$. nocerai $\mathrm{n}$. comb. and the most advanced (and youngest) specimens of $A$. metoecus, in the extreme anterior placement of the paraconid. This causes the trigonid to be buccolingually compressed and to have an unusual prowlike anterior apex. The first lower molar in UW 11372 has a tiny parastylid, a cusp otherwise known only in Bridgerian Aycrossia and Strigorhysis.

Incisor alveoli are preserved in the type specimen of Absarokius gazini and in UW 11372 and 11373 . These are somewhat larger than in any other known species of Absarokius and are about intermediate in size be- 

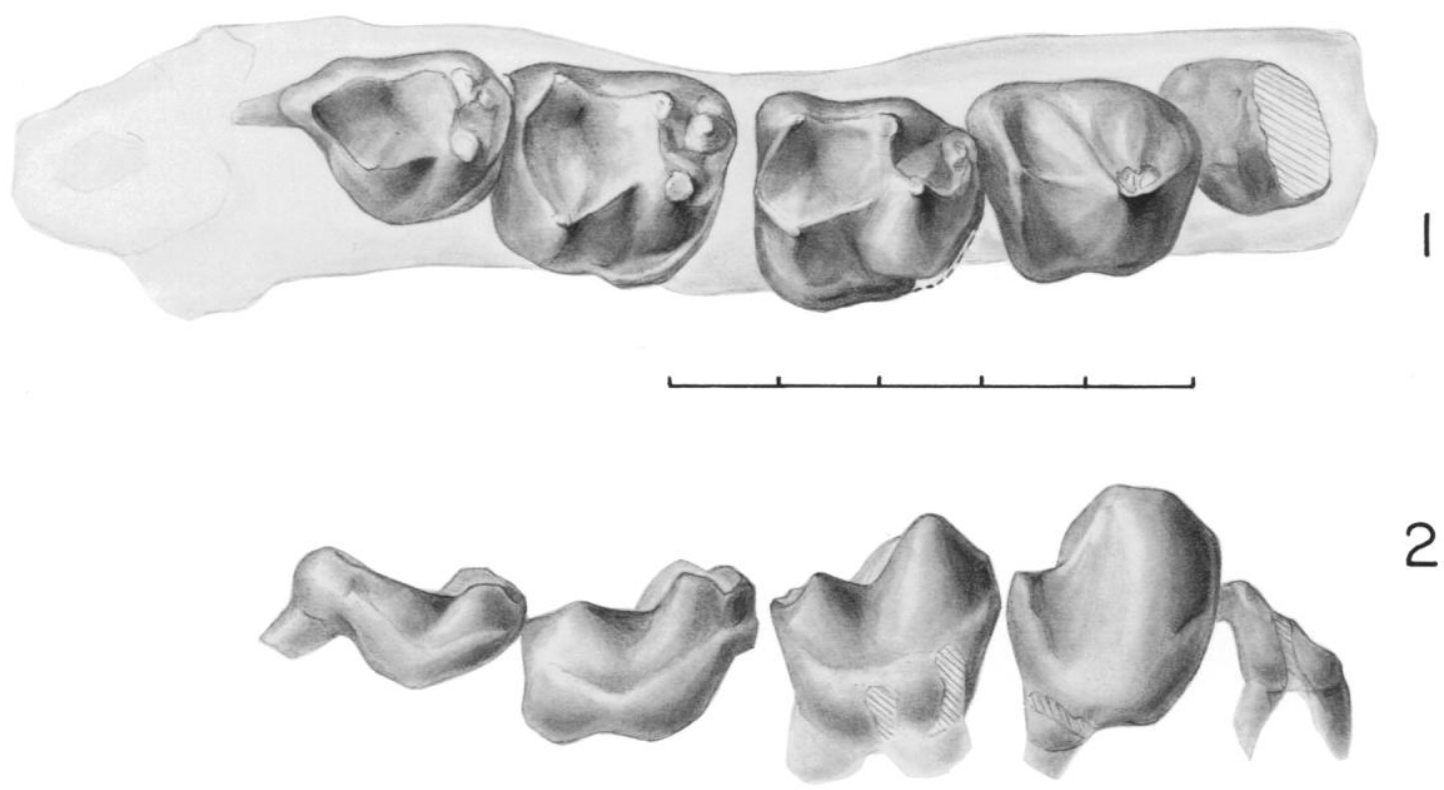

FIGURE 38-Absarokius metoecus n. sp., holotype, USGS 492, right dentary with p4-m3 and part of p3 $(470 \mathrm{~m}) .1,2$, occlusal and lateral views, respectively. Scale is $5 \mathrm{~mm}$.

tween those of $A$. abbotti and Strigorhysis. It is therefore possible that $A$. gazini is an intermediate form or a collateral relative in the A. metoecus-Aycrossia/Strigorhysis lineage. Because the combination of the above characters is unusual and is clearly adequate to
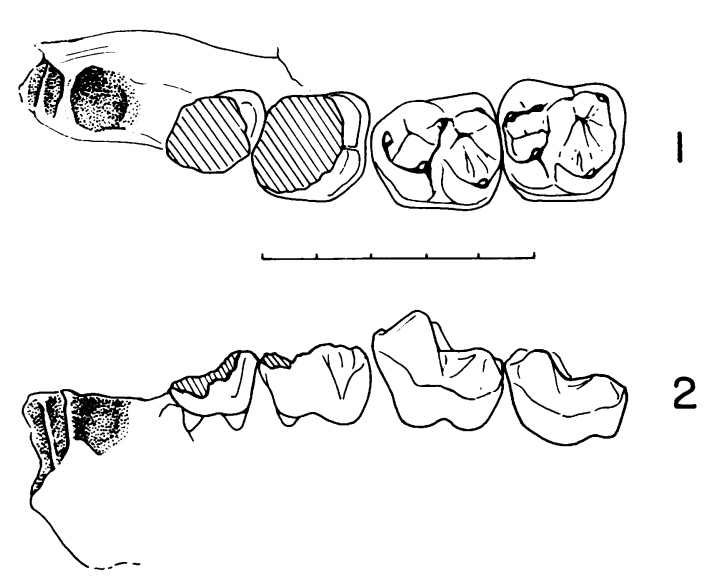

FIGURE 39-Absarokius metoecus n. sp., USGS 8256 , left dentary with $\mathrm{m} 1-2$, part of p3-4, and alveoli of i1-2, c, and p2 (obscured) (470 m). 1 , 2 , occlusal and lateral views, respectively. Scale is $5 \mathrm{~mm}$. diagnose these specimens from all other materials of Absarokius, they are placed in the new species $A$. gazini.

Gazin (1962, p. 37, citing P. O. McGrew for stratigraphic information) reluctantly believed the type specimen of $A$. gazini to have been derived ". . . from the Gray Bull level." If this information is correct, A. gazini would be the first Absarokius reported from rocks of early Wasatchian age. The morphology of the known teeth of $A$. gazini suggests a somewhat higher stratigraphic provenance, probably late Wasatchian. Examination of other mammals from UW locality V-58003 indicates a middle or late Wasatchian age for the type of $A$. gazini, based on the mutual occurrence of Microsyops latidens and Cantius cf. frugivorus. UW 1652, a left p4 referred on the museum label to the condylarth Ectocion sp., actually belongs to a perissodactyl, $X e$ nicohippus or Hyracotherium. This is the only specimen from that locality by which an early Wasatchian age for UW V-58003 might have been surmised. Xenicohippus has a middle and late Wasatchian distribution (Bown and Kihm, 1981). The systematics of Hyracotherium are too poorly understood to be of value in age determinations within the early 

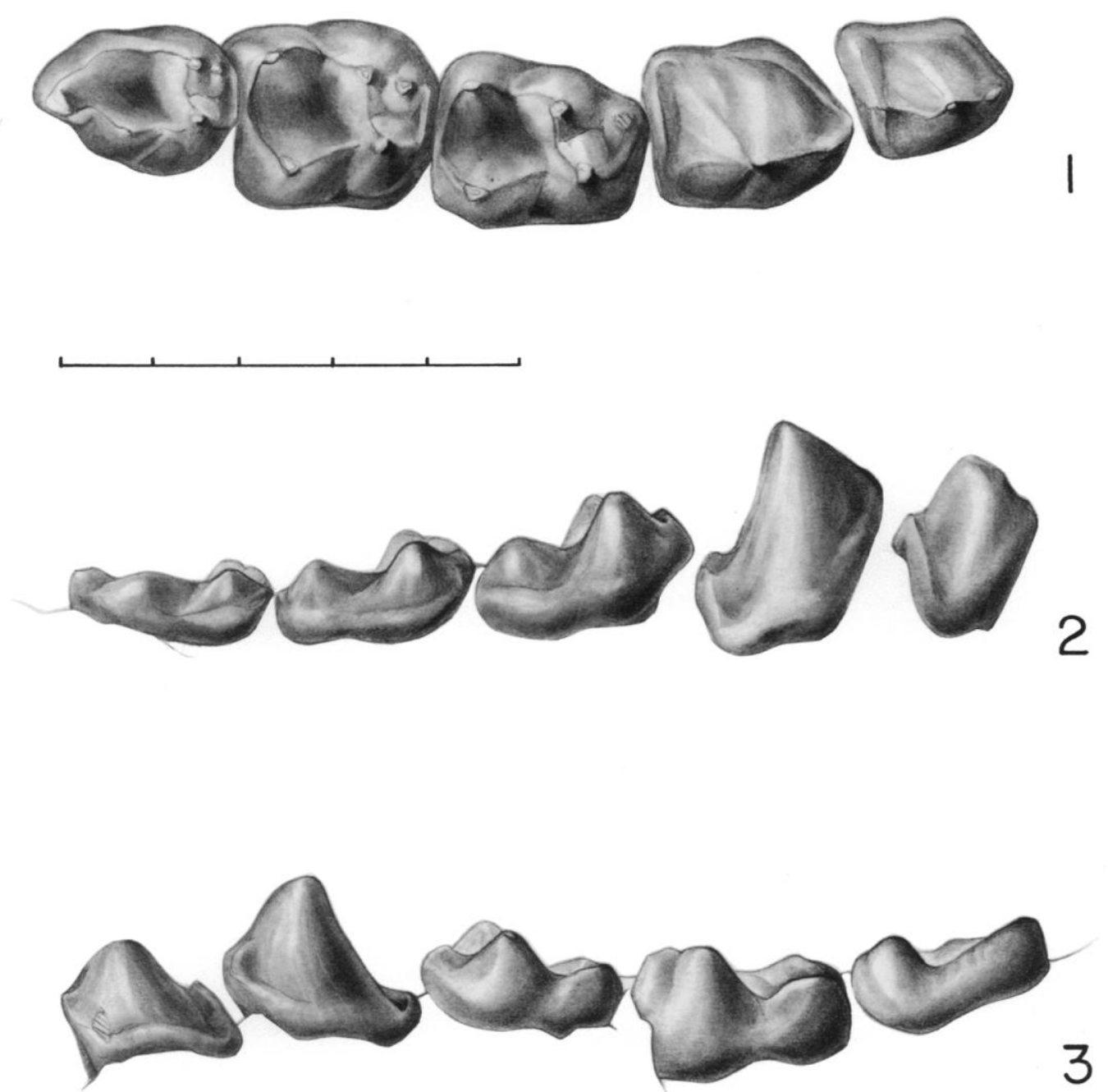

FIGURE 40-Absarokius metoecus n. sp., USGS 5963, right dentary with p3-m3 (519 m). 1-3, occlusal, lateral, and medial views, respectively. Scale is $5 \mathrm{~mm}$.

Eocene. AMNH 14672 is clearly of later Wasatchian ("Lysite") age.

See Appendix 20 for measurements.

\section{ABSAROKIUS NOCERAI} (Robinson, 1966) n. comb. (not figured)

Absarokius noctivagus nocerai RoBINson, 1966, p. 33, Pl. 2, fig. 1 (part).

Absarokius noctivagus Szalay, 1976, p. 238, fig. 51 (part).

Holotype.-AMNH 55215, fragment of left lower jaw with c-m3; locality II, Huerfano Formation, Huerfano Basin, Colorado.
Hypodigm. - The type, AMNH 55270 and 55292.

Distribution. - Locality II, Huerfano Formation, latest Wasatchian (latest early Eocene), Huerfano Basin, Colorado.

Diagnosis. - Lower fourth premolar greatly hypertrophied as in advanced $A$. abbotti and in contrast to $A$. metoecus; molars relatively large in contrast to $A$. gazini and $A$. metoecus. Second lower premolar absent as in $A$. witteri and $A$. australis $\mathrm{n}$. sp., and $\mathrm{p} 3$ single-rooted in contrast to all other $A b s a$ rokius species, except $A$. australis n. sp. Paraconids of m2-3 distinct, appressed to meta- 

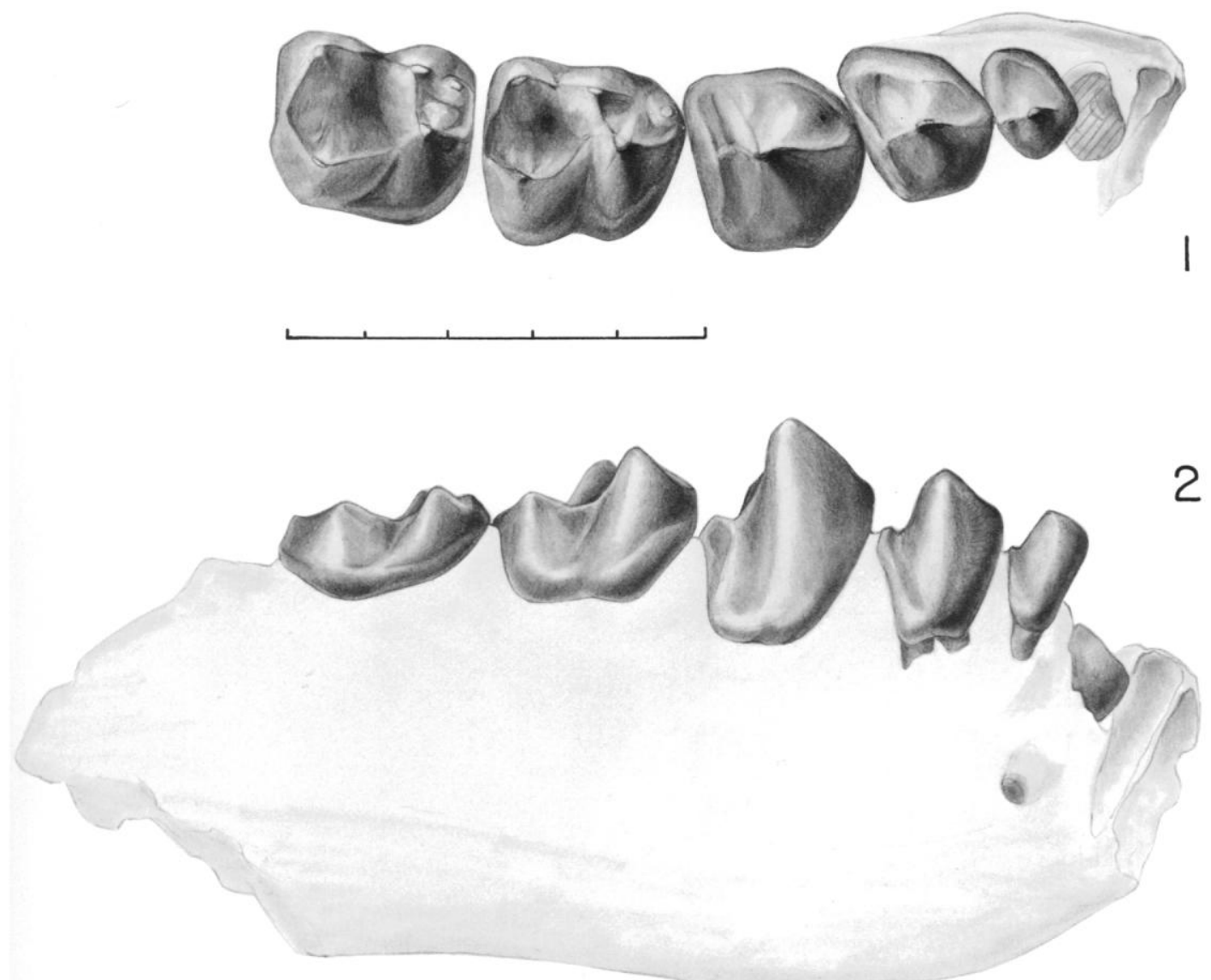

Figure 41-Absarokius metoecus n. sp., YPM 35098, right dentary with p2-m2, root of c, and alveoli of il-2 (570 m). 1, 2, occlusal and lateral views, respectively. Scale is $5 \mathrm{~mm}$.

conids, and $\mathrm{m} 3$ lacking posteriorly enlarged talonid basin-all in contrast to $A$. australis n. sp.

Discussion. - Robinson's (1966) subspecies Absarokius noctivagus nocerai is elevated to specific rank, reflecting the clear loss of $\mathrm{p} 2$ and the presence of but a single p3 root in that species (contra Robinson, 1966, p. 34). Robinson included AMNH 55217, 55218, $55152-55155,55270$, and 55292 as well as the type specimen in his hypodigm of $A$. noctivagus nocerai. AMNH 55270 and 55292 certainly represent $A$. nocerai; however, AMNH 55154 and 55155 belong in $\mathrm{Absa}$ rokius metoecus, 55218 is a new species of Strigorhysis (see below), and 55217 and 55152 belong in the new Absarokius species described below. AMNH 55153 was not seen. Absarokius nocerai appears to be an ad- vanced derivative of the Absarokius abbotti lineage in which reduction in antemolar size and number has begun, in parallel with earlier developments in the Tetonius-Pseudotetonius line.

See Appendix 20 for measurements.

AbSAROKIUS AUSTRALIS n. sp. Figures 44.4, 45, 46.1

Absarokius noctivagus nocerai RoBINSON, 1966, p. 33 (part).

Absarokius noctivagus Szalay, 1976, p. 238 (part).

Holotype.-AMNH 55152, right mandibular fragment with $\mathrm{p} 3-\mathrm{m} 3$ and root for canine (Figures 44.4, 45); Huerfano Formation locality III (late Wasatchian), Huerfano Basin, Colorado. 

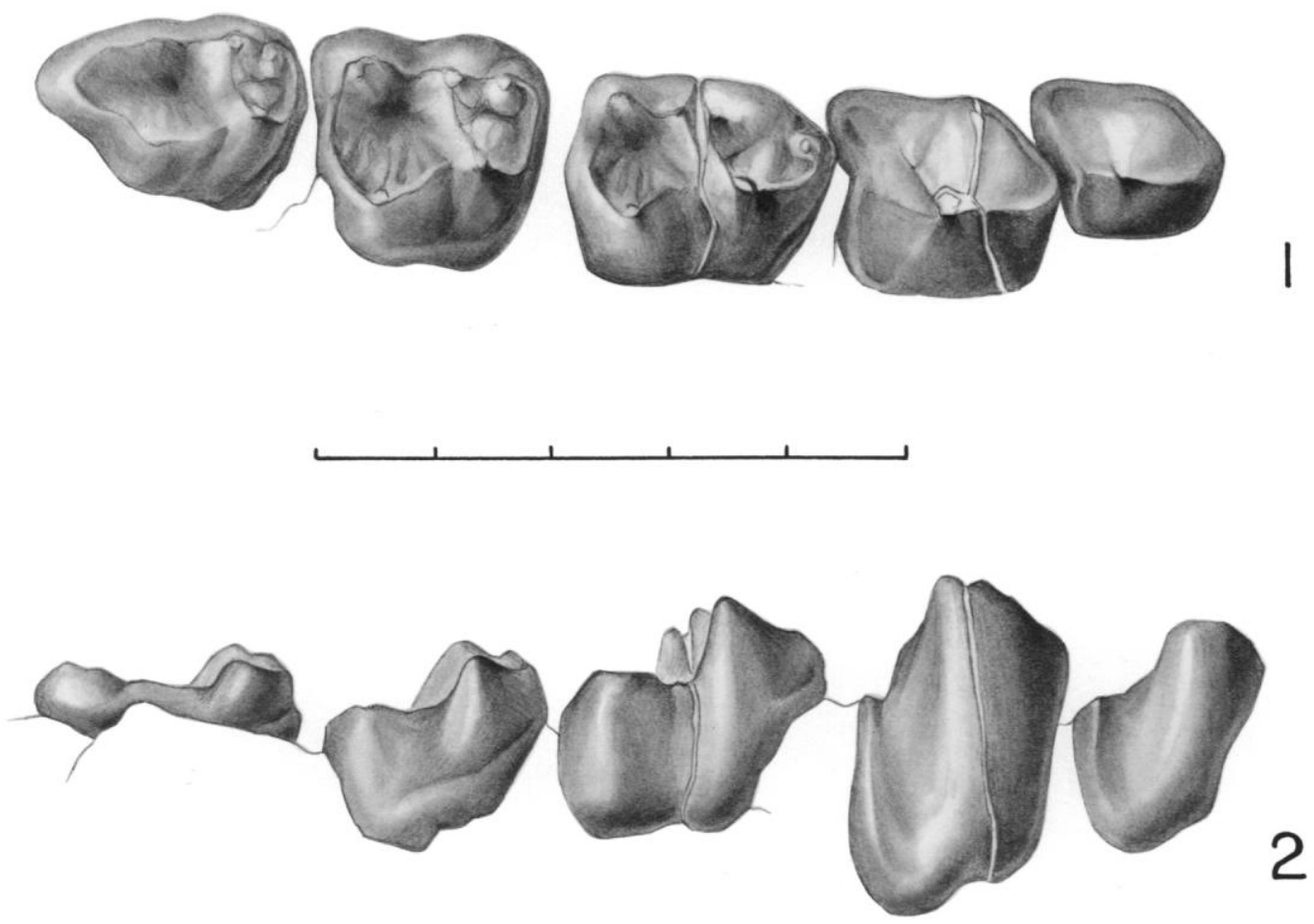

FIGURE 42-Absarokius metoecus n. sp., USGS 10054, right dentary with p3-m3 (590 m). 1, 2, occlusal and lateral views, respectively. Scale is $5 \mathrm{~mm}$.

Hypodigm. - The type and AMNH 55217, right mandibular fragment with $\mathrm{m} 1-3$.

Distribution. - Huerfano Formation locality III (late Wasatchian), Huerfano Basin, Colorado.

Etymology. - Latin australis = southern; the Huerfano Basin is the southernmost area yielding specimens of Absarokius.

Diagnosis. - Second lower premolar absent, p3 very small with respect to p4, and $\mathrm{m} 2-3$ talonid basins faintly crenulate-all as in $A$. nocerai and $A$. witteri and in contrast to $A$. abbotti, $A$. metoecus, and $A$. gazini. Third lower premolar single-rooted as in $A$. nocerai and in contrast to all other Absarokius species. Molars large and with $\mathrm{m} 1$ paraconid not situated far anteriorly in contrast to $A$. gazini and $A$. nocerai; $\mathrm{p} 4$ not greatly hypertrophied as in $A$. nocerai and $A$. witteri. Paraconid of m1-2 much smaller than metaconid and not appressed to that cusp on $\mathrm{m} 2$, paraconid on $\mathrm{m} 3$ absent and $\mathrm{m} 3$ with greatly expanded posterior (third) lobe; all in contrast to other Absarokius species.
Discussion. - Robinson (1966) included AMNH 55152 and 55217 in his hypodigm of Absarokius noctivagus nocerai and (with $A$. nocerai) they were placed in $A$. noctivagus by Szalay (1976). However, Absarokius australis clearly differs from $A$. nocerai in having a much less hypertrophied $\mathrm{p} 4$, in the trigonid constructions of $\mathrm{m} 1-2$, in lacking the paraconid on $\mathrm{m} 3$, and in the great posterior expansion of the talonid basin on $\mathrm{m} 3$. With the exception of Steinius and Strigorhysis, the m3 talonid construction is unique among North American anaptomorphines and mirrors its development in the early Eocene adapid Cantius. Nonetheless, $A$. australis is probably closely related to $A$. nocerai by virtue of the loss of p2, the very small p3 with respect to p4, loss of one p3 root, and development of faint crenulation on the molar talonids.

See Appendix 20 for measurements.

Genus Strigorhysis Bown, 1979

Absarokius Robinson, 1966, p. 33; SzAlay, 1976, p. 229 (part); SzALAY, 1982, p. 155. 

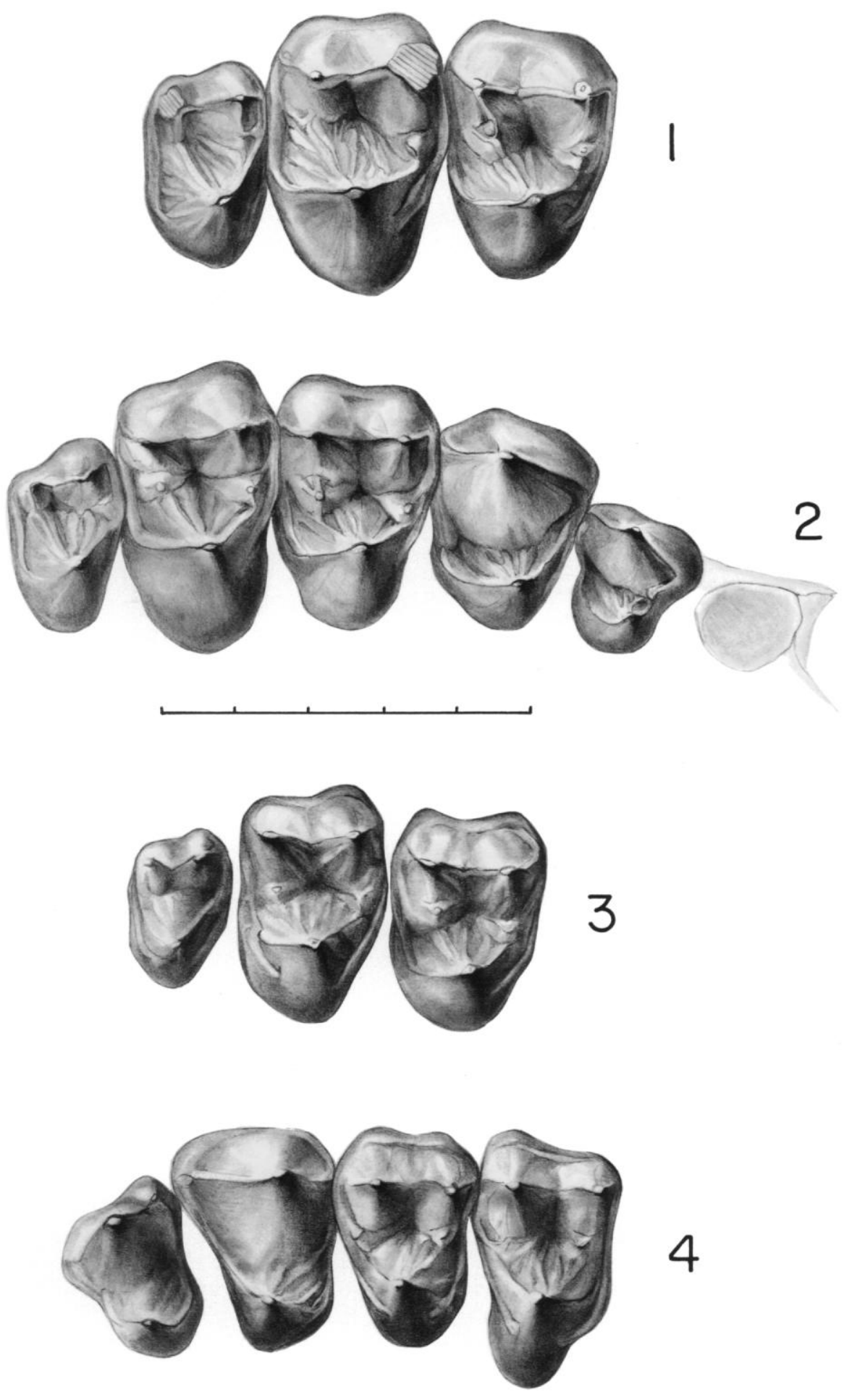

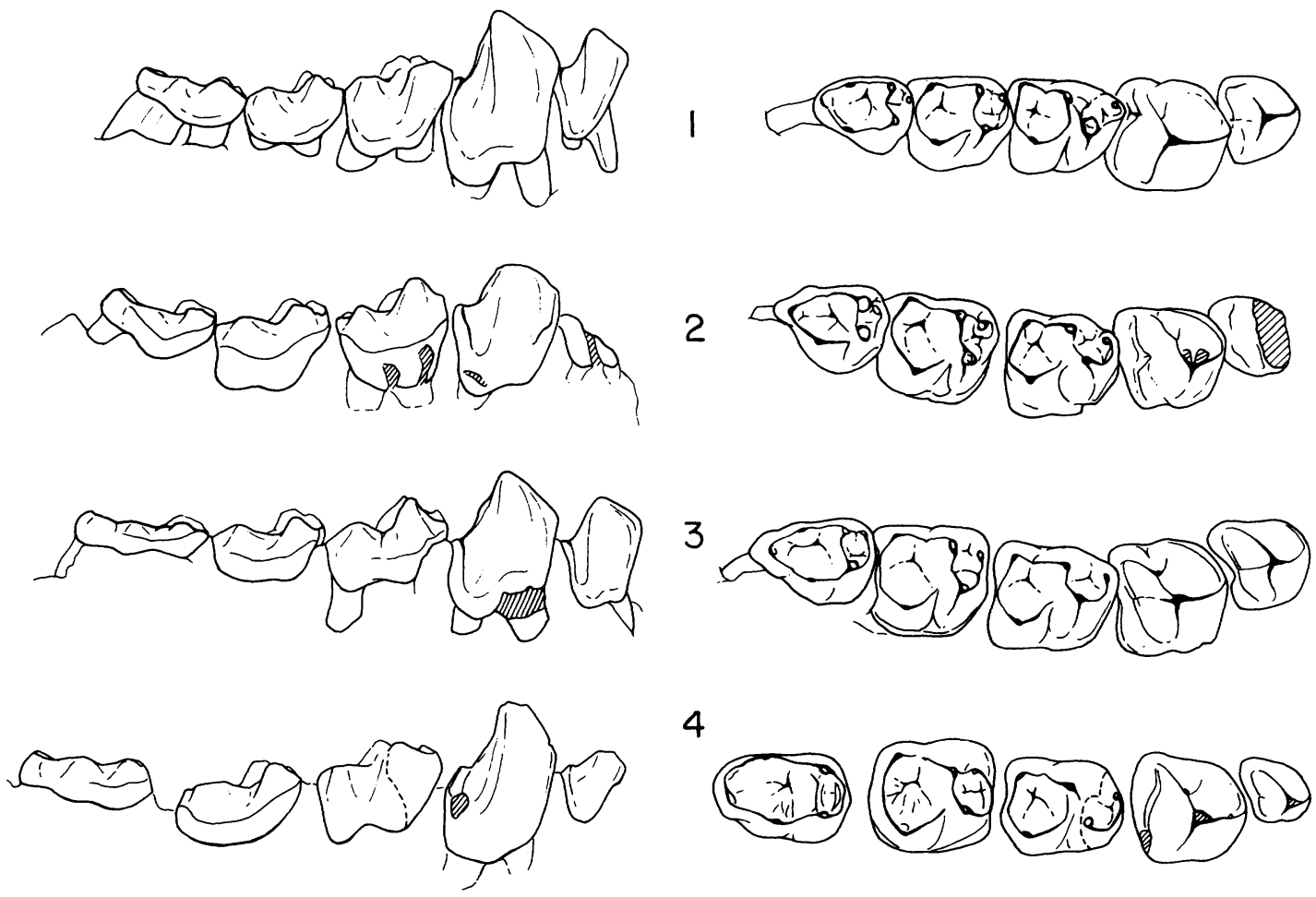

4

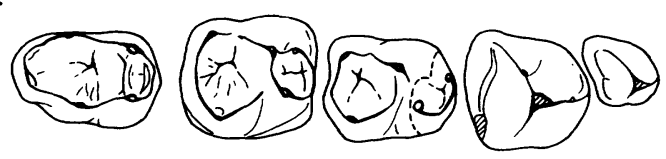

FIGURE 44-Type specimens of Absarokius in lateral (left) and occlusal (right) views. 1, A. gazini n. sp., UW 1644, right p3-m3. 2, A. metoecus, USGS 492, right p3 (part), p4-m3. 3, A. abbotti (Loomis), ACM 3479, right p3-m3. 4, A. australis n. sp., AMNH 55152, right p3-m3 (ml restored from AMNH 55217). Scale is $5 \mathrm{~mm}$.

Strigorhysis Bown, 1979b, p. 60, figs. 2-4. Anaptomorphus GINGERICH, 1981, p. 358 (part).

Type species. - Strigorhysis bridgerensis Bown, 1979b, p. 60.

Included species. $-S$. bridgerensis, $S$. rugosus, and $S$. huerfanensis $\mathrm{n}$. sp.

Distribution. - Late Wasatchian (early Eocene), Bighorn and Wind River Basins of Wyoming and Huerfano Basin of Colorado; early Bridgerian (middle Eocene), Absaroka Range, Wyoming.

Revised diagnosis. - Differs from its closest relative, Absarokius, in the following fea- tures: relatively large lower incisors (nearly as large as in Tetonius), $\mathrm{P} 3 / \mathrm{p} 3$ generally smaller with respect to $\mathrm{P} 4 / \mathrm{p} 4$, Nannopithexfold fully connected to postcingulum, upper molars relatively less transverse and with more lingually expanded bases, parastylid present on $\mathrm{m} 1$, and moderately to strongly crenulated enamel on the molars (especially the uppers).

Discussion. - Recovery of additional specimens of Strigorhysis from the Aycross Formation and the first specimens of this rare genus from the upper part of the Willwood Formation both clarify its relationship to $A b$ -

\footnotetext{
FIGURE 43-Upper teeth of Absarokius and Strigorhysis. 1, S. rugosus Bown, holotype, USNM 250553, right M1-3 (Bridgerian, Aycross Formation). 2, S. bridgerensis Bown, holotype, USNM 250556, palate, right P3-M3 shown (Bridgerian, Aycross Formation). 3, A. metoecus n. sp., YPM 17488, right M1-3 (680 m). 4, A. metoecus, USNM 22267, left P3-M2 (Wind River Basin). Upper scale applies to 1 and 2, lower scale to 3 and 4 . Scale is $5 \mathrm{~mm}$.
} 

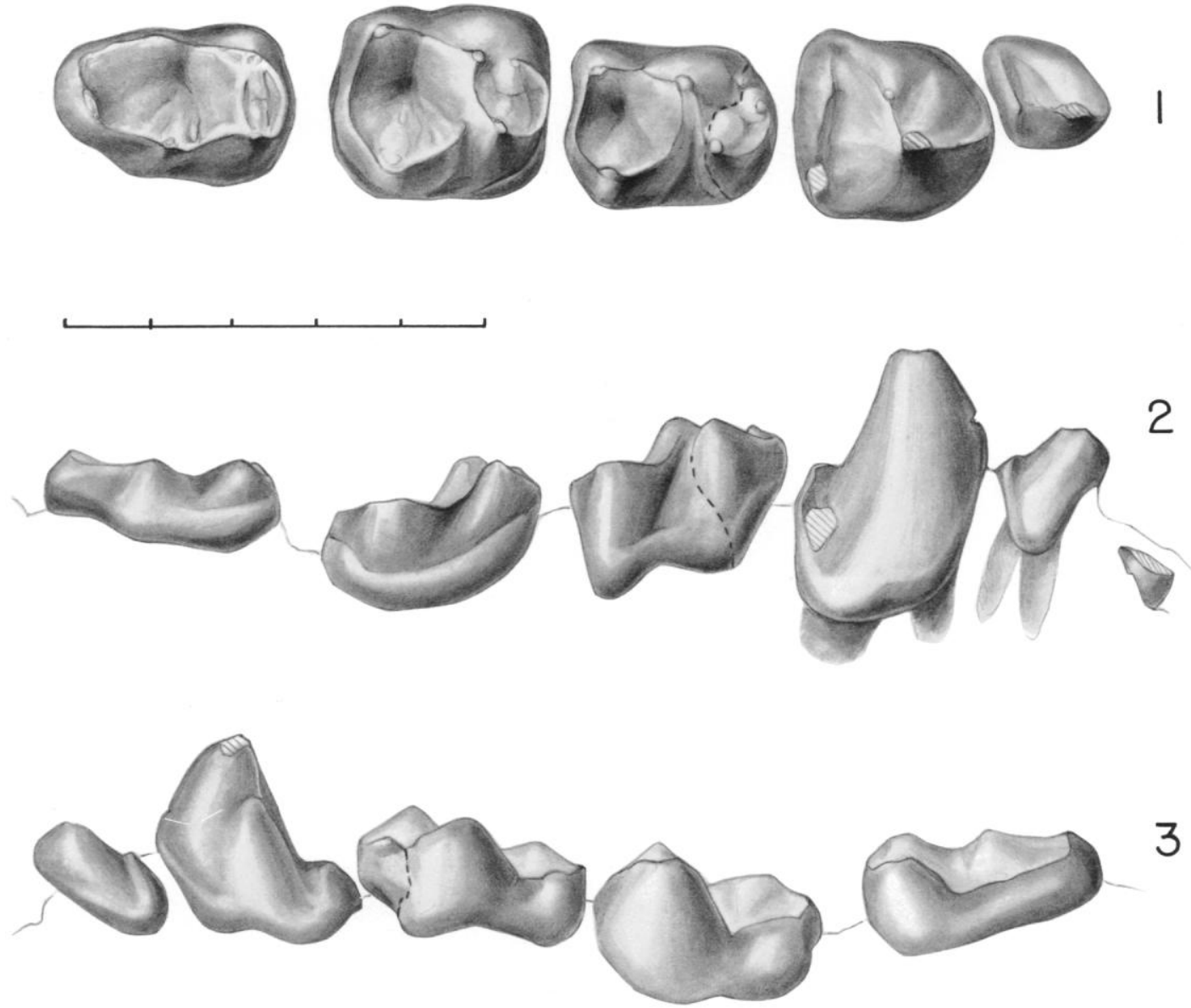

FIGURE 45-Absarokius australis $\mathrm{n}$. sp., holotype, AMNH 55152, right dentary with $\mathrm{p} 3-\mathrm{m} 3$ and root of $\mathrm{c} ; \mathrm{m} 1$ restored from AMNH 55217 (Huerfano III). 1-3, occlusal, lateral, and medial views, respectively. Scale is $5 \mathrm{~mm}$.

sarokius and underscore its distinctiveness from that genus and from Anaptomorphus. Strigorhysis was probably derived from a species of Absarokius close to A. metoecus, and enough is now known of both $A$. metoecus and $S$. bridgerensis to make advanced specimens of the former and generalized specimens of the latter extremely difficult to distinguish.

Bown (1979b) described Strigorhysis bridgerensis and $S$. rugosus along with two other genera, Aycrossia and Gazinius, from the middle Eocene Aycross Formation of the Absaroka Range, Wyoming. Additional materials of Aycrossia were described by Stucky (1982) from rocks of the Wind River Formation that he assigned to Robinson's (1966) "Gardnerbuttean" Land Mammal subage (proposed as a Land Mammal Age by Robinson).

Gingerich $(1981$, p. 359$)$ suggested that all of the Aycross omomyids are better placed

FIGURE 46-Absarokius and Strigorhysis, SEM stereophotographs. 1, A. australis n. sp., holotype, AMNH 55152, right p3-m3 and root of c (Huerfano III). 2, S. huerfanensis n. sp., holotype, AMNH 55218, left p4-m3 (Huerfano I). 3, 4, Strigorhysis cf. bridgerensis Bown, USGS 16438, left m1-2 (about $710 \mathrm{~m}$ ); USGS 16439, left M1-3 (about $710 \mathrm{~m}$ ). Scale is $5 \mathrm{~mm}$. 
EOCENE PRIMATES FROM WYOMING
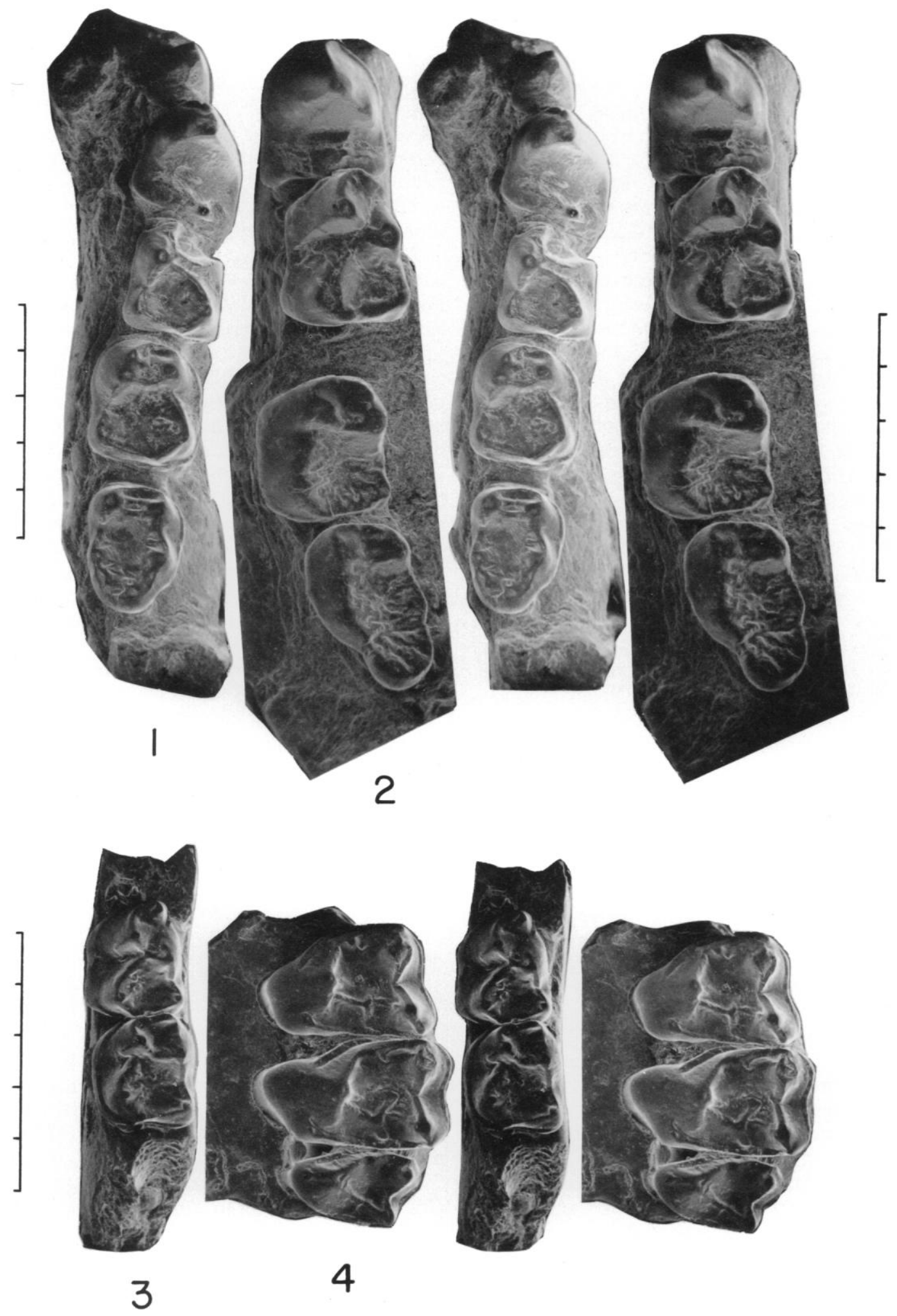
in Anaptomorphus aemulus Cope, whereas Szalay (1982, p. 155-157) transferred both Aycrossia and Strigorhysis to Absarokius. Both authors in part argued their viewpoints from historically understandable bases. At the time of their studies, $A$. metoecus was undescribed and unrecognized in the large Yale collection of Bighorn Basin Absarokius. As detailed above, the younger members of that species were developing many characters in parallel with Aycrossia and Strigorhysis-enough so to strongly indicate a close evolutionary relationship. With Szalay's recognition of only Absarokius abbotti and $A$. noctivagus as valid species of Absarokius in the Bighorn Basin, and ignoring the stratigraphic disposition of the Absarokius samples, it is easy to see how comparison of advanced $A$. metoecus (in the guise of $A$. abbotti or $A$. "noctivagus") with Aycrossia and/or Strigorhysis would lead him to the view that the latter two genera are synonyms of Absarokius. Moreover, Szalay (1976, p. 238) believed YPM 17488 (a very young and advanced specimen of $A$. metoecus) to be from the Wind River Basin and (1976, fig. 49) recorded the same specimen as having been found in the Huerfano Formation of Colorado. This critical specimen is actually from the Bighorn Basin.

Both Absarokius and Anaptomorphus aemulus are typified by retention of primitively small lower incisors (see Szalay, 1976, figs. $10,12,13)$. The lower incisors in both $A y$ crossia and Strigorhysis are not only much larger than in either Anaptomorphus or $A b$ sarokius, but are nearly as large as in Tetonius (Figures 48 and 49 show incisor alveoli of Strigorhysis and Aycrossia, respectively). Because the size of the lower incisors is one of the diagnostic features separating different genera of anaptomorphines (also acknowledged by Szalay, 1976), it is difficult, in conjunction with the other diagnostic criteria outlined by Bown (1979b), to reconcile $A y$ crossia and Strigorhysis with either Anaptomorphus or Absarokius.

Regarding the upper molar structure in Strigorhysis (Figures 43.1, 43.2, 46.4, 47) and Aycrossia, the posterior extension of the postprotocrista to confluence with the postcingulum, the raising of the talon basin to the level of the trigon basin, and crenulation of enamel on the floors of the molar basins are all diagnostic derived features first heralded in the later part of the Absarokius metoecus line. Both Aycrossia and Strigorhysis are probably derivatives of Absarokius, very possibly $A$. metoecus. Nonetheless, the rather large p4 in both Aycrossia and Strigorhysis is more similar to that in early Absarokius abbotti. This morphology might be evidence of relationship to that species, or instead that p4 enlarged convergently with (and later than) the similar development in the $A$. abbott $i$ line.

The Aycrossia lovei-Strigorhysis bridgerensis sample from Vass Quarry in the Aycross Formation (Bown, 1979b, 1982) is now quite large. Study of the entire sample reveals the interrelationship between these species to be complicated. Variability in the sample appears to be similar to that in coeval samples of Tetonius matthewi and Tetonius sp. and of Absarokius metoecus and A. abbotti, in which the broad variability in a rather confined stratigraphic interval seems to reflect an early stage of cladogenetic diversification. Clarification of any taxonomic implications for the genera Aycrossia and Strigorhysis requires further study and larger samples, both from Vass Quarry and from higher levels of the Aycross Formation.

The most advanced members of the $A b$ sarokius metoecus-Strigorhysis lineage are Strigorhysis rugosus (from the Aycross Formation-see Figure 43.1) and Strigorhysis huerfanensis n. sp. (from the Huerfano Formation-see below).

\section{STRIGORHYSIS cf. S. BRIDGERENSIS Bown, 1979 \\ Figures 46.3, 46.4}

Strigorhysis bridgerensis Bown, 1979b, p. 61, figs. 2-4.

Anaptomorphus aemulus GINGERICH, 1981, p. 358 (part).

Absarokius lovei Szalay, 1982, p. 155 (part).

Referred specimens. -USGS 16438, 16439, 16440, 16462.

Discussion. - Four specimens, comprising two lower jaws with m1-2, a lower jaw with $\mathrm{m} 1$, and a maxillary fragment with $\mathrm{M1}-3$, represent the first specimens of Strigorhysis from the Willwood Formation, and are very close in morphology to Strigorhysis bridgerensis (Figures 43.2, 48, 49) from the middle Eocene Aycross Formation of the Absaroka Range. The Willwood Strigorhysis comes from locality D-1651, about $100 \mathrm{~m}$ beneath 

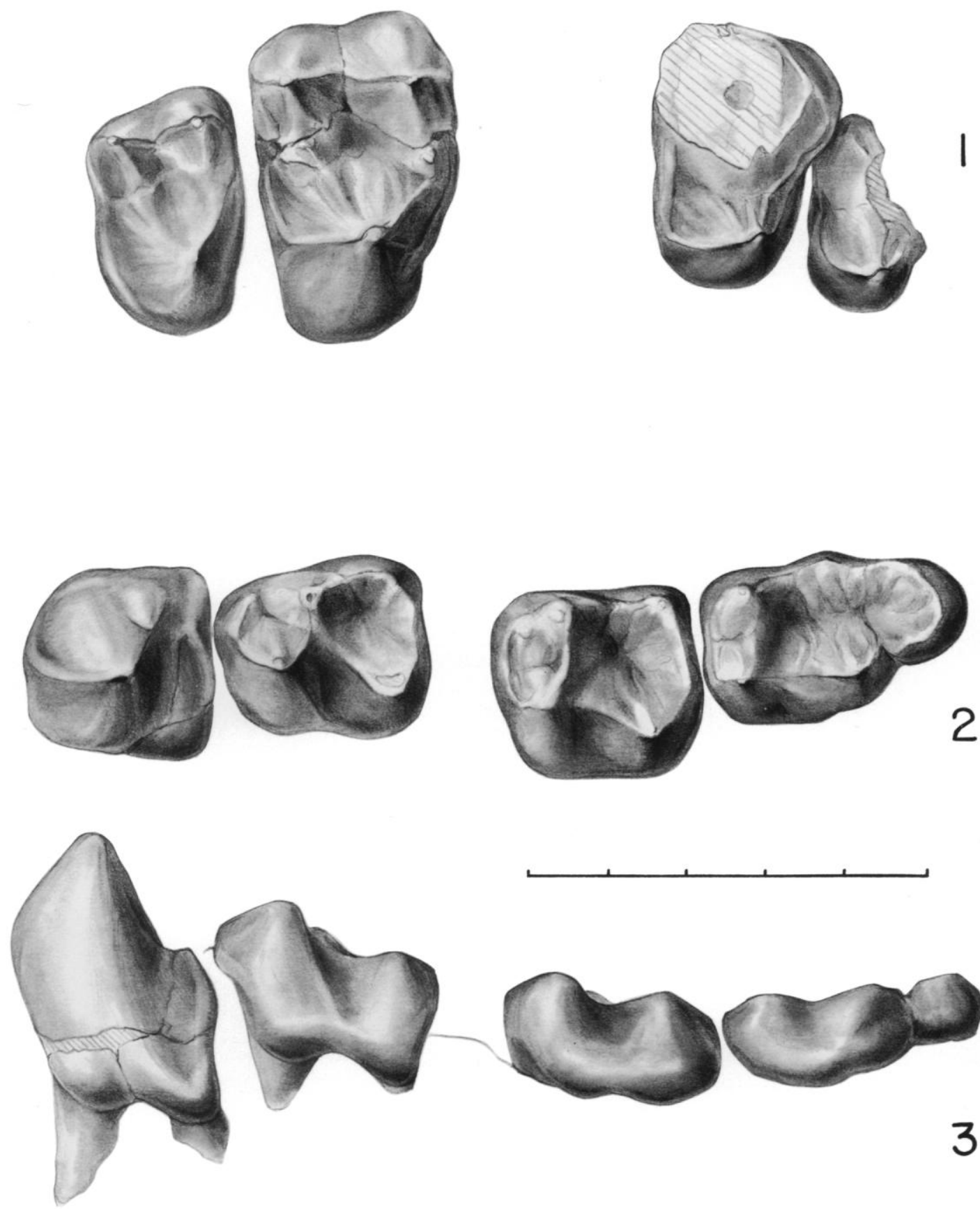

FIGURE 47-Strigorhysis huerfanensis n. sp., holotype, AMNH 55218. 1, right maxilla with P3-4 (part), M2-3; 2, 3, left dentary with p4-m3 in occlusal and lateral views, respectively (Huerfano 1 ). Scale is $5 \mathrm{~mm}$.

the base of the Tatman Formation, a level of clear late early Eocene age and containing the palaeothere Lambdotherium and the advanced esthonychine tillodont Megalestho- nyx (Rose, 1972) associated with the omomyid primates.

These specimens differ only slightly from middle Eocene Strigorhysis and in ways in 

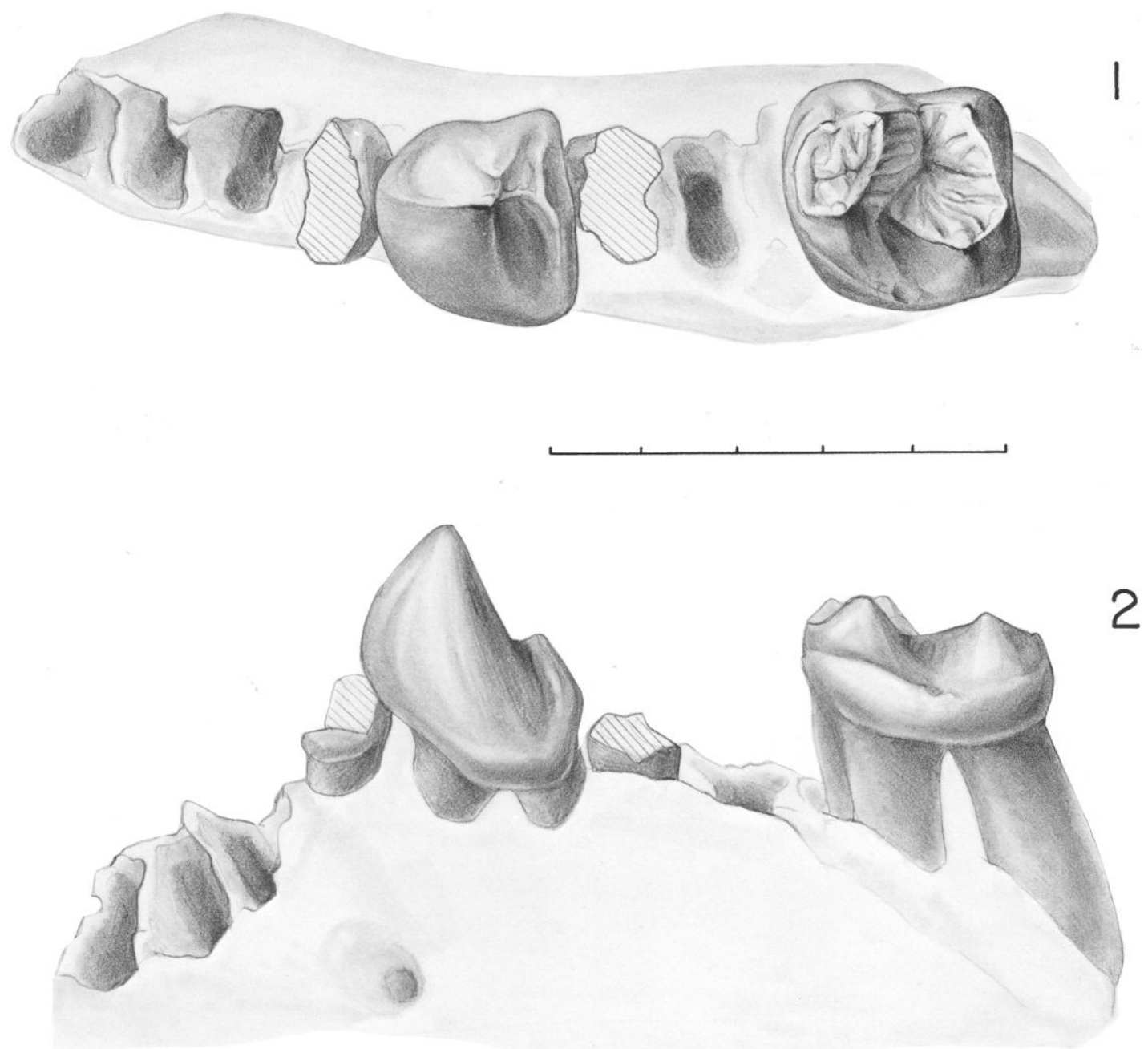

FIGURE 48-Strigorhysis bridgerensis Bown, USNM 250559, left dentary with p4, $\mathrm{m} 2$, and roots or alveoli of i1-2, c, and $\mathrm{ml}$ (Bridgerian, Aycross Formation). 1, 2, occlusal and lateral views, respectively. Scale is $5 \mathrm{~mm}$.

which they closely resemble the most advanced specimens of Absarokius metoecus. There is only incomplete confluence of the postprotocrista with the postcingulum on M1, less completely developed than in the type sample of $S$. bridgerensis. Moreover, the extent of lingual distension of the crowns of M1-2 is less than in S. bridgerensis, resembling most closely its development in USNM 22267 (Figure 43.4), Absarokius metoecus from the Wind River Basin. In contrast, the lower molars are almost identical to those in $S$. bridgerensis, except that the $\mathrm{m} 1$ parastylid is much smaller. Willwood Strigorhysis cf. bridgerensis occurs stratigraphically above the youngest known Willwood sample of $\mathrm{Absa}$ rokius metoecus, but locality D-1651 has not yet been related directly to the measured Willwood section.

See Appendix 21 for measurements.

STRIGORHYSIS HUERFANENSIS n. sp. Figures 46.2, 47

Absarokius noctivagus nocerai RoBINson, 1966, p. 33 (part).

Absarokius noctivagus SzALAY, 1976, p. 238 (part).

Holotype.-AMNH 55218, fragmentary left mandible with $\mathrm{p} 4-\mathrm{m} 3$ and right maxillary fragment preserving P3-4 (damaged), M2-3 

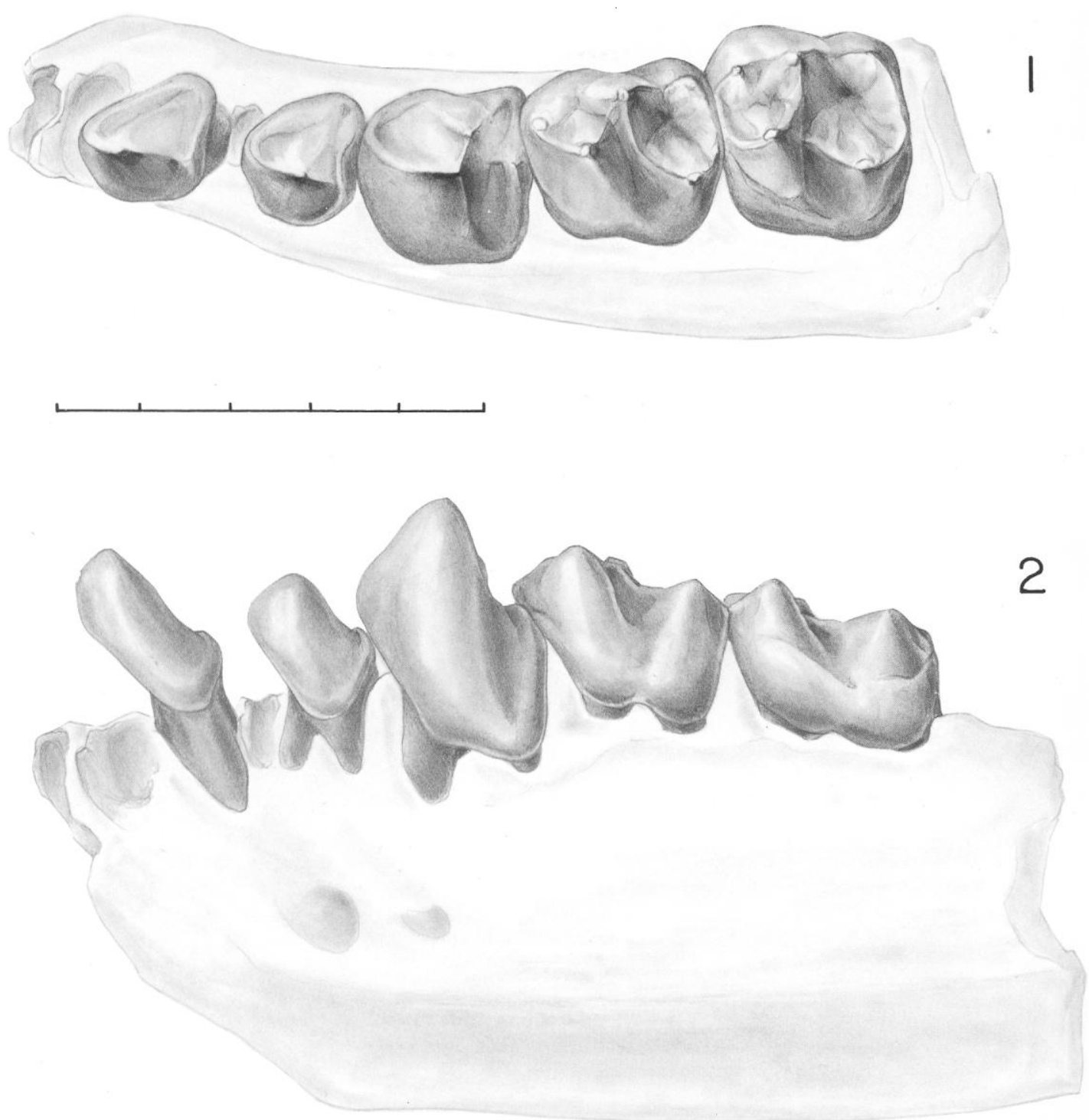

FigURE 49-Aycrossia lovei Bown, USGS 2021, left dentary with c, p3-m2, and alveoli of i1-2 and p2 (Bridgerian, Aycross Formation). 1, 2, occlusal and lateral views, respectively. Scale is $5 \mathrm{~mm}$.

(Figure 47); Huerfano Formation locality I (latest Wasatchian or early Bridgerian), Huerfano Basin, Colorado.

Hypodigm. - The type only.

Distribution. - As for the holotype.

Etymology.-Huerfano, and Latin suffix -ensis, of the Huerfano.

Diagnosis. - Upper and lower teeth 10-25\% larger than in S. bridgerensis and S. rugosus; M2 trigon basin relatively much broader buccolingually and M3 overall much larger with respect to M2 than in latter two species. Mo- lar basin enamel crenulation less pervasive than in $S$. rugosus, developed about as in $S$. bridgerensis. Lower fourth premolar much taller and $\mathrm{m} 2$ talonid broader than in $S$. bridgerensis, and $\mathrm{m} 3$ with much more expanded third (posterior) lobe, approaching the condition in Absarokius australis.

Discussion. - The new species Strigorhysis huerfanensis is the second non-Absaroka Range record of Strigorhysis. In its larger teeth, taller p4, proportionately larger M3, and expanded third lobe of $\mathrm{m} 3, S$. huerfa- 


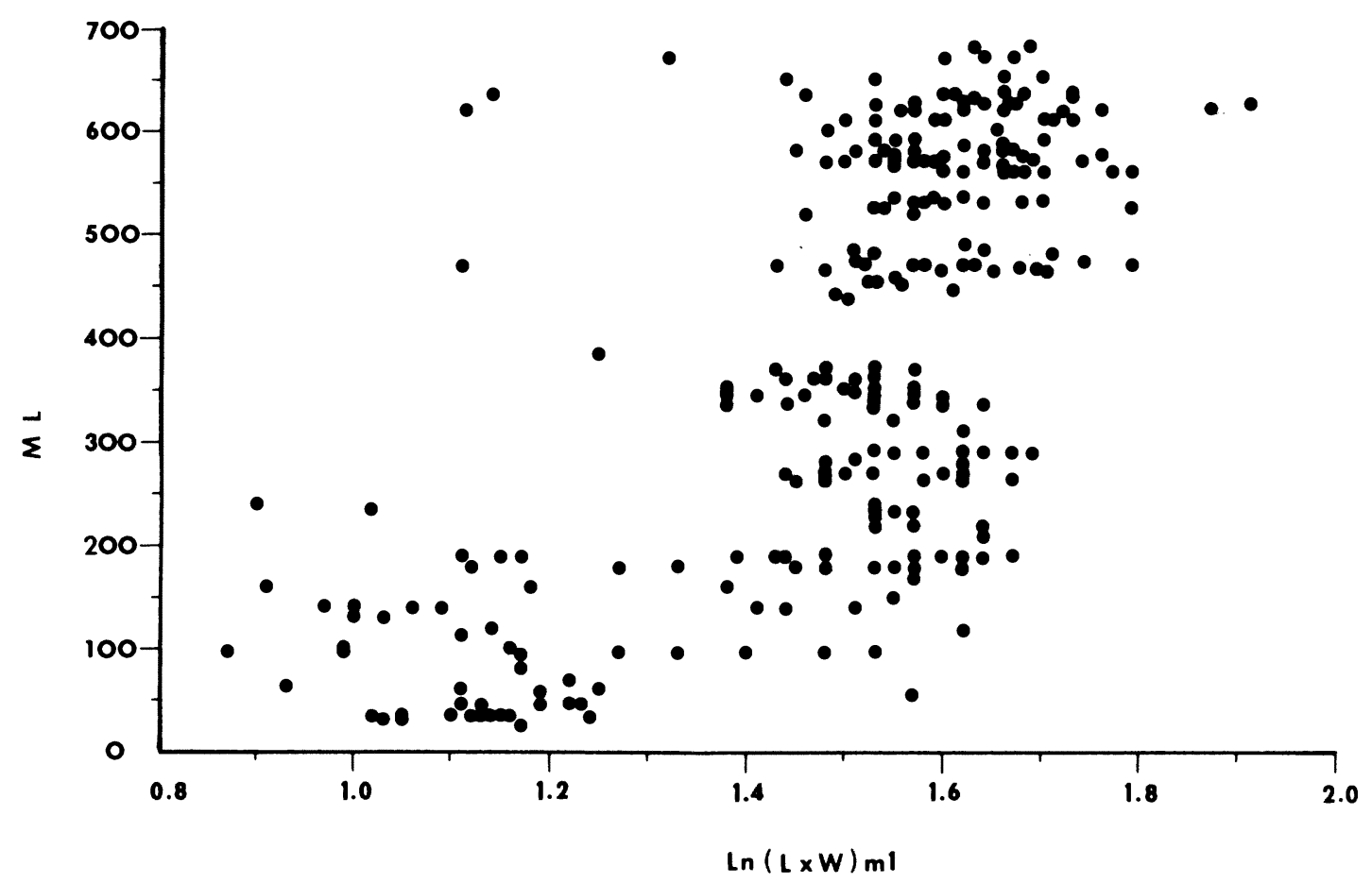

FIGURE 50-Plot of $\mathrm{m} 1$ area (natural logarithm of length $\times$ width) in omomyid specimens from the central and southern Bighorn Basin; ordinate is stratigraphic level (meters) in the Willwood Formation. Some points represent more than one specimen. See Figure 53 for taxonomic designations.

nensis is advanced over Aycross Strigorhysis. However, the more transverse M2 and less crenulated enamel in the molar basins are more generalized than in both $S$. bridgerensis and $S$. rugosus. On this evidence, it seems most likely that the line leading to $S$. huerfanensis diverged from the Absarokius metoecus-S. bridgerensis line near the time of Strigorhysis cf. bridgerensis in the upper part of the Willwood Formation.

See Appendix 21 for measurements.

EVOLUTION OF ANAPTOMORPHINE PRIMATES IN THE BIGHORN BASIN

The systematics section precedes this section simply to provide names for the fossils considered. To a large extent, however, allocation of specimens to taxa came (indeed, was possible) only after detailed study of the stratigraphic occurrences of different temporally-stratified morphologies, without prior consideration of the taxonomic names. The critical importance of stratigraphic data in all parts of this study cannot be overemphasized.

This section seeks to interpret modes and patterns of evolution in Bighorn Basin anaptomorphines and some allied forms from elsewhere. This interpretation has emerged from detailed analyses of morphology in a stratigraphic framework. Aspects considered include dental formulae, crown morphology, root configuration, and tooth size and proportions. As an initial exercise, basic trends and temporal patterns in tooth size can be portrayed in scatter diagrams plotting tooth size against stratigraphic level (e.g., Gingerich, 1974a, 1976, 1980a). Figure 50 shows such a plot prior to identification of the taxa involved. In successive plots (Figures 51-56) the taxonomic assignments of each specimen are indicated (data for these plots are listed in the appendices). Although these plots reveal that some taxa are readily distinguished by tooth size alone (and that certain teeth allow better discrimination of taxa than others), it is also evident that consideration of tooth size alone is insufficient to separate some taxa; it may underestimate actual diversity and, more significantly, fails to reveal some of the more interesting evolutionary trends.

In the following pages, trends and patterns 


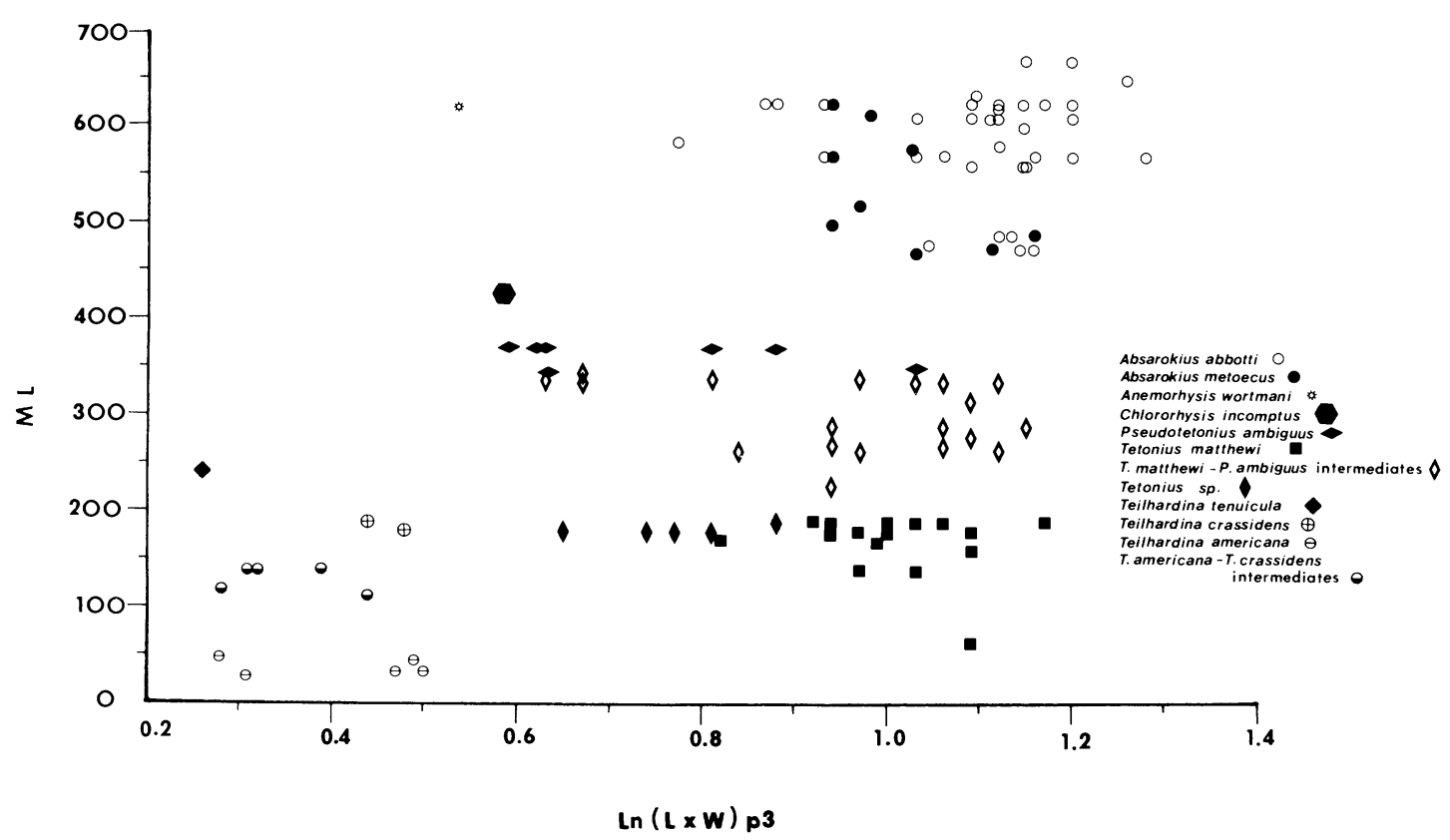

FIGURE 51 -Plot of $\mathrm{p} 3$ area (natural logarithm of length $\times$ width) in omomyid specimens from the central and southern Bighorn Basin; ordinate is stratigraphic level (meters) in the Willwood Formation. Some points represent more than one specimen. Symbols indicate taxonomic designations given in Systematics section; data are from appendices.

of dental evolution are summarized for the three principal clades of anaptomorphine primates from the Bighorn Basin: TeilhardinaAnemorhysis, Tetonius-Pseudotetonius, and Absarokius.

Evolution in the Teilhardina-Anemorhysis clade. - Until very recently, knowledge of the small anaptomorphines here assigned to Teilhardina and Anemorhysis was restricted to a handful of specimens allocated to European Teilhardina belgica or to various species of the North American genera Anemorhysis and Tetonoides (e.g., Szalay, 1976). Perusal of the relevant literature reveals that, apart from $T$. belgica, there has been little agreement on how to assign these specimens or how the various taxa were interrelated. Several factors contributed to this instability: the paucity of specimens, their fragmentary nature, their widely scattered geographic occurrences, and the uncertainty of their relative stratigraphic positions. As a result of collecting efforts in the Bighorn and Clark's Fork Basins during the past decade there are now more than 150 new specimens of these small primates, nearly all with good stratigraphic control. These fossils provide much new an- atomical information and constitute a substantial new data base on which to reappraise their taxonomy, interrelationships, and evolution. Based on the fossils now available, two valid genera are recognized, Teilhardina and Anemorhysis, each with four species. Three species of Teilhardina and two of Anemorhysis are known from the Wasatchian of the Bighorn Basin.

Both Teilhardina and Anemorhysis show trends toward progressive molarization of $\mathrm{p} 4$, as well as foreshortening of the dentary (more extreme in Anemorhysis) and concomitant reduction of anterior teeth, but enlargement of i1. In Teilhardina, elevation and enlargement of the paraconid and especially the metaconid of $\mathrm{p} 4$ resulted in a more molariform trigonid (also seen to a lesser degree in p3), but the talonid remained simple. In Anemorhysis, molarization of $\mathrm{p} 4$ involved the talonid, which became broader and basined as the cristid obliqua shifted buccally. Cheek teeth (especially p3-4) became relatively broader and shorter in Teilhardina, partly resulting from basal inflation. Lower molars of Anemorhysis show less basal inflation, have more peripheral cusps, and are squared pos- 


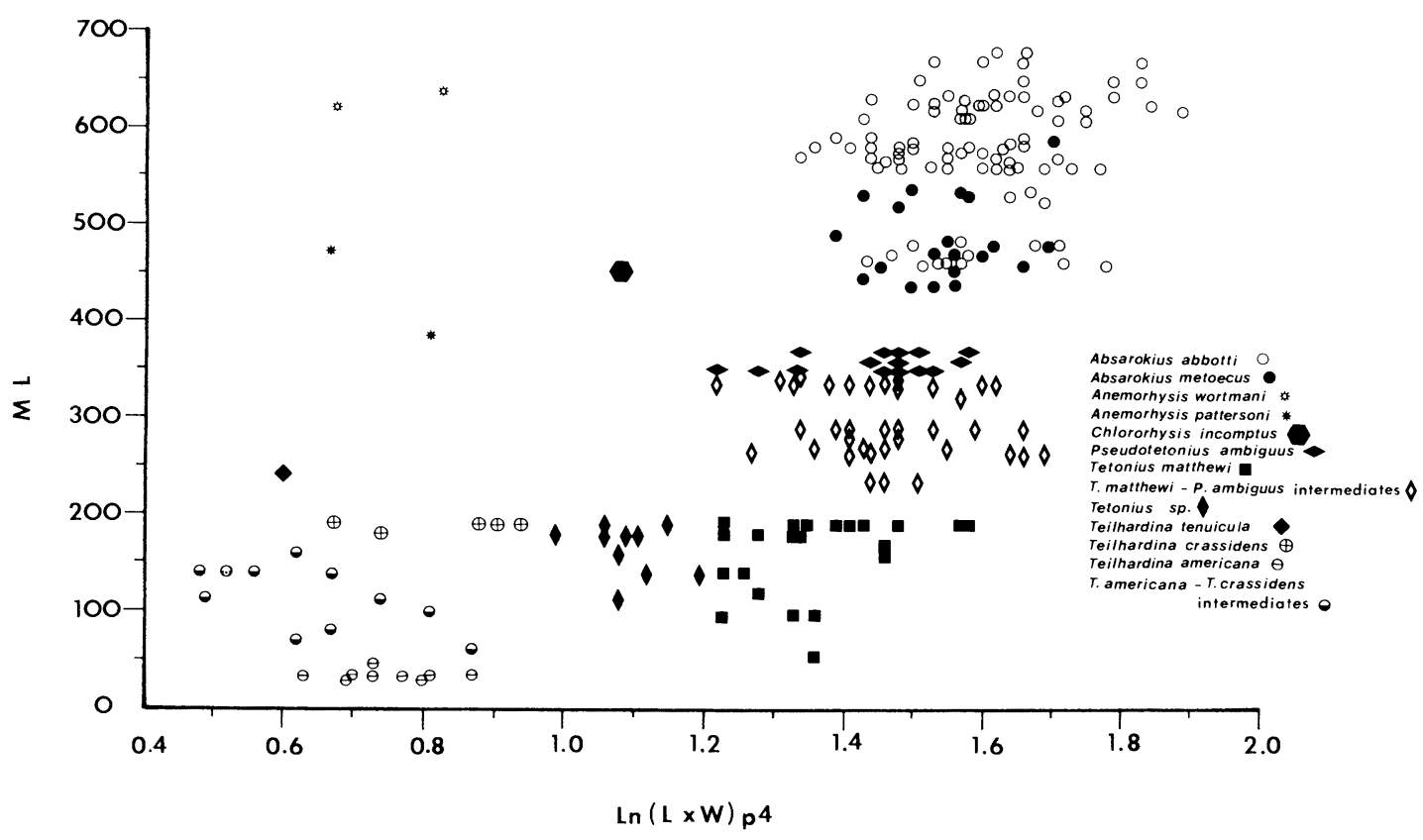

FIGURE 52-Plot of $\mathrm{p} 4$ area in omomyid specimens from the central and southern Bighorn Basin (see Figure 51).

teriorly, but so few specimens are known that it is premature to speculate about trends in these qualities.

The fossil record of Teilhardina in the Bighorn Basin, though much better than that of Anemorhysis, is less densely documented than those of either Tetonius-Pseudotetonius or Absarokius. Consequently, evolutionary pathways are less clear, less well established, and unresolved problems remain. Nonetheless, it is possible to outline, with reasonable confidence, the general pattern of morphological evolution and relationships. It is notable that this pattern has been strengthened with each new discovery.

Teilhardina appears to comprise at least two closely allied lineages in the Bighorn Basin, $T$. americana giving rise to both $T$. crassidens and $T$. tenuicula through a series of transitional stages. The following interpretation is based principally on the record preserved in the southern and central Bighorn Basin, supplemented by that from the Clark's Fork Basin.

Teilhardina americana is the oldest and most primitive known North American omomyid (see also Savage et al., 1977). Comparisons of the large samples now available of both $T$. americana and $T$. belgica indicate, as detailed earlier, that these are very closely allied species that differ only in relatively $\mathrm{mi}$ nor features (Rose and Bown, 1986). Teilhardina belgica is apparently slightly older and probably was in or very near the direct ancestry of T. americana. The latter is slightly larger and characterized by the following more derived traits: 1) cheek teeth relatively broader (more basally inflated); 2) upper molars with "Nannopithex-fold," broad stylar shelves, stronger and more extensive cingula; 3) p4 with slightly higher metaconid (Figure 57), p1 consistently very small or absent; lower canine smaller; and 4) i1 possibly larger. All omomyid specimens found in the lowest $50 \mathrm{~m}$ (more precisely, the $25-46 \mathrm{~m}$ interval) of the Willwood Formation in the southern Bighorn Basin (50-125 m in the Clark's Fork Basin) display uniform morphology characteristic of $T$. americana (Figure 5). Variability in size and morphology within this sample is entirely consistent with that typical of a single species (fossil or extant). This is the only interval in the Willwood Formation in which only one omomyid species is known and it is the only one yielding specimens with the morphology of $T$. americana. 


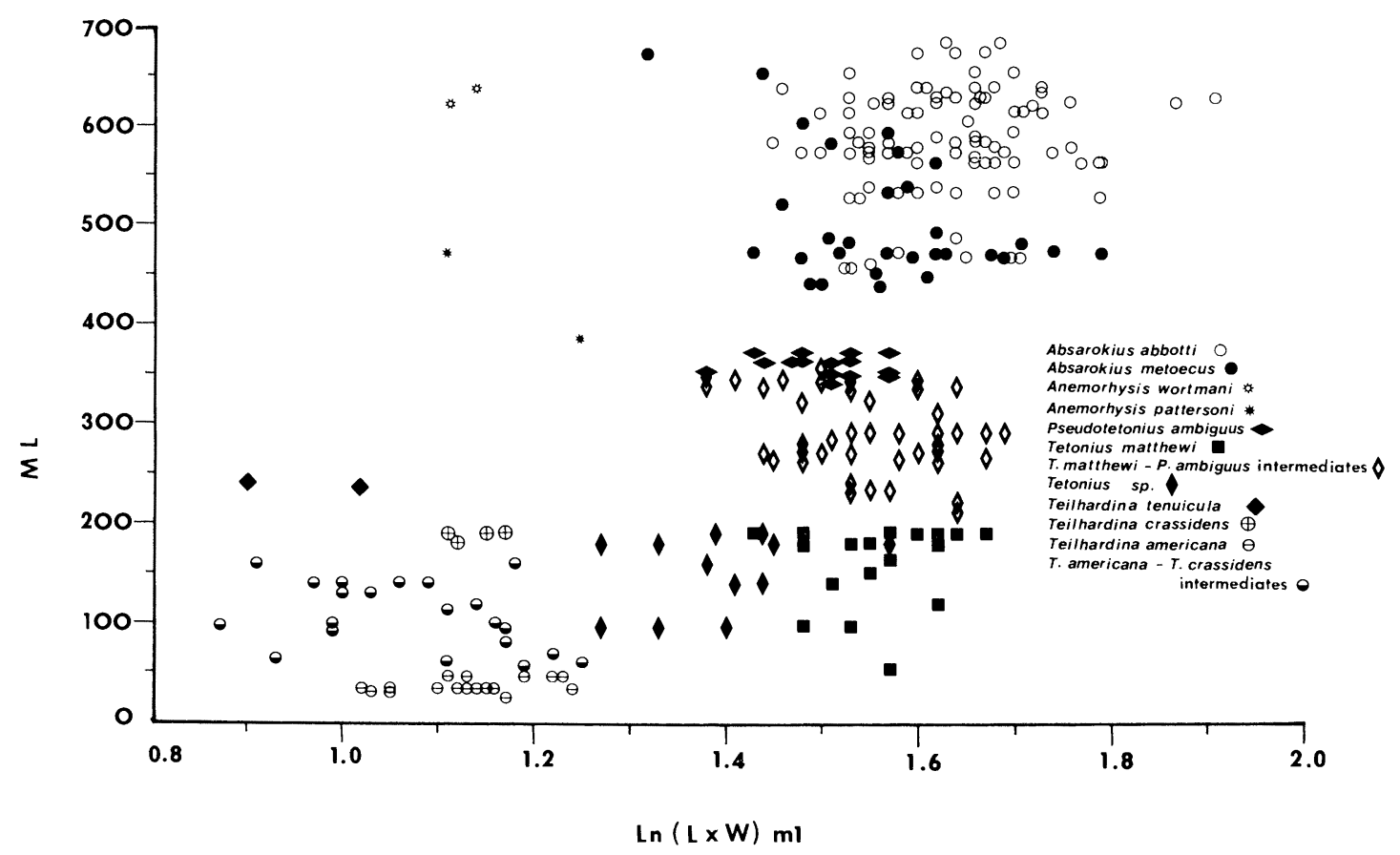

FIGURE 53-Plot of $\mathrm{m} 1$ area in omomyid specimens from the central and southern Bighorn Basin (see

Figure 51).

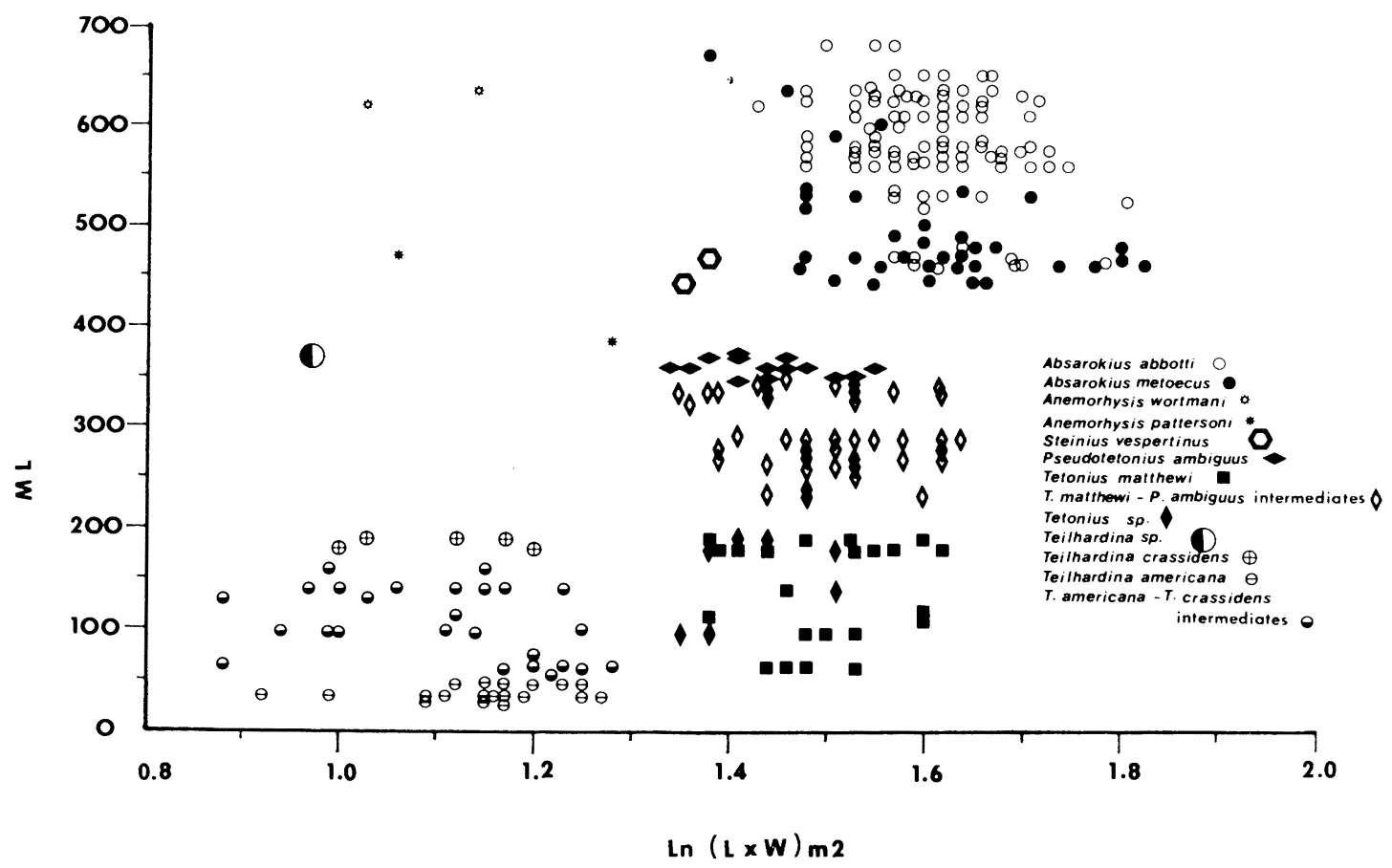

FIGURE 54-Plot of $\mathrm{m} 2$ area in omomyid specimens from the central and southern Bighorn Basin (see Figure 51). 


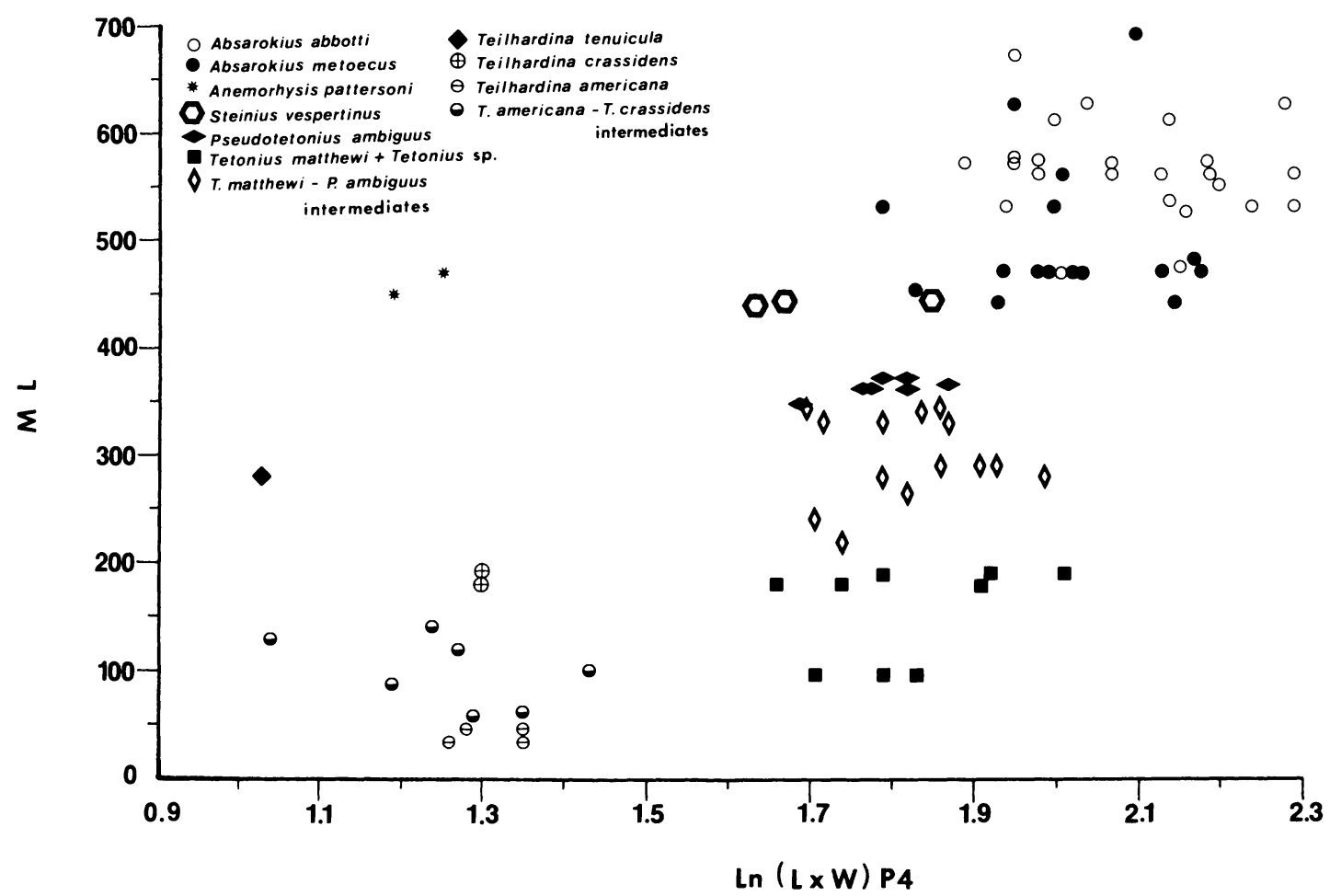

FIGURE 55-Plot of P4 area in omomyid specimens from the central and southern Bighorn Basin (see Figure 51).

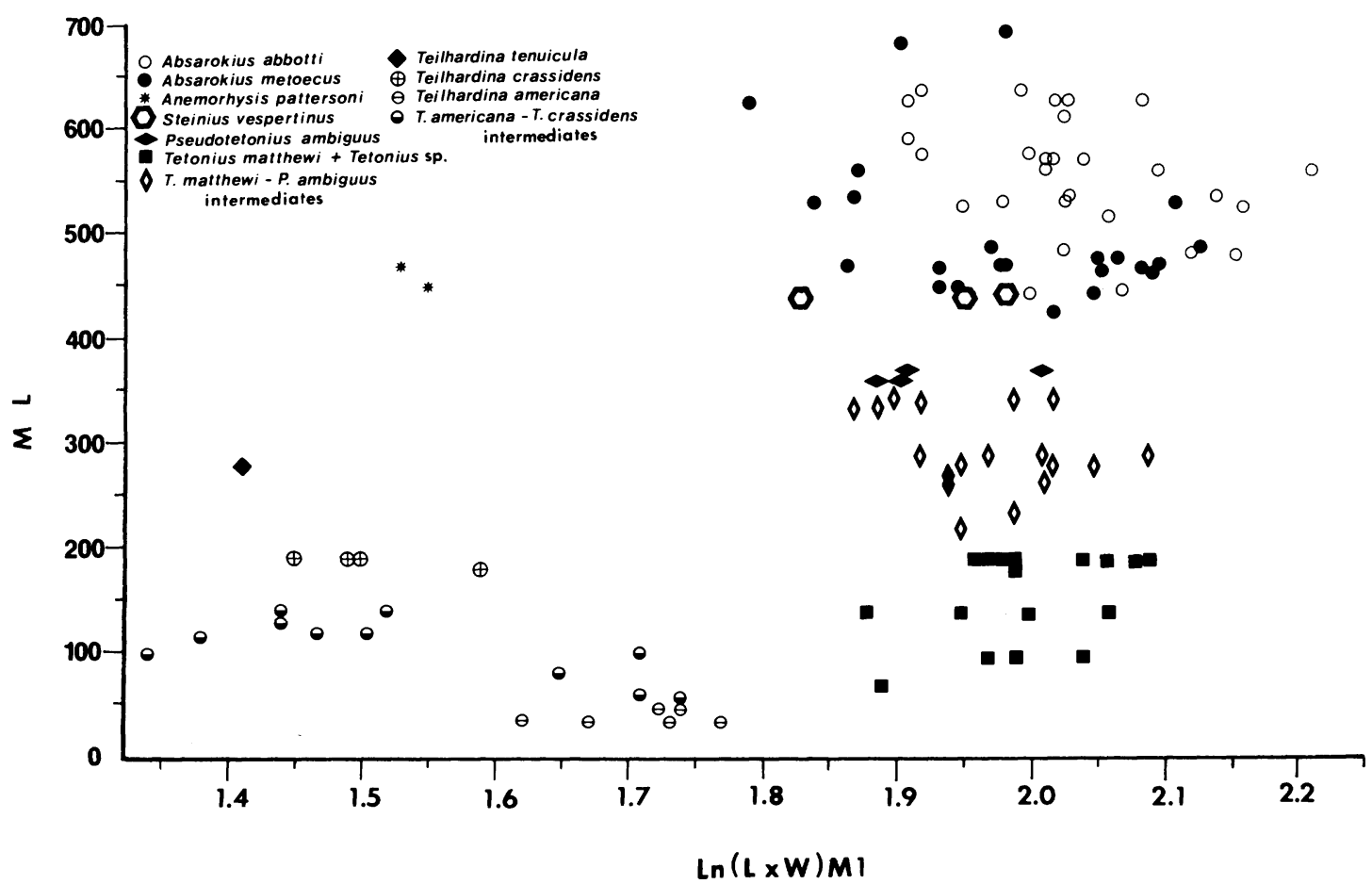

FIGURE 56-Plot of M1 area in omomyid specimens from the central and southern Bighorn Basin (see Figure 51). 

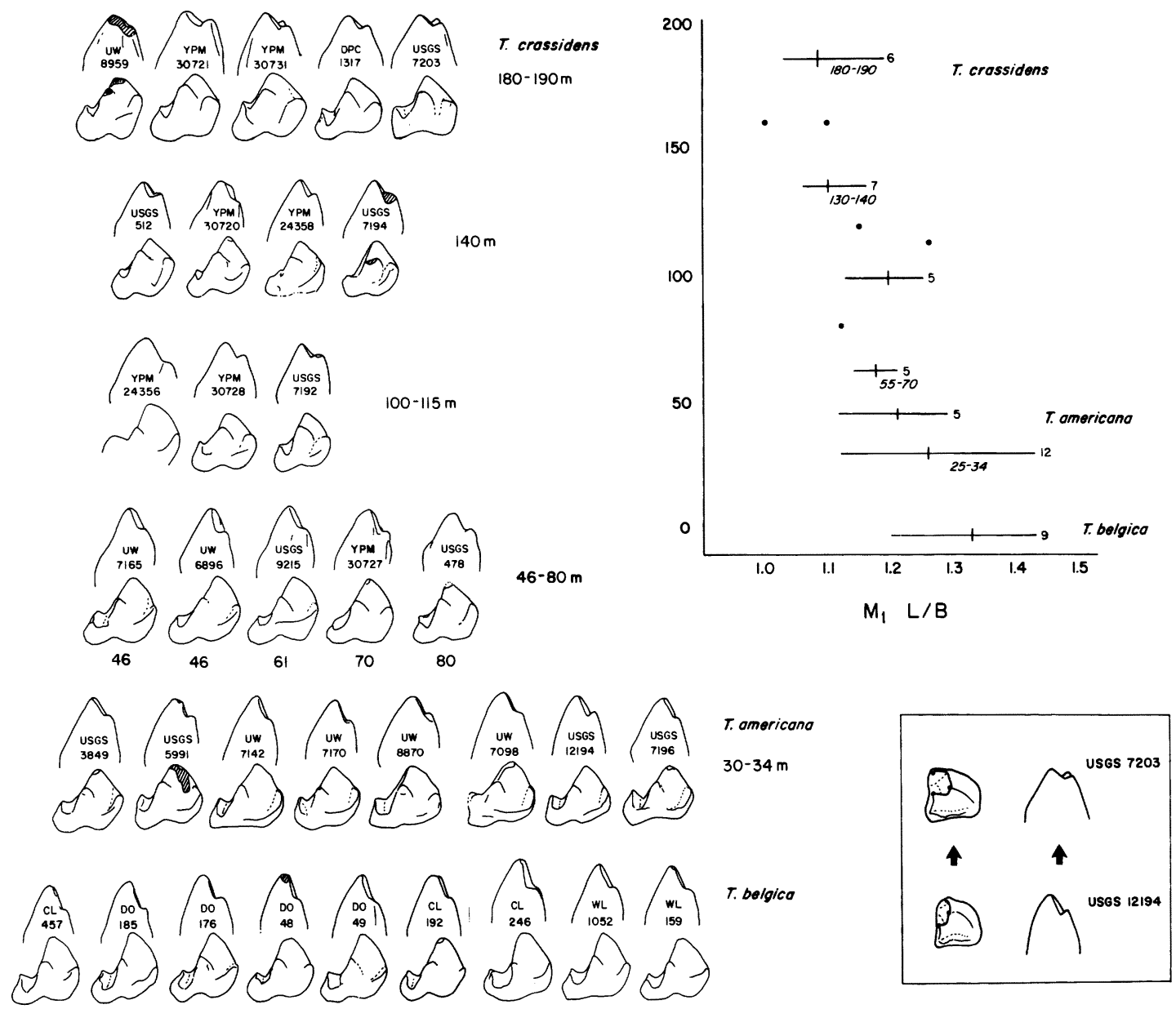

FIGURE 57-Changes in morphology of $\mathrm{p} 4$ and proportions of $\mathrm{m} 1$ in Teilhardina from the central and southern Bighorn Basin. Camera lucida drawings at left depict lingual aspect of $\mathrm{p} 4$ and posterior aspect of its trigonid in specimens from different stratigraphic levels as indicated; inset at lower right shows occlusal view and back of trigonid in T. americana Bown (USGS 12194) and T. crassidens n. sp. (USGS 7203). Note increase in breadth of $\mathrm{p} 4$ and in elevation of metaconid with higher stratigraphic level. Graph at upper right shows range and mean (vertical slash; sample size at right) of $\mathrm{m} 1$ length : width ratio plotted against stratigraphic level. Teilhardina belgica (Teilhard de Chardin) from earliest Sparnacian (Dormaal, Belgium) is shown for comparison; its $0 \mathrm{~m}$ level in $\mathrm{ml}$ plot is arbitrary. Teilhardina belgica specimens designated CL and WL are from the Wouters collection, Institut Royal d'Histoire Naturelle de Belgique; those designated DO are in the collection of Dr. P. Gigase. (Modified from Rose and Bown, 1986.)

Teilhardina persists in the central and southern Bighorn Basin up to the level of 190 m (probably about 1-2 Ma), with a sparse record but no gap between specimens exceeding $20 \mathrm{~m}$ (Figures 51-56). At the top of this sequence (180-190 $\mathrm{m}$ interval) the small sample available, here named Teilhardina crassidens, is again of relatively uniform size and morphology but consistently different than that of $T$. americana. The lower cheek teeth of $T$. crassidens are relatively shorter and broader (more inflated basally). In particular, p3-4 are lower crowned, short, and squat, and their molarization is evident in 

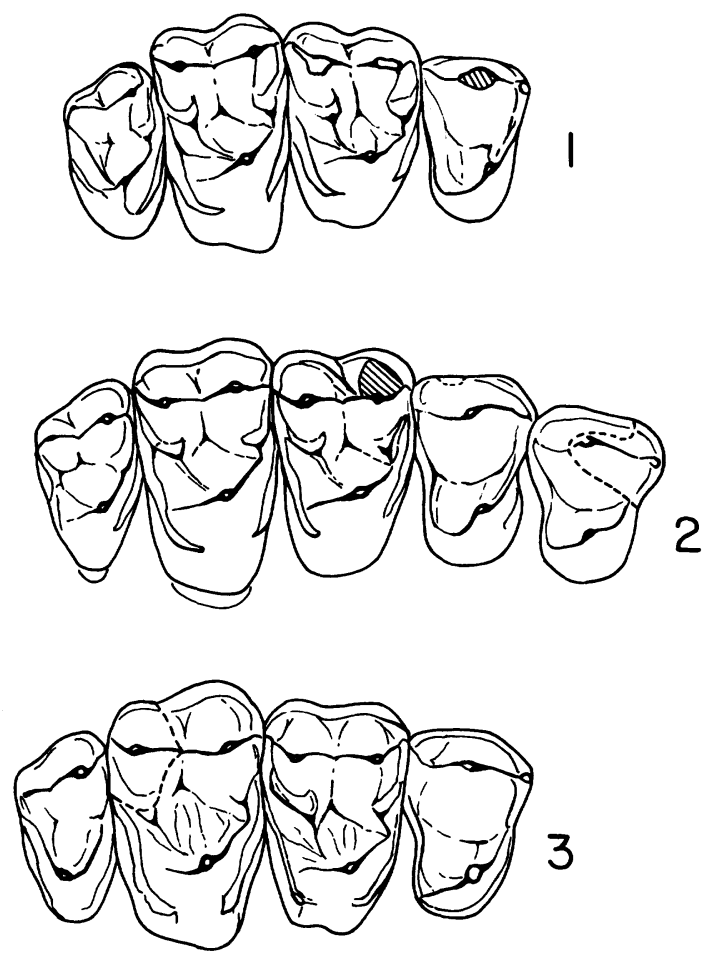

FIGURE 58-Upper cheek teeth in Teilhardina. 1, T. tenuicula (Jepsen) n. comb., holotype, YPMPU 13027, right P4-M3 (stratigraphic level unknown, probably about $250-300 \mathrm{~m}$ ). $2, T$. crassidens n. sp., YPM 24626, right P3-M3, P3 restored from USGS $7204(180 \mathrm{~m})$; note mesostylar crest on M1. 3, T. americana, UW 8871, right P4-M3, M3 restored from UW 8961 (34 $\mathrm{m})$. Scale is $5 \mathrm{~mm}$.

the consistent presence of larger and more elevated metaconid and paraconid cusps on p4 (Figure 57) and a distinct metaconid and stronger paracristid (or small paraconid) on p3. In addition, the dentary is foreshortened, the canine is smaller, and pl is absent, but i1 is decidedly enlarged (Figures 8,9 ).

Specimens found in the $100 \mathrm{~m}$ interval succeeding $T$. americana display considerably more variability in form and size than in either $T$. americana or $T$. crassidens. Morphological variability (apart from size) is essentially directional and includes several successive minor character changes that, through this sequence, appear to document the gradual transition from $T$. americana to $T$. crassidens. As previously discussed, the most obvious changes involve $\mathrm{p} 4$, in which the meta- conid became progressively larger and more elevated, the paraconid somewhat more prominent, and the whole tooth relatively broader, shorter, and lower crowned (Table 3). These modifications, which occurred in small increments, are more easily observed by viewing the medial aspect of $\mathrm{p} 4$ and the back of its trigonid than by comparing specimens in occlusal view (Figure 57).

Concomitant, apparently gradual, changes include relative broadening of $\mathrm{p} 3, \mathrm{~m} 1$, and $\mathrm{m} 2$, appearance of a metaconid on $\mathrm{p} 3$, loss of $\mathrm{p} 1$, progressive foreshortening of the dentary, and enlargement of $i 1$. In the upper molars, they include slight broadening of the stylar shelf and appearance of a mesostyle-like crest on the ectocingulum (Figure 58). However, most of these modifications involve parts of the dentition that are rarely preserved, so it can only be stated that the meager data are consistent with the gradual patterns seen in p4 morphology. For example, faint indications of a metaconid on $\mathrm{p} 3$ are seen in YPM 30728 (110 m), USGS 7192 $(115 \mathrm{~m})$, USGS $7194(140 \mathrm{~m})$, and YPM 30720 (140 m; Figure 11), and a more distinct metaconid is present in USGS $512(140 \mathrm{~m}$; Figures 10,12.2). This cusp is never present on $\mathrm{p} 3$ of $T$. americana but is always present in $T$. crassidens.

Evidence regarding the jaw and dentition anterior to $\mathrm{p} 3$ is especially weak, but the few specimens preserving this region unequivocally have more compressed anterior teeth than in T. americana. In two of them (USGS 512, YPM 24358) this part of the jaw is clearly longer than in $T$. crassidens, whereas three specimens from the Clark's Fork Basin (UM 69147, 71126, YPMPU 17418 (Figures 12.3, 13)) are more compressed, approximating the condition in $T$. crassidens. The Clark's Fork specimens are apparently closer in time to $T$. crassidens. All five lack p1 or its alveolus and, where known (i.e., in all but UM 71126), each possessed a moderately enlarged il slightly smaller than that of $T$. crassidens. Only one intermediate (UM 77391 (Figure 12.1), dentary fragment with $\mathrm{p} 2-3$ and roots of $\mathrm{c}-\mathrm{p} 1$, Clark's Fork Basin, $205 \mathrm{~m}$ level) is known to have retained a tiny $\mathrm{p} 1$, as in $T$. americana. This specimen, however, is structurally intermediate in having a weakly expressed metaconid on $\mathrm{p} 3$.

Although a gradual morphological transi- 

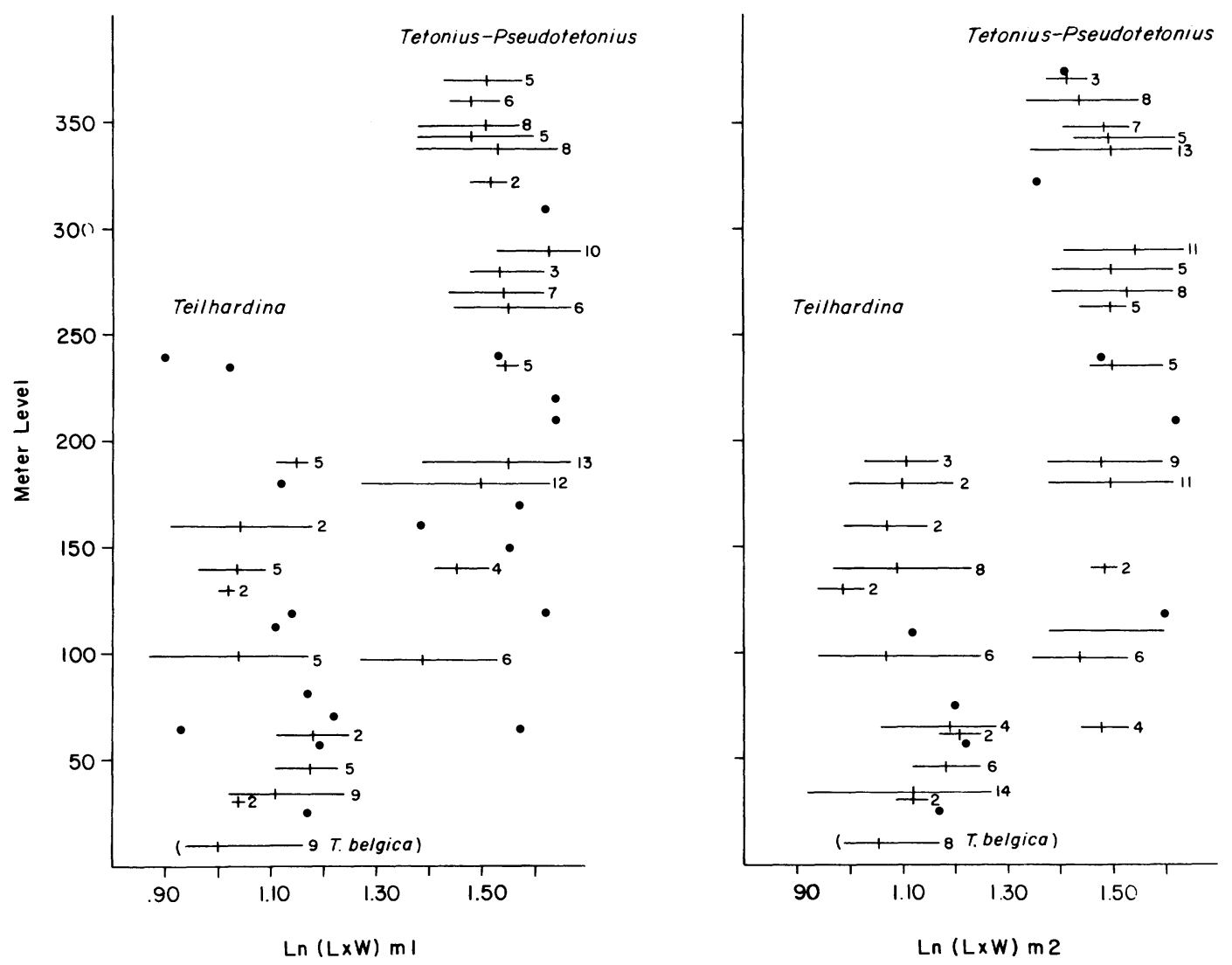

FIGURE 59-Stratigraphic distribution of $\mathrm{m} 1$ and $\mathrm{m} 2$ size (natural logarithm of length $\times$ width) in the Teilhardina and Tetonius-Pseudotetonius lineages from the central and southern Bighorn Basin, showing apparent stasis. Teilhardina belgica Teilhard de Chardin is shown for comparison and its stratigraphic placement is arbitrary. Horizontal bars indicate ranges, vertical slashes are means, sample size shown to right. (Modified from Rose and Bown, 1986.)

tion is inferred, neither $\mathrm{p} 4$ structure nor any other aspect changed perfectly smoothly. For example, YPM $24356(100 \mathrm{~m})$ has a lower p4 metaconid than might be expected, but it is relatively broad, whereas USGS 7192 (115 $\mathrm{m}$ ) has a high metaconid but is comparatively narrow (Figure 57). USGS 7194 (p3-4, 140 $\mathrm{m}$ ) is unusually broad and mesiodistally compressed. Similarly, some specimens with the weakest mesostyles or none at all (USGS 9211, $119 \mathrm{~m}$; YPM 30729, $140 \mathrm{~m}$ ) were found in rocks above the level of the first appearance of a mesostyle $(97 \mathrm{~m})$. Such mosaic acquisition and expression of features is to be expected in a gradual transition of morphology and presumably reflects directional shifts in proportion of variability.

In any transition, gradual or otherwise, only some characters will exhibit change during a particular temporal interval; many will remain relatively constant (Martin, 1984; Rose and Bown, 1986). Throughout their evolution, the lower molars of Teilhardina show few changes, apart from the aforementioned weak trend toward relatively broader, more basally inflated crowns. Consideration of crown area (log or $\ln$ of length $\times$ breadth), which obscures this trend, reveals a pattern of stasis or weak oscillation in molar size (Figure 59). Thus Teilhardina retained conservative molars that changed little, whereas the antemolar dentition underwent progressive, apparently gradual change.

The number of intermediates that preserve the most important traits for interpreting their evolution remains small despite persistent efforts during the past several years to improve this record. It should be emphasized that 


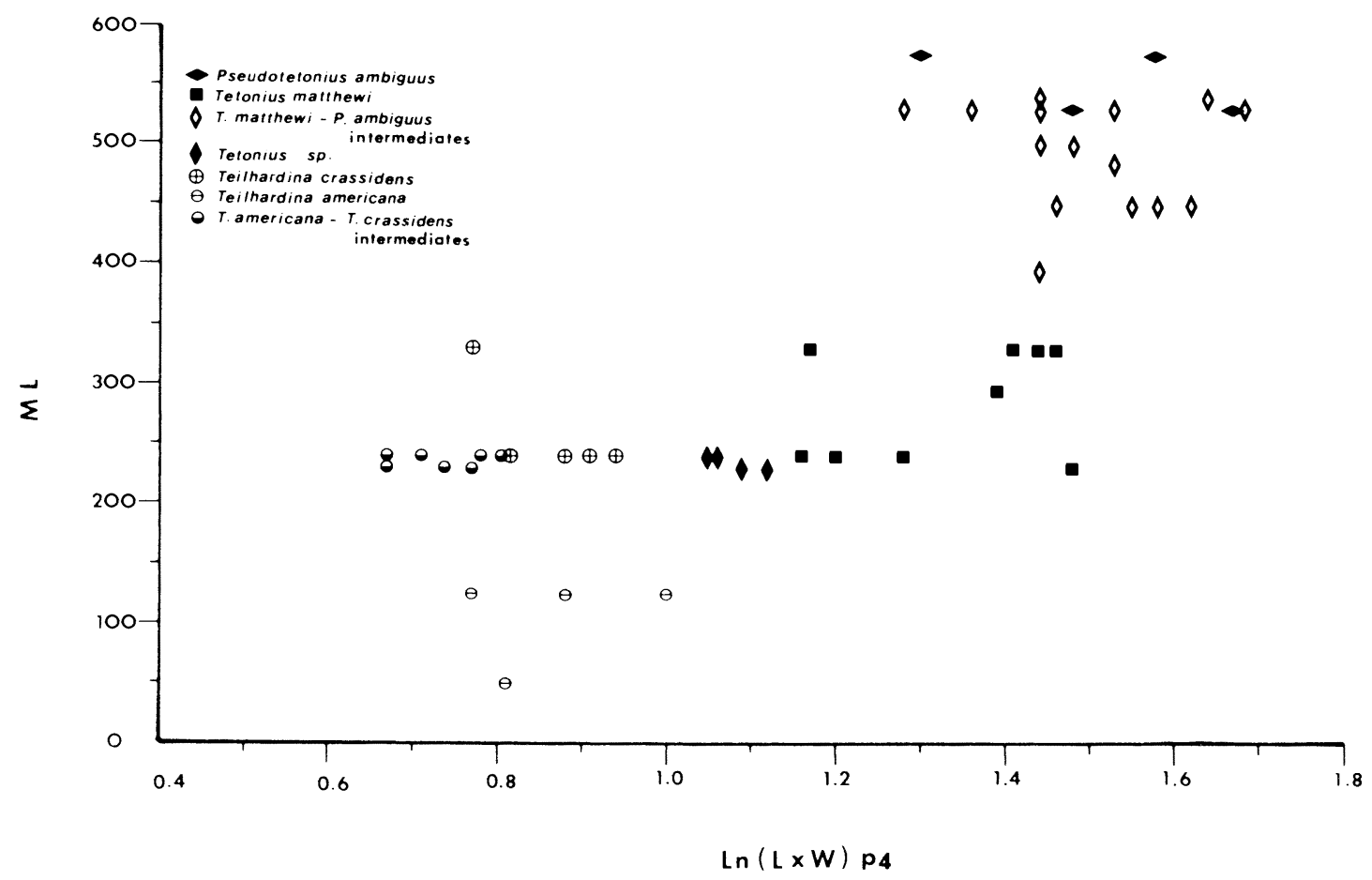

FiguRE 60-Plot of $\mathrm{p} 4$ area in omomyid specimens from the Clark's Fork Basin (see Figure 51); ordinate is stratigraphic level in the Willwood Formation above the Clarkforkian-Wasatchian boundary sandstone. Note similar pattern to lower half of Figure 52 (up to $370 \mathrm{~m}$ ).

omomyids usually constitute only about $1.5 \%$ of the fauna in the lower part of the Willwood Formation, and that only a fraction of those found preserve the most critical teeth.

The Teilhardina americana-T. crassidens lineage evidently became extinct above 190 $\mathrm{m}$ in the central and southern Bighorn Basin (330 $\mathrm{m}$ in the Clark's Fork Basin section), and Teilhardina occurs only sporadically thereafter (Figures 51-56, 60-62). Teilhardina tenuicula appears about $50 \mathrm{~m}$ (or more) above the last appearance of $T$. crassidens, and was probably derived from the Teilhardina intermediates discussed above, but no other transitional specimens are known in the principal study area.

A sample from Hackberry Hollow (UM locality SC-192) in the Clark's Fork Basin, however, may represent such a transitional stage. These specimens differ slightly but consistently from other intermediates in having relatively lower crowned p3-4 with metaconids set closer to the protoconid, and a longer, more open $\mathrm{p} 4$ trigonid with a lingually situated, distinct paraconid. Where known (best seen in YPMPU 17418 (Figures 12.3, 13) and UM 69147), the dentition anterior to $\mathrm{p} 3$ is more compacted than in other intermediates; i2 is labially displaced and the jaw is as short as in $T$. crassidens although il is not quite as large as in the latter. These differences suggest that the Hackberry Hollow sample is more advanced morphologically than most intermediates, but in the direction of Teilhardina tenuicula rather than $T$. crassidens. The stratigraphic level of Hackberry Hollow is unknown but, based on the stage of evolution of Teilhardina, may be about 250-350 $\mathrm{m}$-that is, approximately contemporaneous with the temporal range of T. crassidens.

The Clark's Fork Basin sample, though smaller and more incomplete stratigraphically, documents the same series of changes in the same sequence that is observed in the central and southern Bighorn Basin record of Teilhardina, providing an independent test of, and supporting, the interpretation given above. Teilhardina americana and $T$. crassidens each have restricted, non-overlapping 


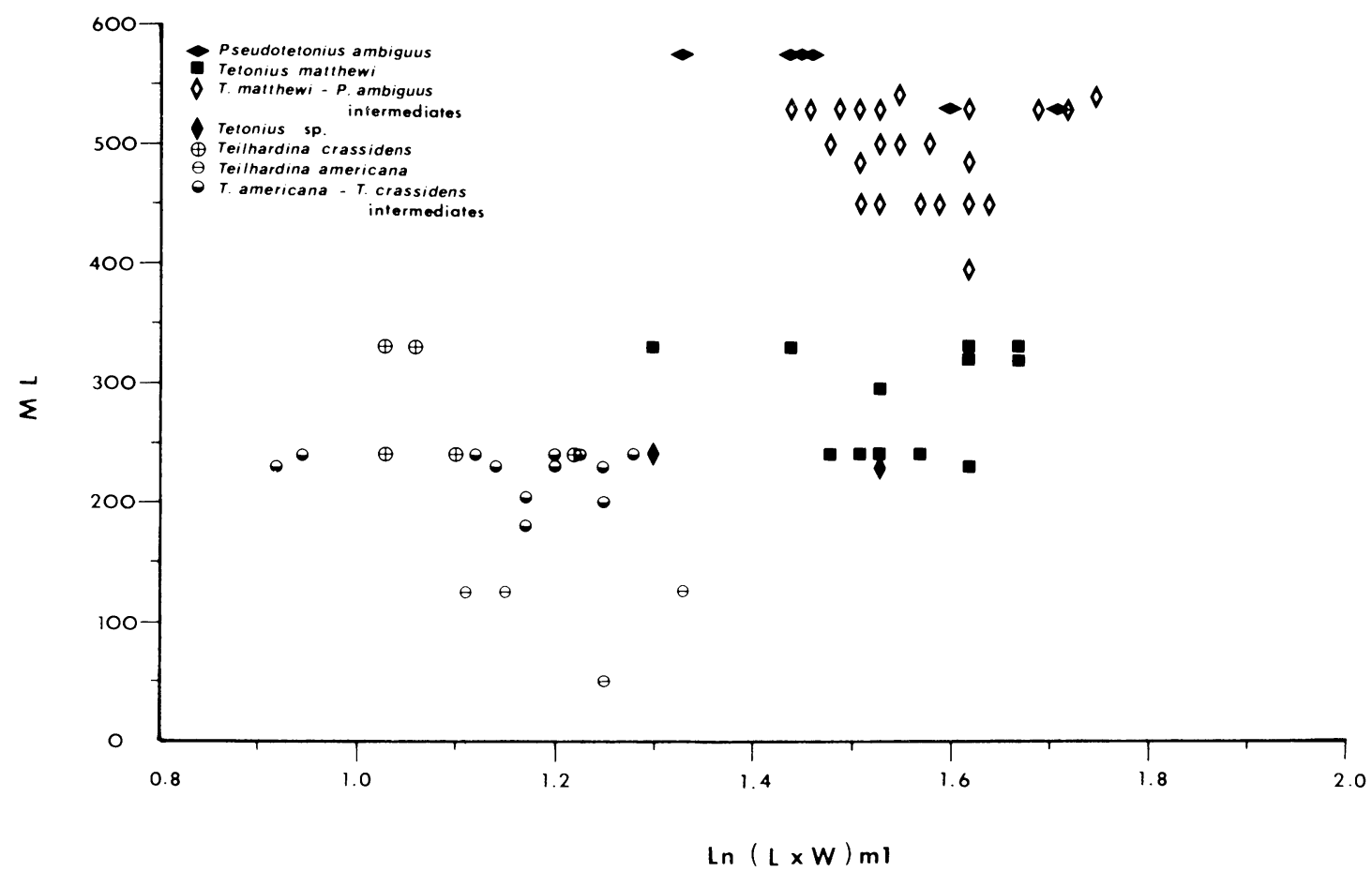

FIGURE 61 -Plot of $\mathrm{m} 1$ area in omomyid specimens from the Clark's Fork Basin (see Figures 51 and $60)$.

stratigraphic ranges, and the latter (as in the central and southern Bighorn Basin) coexisted with Tetonius matthewi (Figures 60-62). Intermediates are known from only part of the intervening strata (180-240 m) and over- lap at $240 \mathrm{~m}$ with $T$. crassidens. This is not to imply that two species of Teilhardina were present at this level; rather, this level yields specimens that are morphologically fullfledged $T$. crassidens together with specimens

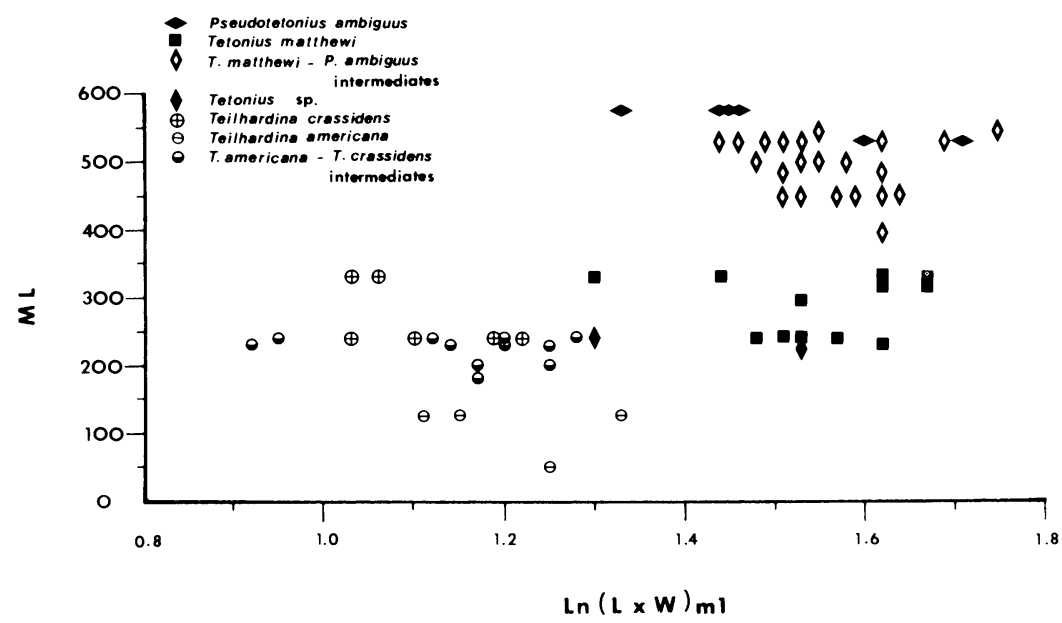

FIGURE 62-Plot of $\mathrm{m} 1$ area as in Figure 61, but vertical scale compressed to approximate more closely that of the comparable part of the section in the central and southern Bighorn Basin. Compare with Figure 53 (up to $370 \mathrm{~m}$ ). 
that, by comparison to the Bighorn Basin sample, are morphologically advanced intermediates. The problem devolves to one of taxonomy; there is simply no place in a gradual transition to draw a line separating "species" of mutually exclusive and diagnostic morphologies.

Gingerich (1980a, p. 416) concluded that the Clark's Fork Basin sample of Teilhardina (then called Tetonoides) "exhibits no change through time." This inference was based on $\mathrm{m} 1$ size in the smaller sample then known and is not inconsistent with the pattern of $\mathrm{m} 1$ area through time in the central and southern Bighorn Basin sample. The larger Clark's Fork Basin sample now available, however, suggests a weak trend toward smaller $\mathrm{ml}$ size through time, and traits in antemolar teeth provide stronger evidence for sustained, gradual evolution. Nonetheless, it remains doubtful that the record from the Clark's Fork Basin is dense enough to permit this conclusion without reference to the better record from the central and southern Bighorn Basin.

Although Anemorhysis remains one of the rarest omomyids and has a very incomplete fossil record, it is possible to offer a few speculations concerning its evolution. The genus, united by its derived p4 talonid structure, must have descended from Teilhardina, but the limited available evidence does not point clearly to any one species or sample as the most likely ancestor and, indeed, suggests several alternatives.

In all Anemorhysis p4 has a buccally-situated cristid obliqua, a shallow hypoflexid, and a variably developed talonid basin, characters that presumably were present in the stem species of the genus. The talonid basin is best developed in $A$. sublettensis and is only slightly less so in $A$. wortmani (the two youngest species) from the Bighorn Basin, showing that these are the two most derived species. Anemorhysis wortmani has an enlarged il and compressed anterior dentition (small i2, c, p2 absent, p3 single-rooted), strengthening this interpretation; the anterior dentition of $A$. sublettensis is unknown. Anemorhysis pearcei and $A$. pattersoni are older than the other two species (although their relative ages are uncertain) and are more primitive in having a less developed talonid basin on $\mathrm{p} 4$ and a tworooted p3. Anemorhysis pearcei retains p2 and shows little compaction of the anterior den- tition, while $A$. pattersoni probably retained p2 but clearly has more compressed anterior teeth. Anemorhysis wortmani, A. sublettensis, and $A$. pearce $i$ have prominent paraconid and metaconid cusps on $\mathrm{p} 4$, whereas $A$. pattersoni has a more open p4 trigonid with small, low paraconid and metaconid. Because the polarity of $\mathrm{p} 4$ trigonid structure is equivocal, the phylogenetic position of $A$. pattersoni is uncertain.

Considering all of these characters, $A$. pearcei appears to be the most primitive species, only slightly derived with respect to Teilhardina crassidens or transitional stages of Teilhardina leading to it. The other species are successively more derived (having progressively better developed talonid basins on $\mathrm{p} 4$, more compressed and reduced anterior dentitions) in the sequence $A$. pattersoni, $A$. wortmani, $A$. sublettensis. But it is unlikely for both morphologic ( $\mathrm{p} 4$ trigonid structure) and geographic reasons ( $A$. sublettensis is from the greater Green River Basin and $A$. pearcei is known only from the Washakie Basin) that all belong to a single lineage. To accommodate all four species in a single lineage would require a reversal - reduction and subsequent enlargement of the p4 paraconid and metaconid (Figure 63.1). Rejecting this, $A$. pattersoni more likely represents a side branch, descended from a form like $A$. pearcei, that reduced the paraconid and metaconid of p4 (i.e., its p4 trigonid structure would be derived; Figure 63.2).

However, if $\mathrm{p} 4$ trigonid structure in $A$. pattersoni is primitive with respect to that in other Anemorhysis (as suggested by its resemblance to that of Teilhardina americana), the situation is more complex. In this case, $A$. pattersoni may have descended from a primitive stem species of Anemorhysis (derived from $T$. americana and retaining its $\mathrm{p} 4$ trigonid structure), undergoing compression of anterior teeth and slight enlargement of the p4 talonid in parallel with other species of the genus (Figure 63.3). The other species would then belong to a separate lineage, also derived from the stem species, that enlarged the trigonid cusps and talonid basin of $\mathrm{p} 4$ and foreshortened the dentary independently. Alternatively, A. pattersoni may actually be directly descended from Teilhardina americana and convergent to Anemorhysis in p4 talonid structure, molar form, and fore- 


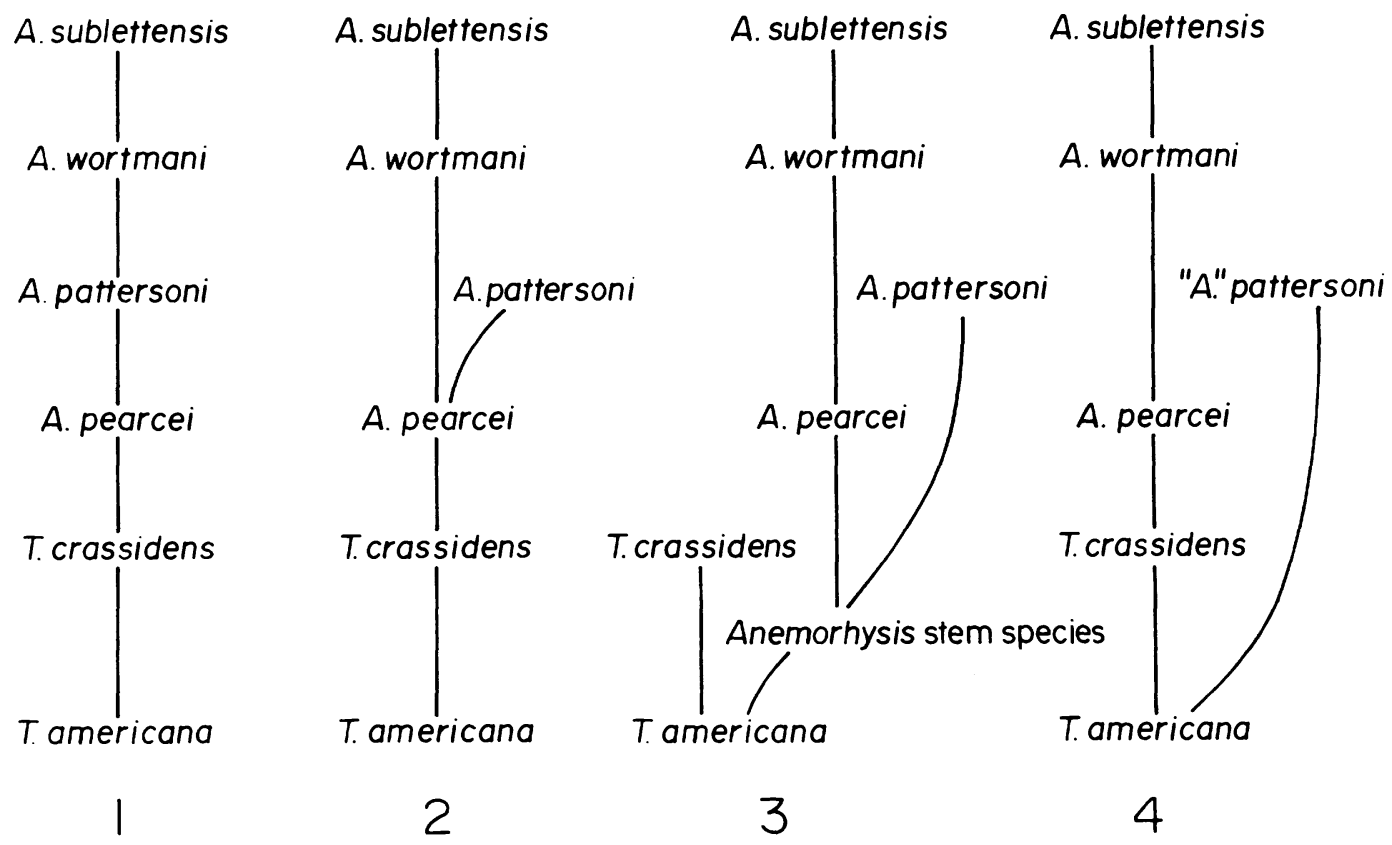

FIGURE 63-Possible relationships of Anemorhysis to Teilhardina and among species of Anemorhysis (see text for explanation).

shortening of the dentary (Figure 63.4). This would require that the characteristic p4 talonid structure of Anemorhysis (as well as other characters) evolved at least twice, and would make the genus as here conceived diphyletic, both of which are regarded as improbable.

Without more evidence, the issue cannot be clearly resolved; but the conclusion that A. pattersoni belongs to a lineage separate from other species of Anemorhysis seems inescapable. It is most parsimonious at present to consider Anemorhysis monophyletic and the reduction of the p4 paraconid and metaconid in $A$. pattersoni derived with respect to $A$. pearcei or a similar species (Figure 63.2).

Evolution in the Tetonius-Pseudotetonius clade.-Tetonius and its successor Pseudotetonius account for the majority of omomyids found in the lower half of the Willwood Formation in the southern and central Bighorn Basin (64-374 m interval; Figures 51-56). In the Clark's Fork Basin, where Willwood deposition began earlier (during the Clarkforkian Land Mammal Age) and Wasatchian time is represented by a greater thickness of rocks, these taxa occur in the
230-595 $\mathrm{m}$ interval of Wasatchian strata (Figures 60-62). Most specimens represent a single lineage from Tetonius matthewi to Pseudotetonius ambiguus, characterized by a trend toward progressive compaction of the anterior teeth (loss of $\mathrm{p} 2$, size reduction of i2, c, p3) and hypertrophy of i1. The lower molars and upper cheek teeth (P3-M3), however, remained conservative. There are no obvious trends in these teeth except for their slightly smaller mean size in $P$. ambiguus, hence individuals preserving only these teeth (which constitute a significant proportion of known specimens) are, in practice, morphologically indistinguishable. Such specimens can be assigned to taxon or stage only by association with diagnostic lower antemolar dentitions or by stratigraphic occurrence. For these reasons, the remaining discussion focuses on the lower antemolar dentition. A second, short-lived, primitive lineage, characterized by smaller overall size and relatively smaller p3-4, appears to be indicated by the sample here designated Tetonius species.

In general, Tetonius segregates from Teilhardina by its larger size, relatively broader (basally more inflated) cheek teeth, relatively 


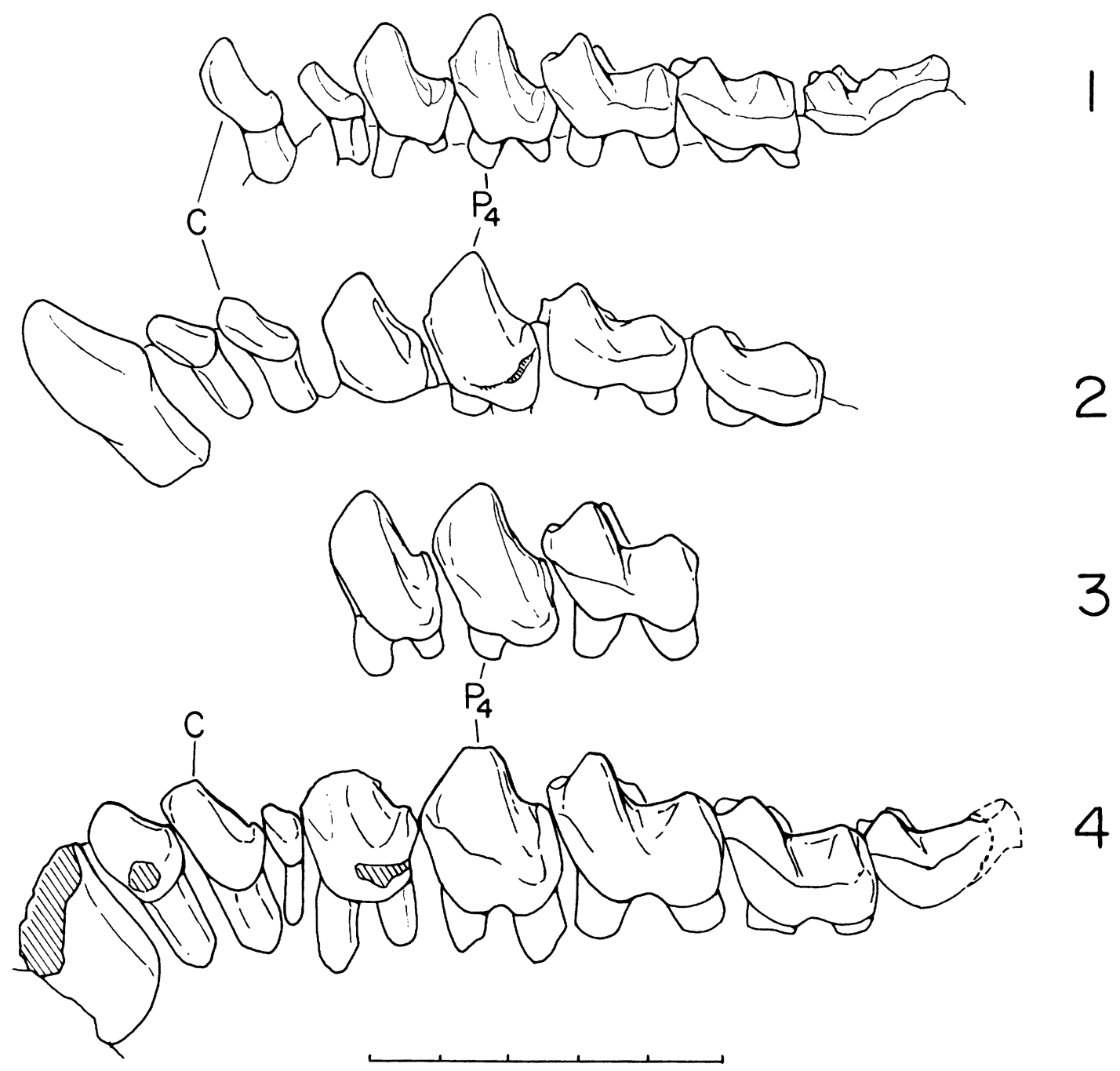

FIGURE 64-Lower dentitions of Teilhardina and Tetonius, showing probable morphological stages of evolution (see text for details). 1, Teilhardina americana Bown (UW 6896, holotype). 2, Tetonius mckennai (UCMP 46192, holotype). 3, Tetonius sp. (USGS 5936). 4, Tetonius matthewi n. sp. (CM 12190 , holotype). Scale is $5 \mathrm{~mm}$.

smaller canine, smaller or absent $\mathrm{p} 2$, and consistent lack of $\mathrm{p} 1$-all derived traits relative to Teilhardina americana. With the exception of larger size and reduction of $\mathrm{p} 2$, these characters also evolved (in parallel) in later stages of the Teilhardina americana-T. crassidens lineage, which coexisted with Tetonius; but Teilhardina crassidens is readily separated from Tetonius by its short, squat cheek teeth and more molarized p3-4. As discussed below, some small individuals of Tetonius approach or overlap with Teilhardina americana and early Teilhardina inter- mediates in cheek tooth size and morphology. Although it is usually easy to distinguish between the two genera using the criteria listed above, this is not true for some isolated molars.

Tetonius first appears in the southern Bighorn Basin at the $64 \mathrm{~m}$ level, just above the last occurrence of Teilhardina americana, presumably as an immigrant (see also Gingerich, 1980a). Through about the next 100 $\mathrm{m}$ its record is sporadic and most specimens consist of very fragmentary jaws or isolated teeth. Many of these are within the size range 

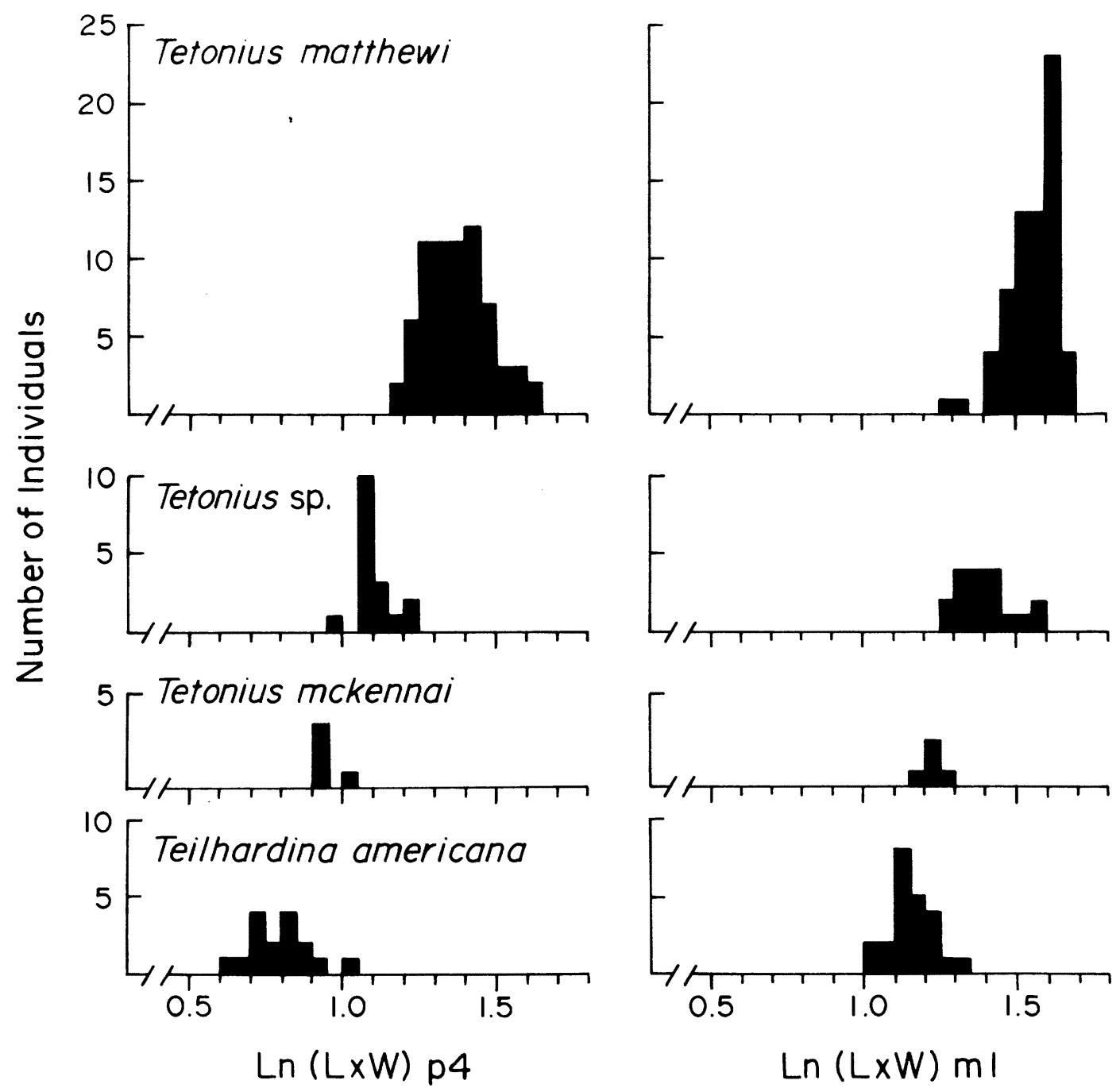

FIGURE 65-Histograms of $\mathrm{p} 4$ and $\mathrm{m} 1$ size (natural logarithm of length $\times$ width) in Teilhardina americana Bown and Tetonius (data from appendices).

of $T$. matthewi (best known from the 180 $190 \mathrm{~m}$ interval) and are morphologically indistinguishable from it. It is evident from Figures 51-56 that these specimens can be distinguished from Teilhardina simply by their larger size. Also present in this interval are smaller specimens here designated $\mathrm{Te}$ tonius species. All early representatives of $T e$ tonius, as far as known, are characterized by an enlarged, procumbent i1, small i2 and canine, a vestigial $\mathrm{p} 2$, and a two-rooted $\mathrm{p} 3$ only slightly smaller than $\mathrm{p} 4$ (traits defining stage 1 ; see below).

Although Tetonius matthewi is more derived than Teilhardina americana in several aspects of the anterior dentition, its antiquity and close resemblance to the latter in structure of the cheek teeth $(\mathrm{p} 3-\mathrm{m} 3)$ suggest close relationship. In fact, two more primitive samples of the genus, Tetonius mckennai and Tetonius species, probably represent the morphological stages (if not the actual pedigree) by which Tetonius matthewi evolved from Teilhardina (Figure 64).

Tetonius mckennai (early Wasatchian Four Mile Fauna) is the most primitive known species of the genus, overlapping in size with the largest individuals of Teilhardina americana (Figure 65). Its cheek teeth (except p4) display little of the basal inflation character- 


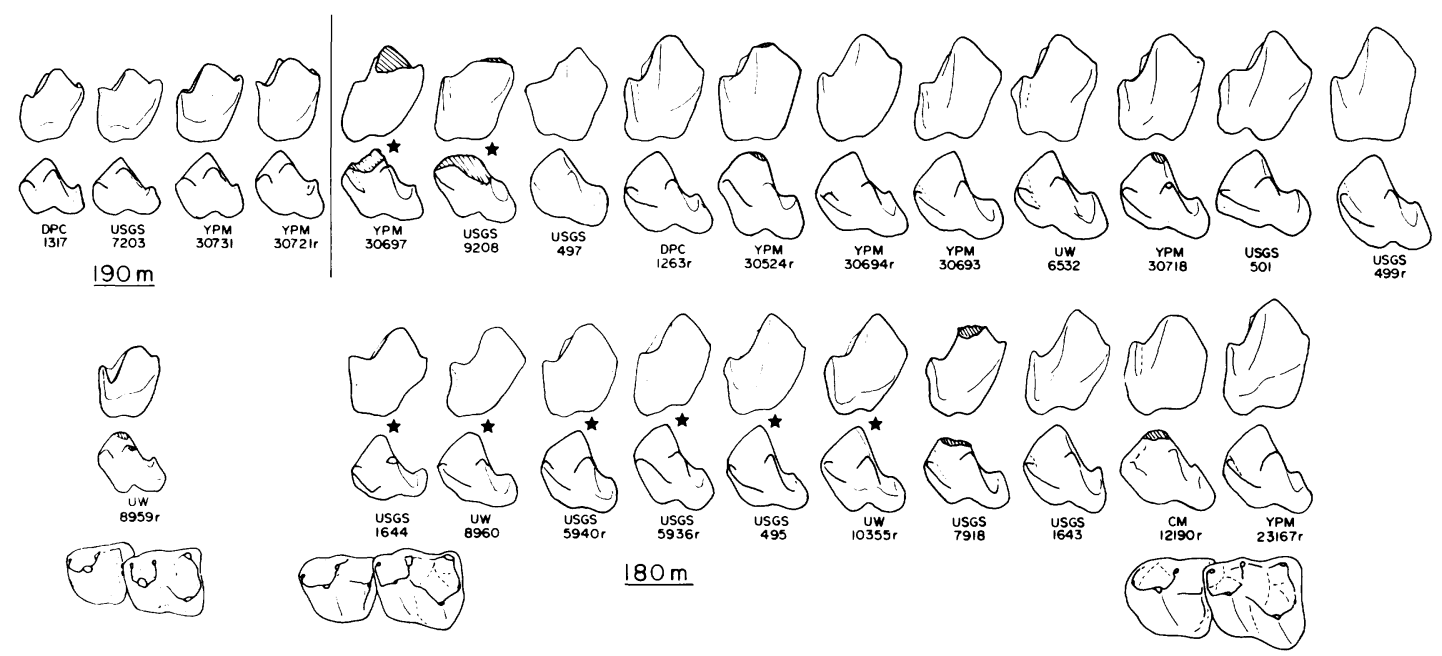

FIGURE 66-Camera lucida tracings of lateral (above) and medial views of $\mathrm{p} 4$ in omomyids from the 180-190 m interval in the central and southern Bighorn Basin, showing variation in size and morphology. Tetonius $\mathrm{sp}$. (indicated by stars) and $T$. matthewi $\mathrm{n}$. $\mathrm{sp}$. coexisted with Teilhardina crassidens n. sp. in this interval. Small individuals of Tetonius sp. closely approach Teilhardina in size of $\mathrm{p} 4$, but in Tetonius $\mathrm{p} 4$ is relatively longer and has lower and less prominent metaconid and paraconid cusps. Occlusal views of $\mathrm{p} 4-\mathrm{m} 1$ in the three taxa are compared below.

istic of other Tetonius. Only relatively trivial modifications are necessary to derive Tetonius mckennai from Teilhardina americana: loss of $\mathrm{p} 1$ (rarely achieved in $T$. americana but typical in later Teilhardina), slight reduction of the canine and probably $\mathrm{p} 2$, and (probably) enlargement of i1.Thus Tetonius mckennai exemplifies a structural stage intermediate between Teilhardina americana and more advanced Tetonius. The known sample cannot represent the actual transitional population, however, since it coexisted with Tetonius matthewi and Tetonius sp. at East Alheit Pocket; but older samples of the species may have been close to the direct line of descent.

As previously discussed, the sample of $T e$ tonius from the 97-190 m interval exhibits a size range exceeding that of other Bighorn Basin anaptomorphine samples (Figure 66). This is particularly apparent in the plots of $\mathrm{p} 4$ and $\mathrm{m} 1$ size (Figures 52, 53), in which several specimens plot below the range for later samples in the Tetonius-Pseudotetonius lineage, closely approaching Teilhardina. These smaller specimens, which retain p2, also typically have relatively smaller p3-4 (compared to molars) than in $T$. matthewi, suggesting that they are slightly more primitive than $T$. matthewi and strengthening the probability that the broad size range reflects the existence of two species (see also Gingerich, 1974b). For these reasons, these smaller specimens are designated Tetonius species, although they intergrade imperceptibly with sympatric specimens of $T$. matthewi. The two may be sibling species. Tetonius sp., whether distinct or a small variant of $T$. matthewi, is an ideal morphological intermediate between $T$. mckennai and typical T. matthewi.

It seems probable that Tetonius sp. represents a lineage of short duration whose early members were directly ancestral to $T$. matthewi. Like $T$. mckennai, known samples of Tetonius sp. cannot have been ancestral to $T$. matthewi, because they coexisted with it in the Bighorn Basin as well as in the Clark's Fork Basin and probably at East Alheit Pocket. Thus Tetonius sp. and T. matthewi may bear the same relationship to each other as Absarokius metoecus and A. abbotti (see following section on Evolution in Absarokius); i.e., T. matthewi may have descended from Tetonius sp. by gradual cladogenesis-but in this case only part of the divergence (subse- 
quent to the initial split) is recorded in the Bighorn Basin. A dense record of the early history of Tetonius sp. and T. matthewi is not yet known.

The close approximation in size and structure between Tetonius sp. and Teilhardina is underscored by a few problematical specimens that are tentatively assigned to the Teilhardina intermediate group (see systematics above) because they are slightly smaller and relatively shorter (e.g., USGS 2562, UW 7224 , UW 8922-all isolated molars). It is notable, however, that the size separation between these specimens and Tetonius sp. is less than that between many specimens of the latter and $T$. matthewi.

To summarize, these primitive samples of Tetonius provide strong evidence that the genus was a direct descendant of Teilhardina, probably $T$. americana. They further suggest that the Tetonius-Pseudotetonius lineage emerged gradually through the sequence Teilhardina americana-Tetonius mckennai-Tetonius species-Tetonius matthewi. As noted earlier, the last three taxa as currently known were at least in part contemporaneous. Whether Tetonius sp. and T. mckennai arose earlier but persisted for a period unchanged or were derived from more primitive stages of the same (or different) species is unknown.

Tetonius matthewi, as mentioned earlier, is recorded from $64 \mathrm{~m}$ to $190 \mathrm{~m}$ in the southern and central Bighorn Basin (230-330 m in the Clark's Fork Basin). Many of the earlier specimens are very fragmentary and are here assigned by default; it is simply not known if they differ in aspects of the anterior dentition (for instance, by having a relatively larger p2 or a relatively smaller i1). More nearly complete lower dentitions are known from the 140-190 m interval (particularly $180-190 \mathrm{~m}$ ). From this interval to about 370 $\mathrm{m}$, the record is relatively dense and continuous and documents a gradual, anagenetic transition from $T$. matthewi to Pseudotetonius ambiguus.

For convenience in discussing this transition, the sample was subdivided into five sequential structural stages (stages 1-5; Figure 67), each defined by a morphological threshold. Each threshold is recognized by a relatively minor change (e.g., loss of p2, coalescence of $\mathrm{p} 3$ roots), and none was sudden in the sense of involving the entire population;

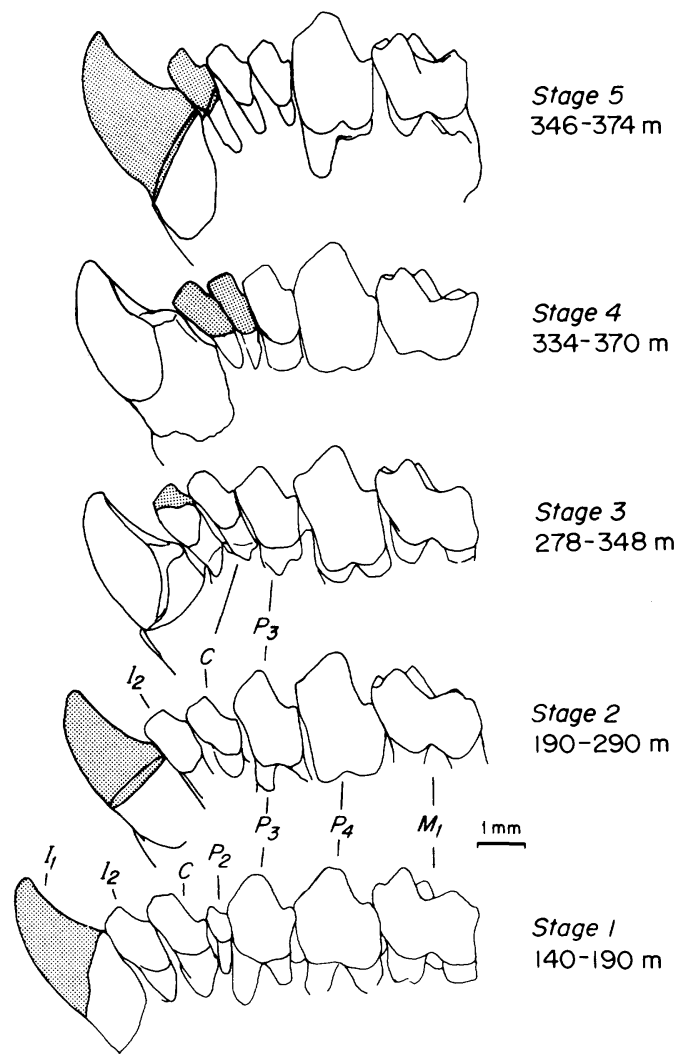

FIGURE 67-Morphologic stages in the TetoniusPseudotetonius lineage (i1-m 1), showing loss of $\mathrm{p} 2$, progressive reduction in size of $\mathrm{i} 2-\mathrm{p} 3$, and hypertrophy of i1. Figures are camera lucida tracings of individual specimens or composites and represent an "average" morphology for each stage; stippled areas are restored based on root size and crown morphology in the closest specimens that preserve these teeth. Stratigraphic intervals indicate the range of typical specimens of each stage.

rather, variability in the pertinent characters increased during transitional periods so that the dominant morphology gradually shifted through time. Thus although the stages employed are essentially time-successive, they also overlap. Two or more stages occur together in several phases of the transition, but the more progressive stage eventually dominates. The ultimate result (the sum of apomorphic characters) was Pseudotetonius ambiguus, a type distinctly different from Tetonius matthewi, in which all of these changes were expressed. The number of stages and the stages themselves are, in fact, arbitrary, because there are no abrupt breaks in 

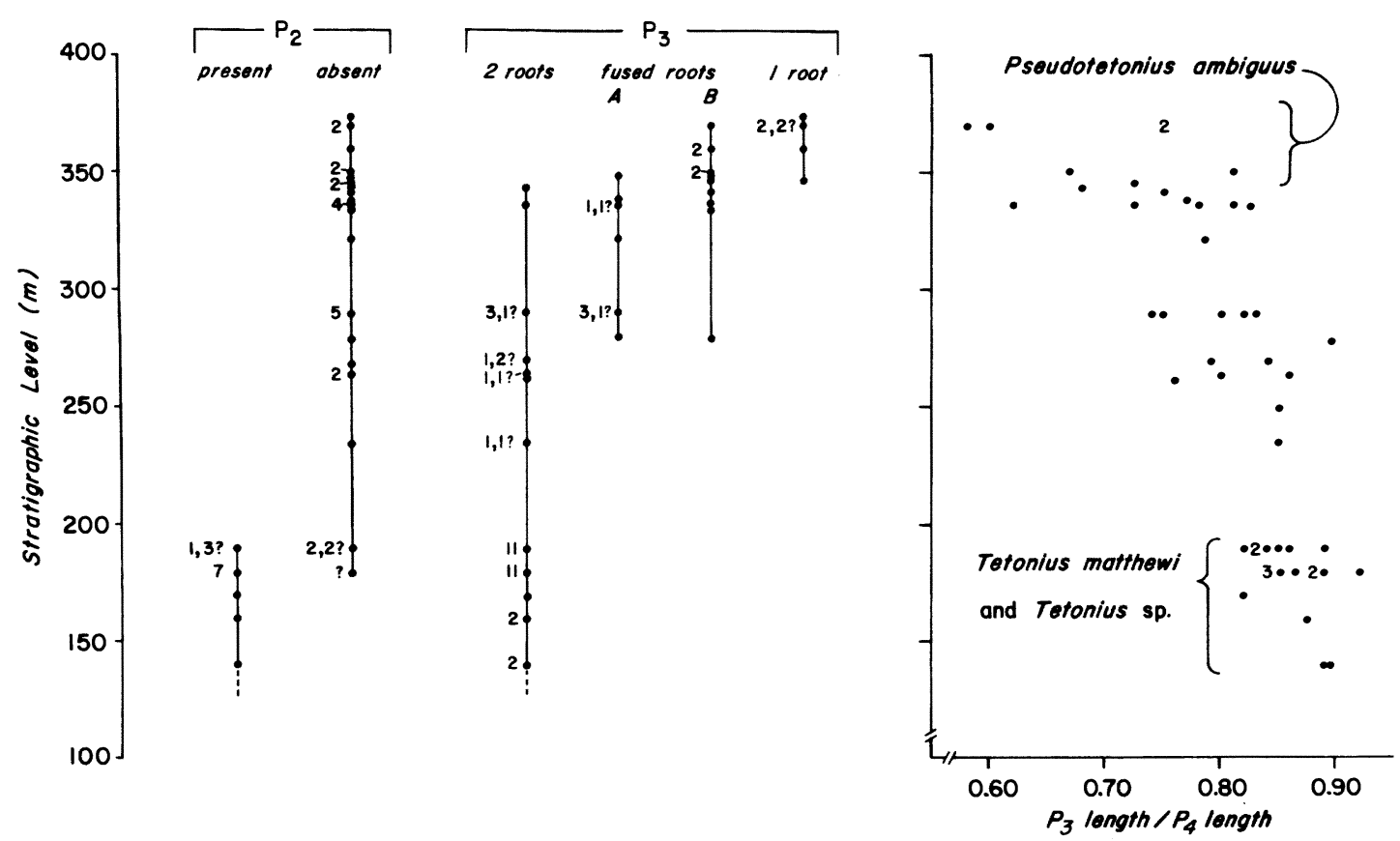

FIGURE 68 -Stratigraphic distribution of lower premolar traits in the Tetonius-Pseudotetonius lineage from the central and southern Bighorn Basin. Points without numbers represent single specimens. Presence or absence of p2 was determined from the crown, root, or alveolus. Specimens of p3 with fused roots were subdivided into two classes, $A$ (stage 3 ) and $B$ (stage 4). See text for further explanation.

Data for p2 (m level in parentheses): Present-YPM 35016 (140), UW 6584 (160), YPM 33246 (170), CM 12190, UK 8662, USGS 5936, 5940, 7198, UW 10355, YPM 23167 (180), DPC 1263?, USGS 483, YPM 30676?, 33223 (190). Absent-USGS 1643? (180), USGS 499?, 3857, UW 6532?, YPM 30524 (190), YPM 25017? (235), USGS 3841, 3853 (264), USGS 504 (270), YPM 26022 (280), YPM 25026, 25034, 25592, 30686, 30708 (290), UW 10212 (322), USGS 3868 (334), USGS 3873, 5997, 9147, 9148 (336), USGS 9140 (338), USGS 5994 (342), USGS 6555 (344), USGS 3867 , 5973 (346), USGS 3881 (348), AMNH 15072, MCZ 19010 (about 350), YPM 25042 (360), JHU 66, YPM 30698 (370), JHU 699 (374).

Data for p3; Two roots-USGS 481, YPM 35016 (140), USGS 7191, UW 6584 (160), YPM 33246 (170), CM 12190, UK 8662, USGS 495, 1643, 5936, 5940, 5941, 7198, UW 6532, 10355, YPM 23167 (180), DPC 1263, USGS 483, 499, 501, 3857, 9208, YPM 30524, 30676, 30693, 30718, 33223 (190), YPM 25015, 25017? (235), USGS 3879 (262), USGS 3841?, 3853 (264), USGS 504?, YPM 24980?, 25044 (270), YPM 25026, 25585, 30686?, 30708 (290), USGS 9148 (336), USGS 6555 (344). Fused roots $(A)-$ YPM 26022 (280), USNM 19151, 19152 (about 290), UW 6192, YPM 25592? (290), UW 10212 (322), USGS 3873, 3874?, 9147 (336), USGS 9140 (338), USGS 3882 (348). Fused roots $(B)$-USGS 3865 (278), USGS 3868 (334), USGS 5997 (336), USGS 5994 (342), USGS 5973 (346), USGS 3881 (348), AMNH 15072, MCZ 19010 (about 350), USGS 6752, YPM 25042 (360), YPM 24981 (370). One root-USGS 3867 (346), USGS 9144 (360), JHU 66, USGS 7199?, YPM 30689?, 30698 (370), JHU 699 (374).

Data for $\mathrm{p} 3 / \mathrm{p} 4$ ratios from appendix.

the sequence. It is also important to point out that some specimens do not fit neatly into one stage or another but instead show characteristics of two stages. This mosaic pattern of change reflects increasing expression of derived traits in the sample rather than recurrence of primitive states.

Of the several traits characterizing stage 1, most important are the presence of a tiny, vestigial $\mathrm{p} 2$ and a relatively unreduced, tworooted p3 (Figures 16-19). All specimens of Tetonius from below $180 \mathrm{~m}$ in the Bighorn Basin (below $300 \mathrm{~m}$ in the Clark's Fork Basin) represent stage 1 . The first individuals that lack p2-the defining feature of stage 2-appear at $190 \mathrm{~m}$ (questionably at $180 \mathrm{~m} ; 330$ 
$m$ in the Clark's Fork Basin) where they occur together with stage 1 specimens and are otherwise indistinguishable from them (Figure 68 ). Hence stage 2 specimens overlap temporally with the youngest stage 1 specimens. Not unexpectedly, in this transitional interval (180-190 m) the presence or absence of an alveolus for $\mathrm{p} 2$ is sometimes ambiguous. Thereafter (above $190 \mathrm{~m}$ ), p2 is invariably absent; i.e., stage 1 no longer exists. The name Tetonius matthewi is employed for stage 1 and coeval stage 2 specimens that fall within the size range of subsequent samples of the lineage; stage 2 individuals from above 190 $\mathrm{m}$ (the last occurrence of stage 1) are arbitrarily excluded and constitute the earliest and most primitive Tetonius matthewi-Pseudotetonius ambiguus intermediates. The coexistence of both stage 1 and stage 2 specimens at East Alheit Pocket and at Hackberry Hollow in the Clark's Fork Basin (Figure 69) suggests that these two sites correlate roughly with the 180-190 m interval in the southern and central Bighorn Basin.

Specimens assigned to stage 2 because of their two-rooted p3 are most common in the 190-290 $\mathrm{m}$ interval in the central Bighorn Basin, with just a few higher records up to $344 \mathrm{~m}$ (Figure 68). Significantly, however, all are not of uniform morphology. With higher stratigraphic level there is an increasing tendency toward anteroposterior compression of the two roots, as well as reduction in $\mathrm{p} 3$ size (especially length) compared to p4 (e.g., USGS 3853, YPM 25044, YPM 25585 from the 250-290 $\mathrm{m}$ interval). The latest occurring specimens with a two-rooted $\mathrm{p} 3$ are decidedly advanced in other characters: in both USGS $9148(336 \mathrm{~m})$ and USGS 6555 (344 m; Figure $22)$, the p3 crown is smaller than in other stage 2 specimens and the dentary is markedly foreshortened. Moreover, both possessed a large central incisor and very reduced canine and (preserved in USGS 6555 only) i2. Although they are assigned to "advanced" stage 2 because of the two-rooted p3, they are more consistent with stage 3 or stage 4 in other aspects. These records underscore the arbitrariness of the stages used here and exemplify the mosaic acquisition of characters during anagenesis.

Overlapping stratigraphically with later stage 2 individuals are some specimens which exhibit such compaction of $\mathrm{p} 3$ roots that two discrete roots can no longer be discerned. Such specimens displaying fused p3 roots (stages 3 and 4) appear for the first time at $280 \mathrm{~m}$ and exist as high as $370 \mathrm{~m}$, thus grading into Pseudotetonius ambiguus (Figure 68). Not surprisingly, in the more primitive individuals of this type, it is sometimes difficult to ascertain whether there are two very closely appressed roots or a single C-shaped or bilobed root (coalescence occurs first on the buccal side); but in more advanced specimens coalescence is unequivocal.

Two classes of fusion of $\mathrm{p} 3$ roots are designated, and these are termed stage 3 and stage 4 . In both stages, p3 typically is smaller and the anterior teeth are more compacted (with concomitant foreshortening of the dentary) than in stage 1 and most stage 2 specimens. Advanced stage 2 specimens, however, may differ from stage 3 only in having a p3 with two separate roots. The fused p3 root in stage 3 is either bilobed on both buccal and lingual aspects or C-shaped (appearing single buccally but two-rooted lingually; Figure 23). In stage 4 coalescence is more complete; the root is only weakly bilobed lingually and usually single or very faintly bilobed buccally (Figures 26, 27). The two stages obviously intergrade and assignment of some specimens to one or the other is equivocal; hence, this division further illustrates the gradual nature of the transition to Pseudotetonius ambiguus.

Stages 3 and 4 coexisted with each other and with advanced stage 2 individuals from about $280 \mathrm{~m}$ to about $350 \mathrm{~m}$, and the more advanced stages had clearly supplanted stage 2 by the end of this interval (Figure 68). Individuals of stage 3 morphology are somewhat more common than the others through most of this interval, but above $340 \mathrm{~m}$ stage 4 predominated briefly until the appearance of stage 5 at about $350 \mathrm{~m}$. The highest stage 3 specimen (USGS $3882,348 \mathrm{~m}$ ) occurs at the lowest part of the range of Pseudotetonius ambiguus, but it is less advanced than specimens of the latter.

In the 350-370 $\mathrm{m}$ interval, all specimens represent either stage 4 or stage 5 (about equally common in this interval) and all are assigned to $P$. ambiguus. Stage 5-the culmination of about 1.5 million years $(200 \mathrm{~m})$ of evolution in this lineage-is characterized by a very foreshortened dentary, a much en- 

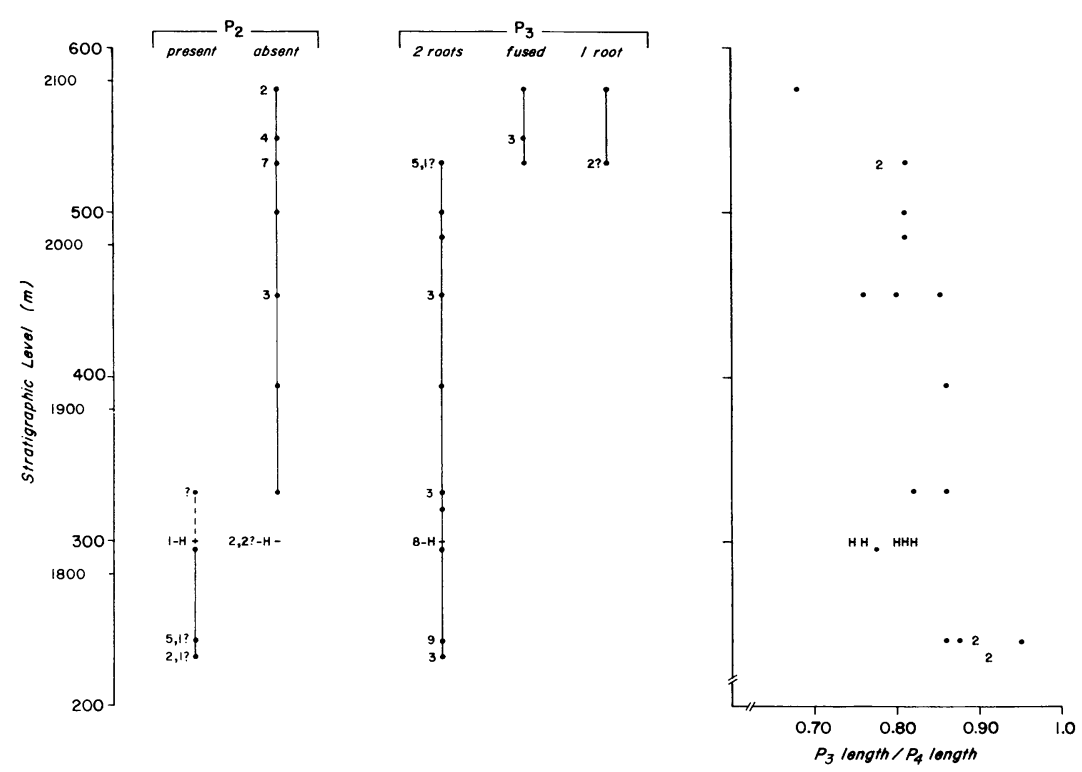

FIGURE 69-Stratigraphic distribution of premolar traits in the Tetonius-Pseudotetonius lineage from the Clark's Fork Basin, depicted as in Figure 68. Meter levels are measured from the ClarkforkianWasatchian boundary sandstone; Gingerich's (1982) levels from the base of the Paleocene are indicated at left. Stratigraphic level of Hackberry Hollow (UM locality SC-192) is unknown but probably about 250-350 m; data from there are indicated by $\mathrm{H}$ and are arbitrarily entered at $300 \mathrm{~m}$.

Data for p2: Present-UM 83122?, 83394, 86219 (230), UM 69787, 69817, 71379, 71393, 79537?, 79540 (240), USGS 2326 (295), UM 76771? (330), UM 79232 (H). Absent-YPMPU 18139?, UM 79332, USGS 479, 2333? (H), UM 76767 (330), UM 66832 (395), UM 66695, 72937, USGS 2457 (450), UM 66807 (500), UM 66821, 73151, 73206, 73231, 73243, 73264, 80152 (530), UM 67306, 67318, 67329, 69700 (545), UM 73453, 75037 (575).

Data for p3: Two roots-UM 83122, 83394, 86219 (230), UM 66219, 69787, 69817, 71379, 71393, 76674, 79537, 79540, USGS 5985 (240), USGS 2326 (295), UM 78969 (320), UM 73913, 76767, 76771 (330), UM 66832 (395), UM 66695, 72937, USGS 2457 (450), UM 72966 (485), UM 66807 (500), UM 73151, 73206, 73231, 73243?, 73264, 80152 (530). Fused roots-UM 66821 (530), UM 67306, 67318, 69700 (545), UM 73453 (575). One root-UM 67329?, 73224? (530), 75037 (575).

Data for $\mathrm{p} 3 / \mathrm{p} 4$ ratios from appendix.

larged i1, and a further reduced $\mathrm{p} 3$ as small as the canine and $\mathrm{i} 2$; the single root of $\mathrm{p} 3$ lacks any indication of the previous two-rooted condition (Figures 29, 67). Although data are sparse, it is evident that i2 and c also underwent reduction and compaction, whereas il became more robust, from stage 1 to stage 5. The molars (m1, m2, M1) display a slight but significant shift toward smaller mean size in $P$. ambiguus, but aside from this they are remarkably constant throughout the lineage (Figure 59).

Although $P$. ambiguus is readily distinguished from Tetonius matthewi, it must be defined arbitrarily using a combination of morphologic and stratigraphic criteria. This definition, all stage 5 and contemporaneous stage 4 specimens, limits the species to the most progressive members of the lineage. As currently known, this includes all stage 4 and stage 5 specimens from $346 \mathrm{~m}$ and above. Other definitions might be valid but would be equally arbitrary. Any strictly stratigraphic or strictly morphologic definition would necessitate either inclusion of some specimens with less progressive morphology (that cannot be distinguished from certain older specimens) or exclusion of some individuals indistinguishable from $P$. ambiguus.

In the Clark's Fork Basin, where a dense, unequivocal record is not yet known, the lower boundary of $P$. ambiguus is even more nebulous. There, stages 4 and 5 coexisted at $575 \mathrm{~m}$ and possibly as low as $530 \mathrm{~m}$ (Figure 


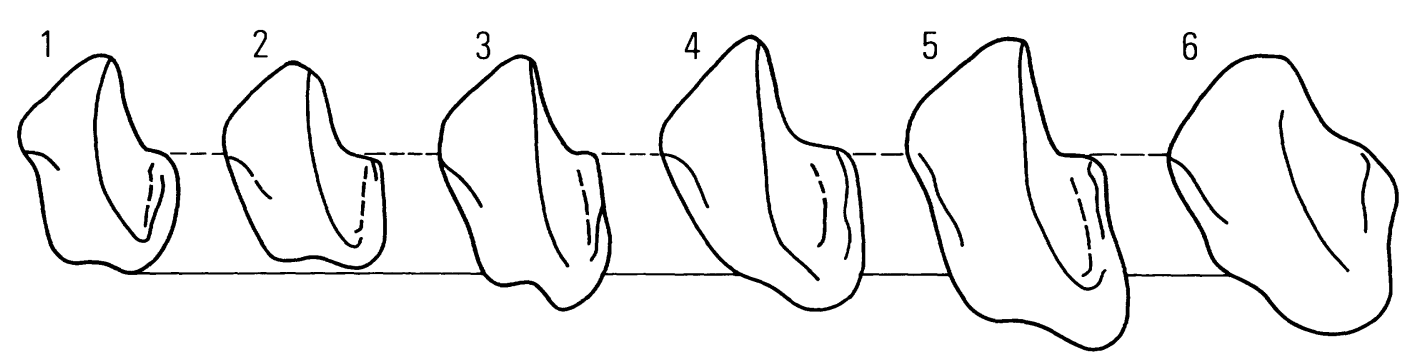

FIGURE 70-Lower fourth premolars of Absarokius (lateral views), showing six sizes and morphologies of crown height and posterobuccal distension of the crowns. 1, 2, Absarokius metoecus n. sp. 3, 4, Absarokius abbotti (Loomis). 5, Absarokius abbotti (type specimen of $A$. "noctivagus" Matthew). 6, type specimen of Absarokius witteri Morris.

69). The distribution of characters in the Tetonius-Pseudotetonius lineage in the Clark's Fork Basin sequence closely parallels that in the Bighorn Basin, strengthening the pattern defined above. In the Four Mile area, P. ambiguus (="Mckennamorphus despairensis") occurs at Despair Quarry, suggesting that this site is much younger than the Alheit quarries.

Whether the impetus for the morphologic shift from Tetonius matthewi to Pseudotetonius ambiguus was a change in diet, mode of ingestion, or some other factor is only speculative. The highest known specimen of $P$. ambiguus occurs at $374 \mathrm{~m}$, after which the Tetonius-Pseudotetonius lineage evidently became extinct in the central Bighorn Basin (just prior to Biohorizon B of Schankler, 1980).

Evolution in the Absarokius clade. - When viewed in stratigraphic context, the large Bighorn Basin sample of Absarokius exhibits more or less continuous intergradation in cheek tooth size (Figures 51-54) and morphology. It has been generally assumed before this study that the sample represented a single species, $A$. abbotti, or a small species (A. abbotti) and a handful of specimens of a larger species (A. noctivagus). Although it is tempting to interpret this sample as a single yet highly variable species (it is impossible to do otherwise without stratigraphic controls), the degree of difference in both size and morphology is too great to be contained in one paleontologic species. For example, stratigraphic plots of cheek tooth size in $A b$ sarokius (Figures 51-56) depict much wider size distributions than have been shown to be normal for many species of mammals (e.g., Gingerich, 1974b; Gingerich and Winkler, 1979). Similarly, the variability in p4 mor- phology (Figure 70) encompasses that formerly used to identify both Tetonius and $A b$ sarokius and to distinguish between them at the generic level.

Variability in both size and morphology can be correlated temporally and different intergrading morphologies succeed one another in dominance through the Willwood record of Absarokius. These relationships appear to indicate gradual intraspecific and interspecific evolution in two closely related species of Absarokius (that, initially, may have been sibling species). The molars of Absarokius are conservative morphologically and, as in the Tetonius-Pseudotetonius lineage, the antemolar teeth are most useful in establishing interrelationships within the genus. Emphasis is placed on the morphology of $\mathrm{p} 4$, which is clearly the most diagnostic tooth for species of Absarokius.

To document the complicated picture of evolution seen in Bighorn Basin Absarokius, the correlatable variation seen in samples at various successive levels of the Willwood Formation is discussed. Variation in cheek tooth size is especially broad in Willwood Absarokius but does not, by itself, separate species. The earliest record of Absarokius in the Bighorn Basin is the first occurrence of $A$. metoecus at the $425 \mathrm{~m}$ level of the Willwood Formation. The next sample occurs at $442 \mathrm{~m}$, and the first large samples at 463 and $470 \mathrm{~m}$, the last level equivalent to the base of the Lower Heptodon Range Zone of Schankler (1980). Both lower and upper cheek teeth are smaller in mean size in the 425-520 $\mathrm{m}$ interval than at $560 \mathrm{~m}$ and above (Figures 51-56) yet most specimens are within one standard deviation of the mean. The observed ranges of successive samples overlap 

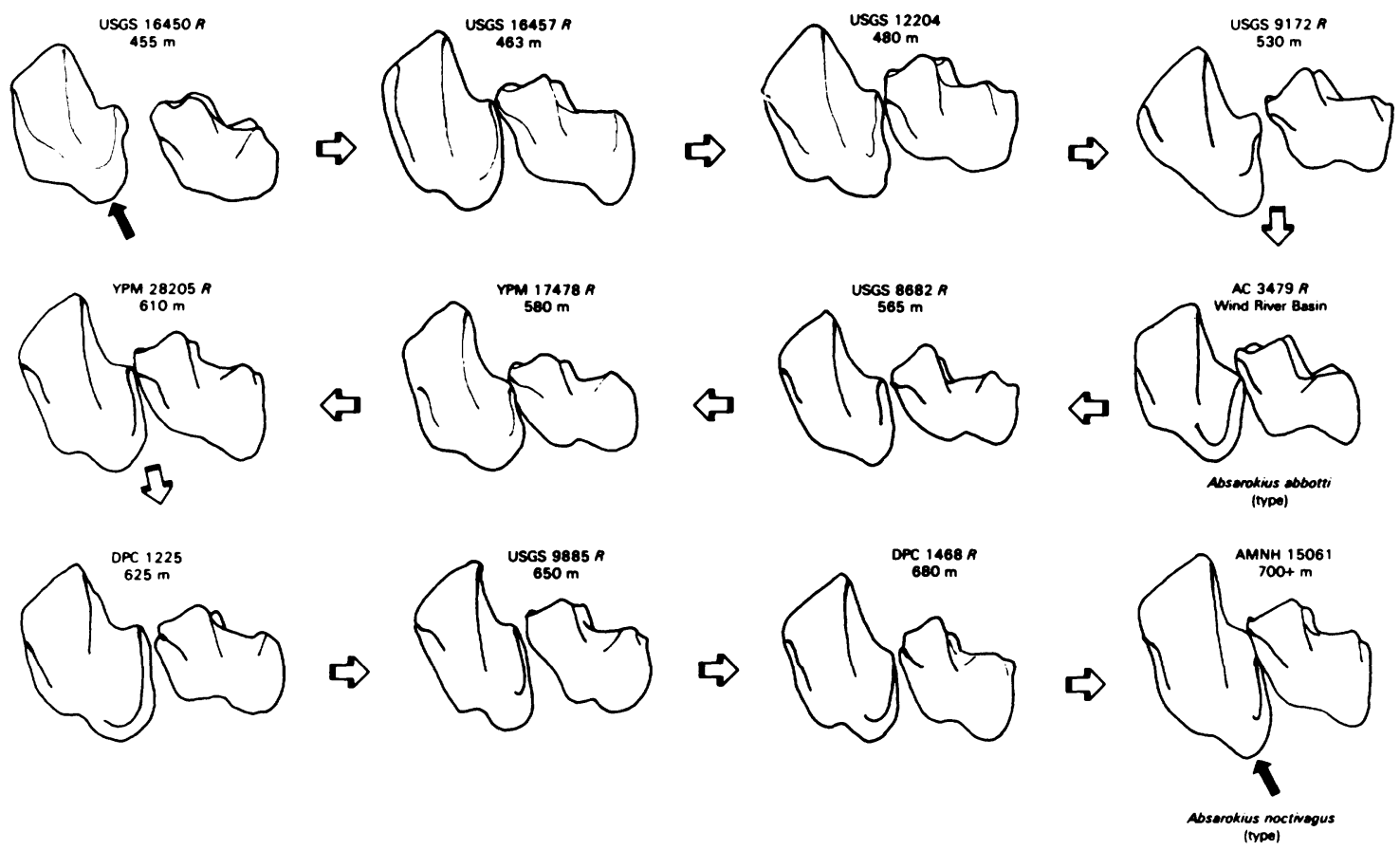

FIGURE 71-Temporally-stratified dental variation in some lower fourth premolars and lower first molars of Absarokius abbotti (Loomis). All specimens from Willwood Formation, Bighorn Basin, except type of $A$. abbotti, and specimens occur higher in the Willwood section ( $\mathrm{m}=$ meters) following the open arrows (the relative position of the type of $A$. abbotti is hypothetical). Note that there is pronounced posterobuccal distension of the p4 crown (solid arrows) throughout the range of this species when compared with the condition in $A$. metoecus n. sp. (Figure 72). $\mathrm{R}$ indicates reversed image.

with those at higher stratigraphic levels. There is no marked bimodality when measurements for lower teeth in the 463-520 m interval are combined with those for the sample as a whole. Bimodality of tooth size does begin to occur in the Absarokius sample at and above the $560 \mathrm{~m}$ level. The sample from the 463-520 $\mathrm{m}$ interval, however, bridges this bimodal distribution and causes the entire sample, when examined independent of stratigraphy, to appear unimodal though highly variable. Moreover, certain specimens plot at the small end of the observed size range in the premolars and/or $\mathrm{m} 1$ or $\mathrm{M} 1$, yet occur in the middle or large end of the ranges for $\mathrm{m} 1, \mathrm{M} 1$, and/or $\mathrm{m} 2, \mathrm{M} 2$. Therefore, if it is desirable to divide the Willwood Absarokius sample into two or more paleontologic species, size alone is inadequate and, especially, at the 463-520 m levels of the Willwood Formation.

The Willwood Absarokius sample from the $463-520 \mathrm{~m}$ interval is united by the common presence of a relatively unreduced $\mathrm{p} 2$, a relatively large $\mathrm{p} 3$ possessing two clearly defined roots, and unenlarged i1-2. These features also characterize the pooled sample of $A b$ sarokius at all higher levels of the Willwood Formation and serve to distinguish it from samples of the older related taxa Tetonius and Pseudotetonius. However, an obvious variable feature in the pooled Absarokius sample is the relative height of p4 (Figures 36, 37), associated with the relative degree of posterobuccal ventral distension of its crown (Figures 71,72 ). Because $\mathrm{p} 4$ morphology has been used to separate not only different species of Absarokius from one another (e.g., Morris, 1954; Robinson, 1966; Szalay, 1976) but also to distinguish between Absarokius and Tetonius (e.g., Szalay, 1976), the stratigraphic distribution of variability in p4 morphology is of considerable interest.

To investigate variability in p4 morphology, four parameters were examined: $p 4$ length ( $\mathrm{p} 4 \mathrm{~L}), \mathrm{p} 4$ crown height ( $\mathrm{p} 4 \mathrm{H}$; broken 

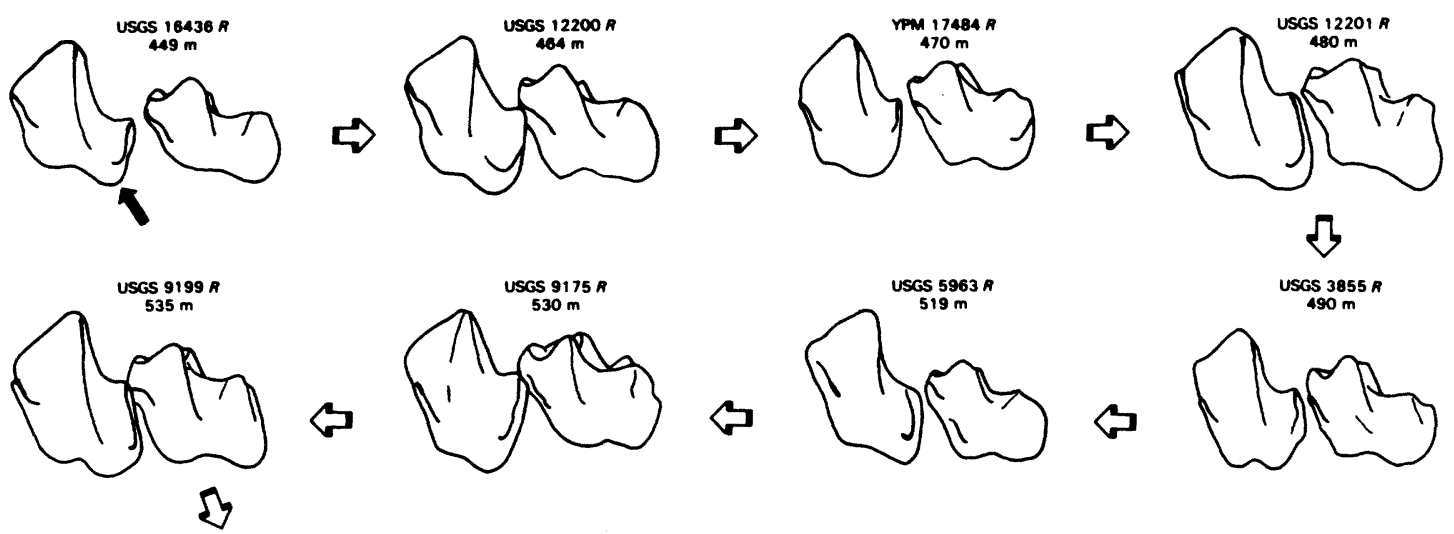

3
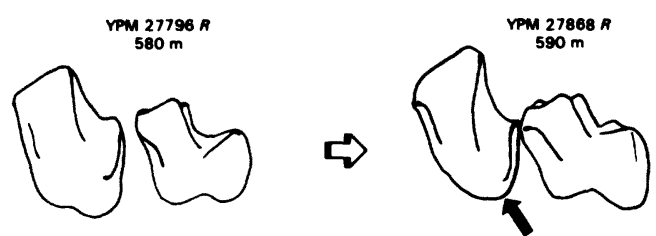

FIGURE 72-Temporally-stratified dental variation in some lower fourth premolars and lower first molars of Absarokius metoecus n. sp. All specimens from Willwood Formation, Bighorn Basin, and specimens occur higher in the Willwood section $(\mathrm{m}=$ meters) following the open arrows. Note that p4 remains relatively low-crowned with respect to that in $A$. abbotti (Loomis) (Figure 71), and that there is little posterobuccal distension of the crown (solid arrows). All are buccal views; $\mathrm{R}$ indicates reversed image.

and heavily worn specimens were ignored), degree of posterobuccal ventral crown distension, and stratigraphic position. The first two and the last of these parameters are continuous variables that were measured directly; the third is a ranked variable for which six categories of $\mathrm{p} 4$ morphology were established, from relatively little to relatively great posterobuccal ventral crown distension (Figure 70). Specimens were assigned to one of these categories by comparing standardized camera lucida tracings. Variability in p4 in a small part of the Absarokius sample is depicted in Figures 71 and 72.

As low as $463 \mathrm{~m}, \mathrm{p} 4$ already has a size range comparable with that in samples in the 560$610 \mathrm{~m}$ interval of the Willwood Formation (Figure 52). There is only a slight tendency to further increase the mean length of $\mathrm{p} 4$ (Figure 35 ), and this only in the $560-680 \mathrm{~m}$ interval. The slight increase in $\mathrm{p} 4 \mathrm{~L}$ in the middle and upper parts of the Willwood section correlates in a general way with increase in p4 $\mathrm{H}$ (Figures 36, 37); however, the Absarokius sample between 463 and $520 \mathrm{~m}$ is clearly dominated by specimens with a moderately long but low-crowned p4 (Figures 35, 36).
Because a p4 length approaching the mean for the pooled Absarokius sample is clearly achieved by some specimens in the sample at its earliest appearance at $442 \mathrm{~m}$, it is important to evaluate separately the stratigraphic distribution of $\mathrm{p} 4 \mathrm{H}$ and to compare this with the categories established for the relative posterobuccal ventral crown distension (Figures 70-72). From these comparisons, it becomes clear that the earliest part of the $A b$ sarokius sample (442-490 m) is characterized by low-crowned $\mathrm{p} 4$ with virtually no posterobuccal crown distension. As stratigraphically successive samples are examined, it is seen that two groups became established as early as the $455-520 \mathrm{~m}$ interval and that these typify the pooled Absarokius sample as high as the $590 \mathrm{~m}$ level. The first group possesses a p4 with a low crown and little or no crown distension and, in $\mathrm{p} 3$ and $\mathrm{m} 1$ size, invariably falls in the lower end of the observed size range for Absarokius. The second group evinces a tendency toward progressively higher $\mathrm{p} 4$ crowns and greater crown distension, coupled with $\mathrm{p} 3$ and $\mathrm{m} 1$ that are larger in mean size. The type specimen of Absarokius abbotti fits best in the second group, 
which is therefore assigned to that species. The holotype of $A$. abbotti is from the Wind River Basin and cannot be directly compared stratigraphically with the sample from the Willwood Formation. Assuming it had a common origin with the Willwood sample referred to $A$. abbotti, the type specimen is an early representative of that species in which $\mathrm{p} 4$ height is less than in much of the remainder of the $A$. abbotti sample (Figures 36, 37), but in which the degree of posterobuccal crown distension is typical of that in the remainder of the sample (Figure 71). Unfortunately, specimens of Absarokius possessing the lower crowned, more generalized p4 (here referred to $A$. metoecus) are rare at and above the $560 \mathrm{~m}$ level of the Willwood Formation. Moreover, there do not appear to be any features other than size by which lower molars of these two groups can be consistently distinguished (except at the highest levels of the Willwood Formation).

Although $A$. metoecus is distinctive and is the only species of Absarokius in the 425$454 \mathrm{~m}$ interval, two interpretations present themselves for identification of Absarokius materials higher in the Willwood section. The first is that $A$. metoecus gave rise to $A$. abbott $i$ through anagenesis; i.e., via the gradual transformation of the first species into the second. Under this hypothesis, specimens retaining the morphology of $A$. metoecus and continuing to cluster at the small end of the size range of the pooled Absarokius sample at levels above $490 \mathrm{~m}$ are simply end member variants of $A$. abbotti. This interpretation is tempting because of the relative rarity of $A b$ sarokius with $A$. metoecus $\mathrm{p} 4$ morphology in successively younger samples.

A second interpretation is that $A$. metoecus gave rise to $A$. abbott $i$ in the time represented by the $455-520 \mathrm{~m}$ interval and that both species then coexisted during the time contained within the 455-680 m interval (sympatric cladogenesis). A third alternative, that $A$. abbotti was introduced into the Bighorn Basin at the time of the $455 \mathrm{~m}$ level and gradually replaced or absorbed populations of the primate termed $A$. metoecus, is belied by the almost continuous intergradation in size and morphology that already exists in the pooled sample at the advent of the first large sample with mean $A$. abbotti size and morphology (560 m level).
The morphology of the upper teeth of $A b$ sarokius (Figures 73, 74) supports both the gradual continuous separation and the coexistence of both species through that time represented by $225 \mathrm{~m}$ of section (455-680 m levels of the Willwood Formation). Examination of the size of P4 and M1 (Figures 55, 56) shows that these teeth, like $\mathrm{p} 4$ and $\mathrm{m} 1$, are smaller in mean size in the $449-490 \mathrm{~m}$ interval than in younger samples, but that the largest of these teeth are near the mean size for samples derived from higher in the section. The 13 maxillary specimens from the 449-490 m interval (USGS 484, 506, 1195 , $12226,16433,16435,16445,16447,16453$, 16458, 16459; DPC 1215, and DPC 1413) possess teeth that resemble those in the majority of larger upper dentitions from $560 \mathrm{~m}$ and above in having transversely broad upper molars and relatively small M2 trigon basins. However, all of them are referred to $A$. metoecus on the basis of their relatively small mean size which, coupled with their lower stratigraphic range, almost certainly associates them with lower teeth of $A$. metoecus at these levels.

In the 500-560 m interval, the sample of Absarokius upper teeth is larger and two different molar morphologies appear. The first, exemplified by USGS 1437 (Figure 74), USGS 3848 , and YPM 17483, consists of M1-2 that are less transverse and M2 with a relatively larger trigon basin than occurs in the remainder of the pooled sample. USGS 3848 $(500 \mathrm{~m})$ has a relatively large M1 that could easily fit within the large sample of Absarokius M1 with a greater mean size found at much higher levels. However, USGS 1437 and YPM 17483 (Figure 74), from $560 \mathrm{~m}$, possess very small P4 and M1. A bimodal size distribution for these teeth is apparent at and above the $560 \mathrm{~m}$ level. Thus, increased distinction in both size and morphology took place in the 500-560 m interval.

Above the $560 \mathrm{~m}$ level, only YPM 17488 at $680 \mathrm{~m}$ and YPM 28317 at $625 \mathrm{~m}$ have distinctively smaller teeth than the remainder of the Absarokius sample. YPM 28317 (Figures $34.1,74$ ) has the transversely narrowest upper molars of any specimen of Bighorn Basin Absarokius and possesses a greatly enlarged M2 trigon basin. YPM 17488, from $680 \mathrm{~m}$ (Figures 43.3, 74), is the youngest specimen of small Absarokius and has the 

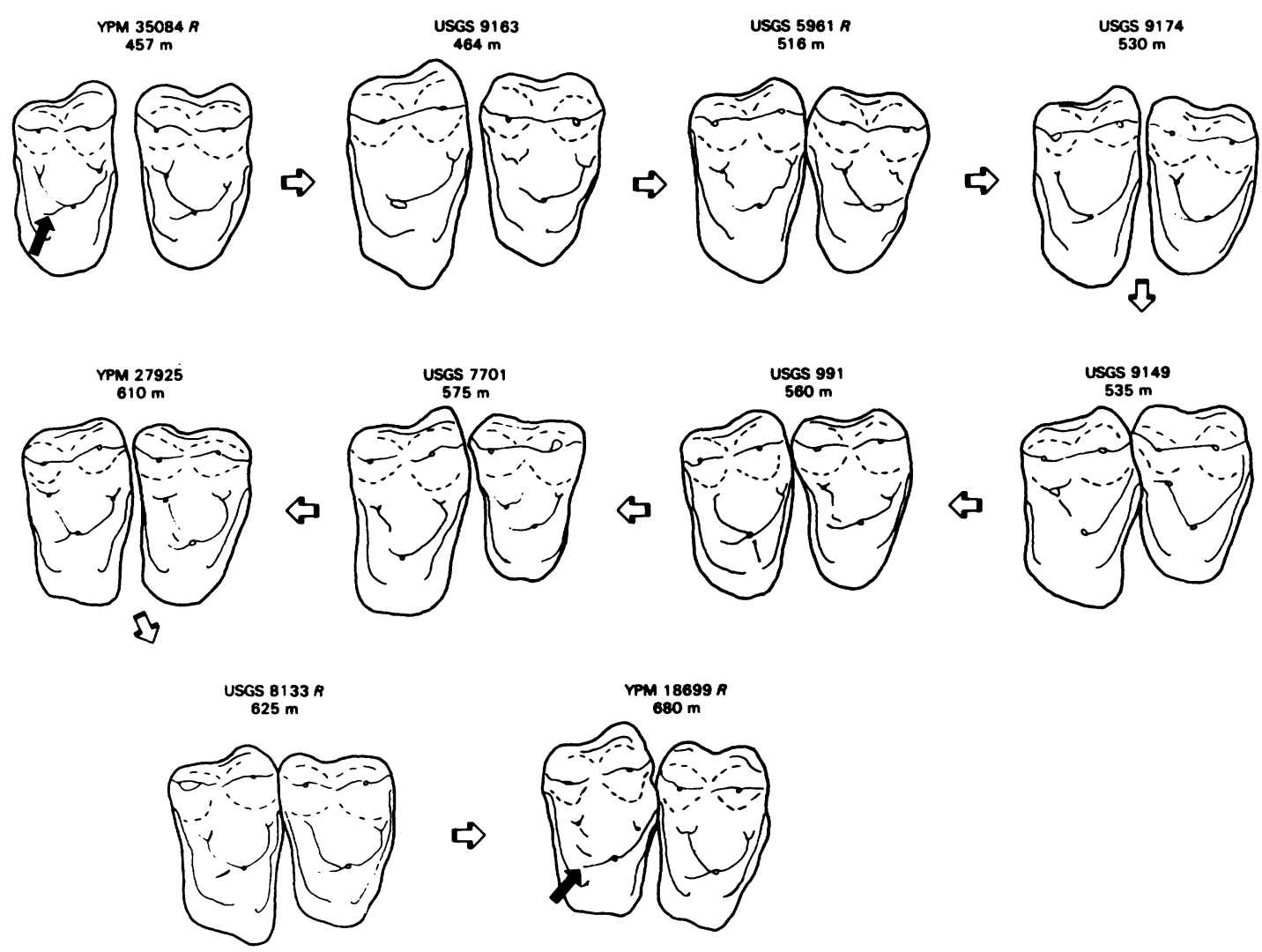

FIGURE 73-Temporally-stratified dental variation in some upper first and second molars of Absarokius abbotti (Loomis). All specimens from Willwood Formation, Bighorn Basin, and specimens occur higher in the Willwood section $(\mathrm{m}=$ meters) following the open arrows. In comparison with the upper molars of $A$. metoecus $\mathrm{n}$. sp. (Figure 74), note that there is no crenulation of molar enamel, no enlargement of molar trigons, and no confluence of postprotocrista (solid arrows) with postcingulum. All are occlusal views; $\mathbf{R}$ indicates reversed image.

most advanced upper teeth in the Bighorn Basin Absarokius sample. It has transversely very narrow P4-M2, an M2 that is not appreciably broader transversely than M1 (in contrast to all other Absarokius), and greatly enlarged M1-2 trigon basins. YPM 17488 and 28317 are highly distinctive when compared with any examples of Absarokius drawn from the sample that is exemplified by larger molars (Figure 73). In addition, YPM 17488 has more expanded M1-2 trigon basins than in other specimens. This has resulted in increased surface area of the trigon and was accomplished not only by reduction in size of the internal bases of the paracone and metacone, as seen in earlier specimens of small Absarokius (e.g., USGS 1437, YPM 28317; Figure 74), but also by extreme posteroventral extension of the postprotocrista, causing it to become confluent with the postcingulum (as also occurs in Bridgerian $A y$ crossia and Strigorhysis; Bown, 1979b). Incipient posteroventral extension of the postprotocrista occurs also in YPM 28317 but is unknown in all specimens beneath the $625 \mathrm{~m}$ level. YPM 17488 also possesses somewhat crenulated enamel in the M1-2 trigon basins, a feature also present but less well developed in USGS 1437 at the $560 \mathrm{~m}$ level. In the development of crenulated enamel, YPM 17488 also resembles upper molars of Aycrossia and Strigorhysis (Figures 43.1, 43.2, 46.4). USNM 22267 (Figure 43.4) from the Wind River Formation of the Wind River Basin and AMNH 55154 and 55155 from locality III of the Huerfano Formation, Huerfano Basin, Colorado, also resemble YPM 17488 in most of these characters and are 

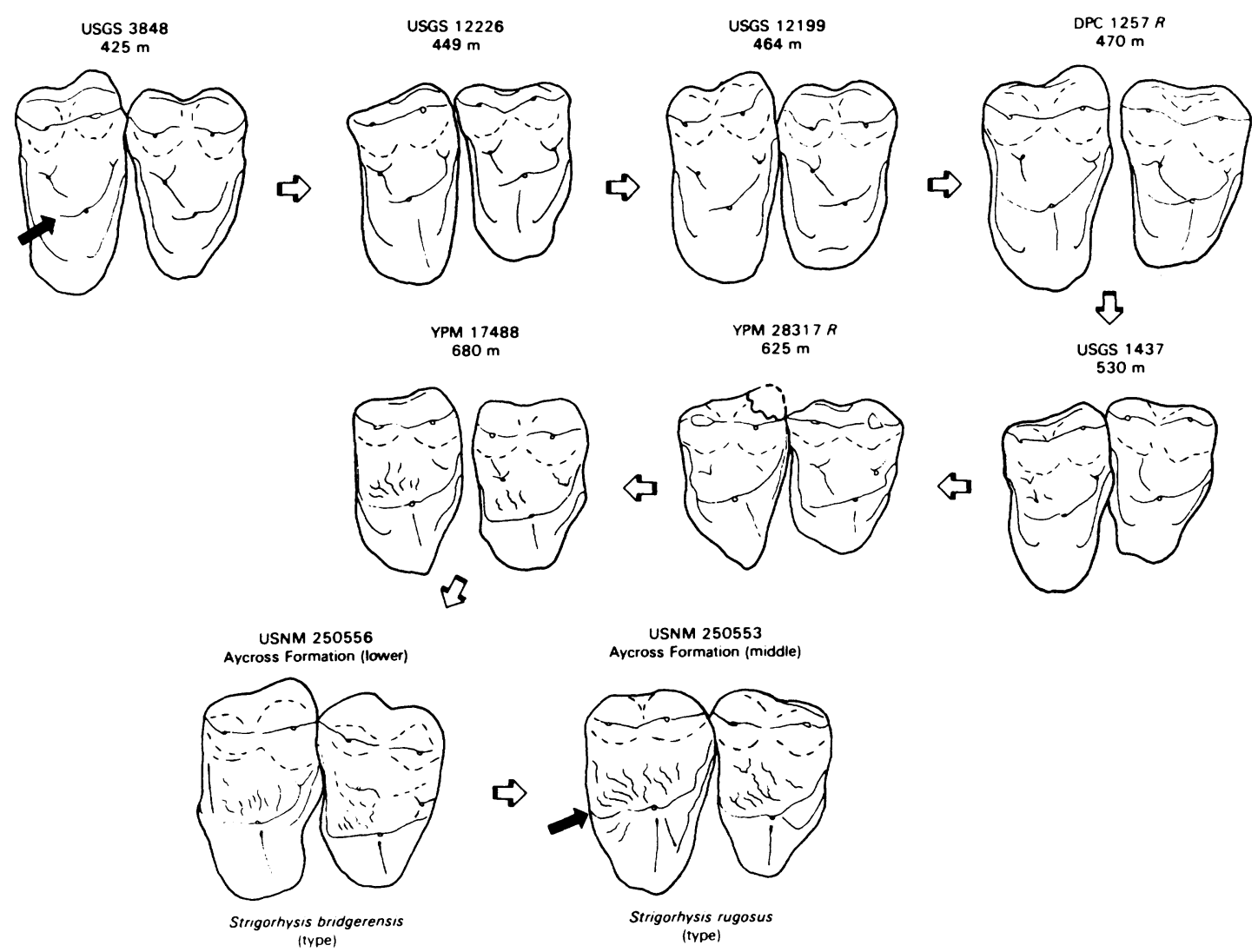

FIGURE 74-Temporally-stratified dental variation in some upper first and second molars of Absarokius metoecus n. sp. (upper two rows), Strigorhysis bridgerensis Bown, and S. rugosus Bown. All Absarokius are from the Willwood Formation, Bighorn Basin, and all Strigorhysis are from the Aycross Formation, Absaroka Range. Specimens occur higher in the Willwood $(\mathrm{m}=$ meters) or Aycross sections following open arrows. Note enlargement of trigon basin and confluence of postprotocrista (solid arrows) with postcingulum up section. Enamel crenulation, first seen as a minor variable character at $530 \mathrm{~m}$, also becomes pronounced later in the lineage (compare with $A$. abbotti (Loomis), Figure 73). All are occlusal views; $R$ indicates reversed image.

here referred to Absarokius metoecus. AMNH 55218 , from the stratigraphically higher Huerfano locality I (Robinson, 1966), is a large new species of Strigorhysis.

Absarokius metoecus and A. abbotti are closely related, partly coeval species that appear to have diverged from each other by gradual cladogenesis in the Bighorn Basin during approximately the time represented by the $455-560 \mathrm{~m}$ interval. These species differ by the characters listed in the diagnoses presented above but, as is clear from the foregoing discussion, the extensive overlap of certain characters and the divergence of others in successively younger samples cause their diagnoses to be highly simplified portrayals of their complex morphological positions with respect to each other. Difficulties in diagnosing continuously evolving closely related organisms is thereby also underlined by analysis of the Absarokius clade in the Bighorn Basin.

Because absolute $\mathrm{p} 4$ size and $\mathrm{p} 4 \mathrm{H}$ can no longer be used as diagnostic in the separation of Absarokius from Tetonius, as was thought by several earlier authors (e.g., Matthew, 1915; Gazin, 1962; Szalay, 1976), a case could be made for including the early members of the species metoecus in Tetonius rather than in Absarokius, and transferring the later members of species metoecus to Strigorhysis. This is indeed a moot point, and evidence 
against the latter solution is in part circumstantial. First, the interrelationships detailed above indicate that $A$. abbott $i$ is a derivative of $A$. metoecus. Second, both $A$. metoecus and $A$. abbotti possess $\mathrm{p} 2$ and this tooth is proportionately much larger than that in the much older Tetonius matthewi. Third, p2 is lost altogether in successively younger samples of the Tetonius-Pseudotetonius lineage, $T$. matthewi being the last to possess it. Fourth, p3 is relatively large and possesses two clearly distinct and separated roots in both $A$. metoecus and $A$. abbotti, whereas in the middle and upper parts of the TetoniusPseudotetonius lineage, $\mathrm{p} 3$ becomes progressively smaller and develops first coalesced roots, then a single root. This constitutes clear evidence that $A$. metoecus almost certainly was not derived from any known species of Bighorn Basin Tetonius, but the possibility still exists that $A$. metoecus is instead a more conservative species of Tetonius that immigrated into the Bighorn Basin. This species would have to have been one that had not reduced $\mathrm{p} 2$ to the vestigial condition already seen in Tetonius matthewi from the Lower Haplomylus-Ectocion Zone.

Szalay (1976), following Matthew (1915) and Gazin (1962), believed that Absarokius is separable from Tetonius in the possession of smaller lower incisors, especially i1, which is greatly enlarged in the latter genus. Unfortunately, only two of the lower jaws belonging to $A$. metoecus preserve the front of the jaw (USGS 8256 and YPM 35098, Figure 41). Nonetheless, comparison of incisor size in those specimens to that in Tetonius indicates that $A$. metoecus shares relatively small incisors with other Absarokius. The species metoecus is therefore assigned to Absarokius on the basis of small lower incisors held in conjunction with a less reduced $\mathrm{p} 2$.

Teilhardina belgica, the earliest known omomyid, possessed small incisors and an unreduced $\mathrm{p} 2$, hence these characters are assumed to be primitive for the Omomyidae. Later members of the Teilhardina lineage and the entire Tetonius-Pseudotetonius lineage are derived relative to Teilhardina belgica in enlargement of the central lower incisor and in reduction of $\mathrm{p} 2$ (eventually lost in the Tetonius-Pseudotetonius lineage). The retention of two small lower incisors is, therefore, an important symplesiomorphy that indicates a retained "primitive" state in incisor morphology linking Absarokius with Bridgerian Anaptomorphus and, possibly, Uintanius (the incisor region of the lower jaw is unknown for Steinius and Chlororhysis).

Retention of plesiomorphous small incisors (especially il) is accompanied in $\mathrm{Absa}$ rokius by the primitive retention of a relatively large $\mathrm{p} 2$, without the more specialized reduction in canine and p3 size and loss of one $\mathrm{p} 3$ root that typifies the more derived Tetonius-Pseudotetonius lineage. Retention of a p2 that is relatively large with respect to that in Tetonius matthewi indicates that the Absarokius-Tetonius complex in the Bighorn Basin shared their last common ancestor prior to the advent of $T$. matthewi.

Absarokius metoecus was clearly an immigrant into the Bighorn Basin at about the time represented by the $425 \mathrm{~m}$ level of the Willwood Formation, although only two specimens (USGS 3846, 3848) are known from that level. Several more specimens are known at the 442,463 , and $470 \mathrm{~m}$ levels. In the southern Bighorn Basin, the $470 \mathrm{~m}$ level is locally coincident with Schankler's (1980) Biohorizon $\mathrm{C}$, a faunal boundary typified by the first appearance (immigration) of many mammals into the basin, including the perissodactyls Heptodon and Xenicohippus (Bown and Kihm, 1981), and the arctocyonid Anacodon. The first appearance of Absarokius, therefore, predates Biohorizon $\mathrm{C}$ (and the middle Wasatchian, or "Lysite" provincial sub-age) in the Bighorn Basin.

The ancestor of $A$. metoecus was probably a species of Tetonius that lived outside the Bighorn Basin and possessed a conservative antemolar dentition most like that of Bighorn Basin T. matthewi, but in which there was no incisor enlargement and no incipient antemolar reduction as exemplified by the vestigial p2 in that species. Trends in the morphology of the upper molars of $A$. metoecus suggest that this species is related to the ancestry of latest Wasatchian and early Bridgerian Strigorhysis and, less certainly, $A y$ crossia from the Aycross and Wind River Formations. The following modifications are necessary to transform middle-late Wasatchian Absarokius metoecus into Bridgerian Strigorhysis: increase in $\mathrm{p} 4 \mathrm{H}$, increase in $\mathrm{p} 4$ posterobuccal crown distension, appearance of a parastylid on $\mathrm{m} 1$, increase in size of $11-2$ and 


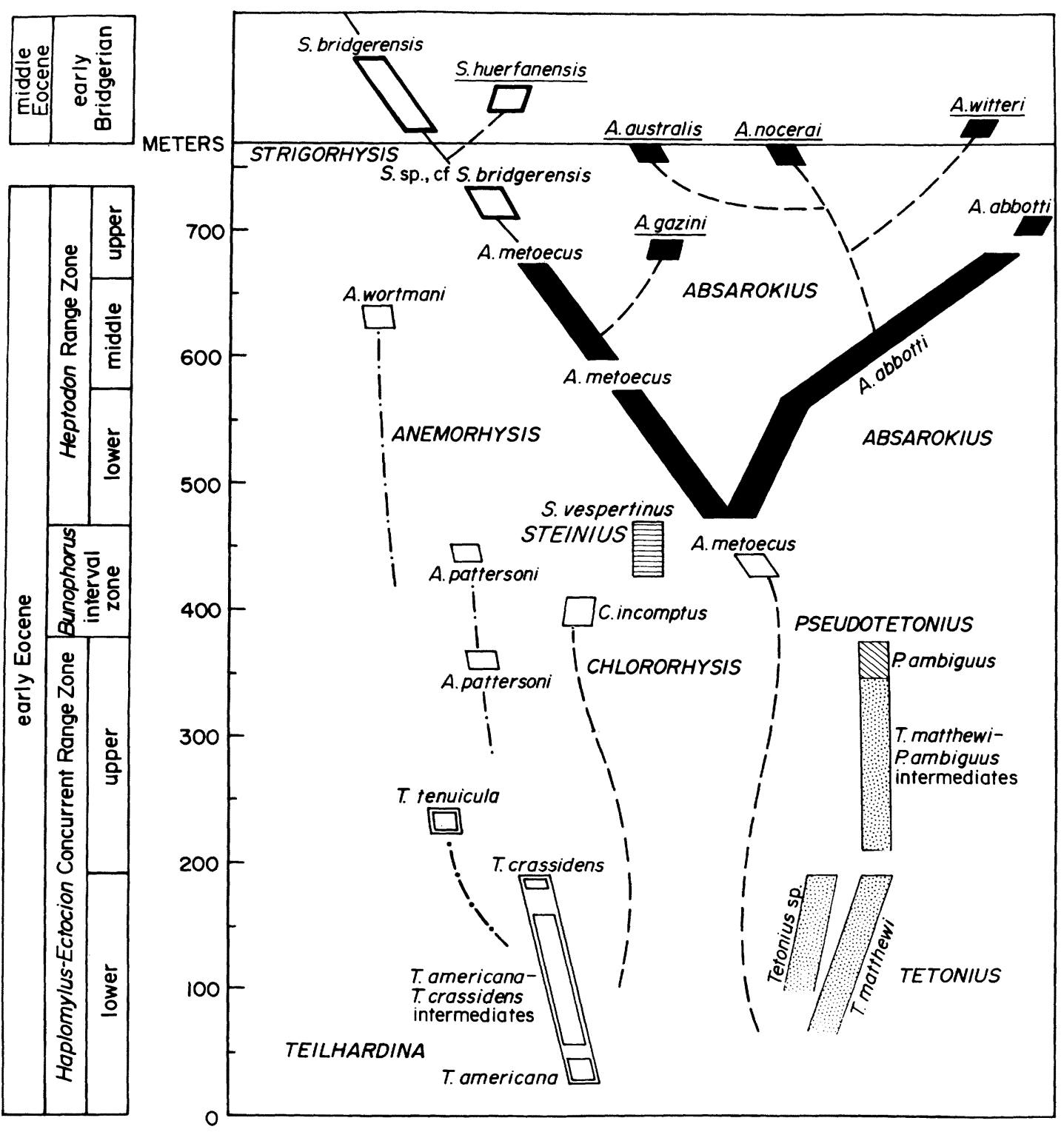

FIGURE 75-Interpretation of evolutionary interrelationships of Bighorn Basin anaptomorphine primates and some pertinent forms from elsewhere. Lineages in block form indicate, approximately, the stratigraphic record of specimens; taxa known only from outside the Bighorn Basin are underlined. Thin lines that are both dotted and dashed indicate hypothetical lineages that probably evolved within the Bighorn Basin; thin lines that are dashed only indicate hypothetical lineages that probably evolved extraneous to the Bighorn Basin. Meter levels (100-700) refer to stratigraphic positions within the Willwood Formation; the relative positions of species occurring only outside the Bighorn Basin are inferred from non-primate faunal evidence. The positions of the Haplomylus-Ectocion Concurrent Range Zone, the Bunophorus Interval Zone, and the Heptodon Range Zone and their subdivisions are from Schankler (1980), as modified by faunal evidence from the Fifteenmile Creek section of the Willwood Formation in the south-central Bighorn Basin (see Figure 3).

of all the cheek teeth, and development of more rugose molars. In addition, in Aycrossia and Strigorhysis, there is an increase in the massiveness of the posterolingual base of the protocone, and a tendency for the pre- and postparacone cristae and the pre- and postmetacone cristae to be straighter than in $A$. abbotti or early $A$. metoecus. Clarification of 
the actual relationships of $A$. metoecus to the Aycross anaptomorphines must await recovery of specimens of anaptomorphines from equivalents of the Tatman Formation which, in the Absaroka Range, lie above the Willwood Formation and beneath the Aycross Formation (Bown, 1982).

The position of Absarokius metoecus with respect to $A$. abbotti is tantalizingly similar to that between Tetonius matthewi and Tetonius sp. discussed above. Both $A$. metoecus and Tetonius sp. have teeth that are relatively small in comparison to $A$. abbotti and $T$. matthewi, respectively, with which they intergrade in both size and morphology. Because of this similar yet unusual relationship between forms in both the Tetonius and $A b$ sarokius lines, it is conceivable that $A$. metoecus is a descendant of Tetonius sp. Although Tetonius sp. appears to be extinct (in the Bighorn Basin) above the $190 \mathrm{~m}$ level of the Willwood Formation, it is possible that the Tetonius sp. line survived somewhere outside that basin and again reappeared there during the time represented by the $425 \mathrm{~m}$ level in the guise of Absarokius metoecus. Such local extinction and ecological re-entry in the Willwood fauna was documented by Schankler (1981) for the condylarth Phenacodus. The validity of this hypothesis unfortunately cannot be tested without additional knowledge of the ancestry of $A$. metoecus or later developments (if any) in the Tetonius sp. line.

A summary of the suggested origins and interrelationships of the Absarokius lineage is depicted in Figure 75.

\section{SUMMARY AND CONCLUSIONS}

At about the beginning of the Wasatchian, the anaptomorphine primate Teilhardina was introduced into the Bighorn Basin. The source of the Bighorn Basin species, T. americana, is unknown but its close morphologic similarity to European Sparnacian $T$. belgica strongly indicates that that species was in its ancestry or was very closely related to it. Teilhardina americana is the oldest North American omomyid and is unknown from any other early Tertiary basin on that continent. If it originated in Europe or from a transported European (or even Asian) population of Teilhardina, its distribution would at one time have included intervening areas (e.g., north- eastern and northwestern United States and Canada); however, for the most part, rocks of suitable age do not occur, have not been sampled, or fossils from them have not been found. Similarly, in the early Tertiary Williston, Powder River, Wind River, Green River, Uinta, Sand Wash, Washakie, Huerfano, and San Juan Basins of the western United States - all critically important to later North American omomyid evolution $-T$. americana is absent for the same reasons. It is nonetheless extremely unlikely that Teilhardina found a suitable North American home only in the Bighorn Basin; rather, it is more probable that it is an artifact of the fossil record that the earliest part of the history of the Omomyidae can be reconstructed only from the Bighorn Basin.

It is therefore to the early Eocene mammal fauna of the Bighorn Basin that one turns to examine the earliest part (and indeed the densest record) of North American anaptomorphine history. This fact derives also from the exceptionally complete, well and continuously exposed sequence of lower Eocene rocks there (Willwood Formation), and from the unusual abundance of fossil vertebrate remains at closely spaced stratigraphic intervals through the sequence. Nonetheless, significant parts of the evolutionary story of the early Eocene anaptomorphine primates are lacking even from the Bighorn Basin. This is due to the inadequate representation of several forms (e.g., Anemorhysis, Chlororhysis, Steinius) or to poor representation of them through continuous sections or at several important points in the section (e.g., Teilhardina-Anemorhysis transition). Anaptomorphine primates were surely not only present but abundant, diverse, and evolving along similar or quite different lines in other early Tertiary basins.

This paper has documented patterns of evolution in the anaptomorphine primates of the Bighorn Basin, treating as well some forms that are closely related to the Bighorn Basin anaptomorphines but which are known only from other basins, or subsequent to the early Eocene. It is acknowledged that this study contains by no means the whole story of the early Eocene Anaptomorphinae; critical evidence from many other areas is needed and, even within the Bighorn Basin lineages, collection of additional material will require re- 
evaluation of the interrelationships of the Anaptomorphinae as a group.

Most authors agree that all omomyid primates could have descended from a form similar to Teilhardina belgica and all North American omomyids could have had an ancestor similar or equivalent to Teilhardina americana. The Bighorn Basin omomyid lineages are composed solely of members of the Anaptomorphinae, the older and more generalized of the two North American omomyid subfamilies, and include 14 species in eight genera: Teilhardina (three species), Anemorhysis (two species), Steinius (one species), Chlororhysis (one species), Tetonius (two or three species), Pseudotetonius (one species), Absarokius (two species), and Strigorhysis (one species). Ignoring Steinius (a possible ancestor of the Omomyini whose record is confined to the Bighorn and Wind River Basins but whose evolutionary history is unknown) and Chlororhysis (whose origin is both geographically and evolutionarily unclear), three clades of anaptomorphines are well documented in the early Eocene of the Bighorn Basin: the Teilhardina-Anemorhysis clade; the Tetonius-Pseudotetonius clade; and the clade comprising Absarokius, its many species, and the probably allied genus Strigorhysis (Figure 75).

The Teilhardina clade (25-635 $\mathrm{m}$ interval, central and southern Bighorn Basin) was characterized by gradual, sympatric, anagenetic and probably cladogenetic dental evolution, which resulted in primates $(T$. crassidens, $T$. tenuicula) with very small teeth, short and squat semimolariform lower premolars widely separated in the jaw, and, except for loss of $\mathrm{p} 1$, no appreciable reduction in the number of teeth. The medial incisor apparently enlarged in this lineage. These trends continued in Anemorhysis, in which the most advanced species lost p2. Anemorhysis probably evolved gradually from Teilhardina, but the record is too poor to document the origin and evolution of Anemorhysis.

Tetonius was almost certainly descended from Teilhardina americana, but the fossil record is not dense enough or continuous enough in any basin to record the transition. The emergence of Tetonius from Teilhardina appears to have followed a pattern of morphologic change not now recorded from any one geographic area but in the sequence: Teil- hardina americana-Tetonius mckennai-Tetonius species-Tetonius matthewi. Tetonius matthewi, the oldest and most generalized named species of Tetonius in the Bighorn Basin, first appears there at the $64 \mathrm{~m}$ level where it co-occurs with the group designated Teilhardina americana-T. crassidens intermediates. The Tetonius-Pseudotetonius lineage (64-about $375 \mathrm{~m}$ interval) also exemplifies gradual, in situ anagenetic evolution of the dentition, but in this case producing primates with larger teeth, a tall premolariform p4, lower antemolar teeth that became situated ever more close together in the dentary, and the appreciable decrease in size of $i 2$ and $c$ and of size, number, and number of roots of the lower premolars. The medial lower incisor also became much larger and the p4 remained large, causing the antemolar dentition of the younger end member of the lineage, Pseudotetonius ambiguus, to appear shrew-like. Similar modifications appear to have developed in parallel in the younger anaptomorphines Trogolemur (middle Eocene; possibly an offshoot of the Anemorhysis lineage) and Nannopithex (a Pseudotetonius-like anaptomorphine from the middle Eocene of Europe), and convergently to developments in the microsyopid uintasoricine NavajoviusNiptomomys lineage. A second, short-lived lineage of Tetonius, here designated Tetonius sp., coexisted with Tetonius matthewi.

The earliest known species of Absarokius, A. metoecus, first appears in the Bighorn Ba$\sin$ at $425 \mathrm{~m}$, but younger, more advanced specimens of this species are also known from the Wind River and Huerfano Basins. Judging from the excellent representation of anaptomorphines in the Bighorn Basin and the total lack of overlap there with its nearest known relative, Tetonius matthewi, Absarokius metoecus was rather clearly an immigrant into that basin; however, its geographic origins cannot now be determined.

Evolution in the Absarokius clade took place principally through lineage-splitting (cladogenesis), even though this too was a gradual process. Although Absarokius metoecus clearly antedates the earliest record of $A$. abbotti, the latter species can be identified morphologically as low as the $455 \mathrm{~m}$ level, and both species coexisted throughout nearly all of the rest of their stratigraphic distribution. Absarokius is typified by retention of $\mathrm{p} 2$ 
(larger than in even Tetonius matthewi), increase in size of p4 with respect to p3, and presence (retention?) of a primitively small medial lower incisor. The $A$. metoecus lineage is characterized by the presence of a lowcrowned $\mathrm{p} 4$ with little or none of the posterobuccal crown distension characteristic of the closely related $A$. abbotti. In successively younger members of the $A$. metoecus lineage, a parastylid developed on $\mathrm{m} 1$, the $\mathrm{m} 1$ trigonid cusps formed a prow-like isosceles triangle with the paraconid at its apex, the upper molars became less transverse and broaderbasined with the Nannopithex-fold increasingly approaching confluence with the postcingulum, and there is a marked tendency toward crenulation of enamel in the molar basins. Because all of these trends are in the direction of latest early Eocene and middle Eocene Strigorhysis, it is probable that the latter genus is the most advanced known member of the Absarokius metoecus lineage.

The A. abbotti lineage, on the other hand, remained relatively conservative in molar evolution, but had a tendency to increase the height of p4 as well as the depth of posterobuccal p4 crown distension. The youngest positive member of this lineage has both traits developed to an extreme (the type specimen of Absarokius noctivagus, here included in $A$. abbotti); however, it is quite likely that most other Absarokius species from other early Tertiary basins were derived from some part of the $A$. abbotti lineage.

Both anagenesis and sympatric cladogenesis were important mechanisms in the evolution of the Bighorn Basin Anaptomorphinae. Both mechanisms appear to have operated gradually; i.e., with no marked leaps from one character state or taxon to another in a relatively brief interval of time. If the record of primate evolution documented here was achieved by the mechanism known as punctuated equilibria, any profound distinction between that mechanism and the more traditional phyletic gradualism can no longer be defended. All of the transitions (character to character, species to species, even genus to genus) involve a succession of very minor morphological differences, any one of which has little or no taxonomic significance by itself. Many aspects of the dental morphology are involved and evolution occurred in mosaic fashion; i.e., initial change in any one character is not necessarily (or even commonly) synchronous with changes in other characters. At the same time, certain traits were in stasis for observable intervals, but there is no evidence that the dentition as a whole (or the organisms) ever displayed stasis. If these character and species and genus transitions were produced by numerous, more or less continuous recolonizations of central populations by "preadapted" peripheral populations possessing (at any one time) only infinitesimally small, yet adaptive geno- and phenotypic differences from the central population, then punctuated equilibria and Darwinian gradualism are the same thing.

The evidence from the record of Bighorn Basin Anaptomorphinae indicates that, in this group, no species, genus, or even character is clearly distinct (or even well defined) at or near the time of its inception. Rather, they emerged through the cumulative effect of continual change, not by an abrupt morphologic shift followed by stasis. This evidence is sharply contrary to predictions of the punctuated equilibria model and requires a re-evaluation of: 1) the nature of the evolutionary process; 2) problems of taxonomic procedure in the light of gradual evolution (see also Rose and Bown, 1986); 3) problems posed for biostratigraphy in the light of gradual evolution; and 4) "rates" of evolution. Also relevant here are some insights on nonpaleontologic factors controlling not only the evolution of these primates but its very record.

The nature of evolution in the Bighorn $\mathrm{Ba}$ sin anaptomorphine record. - It is sometimes assumed that, in cladogenetic speciation, there is an increase in character variability just before or during the initiation of divergence. In the Bighorn Basin anaptomorphine record, an increase in character variability occurs in the course of anagenetic speciation (e.g., Teilhardina americana-T. crassidens and Tetonius matthewi-Pseudotetonius ambiguus transitions). This variability is more explicit in the evolution of character states than between taxa simply because a taxon-level transition generally involves the change of a suite of character states through time; each of these are differentially represented by the fossil materials and, as was discovered for the lineages studied, each of the character states begins to change and stops changing at different times. 


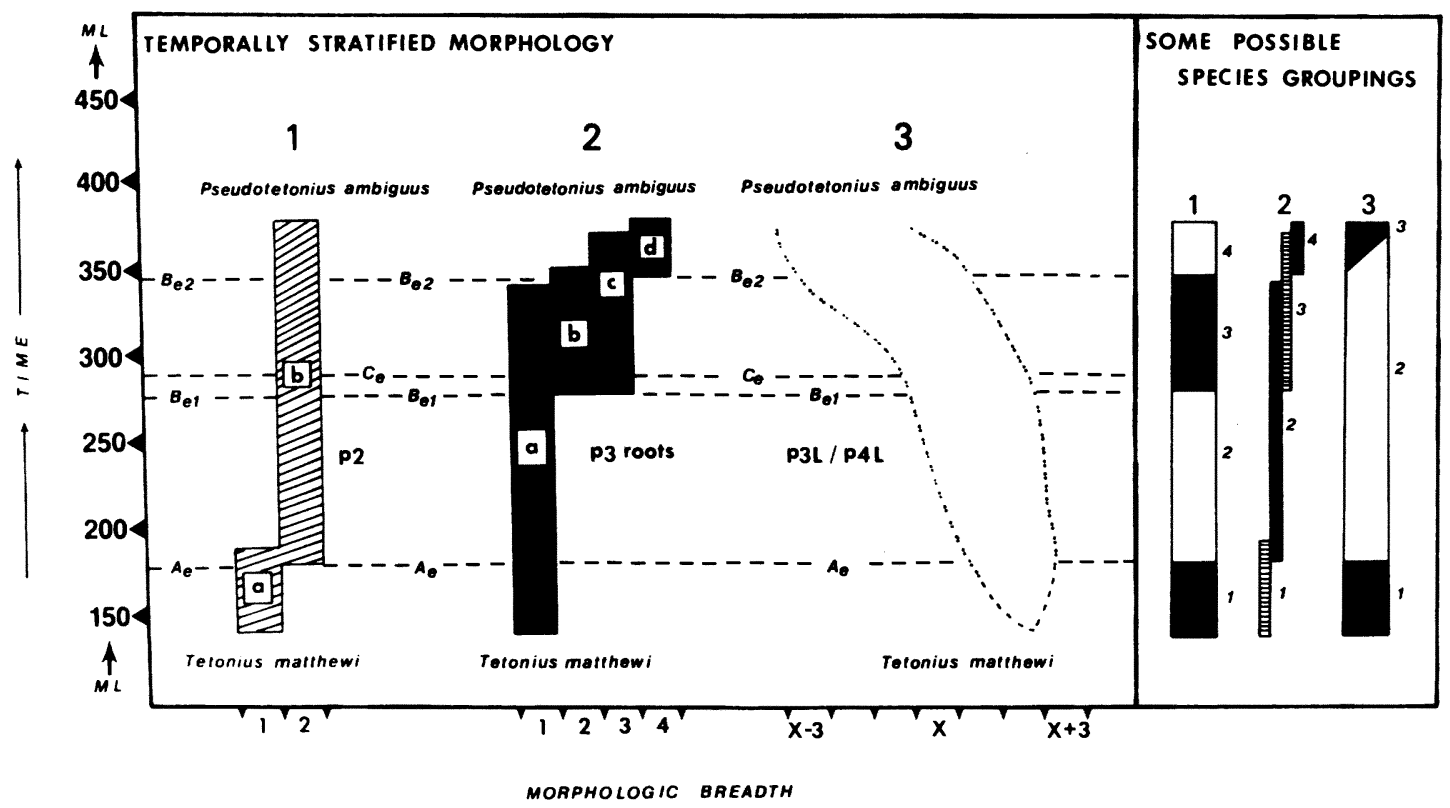

FIGURE 76-Temporally-stratified morphology and morphologic breadth (a measure of variability expressed in arbitrary dimensionless units) in lower premolars of members of the Tetonius-Pseudotetonius lineage (left diagram, 1-3), and some possible species groupings that can be drawn from them (right diagram, 1-3), with respect to time. Time is expressed in successive meter level intervals (ML) above base of Willwood Formation. LEFT DIAGRAM-Temporally-stratified morphology. $1=$ p2; $a=$ present; $b=$ absent; $A e=$ event horizon at which first specimens lacking $\mathrm{p} 2$ appear. $2=\mathrm{p} 3$ roots; $a=p 3$ with two distinct roots; $b=p 3$ with bilobed or $C$-shaped root; $c=p 3$ with single root labially and bilobed root lingually; $\mathrm{d}=\mathrm{p} 3$ with one small root; $\mathrm{Be} 1=$ event horizon at which first specimens with a bilobed or $\mathrm{C}$-shaped $\mathrm{p} 3$ root appear; $\mathrm{Be} 2=$ event horizon at which first specimens with a single small $\mathrm{p} 3$ root appear. 3 = envelope enclosing range of variation for $\mathrm{p} 3 \mathrm{~L} / \mathrm{p} 4 \mathrm{~L}$, expressed as a ratio (note that this ratio decreases up section); $\mathrm{Ce}=$ event horizon at which $\mathrm{p} 3 \mathrm{~L} / \mathrm{p} 4 \mathrm{~L}$ ratio begins to decrease sharply (a less discrete event horizon than the others). The presence or absence of $\mathrm{p} 2(1$, above) is an absolute character, whereas the number and morphology of the p3 roots (2, above) and the ratio p3 L/p4 L (3, above) are transient characters. Note that in characters 1-3 (above) evolution occurred by at first increased, then decreased, morphologic breadth (character variability) and that these transformations were both temporally controlled and morphologically intergrading. RIGHT DIAGRAM-Three of several possible species groupings in the Tetonius matthewi-Pseudotetonius ambiguus lineage. Column 1: Species are discriminated arbitrarily at stratigraphic boundaries with the aid of some morphological landmarks (in this case, first appearance of a new morphology, which is not coincident with last appearance of the antecedent condition). Note that under this scheme, no species co-exist and only species 1 has no morphological overlap with species 3 and 4 because it is the only species (except species 2 ) in which p2 is retained. There is also no way to distinguish consistently between species 1 and 2, and species 3 shows the most variability. Column 2: Species are discriminated strictly by morphology (so that consistent diagnoses can be constructed for taxa), ignoring stratigraphic considerations. Though the first appearance event horizons are utilized, this scheme causes the ranges of certain species to overlap in the same manner that their diagnostic morphologies overlap, resulting in two contemporaneous, sympatric species through much of the record-almost certainly overestimating true species richness at any one time. Column 3: Species are discriminated using a combination of morphological and stratigraphic criteria, but diagnoses are (necessarily) constructed using the morphologic information arbitrarily (in the stratigraphic sense), an artifact of the temporal stratification of morphology. This scheme is the one adopted in this paper, in which species $1=$ Tetonius matthewi, "species" $2=T$. matthewi-Pseudotetonius ambiguus intermediates, and species $3=$ Pseudotetonius ambiguus. Of these three alternatives, only interpretation 2 allows species diagnosis on some combination of mutually exclusive characters. Yet this interpretation almost surely overestimates species richness at any one time and obscures the nature of the actual character evolution. Alternatives 1 and 3 are examples of anagenetic gradual evolution, whereas alternative 2 might appear to represent cladogenetic "punctuated" evolution. However, the character evolution is the same in all three examples; it is gradual and anagenetic, 
In the parlance of the punctuated equilibria school of thought, stasis (i.e., organismic stasis) does not appear to have occurred at any point in the dental evolution of the Bighorn Basin anaptomorphine primates. Although not all characters were changing at once (or even at the same time or "rate"), in any temporal interval where the record is relatively dense, it is clear that some trait was changing. There is no indication of stasis, even in the limited evidence of the dentition.

Characters used to study the evolution of the anaptomorphines were earlier termed: 1) absolute, typified by a simple change from presence to absence; 2) transient, continued presence but also continual modification; and 3) static, no change in the character for a known interval. Figure 76 depicts examples of each of these three kinds of temporally stratified characters in evolutionary context, as they pertain to the Tetonius-Pseudotetonius lineage. The presence or absence of $\mathrm{p} 2$ (Figure 76, left side, 1) is clearly an absolute character because a specimen either possessed it or did not. The configuration (and ultimately the number) of the $\mathrm{p} 3$ roots, and the change in the ratio of $\mathrm{p} 3 \mathrm{~L} / \mathrm{p} 4 \mathrm{~L}$, are transient characters because nothing that was present became lost. Static characters are represented by: 1) specimens that have $\mathrm{p} 2$ but do not overlap with samples lacking it; 2) specimens that lack p2 but do not overlap with samples retaining it; and 3) all specimens with two distinct $\mathrm{p} 3$ roots (or those with a single p3 root) which do not overlap with intermediate forms. In Figure 76 (left side), the evolution of these characters is inferred from their distribution in time (meters above the base of the Willwood Formation) plotted against morphologic breadth, shown in wholly arbitrary dimensionless units. The different styles of transitions from the character states present in Tetonius matthewi (shown at the bottom of the figure) to those present in Pseudotetonius ambiguus (shown at the top of the figure) were, for the reasons discussed above, developed gradually and anagenetically. Yet in each as well as in other character transitions in this lineage and the Teilhardina-Anemorhysis and Absarokius lineages, character change was accomplished by first an increase then a decrease in morphologic breadth. Brief intervals of stasis then occurred in individual characters, but never in the dentition as a whole. For species (or in this case, genus) transitions, the same applies, except that increase and decrease in morphologic breadth would be that for the sum of the absolute and transient character changes in the lineage.

It would be enlightening to have specimens of this lineage through an additional 250-odd meters to examine whether Pseudotetonius ambiguus, once established, ever became static in all dental characters. However, the genus is unknown above about $370 \mathrm{~m}$ in the Bighorn Basin (or comparable time intervals elsewhere) and its descendants (if any) are unknown. Specimens at the top of the known range of this lineage are ascribed to $P$. ambiguus because they are at the top of the lineage. If more evolution in this lineage could be documented in higher stratigraphic intervals, it might be preferable to extend the range of the Tetonius-Pseudotetonius intermediates upward rather than to establish an arbitrary generic threshold.

Similar trends in absolute, transient, and static characters are seen in the Teilhardina americana-T. crassidens lineage (e.g., loss of p1, size changes, foreshortening of dentary, p4 height, p4 paraconid and metaconid positions) and in the Absarokius clade. In the A. metoecus-Strigorhysis line, the lower molars are conservative until high in the section when they develop prow-like trigonids; the upper molars become more broadly basined and progressively less transverse and, concomitant with some of these trends, develop crenulation. The height of p4 stagnates

and was accomplished by an increase followed by a decrease in morphologic breadth. Morphological event horizons are staggered temporally and do not coincide at any point. Coincidences of these first appearances would be expected if the species actually arose rapidly by the mechanism of punctuated equilibria. In spite of the difficulties posed for systematics by these interpretations, the detailed intrabasinal biostratigraphic utility of the first appearance event horizons and the resulting recognition of $T$. matthewi-P. ambiguus lineage stages $1-5$ (in text) is obvious. 
through most of the $A$. metoecus line, but increased early in its collateral relative $A . a b$ botti (and may have done so later, in parallel, in the $A$. metoecus line to produce Strigorhysis).

Therefore, although it is possible to document stasis in individual characters or teeth, there is no evidence for stasis in species or genera in the anaptomorphine lineages studied. Because of the enormous number of character complexes in specific and higher level taxa, it is extremely unlikely that true organismic stasis ever existed at a taxonomically recognizable level in these primates.

Another observation that emerges from this study is the sympatric presence of two species of the same genus at the same time (even at the same locality). This is best seen in the cooccurrence of Absarokius metoecus and A. abbotti, but is also clear with Tetonius matthewi and Tetonius sp. It is stressed that sympatry of species is far from unusual in the Willwood fauna; temporal and spatial sympatry of two species of Cantius (Bown, 1987), two species of Phenacodus (Schankler, 1981), and three or even more species of Hyopsodus (Gingerich, 1974a), as well as other genera, are well known. As will be discussed in the next section, visualization of the co-occurrence of two or more contemporaneous species (or stages of evolution) of the same genus (or species) is also determined by how taxonomy is perceived from the evolutionary perspective. It would be easy to assume through conceptual proclivities that two very closely related, coexisting taxa should belong to different genera; however, this must be counterbalanced by what a classification at the generic level should mean in terms of different adaptations.

In the Anaptomorphinae, evolutionary trend reversals are also fairly clearly established by the increase in relative $\mathrm{p} 3-4$ size in going from Tetonius sp. (or even Teilhardina) to Tetonius matthewi, and the decrease in relative p3 size (very dramatic) and p4 size (less so) in Pseudotetonius ambiguus.

Eldredge (1974) suggested three minimal requirements for a test of phyletic gradualism in samples of fossil organisms: 1) the sample must span a considerable segment of geologic time; 2) the sample must be derived from all available geographic areas and must approximate, as much as possible, the original con- figuration of the depositional basin; and 3) the phylogenetic relationships among these samples must be "... adequately and realistically grasped ...." These are also minimal requirements for a test of punctuated equilibria. The record of anaptomorphine primates analyzed here satisfies these criteria.

Although the age span of the Willwood Formation cannot be established directly by radiometric means, together with the lower $100-150 \mathrm{~m}$ of the conformably overlying Tatman Formation, it is believed to represent most of the early Eocene (about 57.6-51.0 Ma; see Berggren et al., 1985) without any appreciable gaps in time. Eliminating that part of the sequence that thus far yields no omomyids (the lower $25 \mathrm{~m}$ and upper $80 \mathrm{~m}$ of the Willwood Formation and all of the Tatman Formation), the remaining rocks represent about $4.4 \mathrm{Ma}$ and contain a relatively continuous record of omomyid evolution. The longest-lived lineages of omomyids in the Bighorn Basin for which there are excellent, fairly continuous documentation are the Tetonius-Pseudotetonius and Absarokius clades, apparently occupying about $2.14 \mathrm{Ma}$ and $1.98 \mathrm{Ma}$, respectively. This is an adequate period of time with which to document the nature of the evolution that took place, especially in view of the controls on times of accumulation of fossils and the spacing of these accumulations that is afforded by paleosol studies.

It is stressed that sequences of rocks representing appreciably longer cumulative time (e.g., those containing Eldredge's trilobites) have the inherent constraints of being severely compromised by time-averaging (Sadler, 1981). Perhaps more than for any other group of fossil vertebrates and exceeding that for many invertebrates, the Willwood record of omomyid primates is drawn from every available part of the Bighorn Basin, an early Tertiary depositional basin that can be demonstrated by nearly every avenue of available geologic evidence to have been structurally and topographically a basin during the period of omomyid evolution under consideration. Specimens are also known from the adjacent Wind River Basin, with which the Bighorn Basin was confluent during part of the early Eocene. The sample of anaptomorphines from the Clark's Fork area of the Bighorn Basin is especially valuable because, although it has 
been recovered from more than $100 \mathrm{~km}$ north of the central and southern Bighorn Basin sample, the record of anaptomorphine evolution there is practically identical.

Finally, although this study differs with Eldredge (1974) on the proper sequence to pursue the establishment of phylogenetic relationships relative to evolutionary studies, the interrelationships of the early Eocene Anaptomorphinae are now as clear and well established as for any mammalian group.

Thus the early Eocene anaptomorphine primates span a considerable period of time, are well represented throughout the Bighorn Basin (as well as elsewhere), and their phylogenetic relationships have been documented in detail. If they evolved by punctuated equilibria, they should show abrupt (geologically instantaneous) morphologic shifts followed by long periods without change. Such punctuations should occur in " $1 \%$ or less of later existence in stasis" (Gould, 1982, p. 84). Nowhere in the anaptomorphine record analyzed here is this the case. Instead, these primates strongly support the gradual model of evolution as clearly as can be expected by examples from the record of fossil vertebrates.

Implications of gradual evolution for taxonomic and biostratigraphic practice. - The way systematic studies are undertaken is necessarily influenced by the way evolution is viewed, and vice-versa (see, e.g., Rose and Bown, 1986). The concept of punctuated equilibria has as its basis the idea that species arise rapidly by means of a relatively thorough genetic restructuring of the organisms; i.e., a new species is constructed more or less out of whole cloth. Species, then, are presumed to be as distinct from closely related and progenitor species as they are ever to be, from the moment they appear. If one subscribes to this view, the major systematic problems remaining are the origin of higher taxa and where to limit stratified morphologic variation in assigning specimens to species. Aside from its genetic aspects, character evolution, especially the evolution of individual characters, takes a back seat in importance to evolution at the specific level and above, because several characters are assumed to change almost at once in producing the new organism. This very rapid reorganization is viewed to be the reason why evo- lutionary gaps (in the biostratigraphic record) and "missing links" (in the morphologic record) occur. The origin of higher taxa is perceived to proceed in much the same way, except that the level of genetic reorganization is correspondingly greater.

For specimens drawn from discontinuous stratigraphic sections, gaps in the evolutionary record are viewed as times of rapid evolution by the punctuated model, an idea apparently borne out by morphologic advances seemingly achieved suddenly by closely related organisms succeeding the gap. In more continuous sections, temporally stratified morphologic variation is lumped into an earlier species or a later one, because the species is viewed as real and discrete (even temporally); it is the fulcrum upon which not only systematics but also evolutionary biology hinges, and thereby must be capable of definition by diagnosis. Because evolution is perceived to proceed by jumps and is generally viewed as a process of diversification, the cladogram constitutes an adequate depiction not only of relationships, but of evolution itself, because the characters are situated at nodes where the rapid evolution occurs, and not on the branches, which represent intervals of stasis.

The anaptomorphine primates of the Bighorn Basin, as well as other groups of early Eocene mammals, are impressive for the continuous, temporally-graded succession of morphologies that appear when character state variability is arranged stratigraphically. It has been found that with ever increasing stratigraphic resolution of larger and larger samples it is no longer possible to find convenient points at which to draw limits to lumpable variability. Type specimens established many years ago which remain valid were distinctive at the time they were erected because they were morphologic end members for which little if any of the temporally graded morphologic variability connecting them was known. With increased amounts of data from intervening stratigraphic intervals, they are no longer so distinct.

An excellent example of what becomes of temporally and morphologically intermediate forms can be visualized in the systematic treatment of forms placed here in the Teilhardina-Anemorhysis clade. The multitude of names applied to various specimens of 
these animals resulted from ignorance of where any of them fit relative to one another in a temporal sequence, and because there was no way, therefore, to deal with temporally stratified variability. Once a stratigraphic sequence can be established, the relations between vertical-temporal and lateral variability become more clear and can be separated. The distribution of temporally-stratified variability (e.g., the whole stratigraphic range in Figure 75) provides direction for character polarities, whereas the distribution of variability within a single controlled range of time (e.g., 300-325 m interval in Figure 76) shows the range of species variability in individual characters within that interval.

A cladogram is neither an accurate depiction of relationships nor of evolution in Bighorn Basin anaptomorphines because the evolution was not concentrated at the nodes but, rather, occurred continuously (on the branches). In Absarokius, for example, which shows both anagenetic and cladogenetic gradual evolution, it is clear that $A$. metoecus and $A$. abbotti are less separable morphologically from each other at their initial divergence than they became later, and that both species continued to evolve gradually and anagenetically following their initial cladogenesis. The fact that the names $A$. metoecus and $A$. abbott $i$ were given to specimens drawn from the nodal sample in no way underscores their distinctiveness in this meter interval. The earliest samples are assigned to $A$. metoecus because they resemble $A$. metoecus recovered from higher levels more than they do $A$. $a b$ botti from higher levels. The nodal samples display an increase in variability encompassing specimens with many crossing characters shared by both $A$. metoecus and $A$. abbotti. The variability becomes more segregated (bimodal) within each taxon higher in the section. In this example of a gradual splitting of taxa, the species are least distinctive when they are first recognizable.

It is still desirable to give names to taxa and to attempt to set limits to the names by morphologic and biostratigraphic criteria. As shown above, it is impossible to set morphologic limits to a taxon without confining its biostratigraphic limits. Coupled with knowledge that evolution cannot take place without time, this fact emphasizes the importance of stratigraphy in both taxonomic and evolu- tionary studies. In large measure, the ambiguity that remains regarding the most appropriate names to affix to specimens devolves from the lack of precise locality and stratigraphic data for type materials and a poor knowledge of temporally-stratified variability in intermediate morphologies. If a realistic and workable taxonomy for samples drawn from gradually evolving lineages is desirable, then the stratigraphic dispersion of character variability is critically important and must be examined fully before pigeonholing the specimens in taxa. Because the dental characters of the Bighorn Basin Anaptomorphinae arose at different times, almost any number of taxonomies of these animals can be constructed, all of which will necessarily be arbitrary (e.g., Figure 76, right side, 4-6), but all of which will be equally "correct."

The arbitrary nature of taxonomy under the constraints of gradual evolution renders any biostratigraphy derived from it and based on specific names equally arbitrary. However, a much higher resolution biostratigraphy of Bighorn Basin anaptomorphines has emerged from examination of the character evolution in these lineages. There are many points at which might be drawn a morphologic, stratigraphic, or combined morphologic-stratigraphic boundary between Tetonius matthewi and Pseudotetonius ambiguus, or between either genus and the temporallystratified intermediates separating them (Figure 76). But there is only a single point at which the boundaries between different character states (or forms of these states in transient characters) can be established, and always with considerably greater biostratigraphic resolution than is afforded by the named taxa. Thus, it has been useful in this study to establish informal stages of evolution for samples both stratigraphically and morphologically intermediate between samples referred to named taxa. However, even these stages are equivalent to taxa from a biostratigraphic viewpoint. At the level of relative temporal control now possible by paleosol maturation sequences (Bown, 1985; Bown and Kraus, 1987) it should be possible in future years to establish relative contemporaneity of character evolution in Willwood mammals within about 2,000-30,000 years.

One of the uses of North American fossil 
mammal biostratigraphy is to correlate between intermontane basins, and even more disparate areas (e.g., Wood et al., 1941). Mammals, even arboreal primates like the anaptomorphines, are capable of relatively rapid dispersal and there is no reason to assume that the Anaptomorphinae were not present over a much larger geographic area in the early Eocene than their fossil record demonstrates. However, the early Eocene was a time of rather pronounced basin margin evolution in the Rocky Mountain interior, and it is probable that, with increased topographic isolation between basins, evolution of these primates and other mammals proceeded independently in each basin. For example, it seems that a form of Tetonius, but more generalized than Tetonius matthewi, gave rise to Absarokius in one area. However, in the Bighorn Basin, the only known descendant of Tetonius was Pseudotetonius ambiguus. The origins of other species of Tetonius, e.g., T. mckennai and Tetonius sp., are even more obscure, although both might be intermediates in the Teilhardina americana-Tetonius matthewi line. The tendency to assign specimens to the morphologically closest (even though poorlyknown) named taxa occurring in other basins is symptomatic of the need to correlate rocks and faunas. This practice, however, will probably prove to be somewhat ill-founded unless it is recognized that the most important parts of the anatomy in terms of character evolution may often be those that are only rarely preserved (e.g., the anterior dentition in the Anaptomorphinae).

Evolutionary rates in the Bighorn Basin anaptomorphines. - What can be said about rates of speciation when, by the constraints of gradual evolution, there is no one point (except an arbitrary one) at which it can be stated clearly: "here begins a new species?" Even if species boundaries are determined arbitrarily, how are rates of character and species evolution in hyopsodontid condylarths to be compared with those in anaptomorphine primates? How does one adjust the sliding scale for species to accommodate comparison of rates of evolution in species in different genera, families, or orders?

Meaningful comparisons can probably only be made between the same kinds of change in the same character (e.g., tooth loss, loss of the same tooth, loss of the tooth in the same manner). Even if species could somehow be established by use of the same procedural method, the evolving character complexes making up species (and higher level taxa) would be vastly different in total composition. Evaluation of the reliability and even the meaning (if any) of comparative evolutionary rates between taxa with such differing character complexes is well beyond the scope of this work, but it clearly needs to be addressed further in view of the significant role of gradual evolution in mammalian speciation and diversity. For rates of appearance (including divergence) of higher taxa, morphologic isolation (and thereby taxonomic distance) is a function of stratigraphic isolation. Given the degree and rates of morphologic change evinced from this study, and examining the stratigraphic records of Willwood mammals in general, it seems likely that many higher mammalian taxa originated by gradual evolution.

For the Bighorn Basin anaptomorphine primates, meaningful rates of evolution are transferred from the evolution of paleontologic species to the evolution of the specific characters that characterize paleontologic species. These rates can be established for both absolute and transient characters using the approximate amounts of time represented by the stratigraphic sections containing the morphologic transitions. The rate of evolution from one species (or genus) to another is obtained by calculating the time represented by the section that encompasses all of the relevant morphologic transitions. A few evolutionary rates calculated in this manner for Willwood anaptomorphines are presented in Table 9.

Rates such as these, which are based on relative section thicknesses for relative time elapsed, can be misleading. For example, in the lower part of the Willwood Formation, yielding fossils forming part of the TetoniusPseudotetonius transition, paleosols are in general more mature than in that part of the section yielding the Absarokius metoecus and $A$. abbotti lineages. Because mature soils required more time to form than did immature soils, there is positively more time represented in the lower part of the Willwood section than is represented in an equivalent thickness of rock in the upper part of that 
TABLE 9-Estimates of evolutionary rates for characters and species and genera in early Eocene anaptomorphine primates from the Willwood Formation, central Bighorn Basin.

\begin{tabular}{lccc}
\hline \hline Character or taxon transformation & Meters & Duration (Ma) & Rate \\
1) Teilhardina americana-T. crassidens & 134 & 0.960 & $1.04 \mathrm{sp} . / \mathrm{Ma}$ \\
2) Teilhardina americana-Anemorhysis pattersoni & $<339$ & $<2.433$ & $0.41 \mathrm{gen} . / \mathrm{Ma}$ \\
3) Tetonius matthewi-Pseudotetonius ambiguus & 156 & 1.120 & $0.89 \mathrm{gen} . / \mathrm{Ma}$ \\
3a) p2 always present-p2 always absent & $<64$ & $<0.459$ & - \\
3b) p3 always 2 roots-p3 always 1 root & $<105$ & $<0.754$ & $-\overline{3} \mathrm{sp} . / \mathrm{Ma}$ \\
4) Absarokius metoecus - Absarokius abbotti & 105 & 0.754 & $1.33 \mathrm{ga}$ \\
5) Absarokius metoecus-Strigorhysis cf. bridgerensis & $<255$ & $<1.830$ & $0.55 \mathrm{gen} . / \mathrm{Ma}$ \\
\hline
\end{tabular}

section. Almost certainly, then, cladogenesis in this part of the Absarokius clade required relatively much less time than did anagenetic speciation in the Tetonius-Pseudotetonius lineage. The true proportion of time represented in each transition is unknown and can only be documented by exhaustive examination of all of the paleosols involved throughout more than 2,000 m of the master and spur sections of the Willwood Formation.

Although all of the evolution in lineages of Bighorn Basin anaptomorphines seems to have occurred gradually, speciation was accomplished by both ar agenesis and cladogenesis, and anagenetic evolution succeeded the cladogenetic event diversifying the $A b$ sarokius line. Gradual anagenetic evolution, especially that producing such differently adapted animals as Tetonius matthewi and Pseudotetonius ambiguus or Absarokius abbotti and Strigorhysis bridgerensis, can only be termed directional and sustained. The cladogenetic speciation of the early Absarokius lineage appears to have produced two sympatric species in about 750,000 years, doubling the diversity in the Absarokius lineage in the Bighorn Basin. Yet this rate would not appear to be significantly more rapid than the anagenetic transformation producing different genera in the Tetonius-Pseudotetonius lineage, ignoring the paleosol considerations outlined above.

Given the influence of gradual climatic drying on early Eocene mammal evolution in the Bighorn Basin, why did a major cladogenetic speciation event take place in $\mathrm{Absa}$ rokius in the $425-530 \mathrm{~m}$ interval, whereas the principal lineages of earlier Wasatchian anaptomorphines (Teilhardina americana-T. crassidens and Tetonius matthewi-Pseudotetonius ambiguus) evolved in a single lineage? By the beginning of the middle Was- atchian, the hitherto most abundant anaptomorphines (Teilhardina, Tetonius, Pseudotetonius) were gone and, with the exception of a few very rare forms (Anemorhysis, Steinius, Chlororhysis), the highly successful Absarokius metoecus had little intrafamilial competition upon arriving in the Bighorn Basin. The niche that Absarokius came to occupy may have been vacant so that lateral diversification (cladogenesis) in the genus was possible through the availability of suitable habitats; i.e., there was room for two Absarokius-like animals, but apparently not for more than one each of Anemorhysis, Steinius, and Chlororhysis. The circumstantial evidence suggests, but certainly does not prove, that Pseudotetonius found the gradually drying climate unsatisfactory, whereas the immigrant Absarokius metoecus and its descendants accommodated to it.

The fossil evidence for the splitting of $A b$ sarokius into $A$. metoecus and $A$. abbotti is drawn from a single, rather confined geographic area in the south-central Bighorn Basin. It is conceivable that diversification in Absarokius was allopatric on a small scale and that the geographic ranges of the two species came to overlap once they were well differentiated. Indeed, some colleagues would admit to no other possibility. This interpretation is not supported by the fossil evidence. The nature of the alluvial lithotope and some peculiarities of the small-scale geographic dispersion of elements of the Willwood fauna realized in recent years offers some speculative insight into how two species of the same genus might evolve in the same general area. Recognition of the pedofacies (Bown and Kraus, 1987) is a reminder that not only paleosol morphologies and maturities but also floral and other microhabitat differences can be quite significant in the lateral dimension.

The pedofacies (Bown and Kraus, 1987) 
offers a means by which lateral control for these vertebrate microhabitats can be maintained. The relative abundances of the sympatric adapid primate genera Cantius and Copelemur vary systematically across levee deposits (proximal to distal from the alluvial ridge) in localities developed at the $625 \mathrm{~m}$ level of the Willwood Formation (Beard et al., 1986). Similarly, Bown (1987) observed consistent systematic lateral distribution differences in sympatric species of Cantius, the small condylarth Hyopsodus, and other mammals in the same (as well as other) laterally distributed paleosol complexes of the Willwood Formation. Also instructive is the fact that samples of Teilhardina intermediates collected from Hackberry Hollow in the northern Bighorn Basin differ from all other samples of these intermediates in ways that foreshadow Teilhardina tenuicula. The associated mammal fauna from Hackberry Hollow shows rather clearly that this locality represents a local paleoenvironmental setting only sparsely represented elsewhere in the Willwood Formation, if at all. Finally, the earliest occurrences of Absarokius (as now understood) are invariably from immature soils developed on natural levee depositsnot in any of the more mature soils of the proximal and distal floodbasin occurring in the same meter interval.

From the foregoing, it seems evident that some sympatric species of the same genus, as well as more distantly related species and genera, might well have preferred environments more typically developed on or confined to certain kinds (and maturities) of paleosols. Most Willwood fossil mammals occur in the upper parts of paleosols (Bown and Kraus, 1981b; Bown, 1987), and soil type and maturity is a direct function of the proximity of the soil to the ancient alluvial ridge (Bown, 1985, 1987; Bown and Kraus, 1987). Knowledge of these relations will allow controlled examination of distributional controls on other Willwood mammals in the future, enabling further assessment of the influence of these controls on mammal evolution.

\section{ACKNOWLEDGMENTS}

For loan of specimens and casts in their care, we thank D. Baird (Princeton University), R. T. Bakker (University of Colorado, Boulder), M. C. Coombs (ACM), M. R. Daw- son (CM), R. J. Emry (USNM), P. Gigase, P. D. Gingerich (UM), M. Godinot (Montpellier), F. A. Jenkins (MCZ), L. Krishtalka (CM), J. A. Lillegraven (UW), L. G. Martin (UKMNH), M. C. McKenna (AMNH), G. E. Meyer (RAM), J. H. Ostrom (YPM), P. Robinson (UCM), D. E. Russell (Institut de Paléontologie, Paris), P. Sartenaer (Brussels, Belgium), D. E. Savage (UCMP), C. R. Schaff (MCZ), and E. L. Simons (DPC). B. H. Breithaupt (UW), R. W. Wilson (UKMNH), G. Wouters, and G. S. Winterfeld (Denver, CO) provided detailed information on the provenance of several specimens, and P. D. Gingerich, G. F. Gunnell (UM), and D. Schankler (Princeton, NJ) gave access to much detailed and unpublished information about their sections of the Willwood Formation.

A significant number of specimens used in this study were collected during the authors' Bighorn Basin field project of the past several years, and we thank the members of our field parties for their help. In gathering stratigraphic and other field data we were ably assisted by K. C. Beard (The Johns Hopkins University), S. Johnson (University of Northern Arizona), B. McKenna (New York, NY), and V. L. Yingling (UW). Other crew members who participated in collecting fossils reported here include M. Brown, M. Diamond, A. Fraser, D. Gebo, J. Kurtz, L. Ladocsi, A. Latief, R. Madden, A. McKenna, K. C. McKinney, R. W. O'Donnell, D. T. Rasmussen, and J. Rose. Nearly all of the specimens of Willwood omomyids in the Yale Peabody Museum collection were acquired on expeditions led by E. L. Simons (DPC) from 1961-1974, and it was Simons' generosity in allowing us to examine these specimens and participate in his expeditions that fostered our interest in them. Simons's expeditions were supported by grants from the Boise Fund (Oxford University), the J. T. Doneghy Fund (Yale University), the Wenner-Gren Foundation, and, in later years, the Duke University Research Council.

We are especially grateful to the artists who prepared most of the illustrations. Their contributions to this work have been particularly important. E. Kasmer, M. Leggitt, and L. Ulibarri drafted many of the charts and graphs, and L. Kibiuk made the drawings in the frontispiece and Figures 8, 10, 18-20, and 28. All other half-tone drawings are the work of $E$. 
Kasmer, who devoted considerable time and effort to ensure the accuracy of these representations. T. Urquhart prepared photographs of all illustrations, K. C. Beard assisted with SEM photography, and V. J. Cleeves, D.D.S. (Boulder, CO) donated his time to X-ray several specimens.

We have benefited much from discussions with J. D. Archibald (San Diego State University), J. G. Fleagle (State University of New York at Stony Brook), P. D. Gingerich, M. Godinot, J. G. Honey (U.S. Geological Survey), M. J. Kraus (University of Colorado), J. A. Lillegraven, M. C. McKenna, G. G. Simpson, M. F. Teaford (The Johns Hopkins University), A. C. Walker (The Johns Hopkins University), D. B. Weishampel (The Johns Hopkins University), and S. L. Wing (USNM). We thank K. C. Beard, M. Dagosto, P. D. Gingerich, D. W. Krause, J. A. Lillegraven, C. A. Repenning, and F. S. Szalay for insightful reviews of the manuscript.

This research was supported by the U.S. Geological Survey and by National Science Foundation grants BSR-8215099 and BSR8500732, National Geographic Society grant 2366-81, and American Philosophical Society Penrose grant 9269 to K. D. Rose. Research pertaining to paleosols and the stratigraphic section was supported in part by a $\mathrm{G}$. K. Gilbert Professional Fellowship to T. M. Bown.

\section{REFERENCES}

BEARD, K. C., K. D. Rose, AND T. M. Bown. 1986. Dental variation in the early Eocene Adapidae Cantius and Copelemur, and some paleoecological implications. American Journal of Physical Anthropology, 69:174.

Bell, M. A., J. V. BAumgartner, AND E. C. Olson. 1985. Patterns of temporal change in single morphological characters of a Miocene stickleback fish. Paleobiology, 11:258-271.

Bergaren, W. A., D. V. Kent, J. J. FlynN, AND J. A. VAn Couvering. 1985. Cenozoic geochronology. Geological Society of America Bulletin, 96:1407-1418.

BILlingS, M. P. 1965. Structural Geology (2nd ed.). Prentice-Hall, Englewood Cliffs, 514 p.

Bookstein, F. L., P. D. Gingerich, AND A. G. KLUGE. 1977. Hierarchical linear modeling of the tempo and mode of evolution. Paleobiology, 4:120-134.

Bown, T. M. 1974. Notes on some early Eocene anaptomorphine primates. Contributions to Geology, 13:19-26.
1976. Affinities of Teilhardina (Primates, Omomyidae), with description of a new species from North America. Folia Primatologica, 25: 62-72.

- 1979a. Geology and mammalian paleontology of the Sand Creek facies, lower Willwood Formation (lower Eocene), Washakie County, Wyoming. Geological Survey of Wyoming Memoir 2, $151 \mathrm{p}$.

- 1979b. New omomyid primates (Haplorhini, Tarsiiformes) from middle Eocene rocks of west-central Hot Springs County, Wyoming. Folia Primatologica, 31:48-73.

- 1980a. The Willwood Formation (lower Eocene) of the southern Bighorn Basin, Wyoming, and its mammalian fauna, p. 127-138. In P. D. Gingerich (ed.), Early Cenozoic Paleontology and Stratigraphy of the Bighorn Basin, Wyoming. University of Michigan Papers on Paleontology, 24.

- $1980 \mathrm{~b}$. Summary of latest Cretaceous and Cenozoic sedimentary, tectonic, and erosional events, Bighorn Basin, Wyoming, p. 25-32. In P. D. Gingerich (ed.), Early Cenozoic Paleontology and Stratigraphy of the Bighorn Basin, Wyoming. University of Michigan Papers on Paleontology, 24.

-. 1981. "Evolutionary History of the Primates," by Frederick S. Szalay and Eric Delson, 1979, Academic Press, New York, 580 p. (Review.) Journal of Vertebrate Paleontology, 1: 117-119.

- 1982. Geology, paleontology, and correlation of Eocene volcaniclastic rocks, southeast Absaroka Range, Hot Springs County, Wyoming. U.S. Geological Survey Professional Paper 1201-A, 75 p.

- 1984. Biostratigraphic significance of baselevel changes during deposition of the Willwood Formation (lower Eocene), Bighorn Basin, northwest Wyoming. Geological Society of America Annual Meeting, Abstracts with Programs, 16:216.

- 1985. Maturation sequences in lower Eocene alluvial paleosols, Willwood Formation, p. 20-26. In R. M. Flores and M. Harvey (eds.), Field Guidebook to Modern and Ancient Fluvial Systems in the United States. Third International Fluvial Sedimentology Conference, Fort Collins, Colorado.

- 1987. Vertebrate taphonomy and the mammalian pedofacies; Willwood Formation (lower Eocene), Bighorn Basin, Wyoming. Geological Society of America, 1987 Annual Meeting of Rocky Mountain Section, Symposium "Dawn of the Age of Mammals in the Northern Part of the Western Interior," Abstracts with Programs, 19:262.

- AND P. D. GINGERICH. 1972. Dentition of the early Eocene primates Niptomomys and $A b$ sarokius. Postilla, 158:1-10.

- , AND A. KInM. 1981. Xenicohippus, an un- 
usual new hyracotheriine (Mammalia, Perissodactyla) from lower Eocene rocks of Wyoming, Colorado, and new Mexico. Journal of Paleontology, 55:257-270.

, AND M. J. KRAUS. 1981a. Lower Eocene alluvial paleosols (Willwood Formation, northwest Wyoming, U.S.A.), and their significance for paleoecology, paleoclimatology, and basin analysis. Palaeogeography, Palaeoclimatology, Palaeoecology, 34:1-30.

— AND — . 1981b. Vertebrate fossil-bearing paleosol units (Willwood Formation, lower Eocene, northwest Wyoming, U.S.A.): implications for taphonomy, biostratigraphy, and assemblage analysis. Palaeogeography, Palaeoclimatology, Palaeoecology, 34:31-56.

—, AND - 1987. Integration of channel and floodplain suites in aggrading alluvial systems: I. Developmental sequence and lateral relations of lower Eocene alluvial paleosols. Journal of Sedimentary Petrology, 57:587-601.

- AND K. D. RosE. 1984. Reassessment of some early Eocene Omomyidae, with description of a new genus and three new species. Folia Primatologica, 43:97-112.

-, AND D. M. SChANKLER. 1982. A review of the Proteutheria and Insectivora of the Willwood Formation (lower Eocene), Bighorn Basin, Wyoming. U.S. Geological Survey Bulletin, $1523,79 \mathrm{p}$.

BRANSCOMB, L. M. 1985. Integrity in science. American Scientist, 73:421-423.

CARTMILl, M. 1980. The order Primates. Science, 208:720-721.

Clemens, W. A., J. A. Lillegraven, E. H. Lindsay, AND G. G. SIMPSON. 1979. Where, when, and what-a survey of known Mesozoic mammal distribution, p. 7-58. In J. A. Lillegraven, Z. Kielan-Jaworowska, and W. A. Clemens (eds.), Mesozoic Mammals: The First Two-thirds of Mammalian History. University of California Press, Berkeley.

COPE, E. D. 1872. On a new vertebrate genus from the northern part of the Tertiary basin of Green River. Proceedings of the American Philosophical Society, 12:554.

. 1882a. Contributions to the history of the Vertebrata of the lower Eocene of Wyoming and New Mexico, made during 1881. I. The fauna of the Wasatch beds of the basin of the Bighorn River. II. The fauna of the Catathlaeus beds, or lowest Eocene, New Mexico. Proceedings of the American Philosophical Society, 20:139-197.

- 1882b. An anthropomorphous lemur. American Naturalist, 16:73-74.

- 1883 . On the mutual relations of the bunotherian Mammalia. Proceedings of the Philadelphia Academy of Natural Sciences, 35:7783.

2. 1884. The Vertebrata of the Tertiary formations of the west. Book I. Report of U.S. Geological Survey of the Territories, F. V. Hay- den, U.S. Geologist-in-charge, Washington, $1009 \mathrm{p}$.

DashzeVEG, D., AND M. C. McKenna. 1977. Tarsioid primate from the early Tertiary of the Mongolian People's Republic. Acta Paleontologica Polonica, 22:119-137.

Delson, E. 1971. Fossil mammals of the early Wasatchian Powder River Local Fauna, Eocene of northeast Wyoming. American Museum of Natural History Bulletin, 146:305-364.

ElDREDGE, N. 1974. Testing evolutionary hypotheses in paleontology: a comment on Makurath and Anderson (1973). Evolution, 28:479481.

- AND S. J. Gould. 1972. Punctuated equilibria: an alternative to phyletic gradualism, $p$. 82-115. In T. J. M. Schopf (ed.), Models in Paleobiology. Freeman, Cooper, San Francisco. —, AND - 1974. Morphological transformation, the fossil record, and the mechanisms of evolution: a debate, Part II, The reply. Evolutionary Biology, 7:303-308.

GazIN, C. L. 1952. The lower Eocene Knight Formation of western Wyoming and its mammalian faunas. Smithsonian Miscellaneous Collections, $117,82 \mathrm{p}$.

- 1958. A review of the middle and upper Eocene primates of North America. Smithsonian Miscellaneous Collections, 136, 112 p.

- 1962. A further study of the lower Eocene mammalian faunas of southwestern Wyoming. Smithsonian Miscellaneous Collections, 144, $98 \mathrm{p}$.

- 1968. A study of the Eocene condylarthran mammal Hyopsodus. Smithsonian Miscellaneous Collections, 153, $90 \mathrm{p}$.

GINGERICH, P. D. 1974a. Stratigraphic record of early Eocene Hyopsodus and the geometry of mammalian phylogeny. Nature, 248:107-109.

—. 1974b. Size variability of the teeth in living mammals and the diagnosis of closely related sympatric fossil species. Journal of Paleontology, 48:895-903.

- 1976. Paleontology and phylogeny: patterns of evolution at the species level in early Tertiary mammals. American Journal of Science, 276:1-28.

- 1977a. Patterns of evolution in the mammalian fossil record, p. 469-500. In A. Hallam (ed.), Patterns of Evolution. Elsevier, Amsterdam.

- 1977b. Dental variation in early Eocene Teilhardina belgica, with notes on the anterior dentition of some early Tarsiiformes. Folia Primatologica, 26:144-153.

- 1979. The stratophenetic approach to phylogeny reconstruction in vertebrate paleontology, p. 41-77. In J. Cracraft and N. Eldredge (eds.), Phylogenetic Analysis and Paleontology. Columbia University Press, New York.

—. 1980a. Evolutionary patterns in Early Ce- 
nozoic mammals. Annals of the Review of Earth and Planetary Sciences, 8:407-424.

- 1980b. History of Early Cenozoic vertebrate paleontology in the Bighorn Basin, p. 724. In P. D. Gingerich (ed.), Early Cenozoic Paleontology and Stratigraphy of the Bighorn Basin, Wyoming. University of Michigan Papers on Paleontology, 24.

- 1981. Early Cenozoic Omomyidae and the evolutionary history of tarsiiform primates. Journal of Human Evolution, 10:345-374.

- 1982. Time resolution in mammalian evolution: sampling, lineages, and faunal turnover. Proceedings of the Third North American Paleontological Convention, 1:205-210.

- 1984. Punctuated equilibria - where is the evidence? Systematic Zoology, 33:335-338.

- 1985. Species in the fossil record: concepts, trends, and transitions. Paleobiology, 11:27-41.

and evolution of the genus Esthonyx (Mammalia, Tillodontia) in the early Eocene of North America. Contributions from the Museum of Paleontology, University of Michigan, 25:125153.

-, AND M. SChoeninger. 1977. The fossil record and primate phylogeny. Journal of $\mathrm{Hu}$ man Evolution, 6:483-505.

- AND E. L. SimONS. 1977. Systematics, phylogeny, and evolution of early Eocene Adapidae (Mammalia, Primates) in North America. Contributions from the Museum of Paleontology, University of Michigan, 24:245-279.

—, AND D. A. WINKIER. 1979. Patterns of variation and correlation in the dentition of the red fox, Vulpes vulpes. Journal of Mammalogy, 60:691-704.

GodinOt, M. 1982. Aspects nouveaux des échanges entre les faunes mammaliènnes d'Europe et d'Amérique du Nord à la base de l'Éocène. Géobios, Mémoire Spécial, 6:403-412.

Gould, S. J. 1977. Ontogeny and Phylogeny. Harvard University Press, Cambridge, $501 \mathrm{p}$.

- 1982. The meaning of punctuated equilibrium and its role in validating a hierarchical approach to macroevolution, p. 83-104. In R. Milkman (ed.), Perspectives on Evolution. Sinauer Associates, Sunderland, Massachusetts.

- 1983. Dix-huit points au sujet des équilibres ponctués, p. 39-41. In J. Chaline (ed.), Modalités, rythmes, mécanismes de l'évolution biologique. Colloques Internationaux du Centre National de la Recherche Scientifique, no. 330, Paris.

- AND N. Eldredge. 1977. Punctuated equilibria: the tempo and mode of evolution reconsidered. Paleobiology, 3:115-151.

GRANGER, W. 1914. On the names of lower Eocene faunal horizons of Wyoming and New Mexico. American Museum of Natural History Bulletin, 33:201-207.
GreGory, W. K. 1915. On the classification and phylogeny of the Lemuroidea. Geological Society of America Bulletin, 26:426-446.

- 1920. On the structure and relations of Notharctus, an American Eocene primate. Memoirs of the American Museum of Natural History, 3:53-243.

GUTHRIE, D. A. 1967. The mammalian fauna of the Lysite Member, Wind River Formation (early Eocene), of Wyoming. Southern California Academy of Sciences Memoirs, 5, $53 \mathrm{p}$.

1971. The mammalian fauna of the Lost Cabin Member, Wind River Formation (lower Eocene), of Wyoming. Annals of the Carnegie Museum, 43:47-113.

HECHT, M. K. 1983. Microevolution, developmental processes, paleontology, and the origin of vertebrate higher categories. Colloques Internationaux du C.N.R.S., 330:289-294.

HenNig, W. 1966. Phylogenetic Systematics. University of Illinois Press, Urbana, 263 p.

HICKEY, L. J. 1980. Paleocene stratigraphy and flora of the Clark's Fork Basin, p. 33-50. In P. D. Gingerich (ed.), Early Cenozoic Paleontology and Stratigraphy of the Bighorn Basin, Wyoming. University of Michigan Papers on Paleontology, 24.

JEPSEN, G. L. 1930. New vertebrate fossils from the lower Eocene of the Bighorn Basin, Wyoming. Proceedings of the American Philosophical Society, 69:117-131.

-. 1963. Eocene vertebrates, coprolites, and plants in the Golden Valley Formation of western North Dakota. Geological Society of America Bulletin, 74:673-684.

KAY, R. F. 1980. Paleoprimatology-documenting our antecedents. Paleobiology, 6:517520.

Kelley, D. R., AND A. E. Wood. 1954. The Eocene mammals from the Lysite Member, Wind River Formation of Wyoming. Journal of Paleontology, 28:337-366.

KITTS, D. B. 1956. American Hyracotherium (Perissodactyla, Equidae). American Museum of Natural History Bulletin, 110, 60 p.

KraUS, M. J., AND T. M. Bown. 1986. Paleosols and time resolution in alluvial stratigraphy, $p$. 180-207. In P. V. Wright (ed.), Paleosols: Their Classification, Recognition, and Significance. Blackwell, London.

KRAUSE, D. W. 1982. Multituberculates from the Wasatchian Land-Mammal Age, early Eocene, of Western North America. Journal of Paleontology, 56:271-294.

KRISHTALKA, L. 1978. Szalay, Frederick Sigmond, "Systematics of the Omomyidae (Tarsiiformes, Primates); Taxonomy, Phylogeny, and Adaptations," Bulletin of the American Museum of Natural History, 156:157-450. (Review.) Journal of Mammalogy, 59:901-903.

- AND J. H. Schwartz. 1978. Phylogenetic 
relationships of plesiadapiform-tarsiiform primates. Annals of the Carnegie Museum, 47:515540.

- AND R. K. StUCKy. 1985. Revision of the Wind River faunas, early Eocene of central Wyoming. Part 7. Revision of Diacodexis (Mammalia, Artiodactyla). Annals of the Carnegie Museum, 54:413-486.

Lazarus, D. B., AND D. R. Prothero. 1984. The role of stratigraphic and morphologic data in phylogeny. Journal of Paleontology, 58:163-172.

Lillegraven, J. A., M. C. MCKenNA, AND L. KRISHTALKA. 1981. Evolutionary relationships of middle Eocene and younger species of Centetodon (Mammalia, Insectivora, Geolabididae) with a description of the dentition of $\mathrm{An}$ kylodon (Adapisoricidae). University of Wyoming Publications, 45, $115 \mathrm{p}$.

LoomIs, F. B. 1906. Wasatch and Wind River primates. American Journal of Science, ser. 4, 21:277-285.

- 1907. Origin of the Wasatch deposits. American Journal of Science, ser. 4, 23:356364.

LOvE, J. D. 1939. Geology along the southern margin of the Absaroka Range, Wyoming. Geological Society of America Special Paper 20, $133 \mathrm{p}$.

LuCKett, W. P., ANd M. Maier. 1982. Development of deciduous and permanent dentition in Tarsius and its phylogenetic significance. Folia Primatologica, 37:1-36.

MACDONALD, J. R. 1963. The Miocene faunas from the Wounded Knee area of western South Dakota. American Museum of Natural History Bulletin, 125:139-238.

MAGLIO, V. J. 1973. Origin and evolution of the Elephantidae. Transactions of the American Philosophical Society, n. ser., 63, 149 p.

MarTin, L. D. 1984. Phyletic trends and evolutionary rates. Special Publications of the Carnegie Museum of Natural History, 8:526-538.

MatTHEW, W. D. 1915. A revision of the lower Eocene Wasatch and Wind River faunas. Part IV. Entelonychia, Primates, Insectivora (part). American Museum of Natural History Bulletin, 34:429-483.

MAYR, E. 1942. Systematics and the Origin of Species. Columbia University Press, New York. $433 \mathrm{p}$.

McKenna, M. C. 1960. Fossil Mammalia from the early Wasatchian Four Mile Fauna, Eocene of northwest Colorado. University of California Publications in Geological Sciences, 37:1-130.

- 1975. Toward a phylogenetic classification of the Mammalia, p. 21-46. In W. P. Lucket $\rightarrow$ and F. S. Szalay (eds.), Phylogeny of the Primates. Plenum, New York.

MORRIS, W. J. 1954. An Eocene fauna from the Cathedral Bluffs Tongue of the Washakie Basin, Wyoming. Journal of Paleontology, 28:195-203.
Musser, G. G., AND M. Dagosto. 1987. The identity of Tarsius pumilus, a pygmy species endemic to the montane mossy forests of central Suelawesi. American Museum of Natural History Novitates, $2867,53 \mathrm{p}$.

Neasham, J. W. 1970. Sedimentology of the Willwood Formation (lower Eocene): an alluvial molasse facies in northwestern Wyoming. Unpubl. Ph.D. dissertation, Iowa State University, Ames, 98 p.

NovACEK, M. J. 1986. The primitive eutherian dental formula. Journal of Vertebrate Paleontology, 6:191-196.

OsBorn, H. F. 1902. American Eocene primates, and the supposed rodent family Mixodectidae. American Museum of Natural History Bulletin, 16:169-214.

Patterson, C. 1981. The significance of fossils in determining evolutionary relationships. Annual Review of Ecology and Systematics, 12: 195-223.

PENNY, D. 1985. Two hypotheses on Darwin's gradualism. Systematic Zoology, 34:201-205.

QUINET, G. E. 1966. Teilhardina belgica, ancêtre des Anthropoidea de l'ancien monde. Institut Royal des Sciences Naturelles de Belgique Bulletin, 42:1-14.

Robinson, P. 1966. Fossil Mammalia of the Huerfano Formation, Eocene, of Colorado. Peabody Museum of Natural History (Yale) Bulletin, 21:1-95.

- 1967. The mandibular dentition of ?Tetonoides (Primates, Anaptomorphidae). Annals of the Carnegie Museum, 39:187-191.

Rose, K. D. 1972. A new tillodont from the Eocene upper Willwood Formation of Wyoming. Postilla, 155:1-13.

-. 1981a. "Evolutionary History of the Primates," by Frederick S. Szalay and Eric Delson, 1979: Academic Press, New York, 580 p. (Review.) Journal of Paleontology, 55:910-913.

- 1981b. The Clarkforkian Land Mammal Age and mammalian faunal composition across the Paleocene-Eocene boundary. University of Michigan Papers on Paleontology, 26, 197 p.

- AND T. M. Bown. 1984. Gradual phyletic evolution at the generic level in early Eocene omomyid primates. Nature, 309:250-252.

— AND —. 1986. Gradual evolution and species discrimination in the fossil record, $p$. 119-130. In K. Flanagan and J. A. Lillegraven (eds.), Vertebrates, Phylogeny, and Philosophy. University of Wyoming Contributions to Geology Special Paper, 3.

$\rightarrow$ - AND D. W. KRAUSE. 1984. Affinities of the primate Altanius from the early Tertiary of Mongolia. Journal of Mammalogy, 65:721-726.

Rosen, D. E., P. L. Forey, B. G. GARDINER, AND C. PAtTerson. 1981. Lungfishes, tetrapods, paleontology, and plesiomorphy. Bulletin of the 
American Museum of Natural History, 167:159_ 276.

RusSell, D. E., AND P. D. Gingerich. 1980. Un nouveau Primate omomyide dans l'Éocene du Pakistan. Comptes Rendus de l'Académie des Sciences, Paris, 291:621-624.

—, P. Louis, and D. E. Savage. 1967. Primates of the French early Eocene. University of California Publications in the Geological Sciences, 93, $46 \mathrm{p}$.

SADLER, P. M. 1981. Sediment accumulation rates and the completeness of stratigraphic sections. Journal of Geology, 89:569-584.

Savage, D. E., AND J. H. Hutchison. 1972. Wasatchian succession at Bitter Creek Station, northwestern border of the Washakie Basin, Wyoming, p. 32-39. In R. M. West (ed.), Society of Vertebate Paleontology Field Conference on Tertiary Biostratigraphy of Southern and Western Wyoming. (Privately distributed to field conference members in mimeographed form.)

- AND B. T. WATERS. 1978. A new omomyid primate from the Wasatch Formation of southern Wyoming. Folia Primatologica, 30:1-29.

- D. E. Russell, AND B. T. WATERS. 1977. Critique of certain early Eocene primate taxa. Géobios, Mémoire Spécial, 1:159-164.

SCHAFFER, B., M. K. HEChT, AND N. EldREDGE. 1972. Paleontology and phylogeny. Evolutionary Biology, 6:31-46.

SCHANKLER, D. M. 1980. Faunal zonation of the Willwood Formation in the central Bighorn Basin, Wyoming, p. 99-114. In P. D. Gingerich (ed.), Early Cenozoic Paleontology and Stratigraphy of the Bighorn Basin, Wyoming. University of Michigan Papers on Paleontology, 24.

- 1981. Local extinction and ecological reentry of early Eocene mammals. Nature, 293: 135-138.

SCHOPF, T. J. M. 1982. A critical assessment of punctuated equilibria, I. Duration of taxa. Evolution, 36:1144-1157.

SChwaRTZ, J. H. 1978. Dental development, homologies, and primate phylogeny. Evolutionary Theory, 4:1-32.

Seton, H. 1940. Two new primates from the lower Eocene of Wyoming. Proceedings of the New England Zoological Club, 18:39-42.

SimONS, E. L. 1972. Primate Evolution: An Introduction to Man's Place in Nature. Macmillan, New York, 322 p.

- AND T. M. Bown. 1985. Afrotarsius chatrathi, first tarsiiform primate (?Tarsiidae) from Africa. Nature, 313:475-477.

- T. M. Bown, AND D. T. Rasmussen. 1986. Discovery of two additional prosimian primate families (Omomyidae, Lorisidae) in the African Oligocene. Journal of Human Evolution, 15: 431-437.

SimPSON, G. G. 1940. Studies on the earliest primates. American Museum of Natural History Bulletin, 77:185-212.
- 1943. Criteria for genera, species and subspecies in zoology and paleozoology. Annals of the New York Academy of Science, 44:145-178.

SINCLAIR, W. J., AND W. GRANGER. 1911. Eocene and Oligocene of the Wind River and Bighorn Basins. American Museum of Natural History Bulletin, 30:83-117.

- 1912. Notes on the Tertiary deposits of the Bighorn Basin. American Museum of Natural History Bulletin, 31:57-67.

Smedes, H. W., AND H. J. ProstKa. 1972. Stratigraphic framework of the Absaroka Volcanic Supergroup in the Yellowstone National Park Region. U.S. Geological Survey Professional Paper, 729-C:1-33.

STANLEY, S. M. 1982. Macroevolution and the fossil record. Evolution, 36:460-473.

- 1985. Rates of evolution. Paleobiology, 11: 13-26.

STUCKY, R. K. 1982. Mammalian fauna and biostratigraphy of the upper part of the Wind River Formation (early to middle Eocene), Natrona County, Wyoming, and the Wasatchian-Bridgerian boundary. Unpubl. Ph.D. dissertation, University of Colorado, Department of Anthropology, Boulder, $285 \mathrm{p}$.

SwINDLER, D. R. 1976. Dentition of Living Primates. Academic Press, New York, 308 p.

Szalay, F. S. 1969. Uintasoricinae, a new subfamily of early Tertiary mammals. American Museum Novitates, 2363, 36 p.

- 1976. Systematics of the Omomyidae (Tarsiiformes, Primates), taxonomy, phylogeny, and adaptations. American Museum of Natural History Bulletin, 156:157-450.

- 1982. A critique of some recently proposed Paleogene primate taxa and suggested relationships. Folia Primatologica, 37:153-162.

—, AND E. DELSON. 1979. Evolutionary History of the Primates. Academic Press, New York, $580 \mathrm{p}$.

- AND C. K. LI. 1986. Middle Paleocene euprimate from southern China and the distribution of primates in the Paleogene. Journal of Human Evolution, 15:387-397.

Teilhard de Chardin, P. 1927. Les mammifères de l'Éocène inférieur de la Belgique. Mémoires du Musée Royal d'Histoire Naturelle de Belgique, 36:1-33.

Trouessart, E. L. 1879. Catalogue des Mammifères vivants et fossiles. Revue Magazine de Zoologie, 7:219-285.

VAN HINTE, J. E. 1969. The nature of biostratigraphic zones, p. 391-424. In Proceedings of the International Conference on Planktonic Microfossils, 1st, Geneva, 1967, 2. E. J. Brill, Leiden.

Van Houten, F. B. 1944. Stratigraphy of the Willwood and Tatman Formations in northwestern Wyoming. Geological Society of America Bulletin, 55:165-210.

WEST, R. M. 1979. Apparent prolonged evolu- 
tionary stasis in the middle Eocene hoofed mammal Hyopsodus. Paleobiology, 5:252-260.

Wilson, J. A. 1966. A new primate from the earliest Oligocene, West Texas, preliminary report. Folia Primatologica, 4:227-248.

WING, S. L. 1980. Fossil floras and plant-bearing beds of the central Bighorn Basin, p. 119-126. In P. D. Gingerich (ed.), Early Cenozoic Paleontology and Stratigraphy of the Bighorn Basin. University of Michigan Papers on Paleontology, 24.

-. 1984. Relation of paleovegetation to geometry and cyclicity of some fluvial carbonaceous deposits. Journal of Sedimentary Petrology, 54:52-66.

- AND T. M. Bown. 1985. Fine scale reconstruction of late Paleocene-early Eocene paleogeography in the Bighorn Basin of northern Wyoming, p. 93-106. In R. M. Flores and S. S. Kaplan (eds.), Cenozoic Paleogeography of the West-central United States. Society of Economic Paleontologists and Mineralogists Rocky Mountain Paleogeography Symposium 3, Silers, Denver.

WINTERFELD, G. V. 1986. Laramide tectonism, deposition, and early Cenozoic stratigraphy of the northwestern Wind River Basin and Washakie Range, Wyoming. Unpubl. Ph.D. dissertation, University of Wyoming, Laramie, $248 \mathrm{p}$. Wood, H. E., II, R. W. Chaney, J. Clark, E. H. Colbert, G. L. Jepsen, J. B. Reeside, Jr., AND C. STOCK. 1941. Nomenclature and correlation of the North American continental Tertiary. Geological Society of America Bulletin, 52:1-48.

WORTMAN, J. L. 1904. Studies of Eocene Mammalia in the Marsh collection, Peabody $\mathrm{Mu}-$ seum. Part II. Primates. American Journal of Science, 17:239-250.

WRIGHT, S. 1948. On the roles of directed and random changes in gene frequency in the genetics of populations. Evolution, 2:279-294.

Wyoming Geological Association. 1968. Tertiary well logs in all Wyoming basins (Log \#4, Washakie County, Gulf Oil Corporation, \#1 Teeters).

Xu, Q. 1977. Two new genera of old Ungulata from the Paleocene of Qianshan Basin, Anhui. Vertebrata PalAsiatica, 15:119-125. 


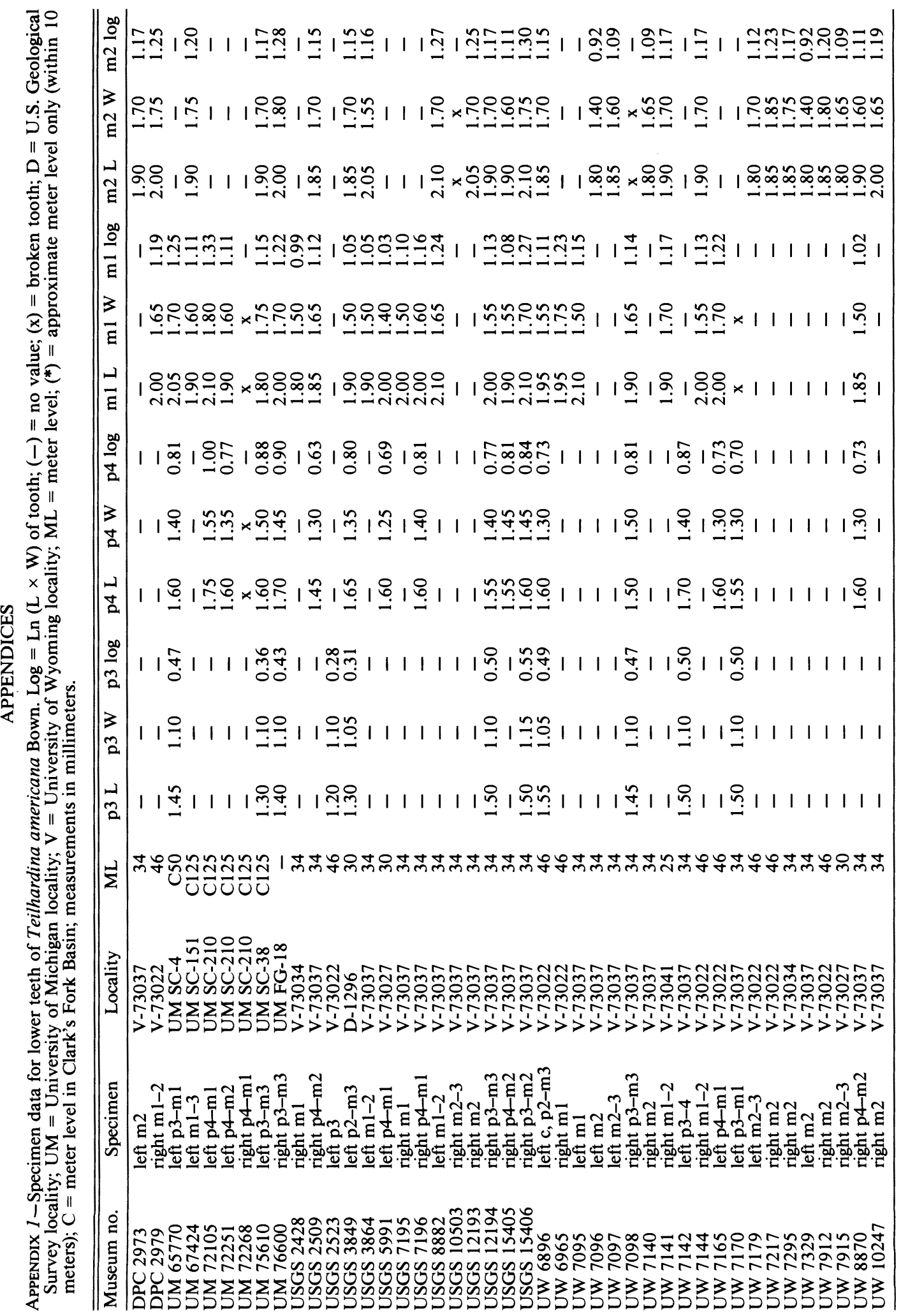



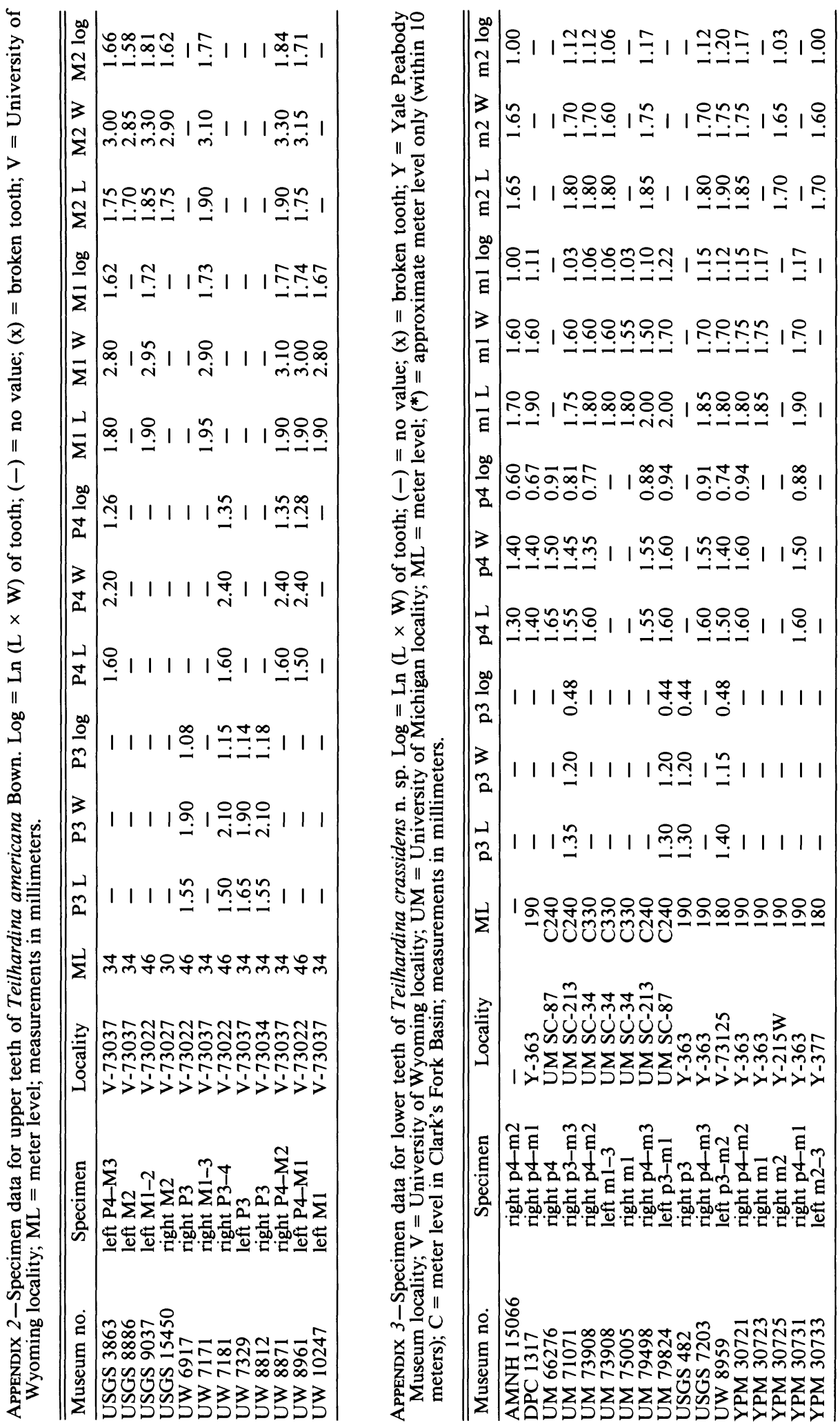


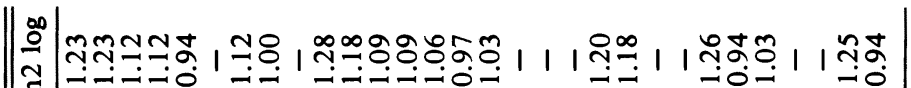
承出密

율

I

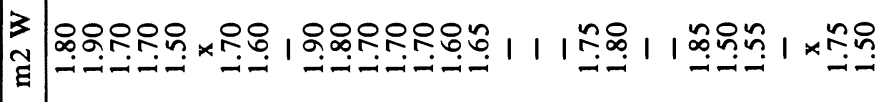

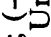

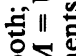

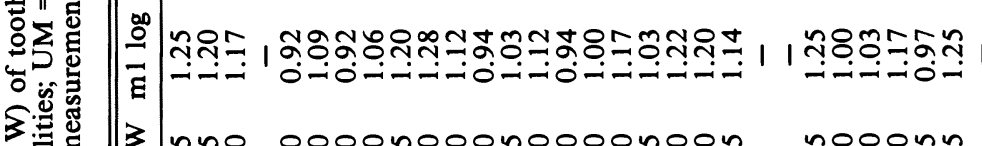

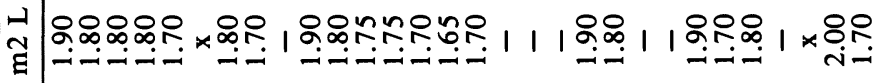

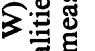

$\times$ 을.

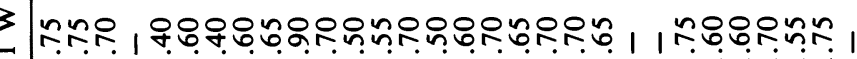

s.

II 형군

11

要

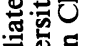

.

空家

.

हो

氝.

s。

ำ 륭

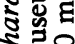

촟은

T穴白

ปั

造

รัฮ

के

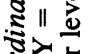

实

휴워

능 으

击

解

亏ें ॥ี

훙응

密

包

ฝี

हूํㅔ

कीज्ञ

n.

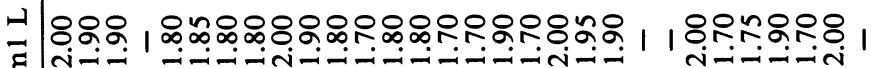

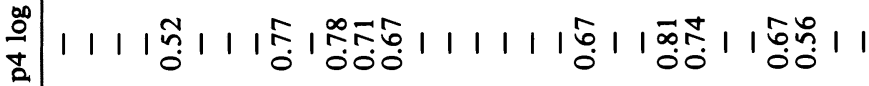

苔 111110

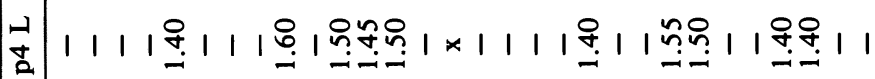

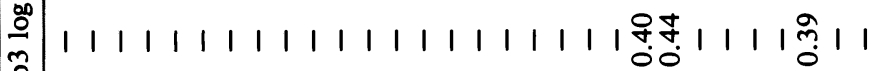

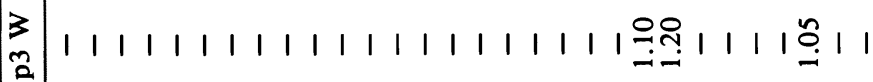

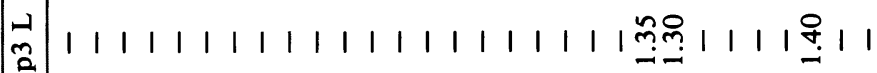

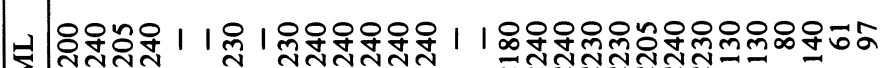

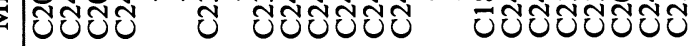

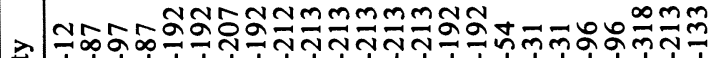

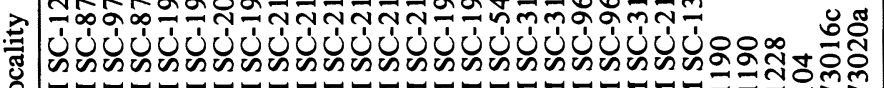

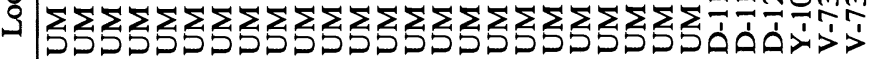

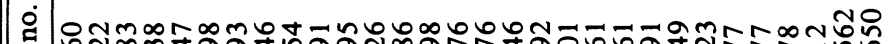

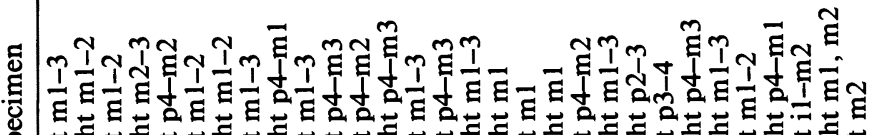

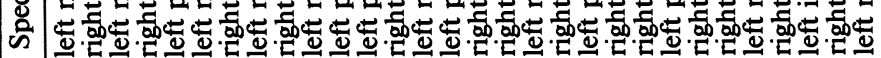




\begin{tabular}{|c|c|}
\hline 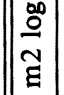 & 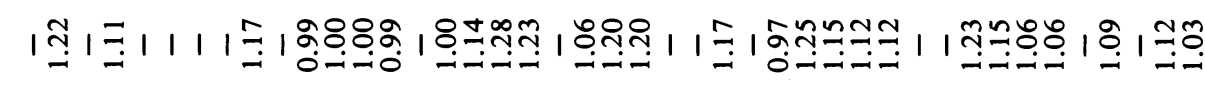 \\
\hline $\begin{array}{l}3 \\
\text { है }\end{array}$ & 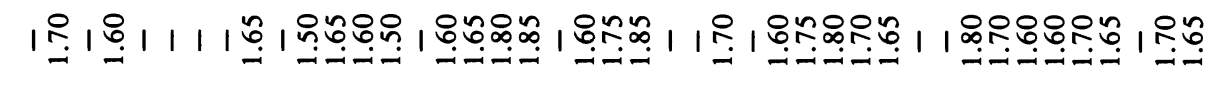 \\
\hline సี & । \\
\hline$\frac{80}{\bar{g}}$ & । \\
\hline$\overline{\mathrm{B}}$ & 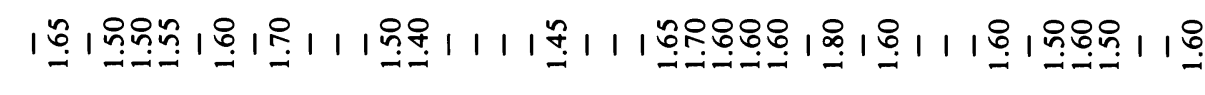 \\
\hline $\overrightarrow{\mathrm{g}}$ & 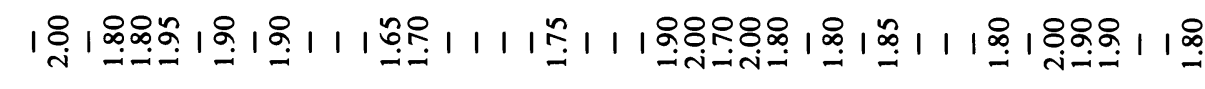 \\
\hline$\frac{n}{0}$ & 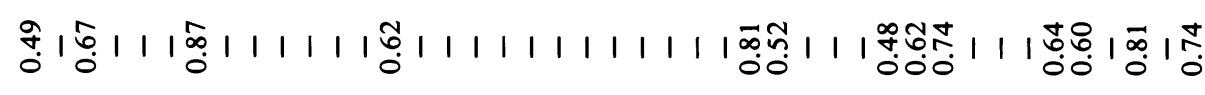 \\
\hline $\begin{array}{l}3 \\
\vdots \\
\vdots\end{array}$ & 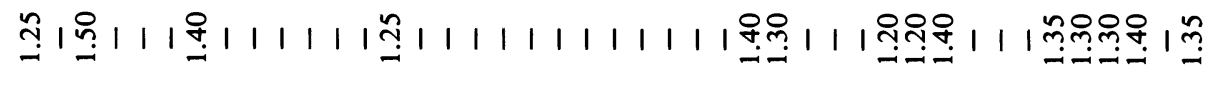 \\
\hline 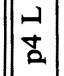 & 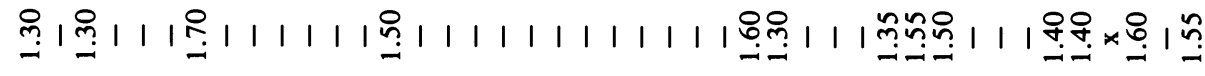 \\
\hline$\frac{\infty}{2}$ & 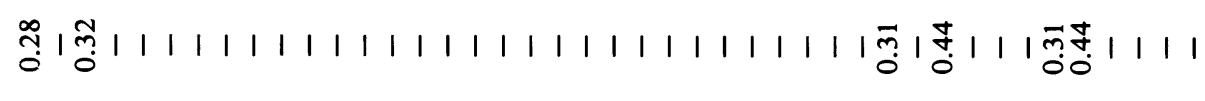 \\
\hline $\begin{array}{l}3 \\
\tilde{z}\end{array}$ & $|1| 1|1| 1|1| 1|1| 1|1| 1|1| 1|1| 1|1| 1|1| 10$ \\
\hline$\hat{m}$ & 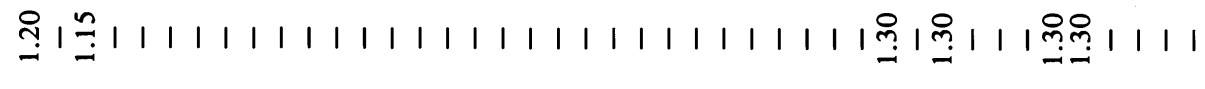 \\
\hline$\dot{\Sigma}$ & 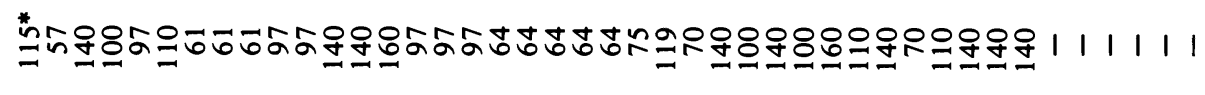 \\
\hline 至 & 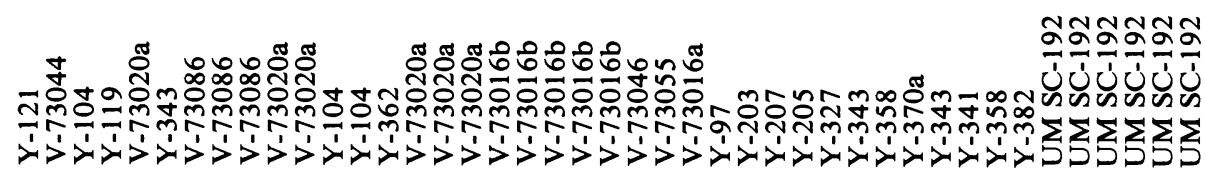 \\
\hline 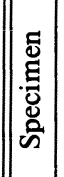 & 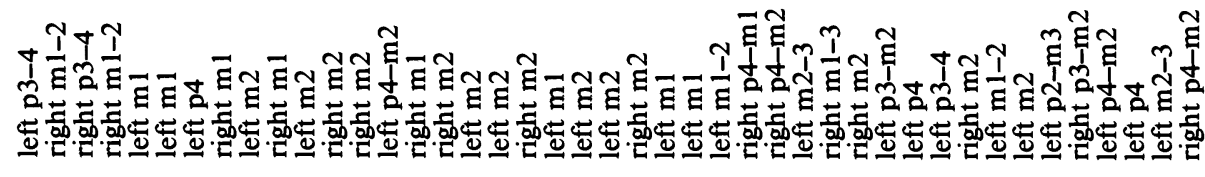 \\
\hline 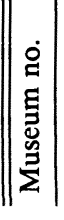 & 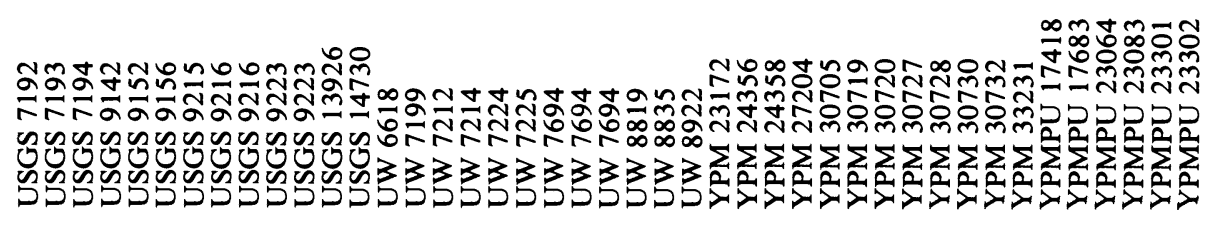 \\
\hline
\end{tabular}




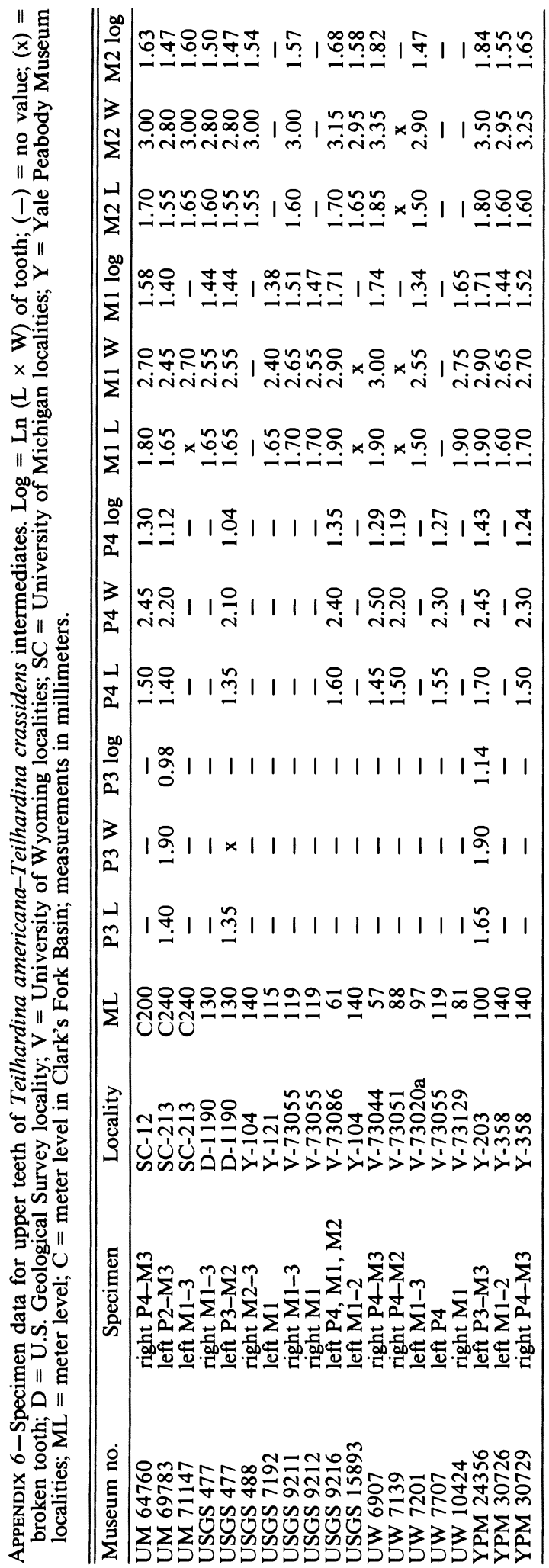




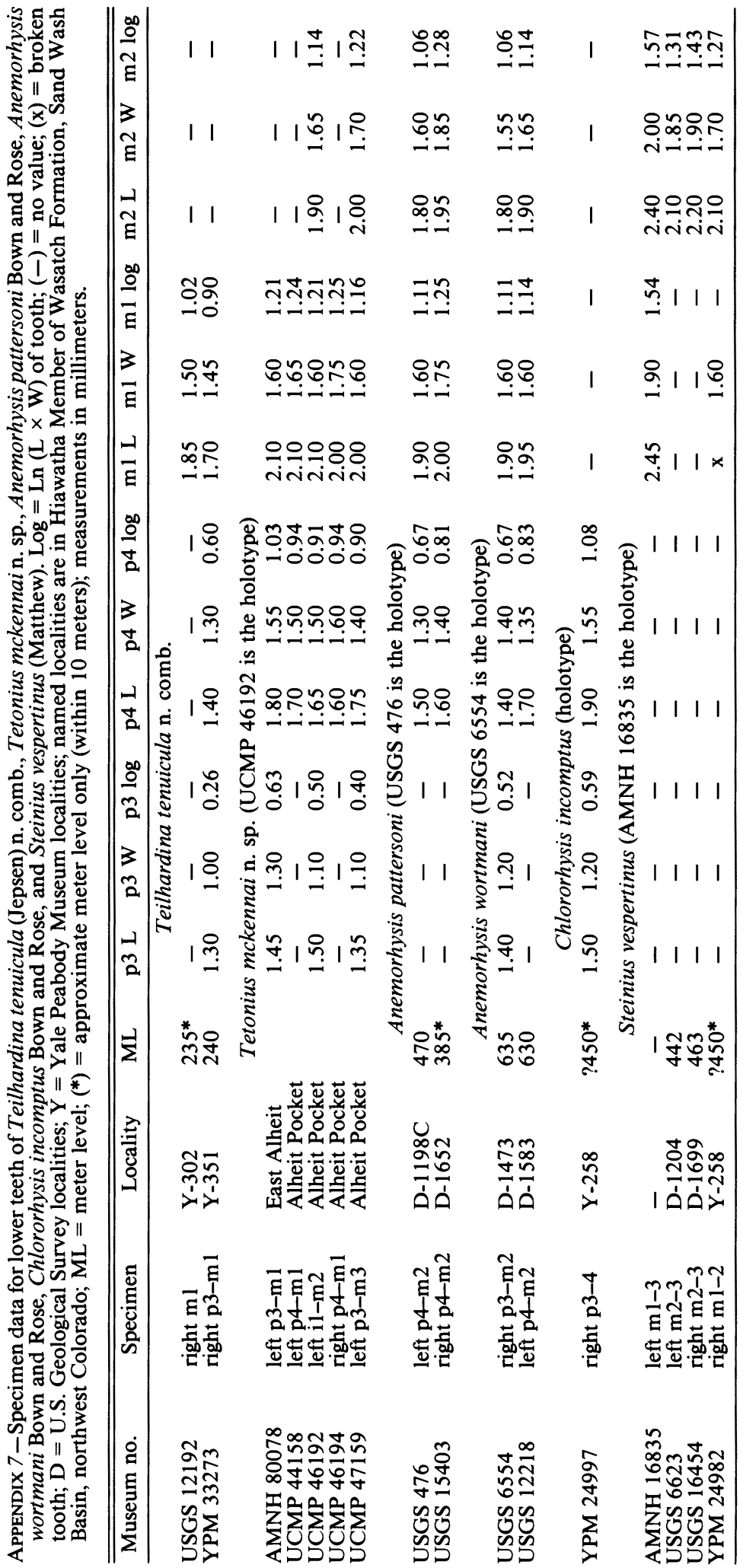




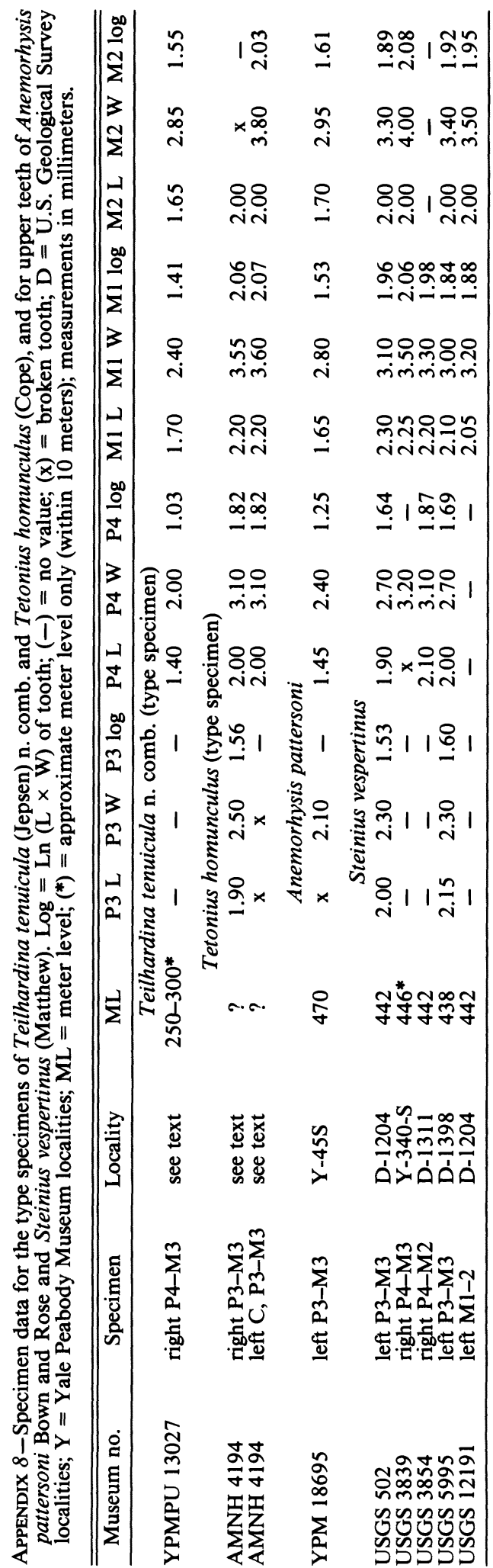




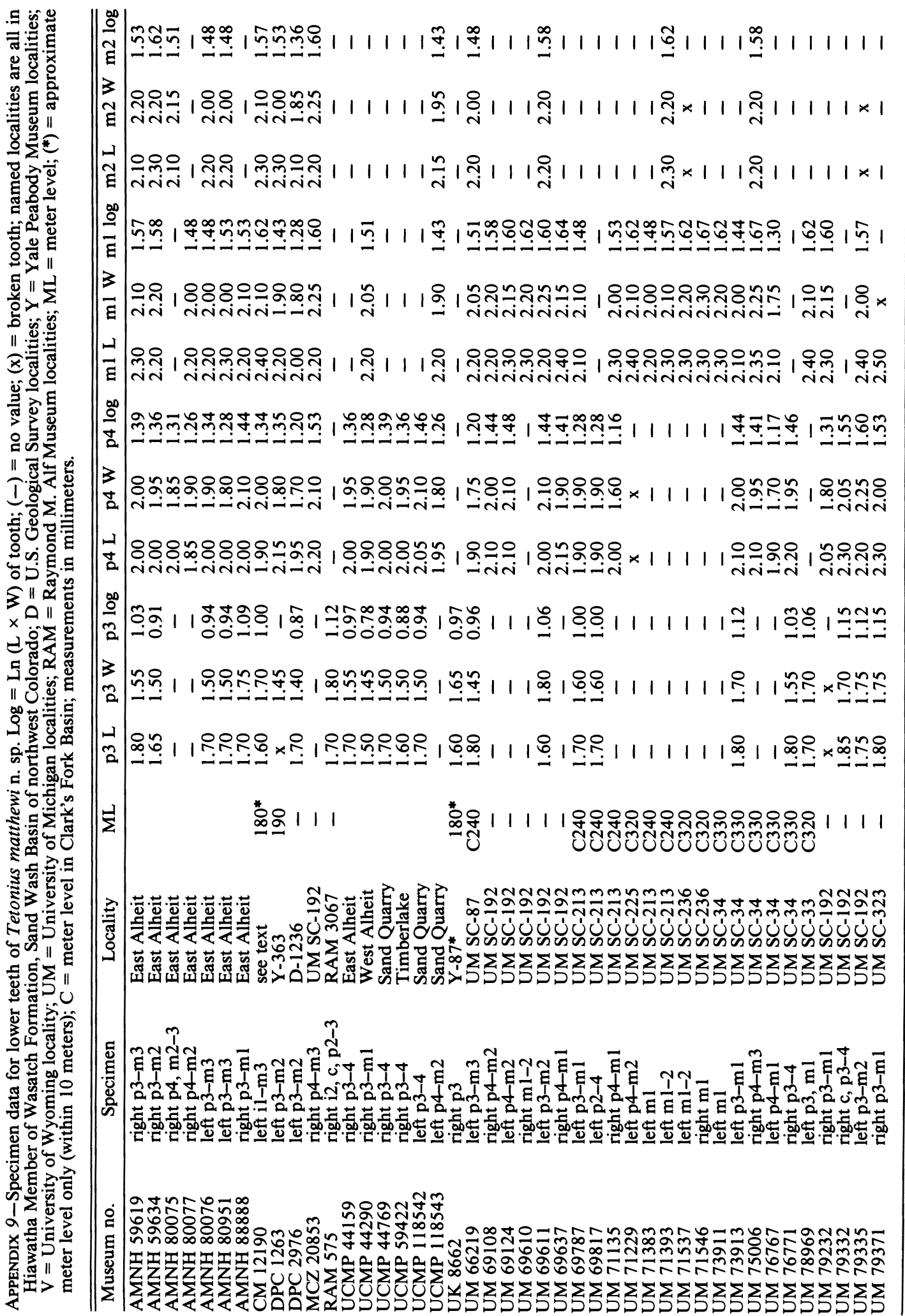




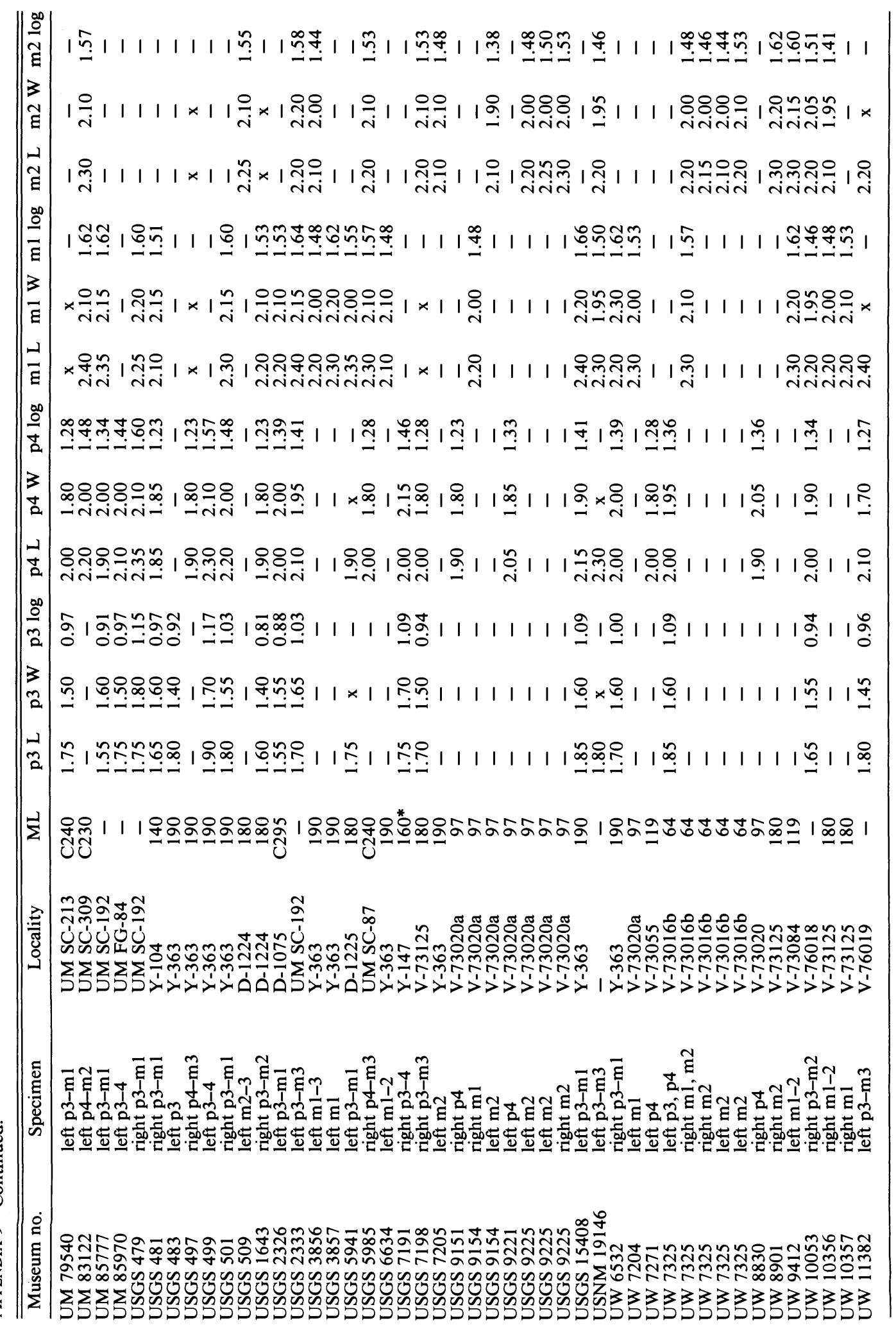




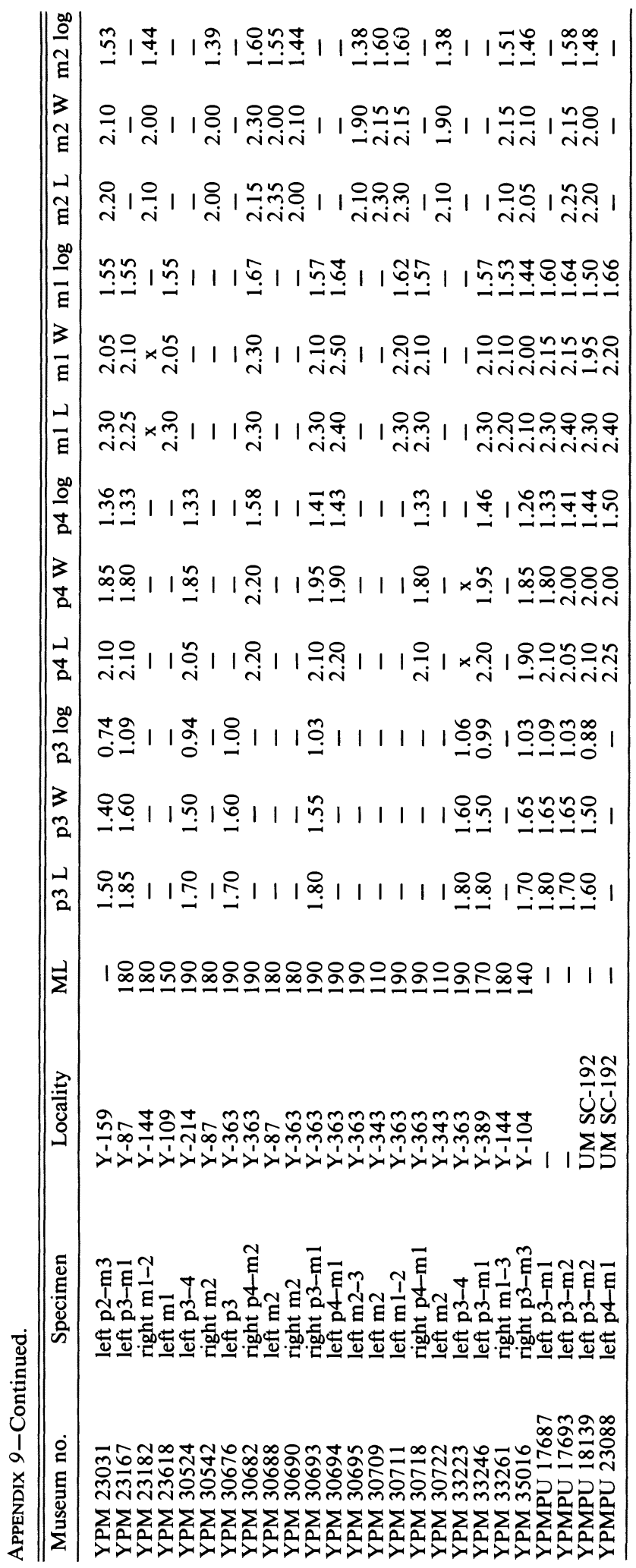




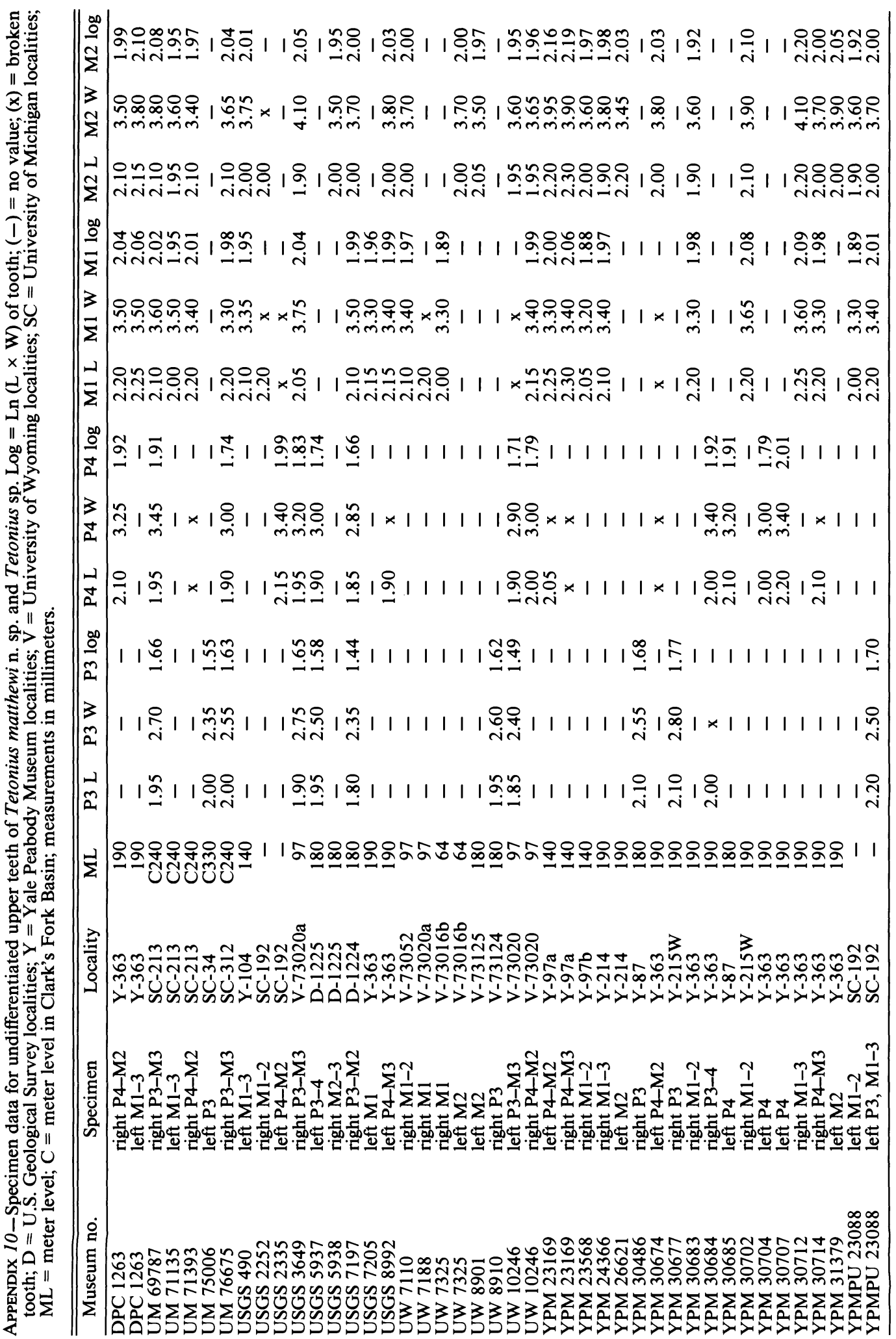




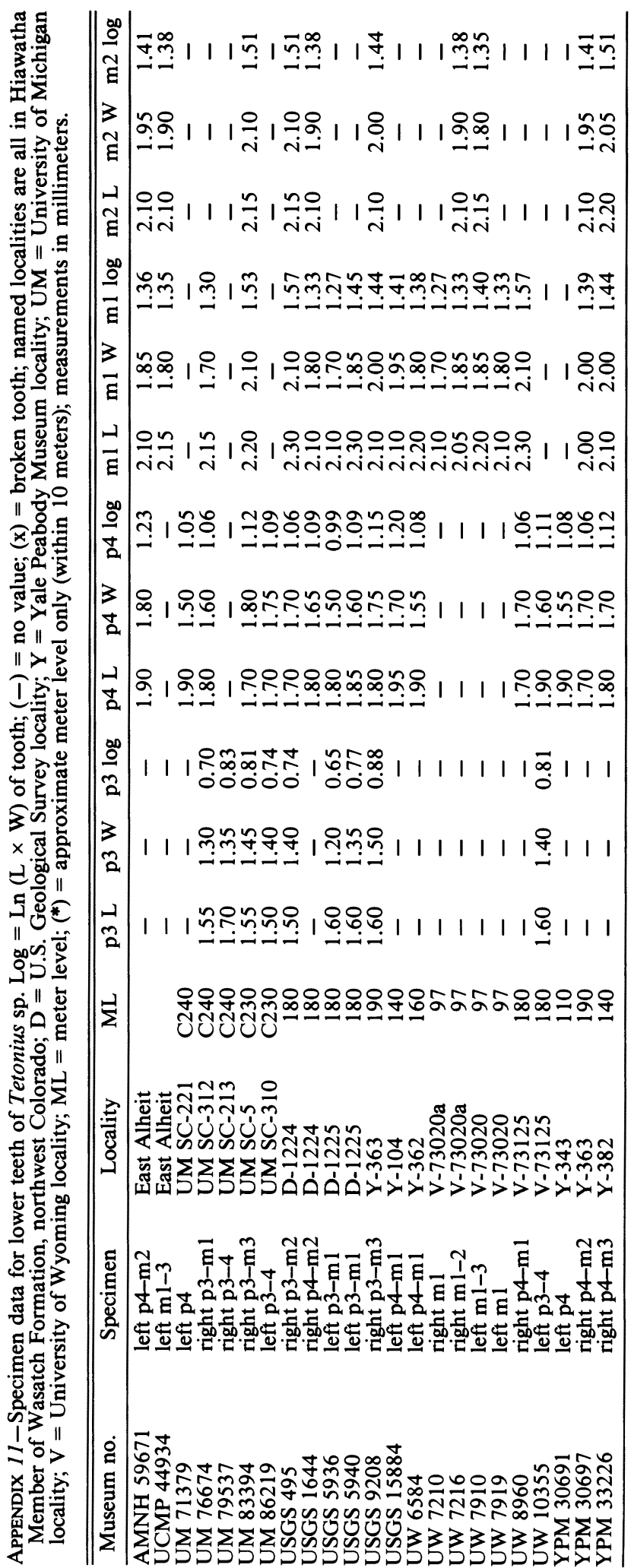




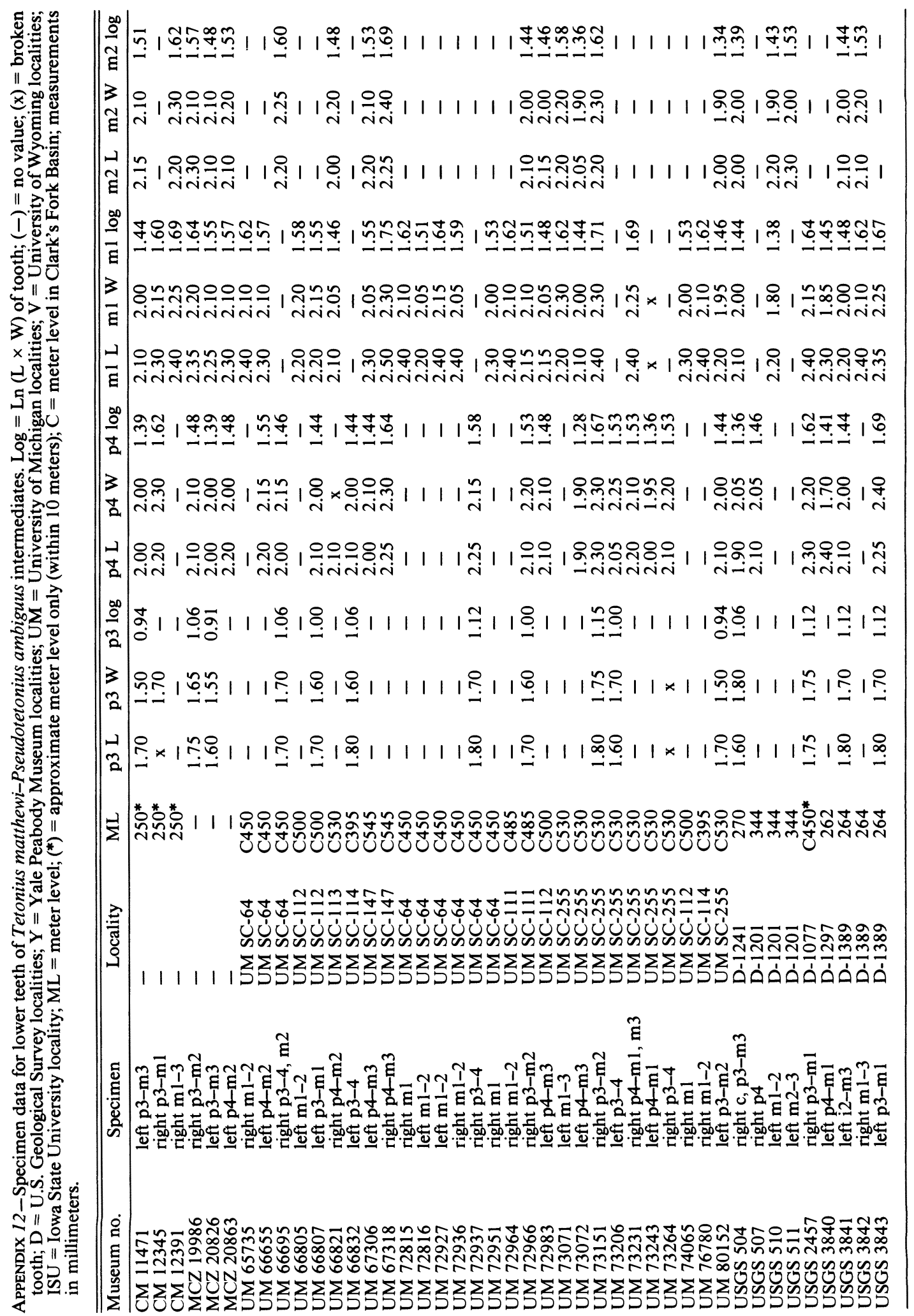




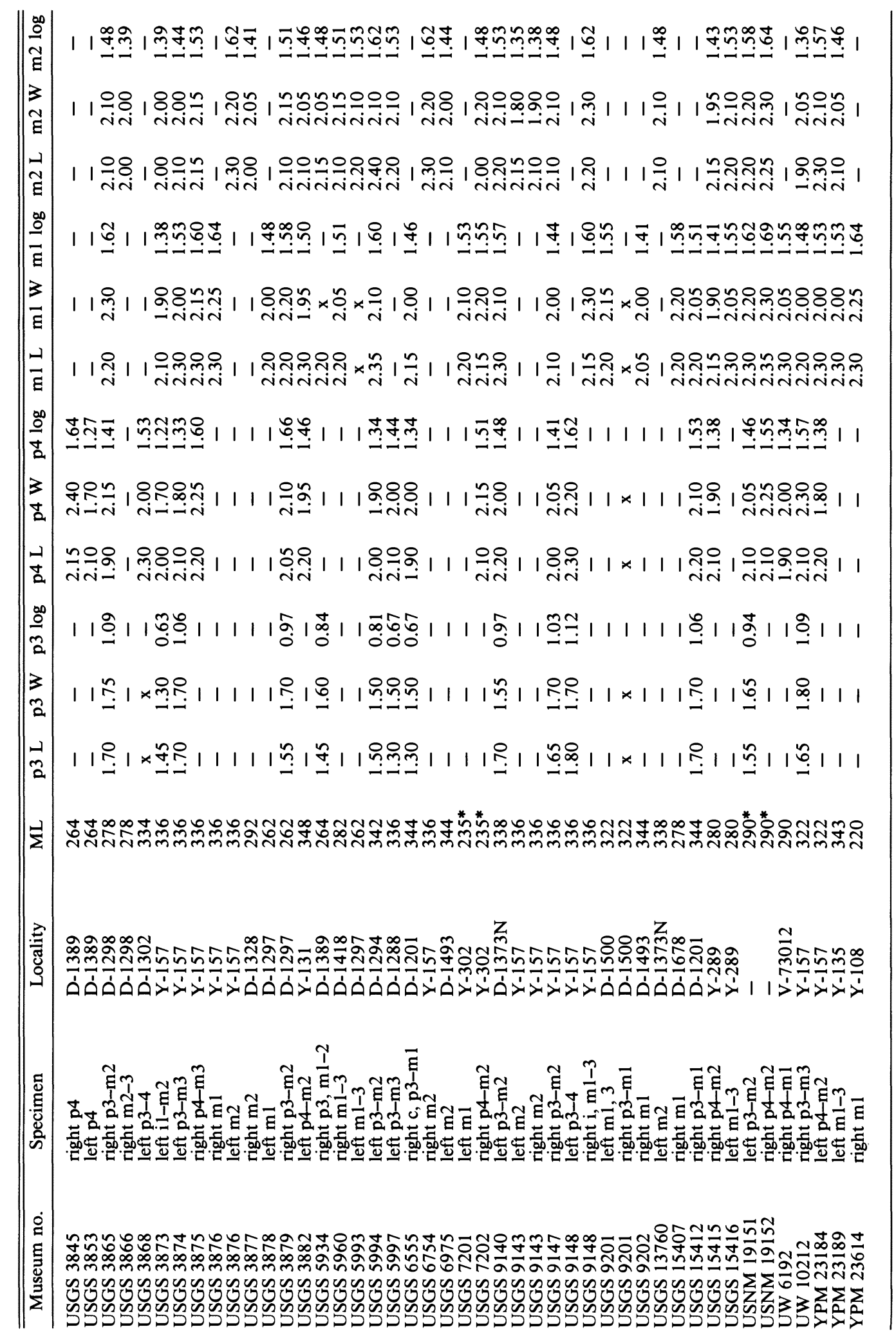




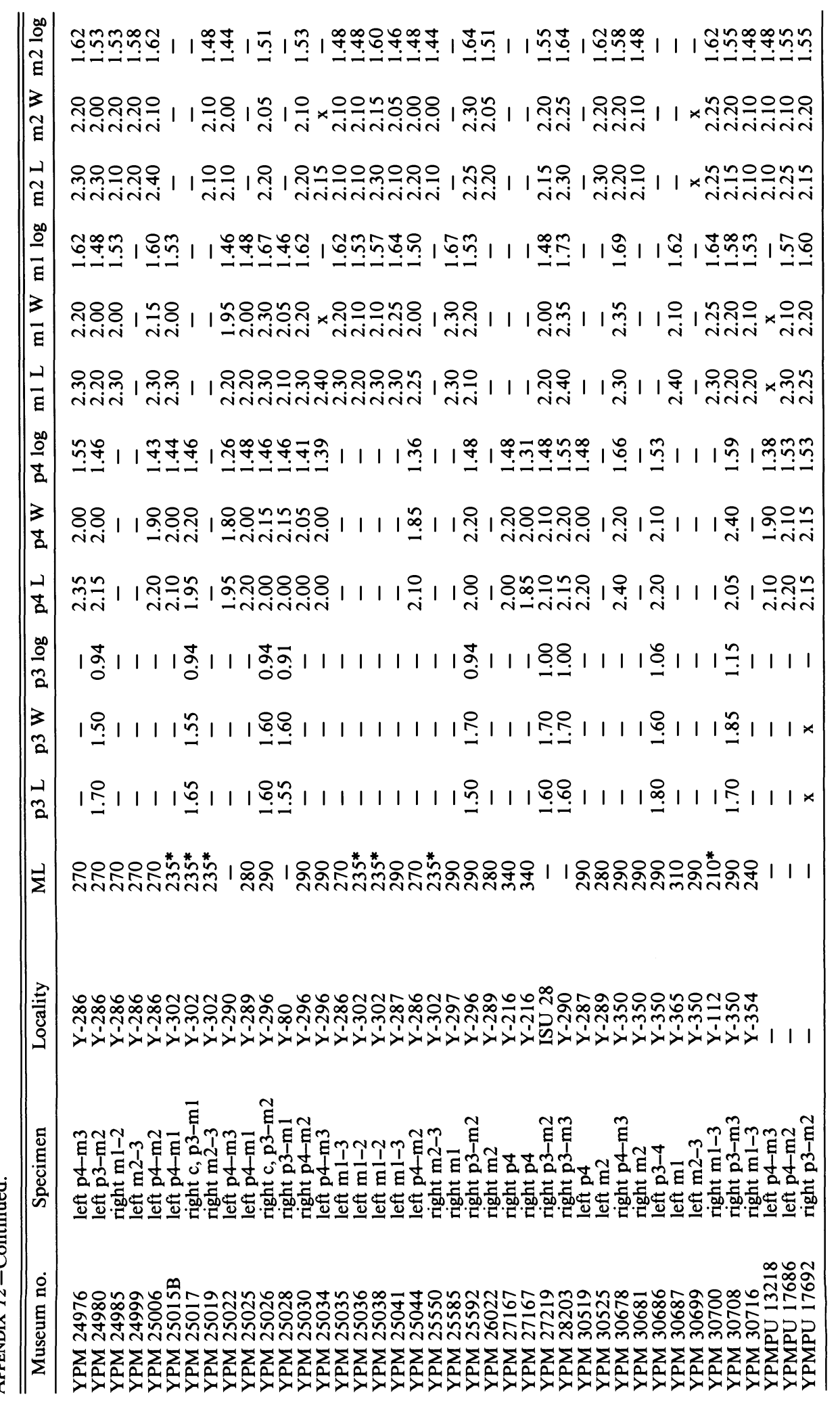




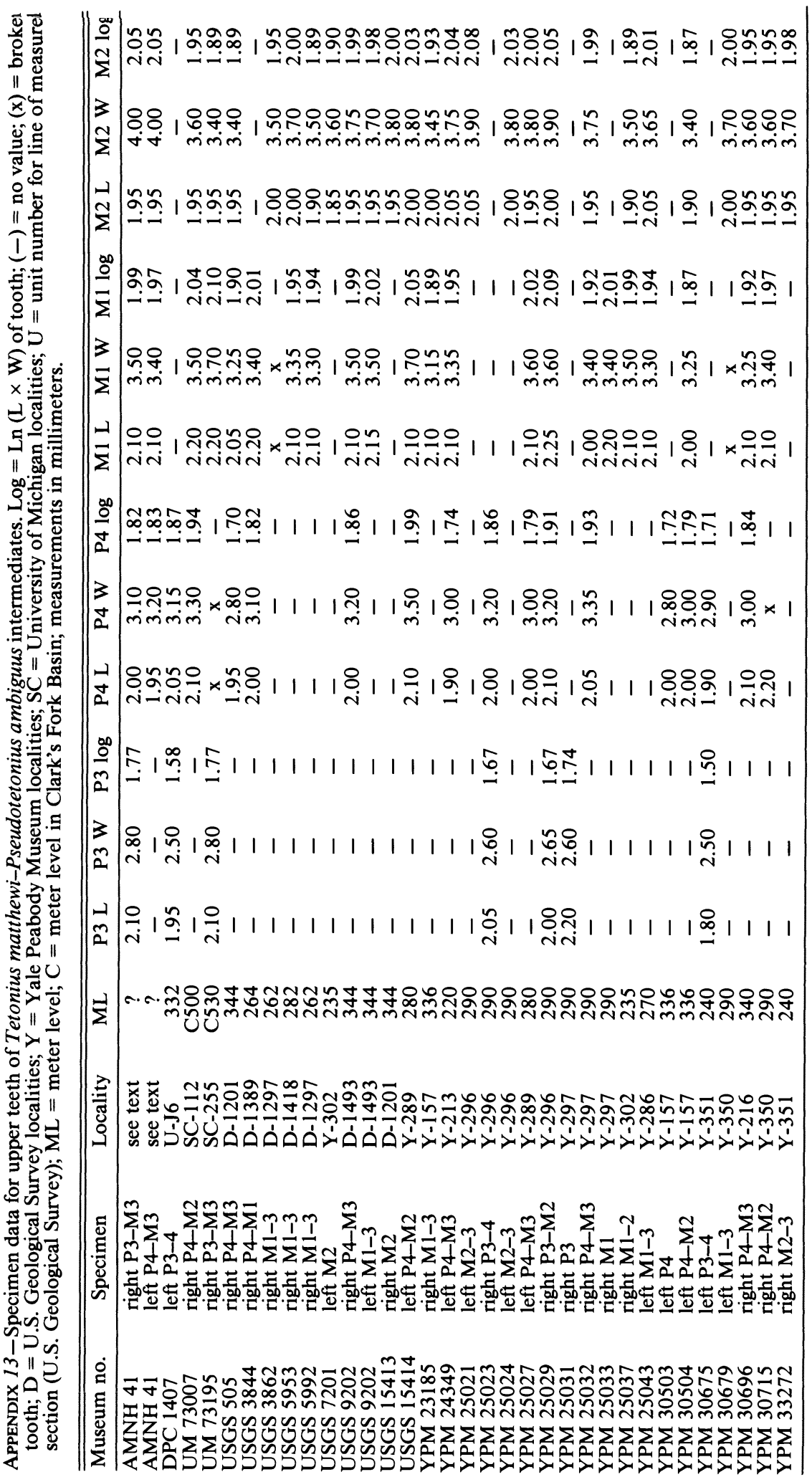




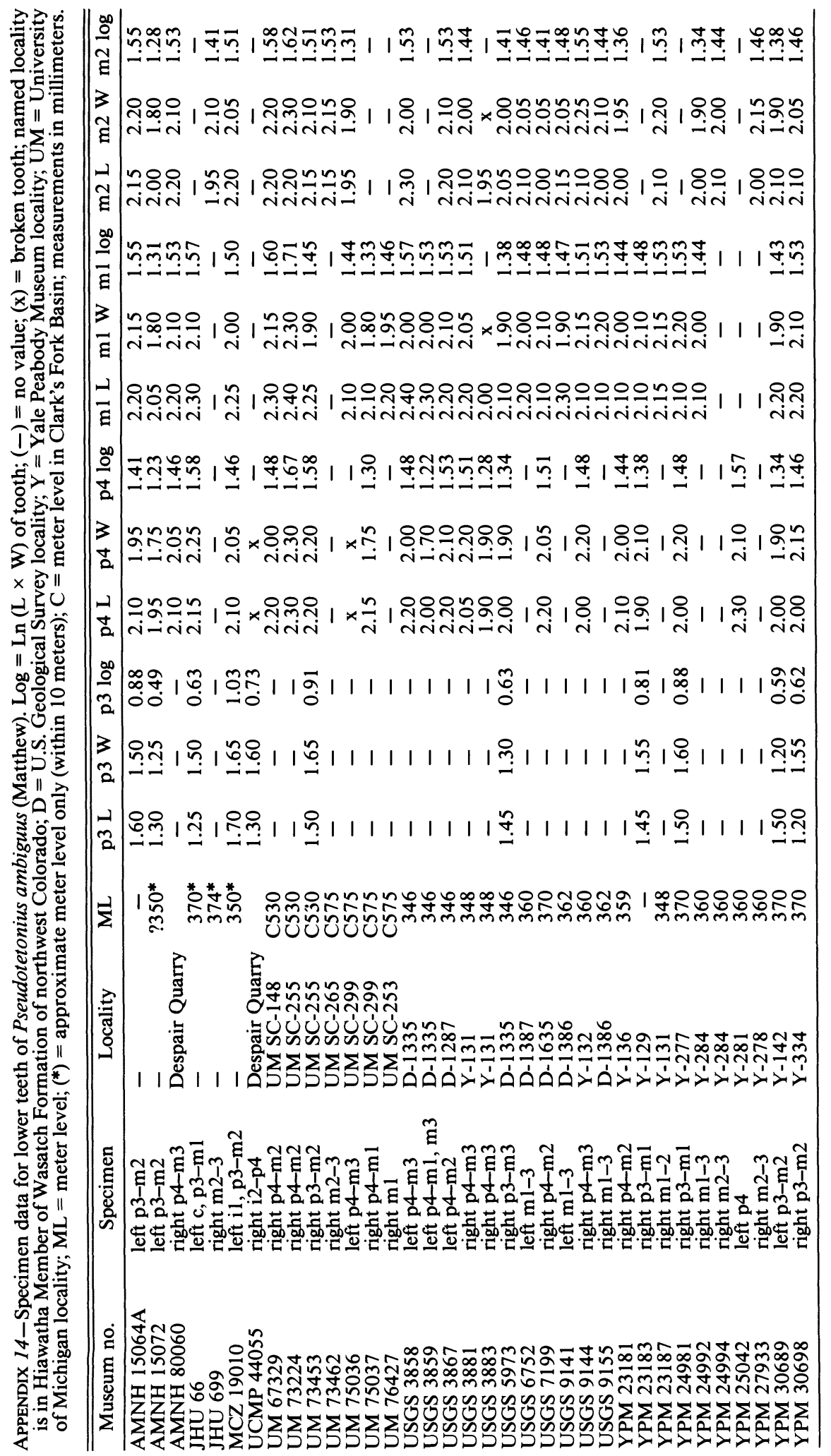




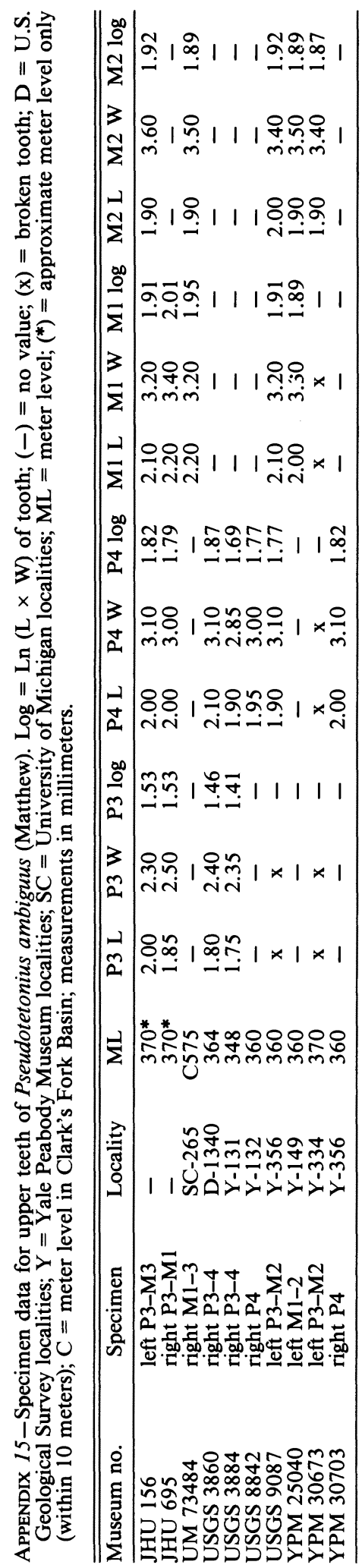




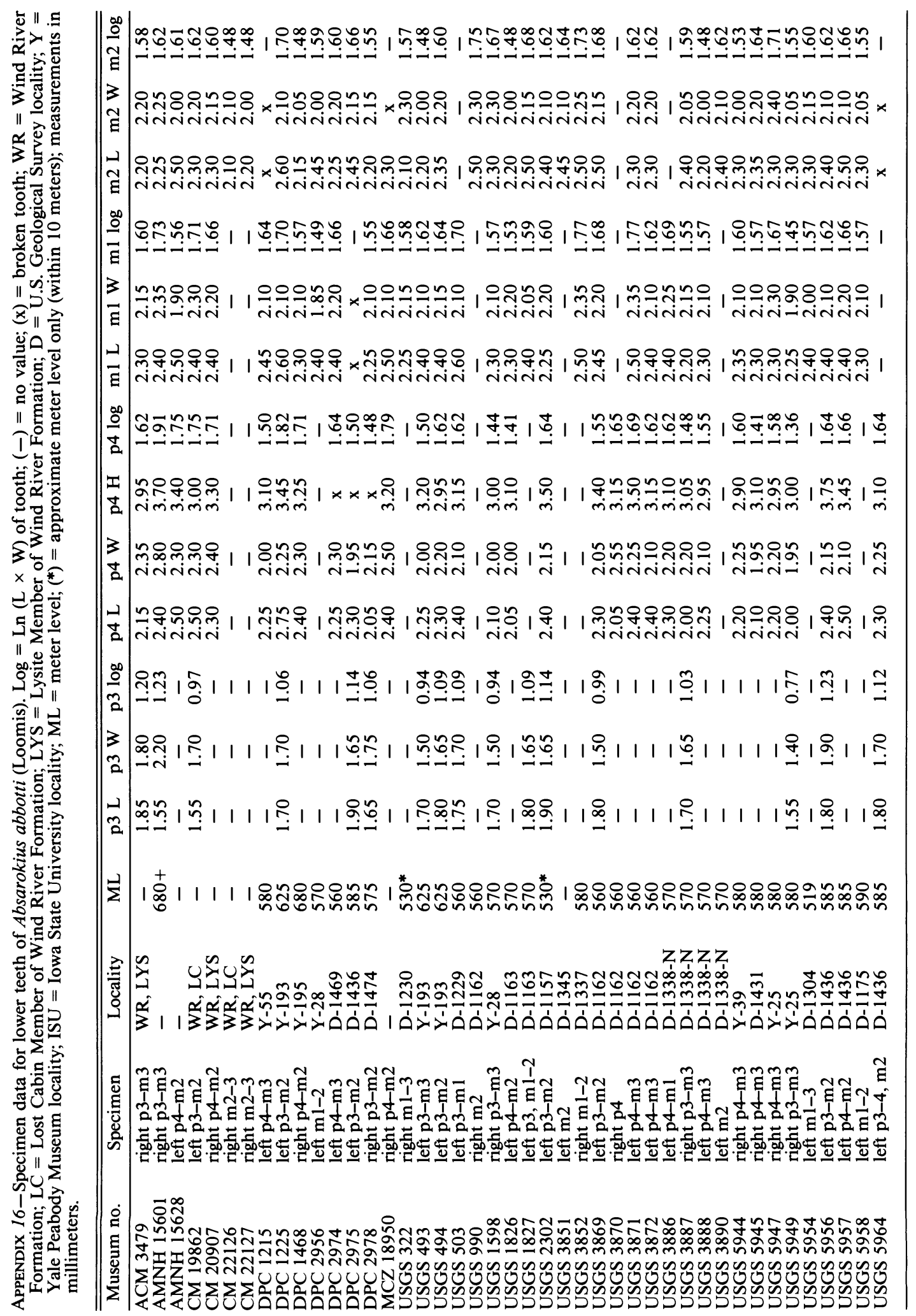




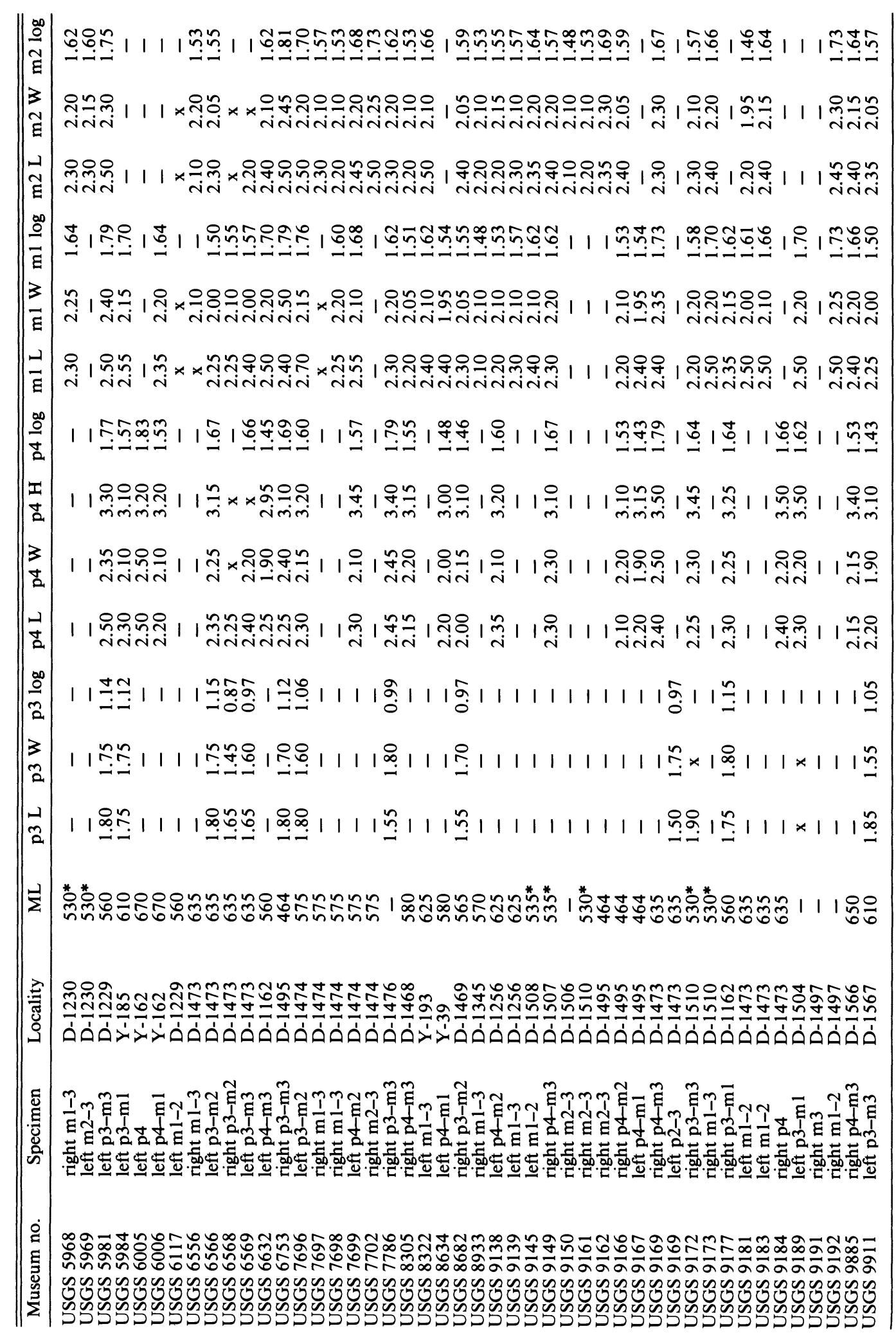




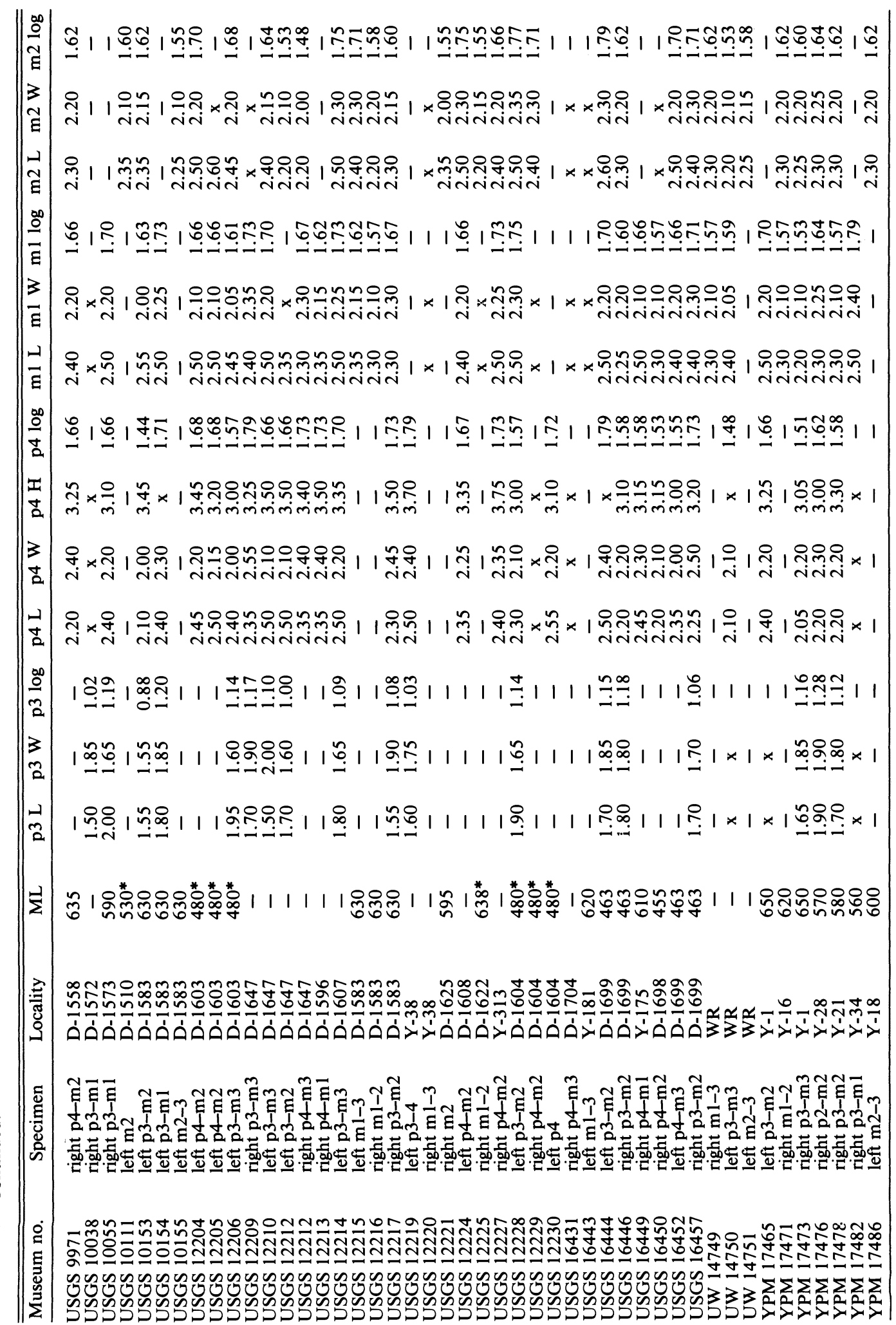




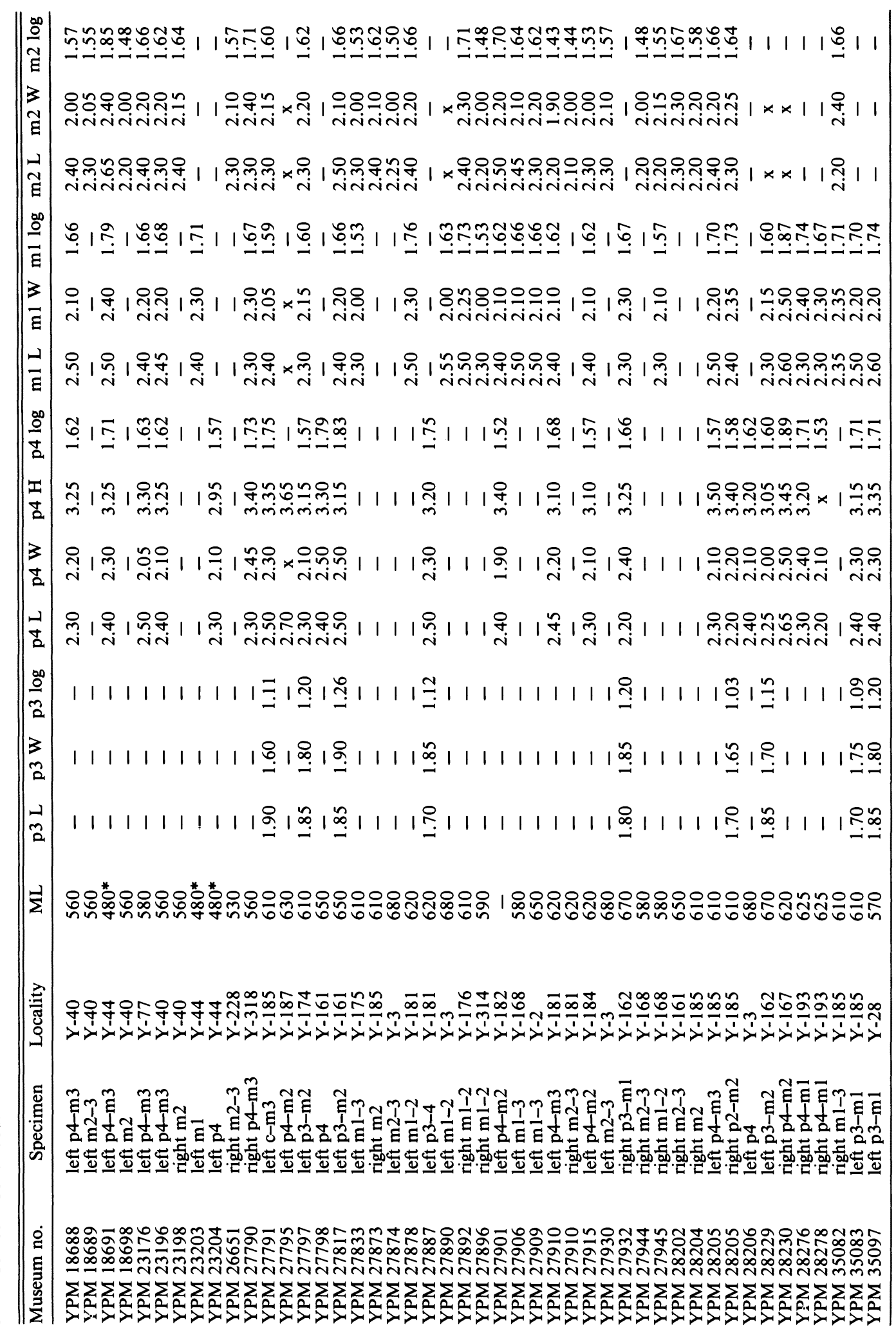




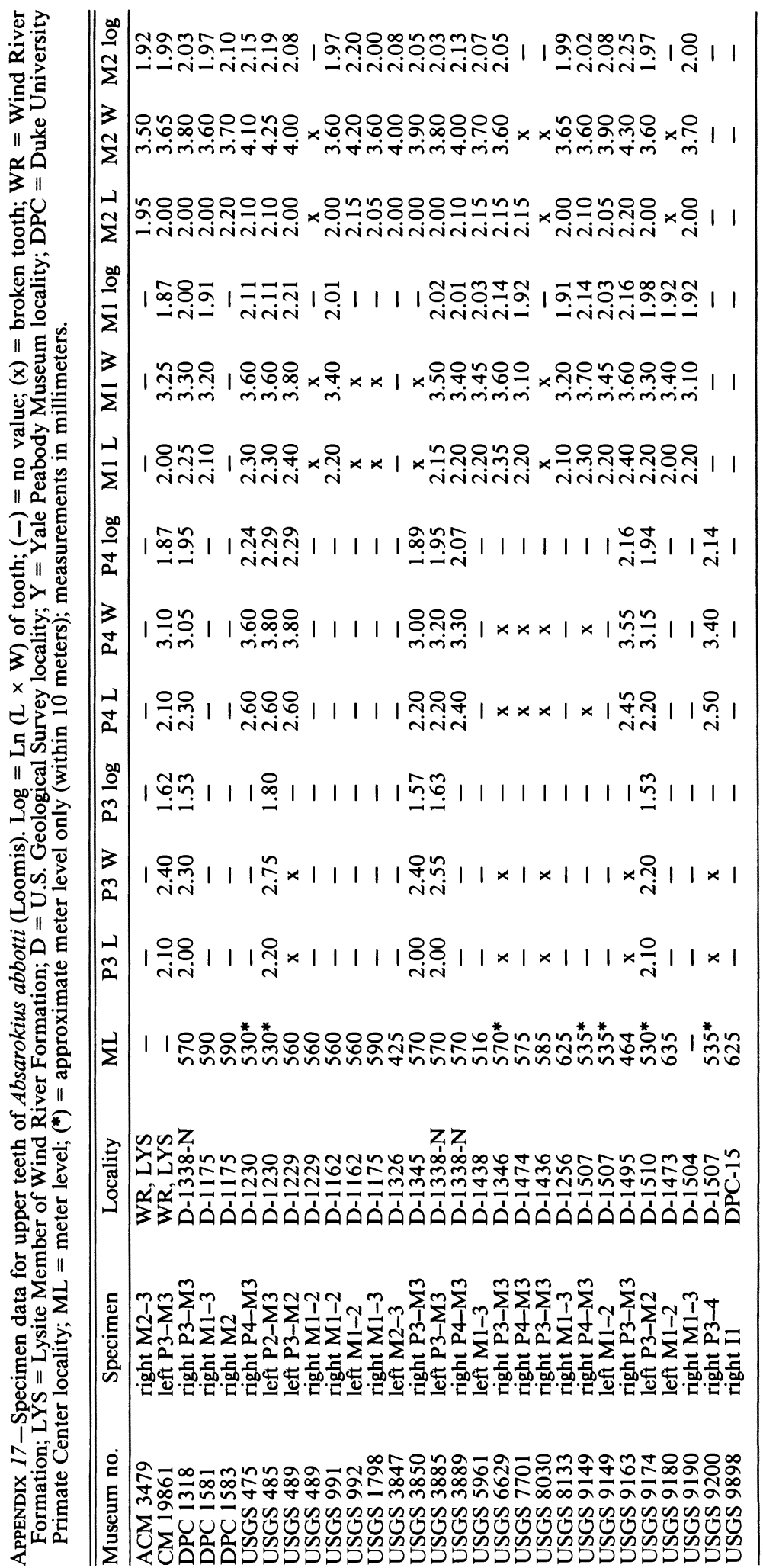




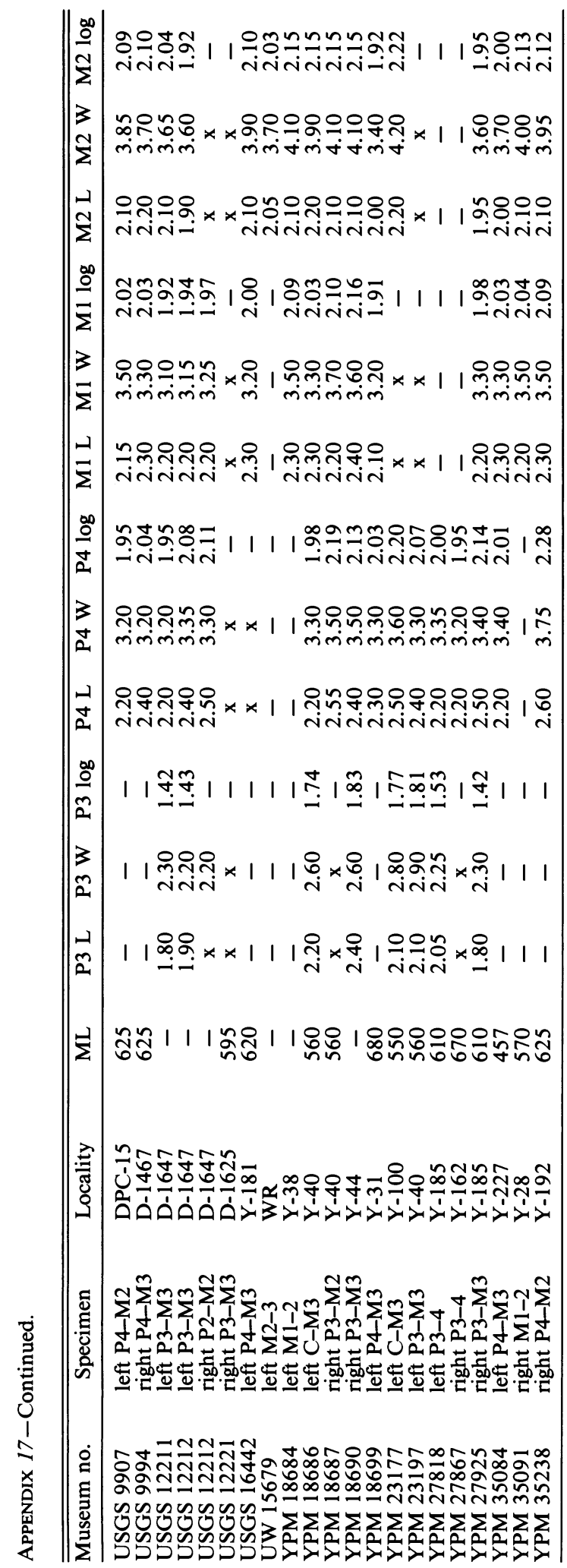




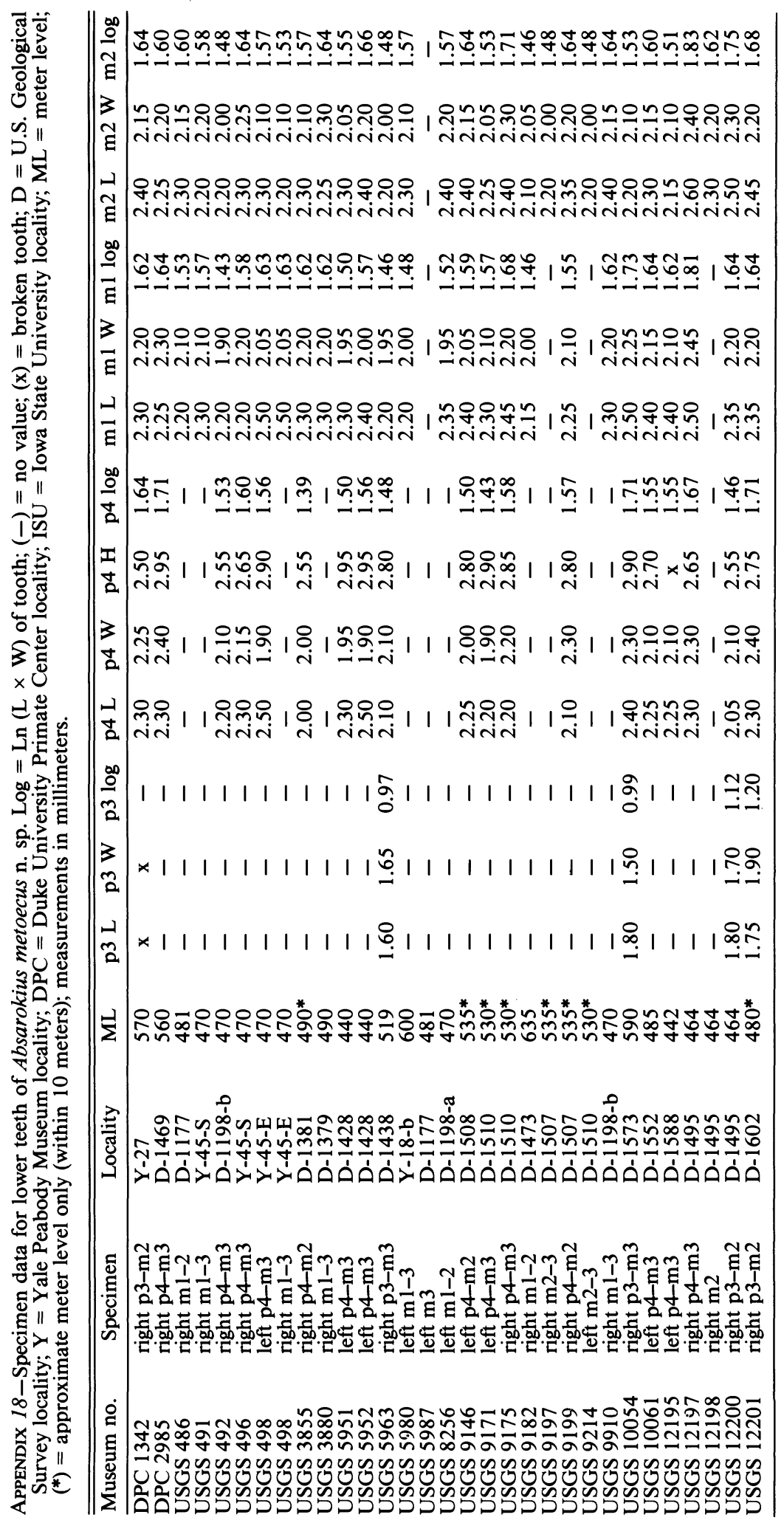




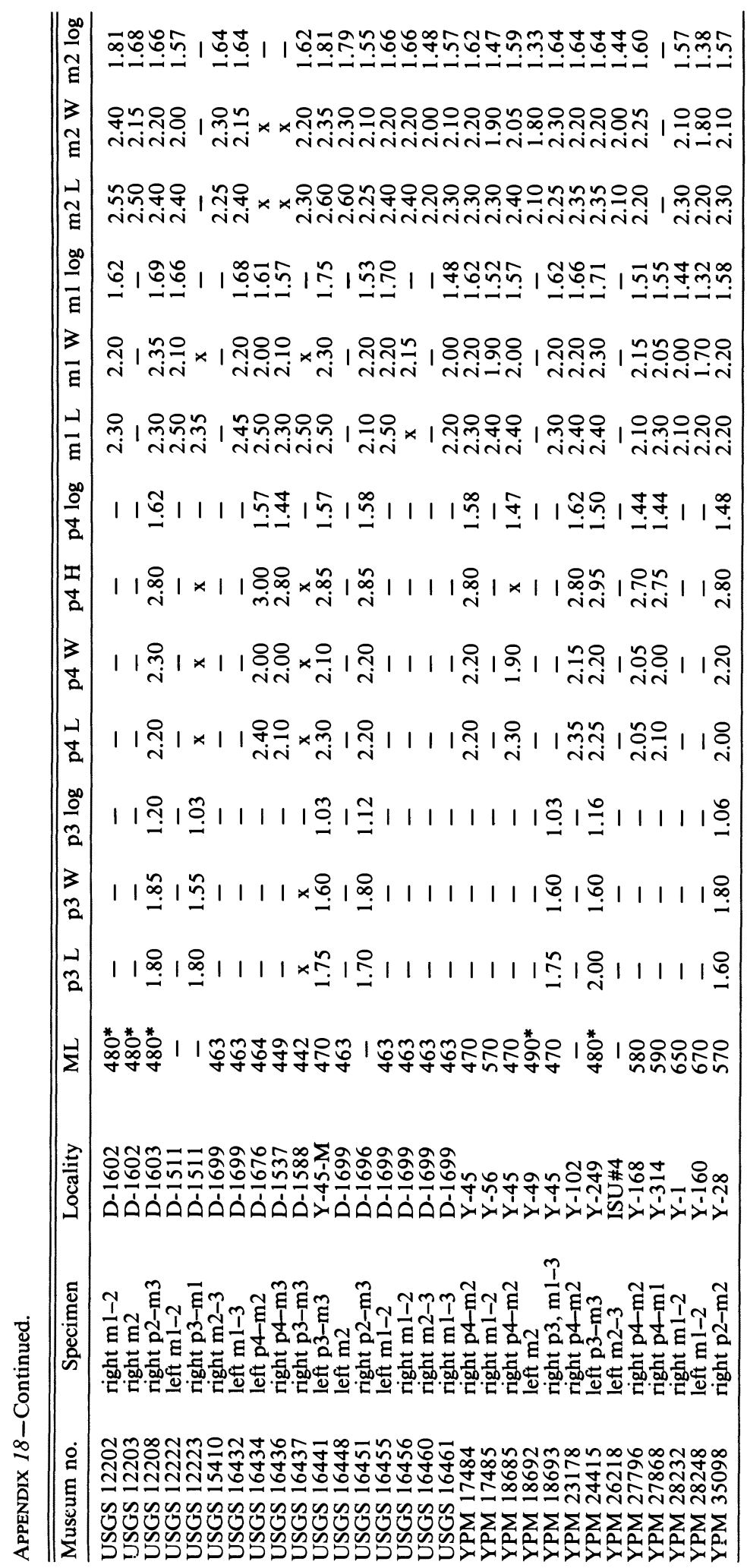




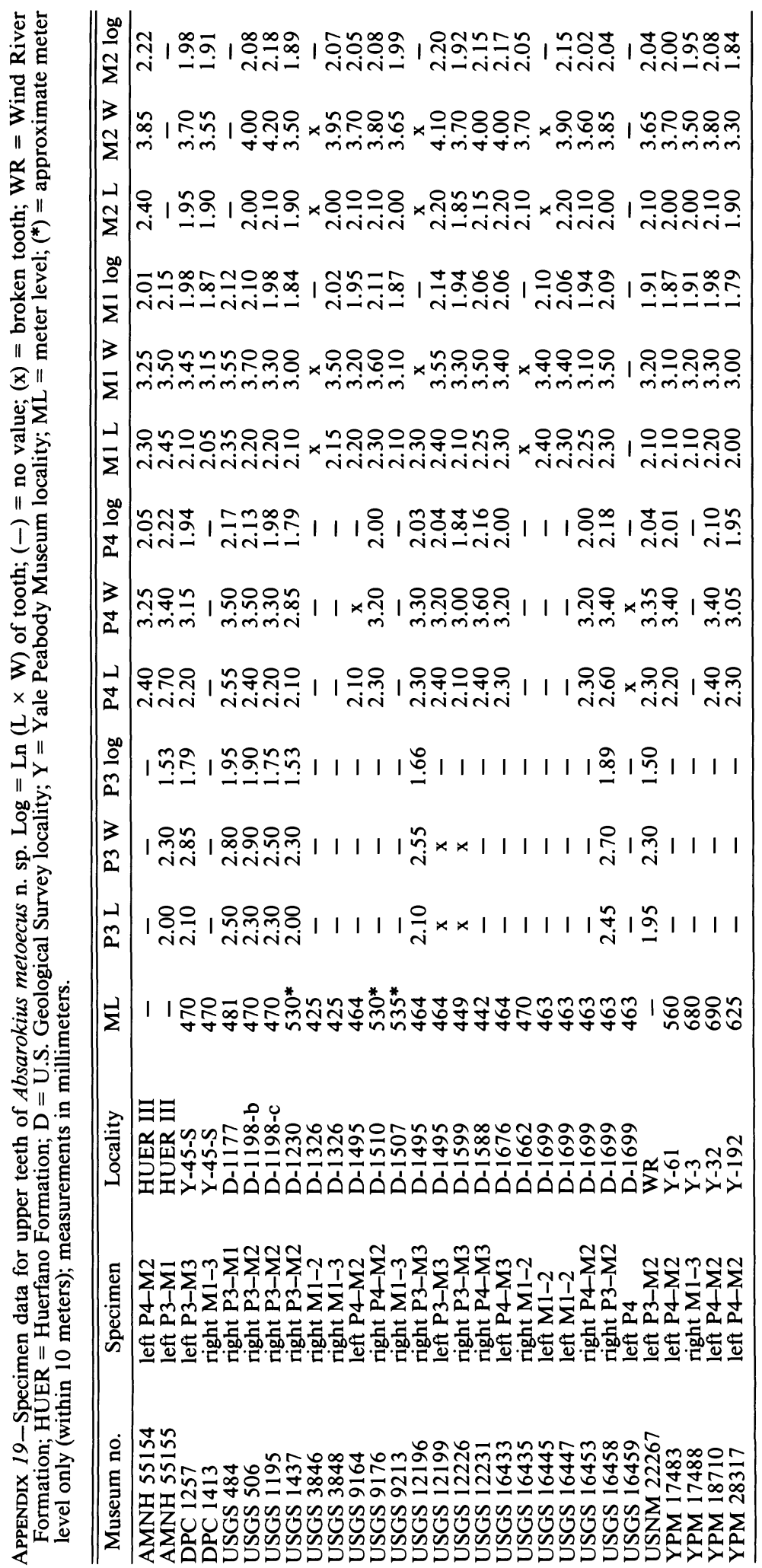




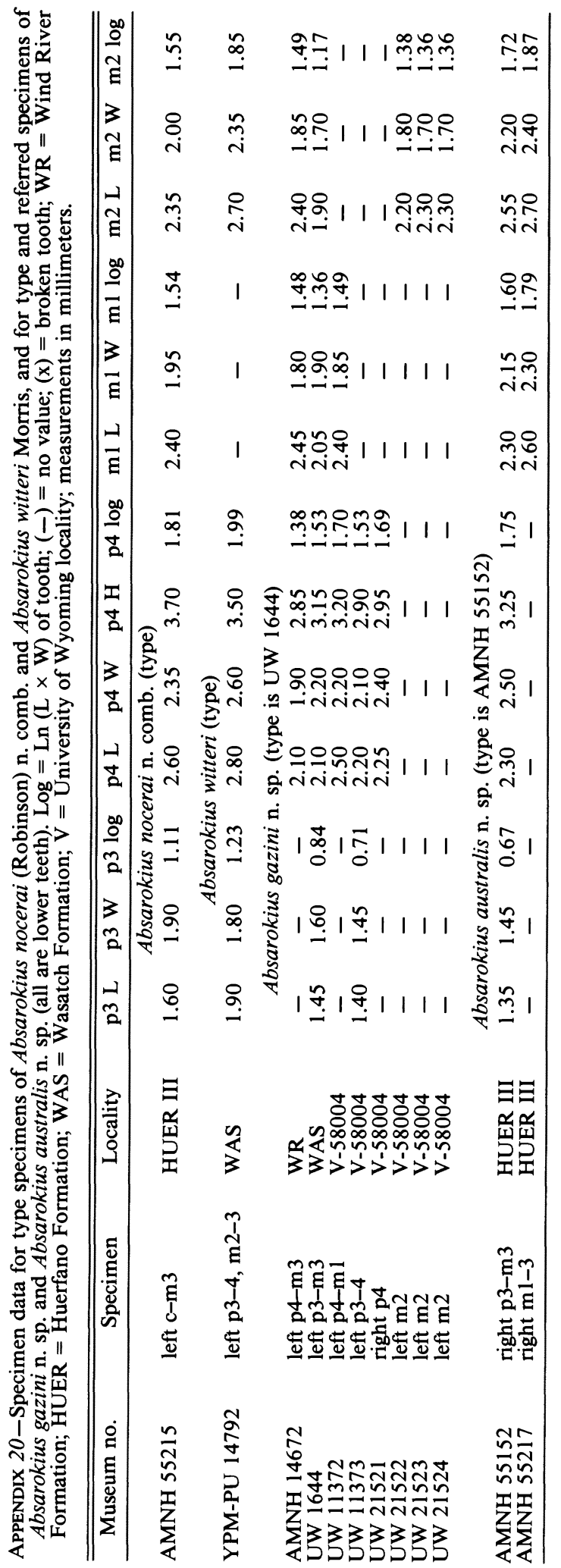




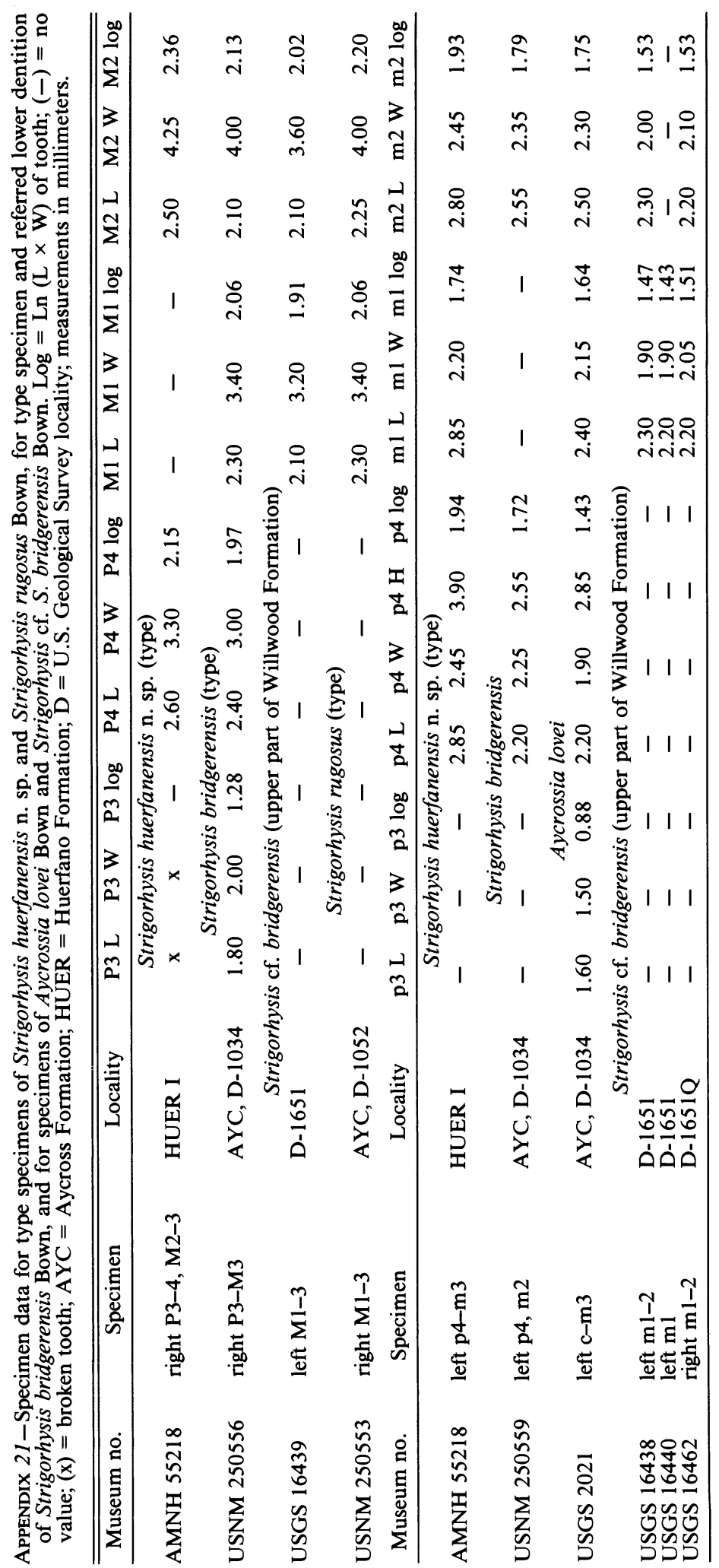

